\title{
Spatial dynamics and life history characteristics of an aggregating species, Petrolisthes elongatus
}

by

\section{Nicolai Truemper}

\begin{abstract}
A dissertation
submitted to the Victoria University of Wellington in fulfilment of the requirements for the degree of Doctor of Philosophy
\end{abstract} in Marine Ecology \& Biodiversity.

VICTORIA UNIVERSITY OF WELLINGTON Te Whare Wānanga o te Ūpoko o te Ika a Māui

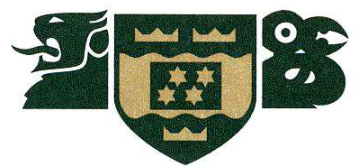

Victoria University of Wellington 


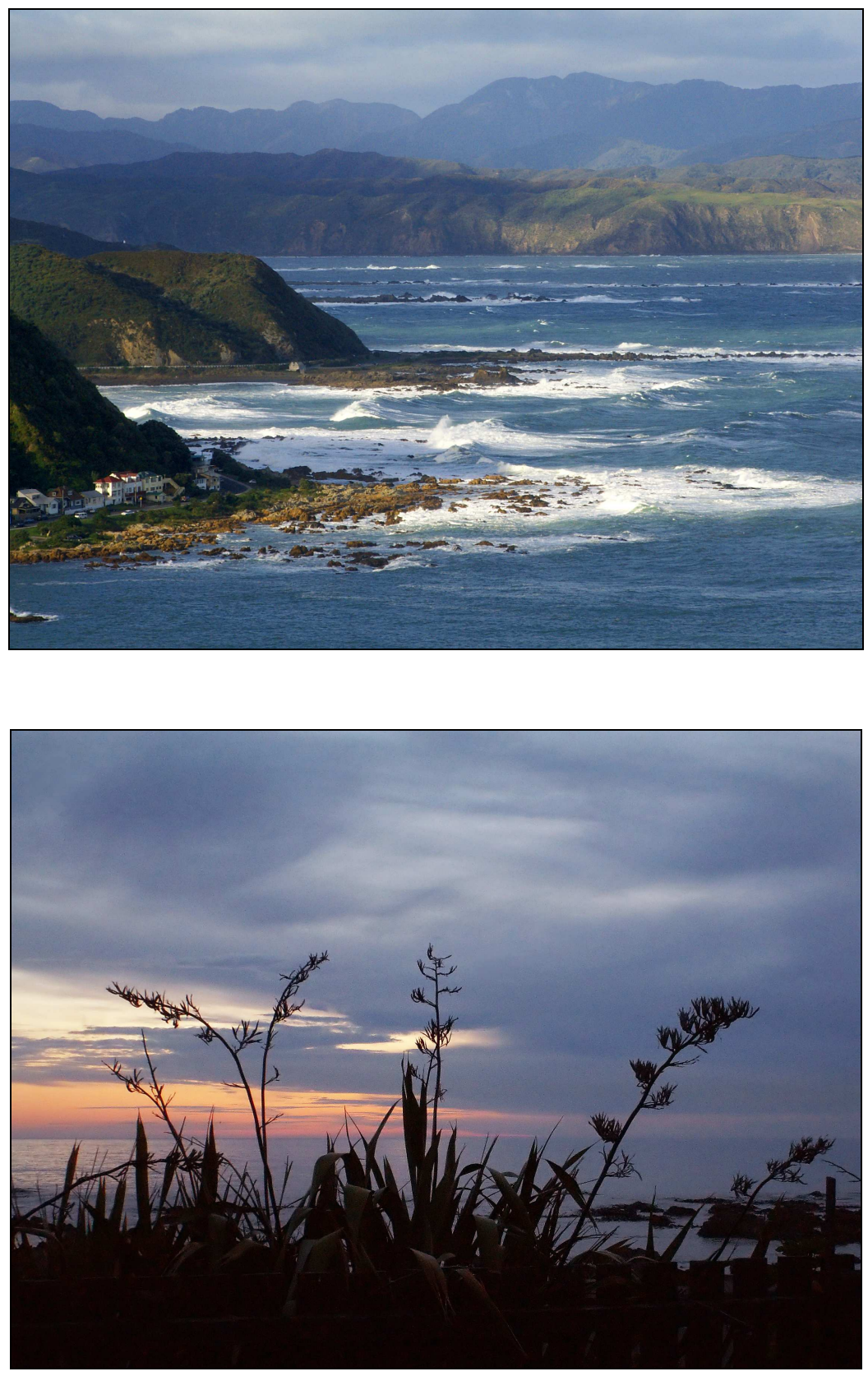

"The world and the universe is an extremely beautiful place, and the more we understand about it the more beautiful does it appear".

Richard Dawkins 


\section{Abstract}

Intertidal boulder fields are heterogeneous mosaics of different micro-habitat patches providing high structural complexity and spatial variability of environmental conditions that shape the heterogeneity of abundance of species. The influence of the spatial scale at which ecological patterns are measured has gained much attention over the last two decades. The adaptations to environmental conditions as well as the ability to disperse vary among species and, consequently, result in species-specific responses to heterogeneous environments. Understanding the causes and consequences of spatial patterns of abundance of organisms is a central problem in ecology and insight in underlying mechanisms may have important implications for fisheries management and conservation biology. The competing demands organisms are subject to require compromises to optimise fitness and facilitate the persistence of a population. Reproductive trade-offs, for example, may be largely the result of adaptive processes, constrained by phylogenetic effects. Generally, trade-offs are regarded as a key to understand the evolution of life history characteristics.

The present study investigates the spatial dynamics and life history adaptations of an aggregating species, the New Zealand half crab, Petrolisthes elongatus. This species has a biphasic lifecycle and occurs in geographically isolated benthic metapopulations that are associated with cobble beaches, where it reaches extremely high densities. Even though sampling was conducted exclusively in the Wellington region, sites at Cook Strait as well as within Wellington Harbour exhibited considerable differences in habitat structure and temperatures as well as wave exposure and food supply.

Cobble size was an excellent predictor of both population density and mean carapace width on almost every scale of observation and, therefore, appeared to be an important indicator of habitat quality for $P$. elongates because cobble size is closely related to availability and size of interstitial space between boulders the crabs utilize as shelters against predation and desiccation pressure. 
Crab densities were significantly (6-fold) higher within the harbour compared to south coast sites, presumably due to 1) the different availability of shelter space, 2) lower settlement and recruitment rates at Cook Strait, and 3) higher food supply within the harbour.

Population structure was mainly influenced by settlement and recruitment, but also by rock size (i.e. shelter size), size selective predation and a higher mobility of larger crabs. Under laboratory conditions, predation rates among small crabs strongly depended on rock size, whereas large crabs were generally rarely to never preyed upon.

Migrated distances did not exceed $100 \mathrm{~cm}$ over $25 \mathrm{~h}$ in most cases but were different at different sites. While structural complexity could affect mobility (i.e. easier movement among larger rocks), local density and resulting levels of intraspecific competition were possibly the main drivers of limited mobility of adult crabs.

P. elongatus exhibits a high phenotypic plasticity of reproductive traits in response to the variable environmental conditions across sites. Female crabs at Island Bay (Cook Strait) showed the highest fecundity, higher percentage of ovigerous females, higher proportion of clutch to body weight (i.e. reproductive output) and higher egg numbers among large individuals compared to similarsized individuals at other sites at the harbour entrance (Breaker Bay) as well as within the harbour (Hutt River mouth).

Larvae of $P$. elongatus strongly responded to waterborne settlement cues released by conspecific adults both in the laboratory and in the field. The average numbers of settlers was 4-fold higher in basket traps deployed in the field if conspecific adults were present. Therefore, settlement patters are strongly influenced by conspecific density, even on a small spatial scale (tens of centimetres). Recently metamorphosed individuals may still respond to conspecific cues, presumably providing guidance to conspecific adults that protect juveniles from predation and desiccation pressure in addition to shelters between boulders. 
Under laboratory conditions, individual growth rates as well as mortality depended on density but not on food level. Differences in density dependent growth rates and mortality varied with body size and were both more pronounced among smaller crabs.

Limb loss significantly influenced the increase in body weight over time, especially among small individuals; however, no differences could be detected regarding changes in body size due to few moults over the course of the experiment. Crabs with removed chelipeds gained more weight over 7 weeks relative to uninjured individuals, presumably due to the limb regeneration process. Reproductive output, however, appeared not to be affected by limb loss and the associated costs of regenerating chelipeds; however, sample sizes were low to reliably detect such differences.

The results of my thesis underline the importance of the consideration of spatial scale in ecological studies in order to meaningfully compare results with other studies. Additionally, the present study contributes to elucidate the influence of environmental conditions on density dependence and reproductive traits of mobile intertidal invertebrates. 


\section{Acknowledgements}

For their guidance and support throughout my $\mathrm{PhD}$, but also for pizza nights and barbecues, I would like to thank my supervisors Nicole Phillips and Jeff Shima. Nicole Phillips in particular has provided me with expert assistance, both practical and theoretical. She has always been available for advice and discussion on the many facets of this work and I am grateful for her support and encouragement.

I also like to express my gratitude to the "Marine Discussion Group", especially Alejandro Perez-Matus, Pelayo Salinas, Erasmo Macaya, Phillip Neubauer, Christopher Gibbons, and Tyler Eddy who have been great colleagues and friends throughout my PhD. Big thanks also to the members of the "Shima - Phillips Lab Group”, especially to Bionda Morelissen, Anna Smith, Lesley McLeod, David Aguirre, Shane Geange, Chris Cornwall, Janine Russell, and Rahul Demello for sharing ideas, showing genuine interest in my project, and many helpful comments and suggestions.

Special thanks to my close friends, colleagues and coffee mates, Peter Martin, Marc Hasenbank, Rudi Schnitzler, Sonja Miller, and John Vandersman for many fruitful or diverting discussions, an inspiring exchange of ideas and thoughts, and good, meaningful times at uni as well as beyond. Big thanks to Marc for bailing me out with great statistical advice.

For having been friends and good fellow students or both I would like to thank Waltraud Schiedermayr, Hilary Miller, Monica Awasthy, Gesine Pufal, Elizabeth Heeg, Gaius Wilson, Meghana Amarnath Rajanahally, Bruce Dudley, and Beaux Berkeley.

Many thanks to Cameron Jack, Sandra Taylor, Marry Murray, Patricia Stein and Paul Marsden who created an enjoyable working atmosphere at the School of Biological Sciences. Patricia's assistance and advocacy in particular was much appreciated. For all the kind help and technical support I got from Jo Long, Jo Davy and Kasey Beveridge I am especially thankful.

I am grateful for the financial support given to me by Victoria University of Wellington, without which this project would not have been possible. 
The Victoria University of Wellington Tramping Club provided the right amount of positive distraction and physical exercise as a way to gather new strength for work in front of the computer. Not only did I learn a lot about how to go bush safely and return from wilderness and rugged mountaintops happily but I also found many good friends there, had lots of fun and share some unforgettable memories especially with Alyn Higgins, Shawn Johnson, Scott Tremain, Bernard Smithyman, Kieran Paton, Annabel Beattie, Tim Doyle, Hazel Bidmead, Jessica Clark, Jenny Long, Sophie Allen, Craig Scott, Craig Ryburn, Sarah Miller, Juho Särkilä, Dan Wilson, Amelia Opie, Terra Dumont, Bryan O’Leary, Michael Pohl, Michael Instone, Sam Baker, Matthias Kübel, Andred Saker and Amelia Geary.

Jenny and Jim Pryor became close friends who embraced my wife and me as part of their family, giving us both great support and a sense of home. The same is true for Nicky Chapman and Beverly Wakem whom we just recently met, even though it feels like a lifetime.

My $\mathrm{PhD}$ has been a long journey and I would not have made it without the unwavering support of my parents Ingrid and Gerhard, as well as my brother Michael. Far away most of the time - and yet very close, they have always encouraged me to live my dreams, to "gaze at the stars but watch my step". Their support on so many levels kept me going and substantially contributed to bringing this work to a successful end.

No one has experienced the highs and lows of my life over the past few years more intimately than my wife Carola Bruns (now Trümper). She has always been there for me, here in Wellington as well as over the longest possible geographic distance on this planet during the first two and a half years of my PhD. For her understanding, her love and support I am forever grateful.

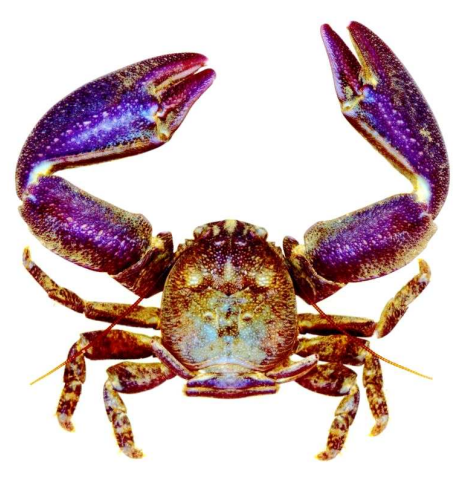




\section{Table of Contents}

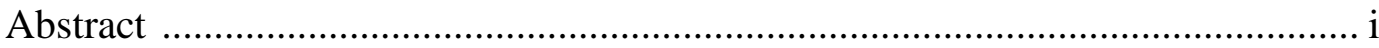

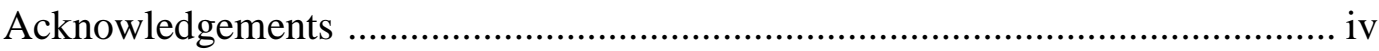

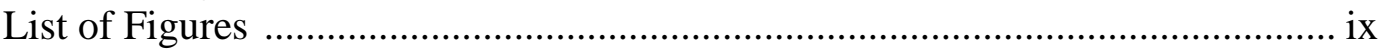

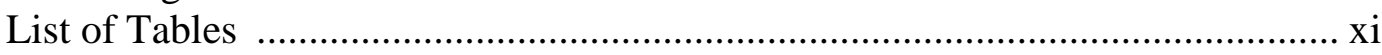

\section{CHAPTER ONE}

\section{General introduction}

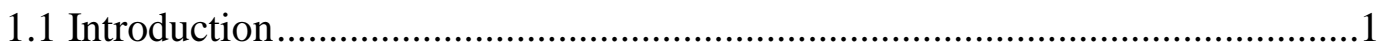

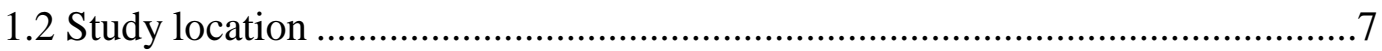

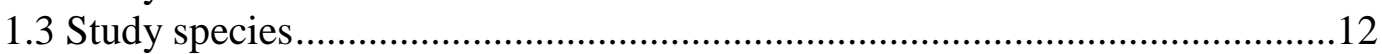

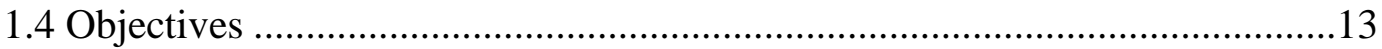

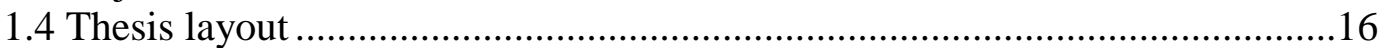

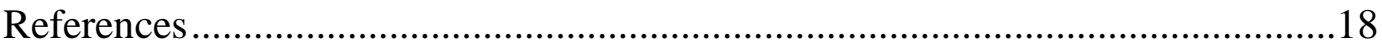

\section{CHAPTER TWO}

Effects of cobble size on population structure, predation risk and movement of Petrolisthes elongatus.

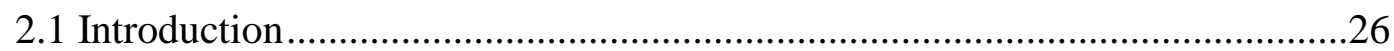

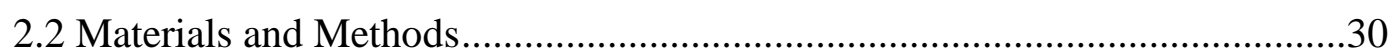

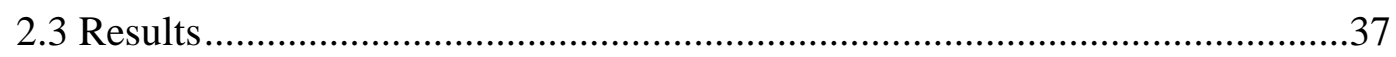

2.3.1 Field survey: Density and crab size relative to cobble size ....................37

2.3.2 Field exp.: Cobble size and colonization .............................................46

2.3.3 Lab. exp.: Influence of cobble size on predation ...................................4

2.3.4 Field exp.: Mobility and migration among cobbles ..............................49

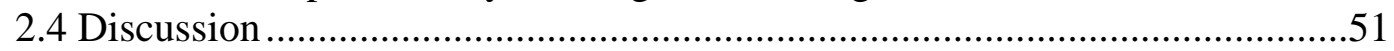

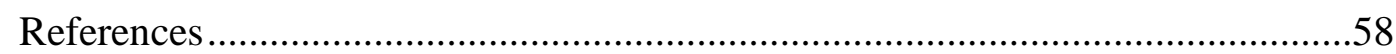

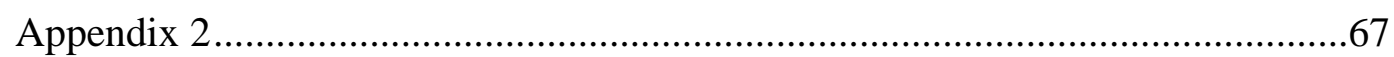

Appendix 2.1 Size frequency distribution of crabs at Hutt River mouth...............67

Appendix 2.2 Size frequency distribution of crabs at Breaker Bay.......................68

Appendix 2.3 Size frequency distribution of crabs at Island Bay........................69

Appendix 2.4 Mean crab density within quadrats at all sites ...............................70

Appendix 2.5 Mean carapace width within quadrats at all sites..........................71

Appendix 2.6 Mean rock size within quadrats at all sites...................................72

Appendix 2.7 Mean rock size vs. total density within quadrats .........................73

Appendix 2.8 Mean rock size vs. adult density within quadrats ..........................73

Appendix 2.9 Mean index of dispersion for all sample sites ...............................74

Appendix 2.10 ANOVA results M\&R survey (fully saturated model) .................74 


\section{CHAPTER THREE}

Effects of habitat quality on life history traits

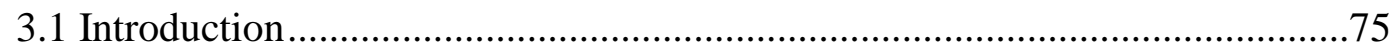

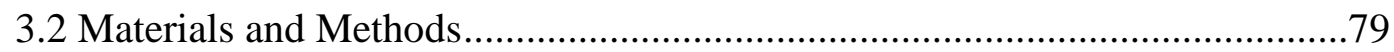

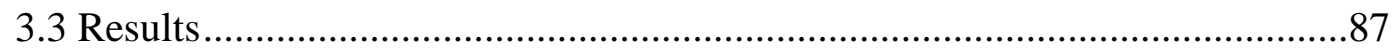

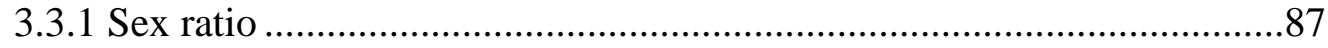

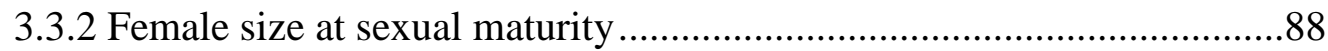

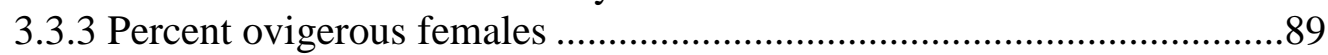

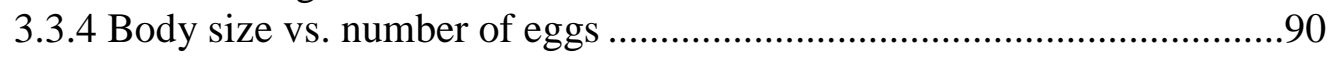

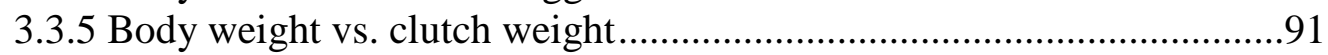

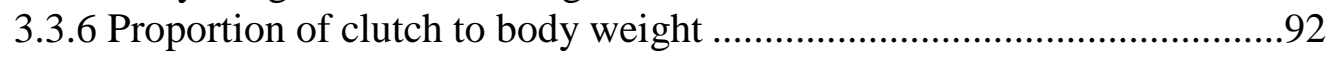

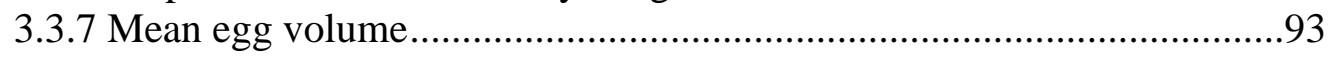

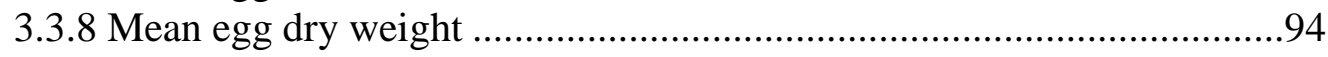

3.3.9 Mean egg water content ................................................................95

3.3.10 Egg wet weight vs. developmental stage of eggs .............................96

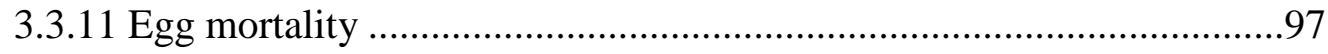

3.3.12 Density of ovigerous females vs. reproductive output.......................98

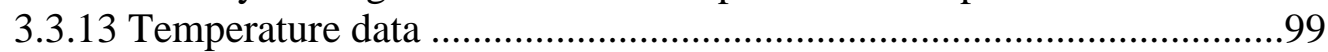

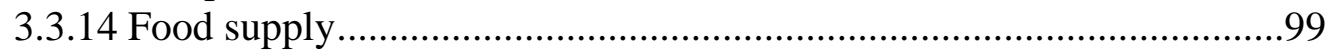

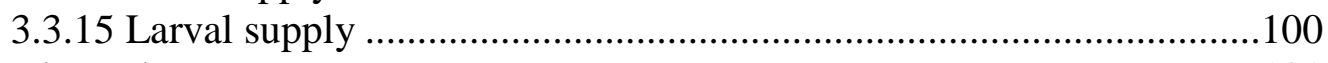

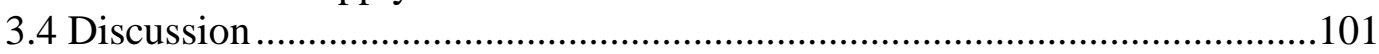

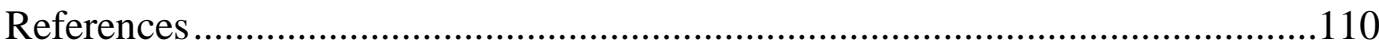

\section{CHAPTER FOUR}

Larval response to settlement cues

4.1 Introduction

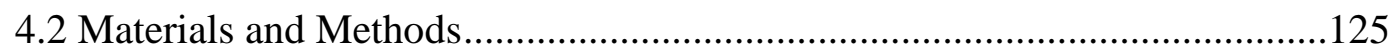

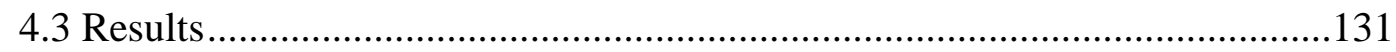

4.3.1 Attraction effects on larvae and juveniles conspecific adults and other potential sources of settlement cues in a laboratory experiment ..........131

4.3.1.1 Effect of potential settlement cues on larvae .....................................131

4.3.1.2 Effect of potential settlement cues on juveniles ..............................133

4.3.2 Attraction effects on larvae caused by conspecific adults (field exp.) 136

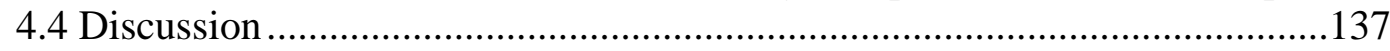

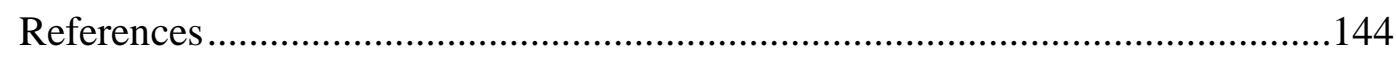

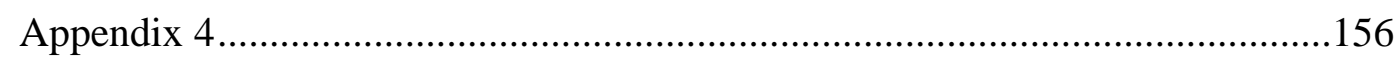

Appendix 4.1 Potential conspecific cues .........................................................156

Appendix 4.1.1 "Probability paths" of swimming P. elongatus larvae .............. 156

Appendix 4.1.2 "Probability paths" of $P$. elongatus juveniles ............................157

Appendix 4.2 Potential heterospecific and habitat cues ....................................158

Appendix 4.2.1 "Probability paths" of swimming P. elongatus larvae ................158

Appendix 4.3 Total time larvae and juv. spent in choice chamber sections........159 


\section{CHAPTER FIVE}

Density dependence: effects of conspecific density on survival, individual growth, feeding efficiency and reproduction.

5.1 Introduction 160

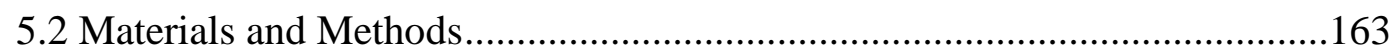

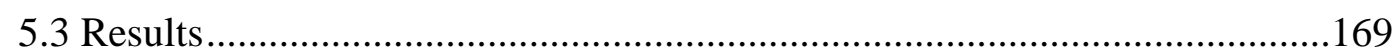

5.3.1 Effect of population density and food availability on growth rate .......169

5.3.2 Effect of density on frequency of filter-feeding .................................171

5.3.3 Effects of limb loss on growth rate ..................................................173

5.3.4 Effects of population density on frequency of limb loss .....................178

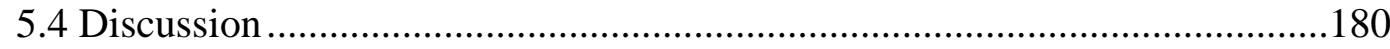

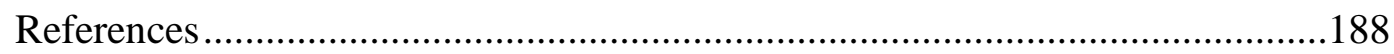

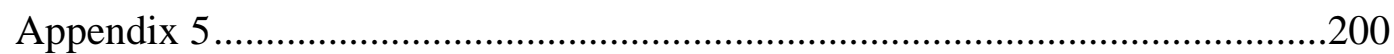

Appendix 5.1 Weekly changes in body mass [\%] ............................................200

Appendix 5.2 Weekly size changes [mm carapace width] ..............................201

Appendix 5.3 Frequency of developmental stages of limb regeneration.............202

Appendix 5.4 Percentage at which each limb pair was found regenerating ........202

Appendix 5.5 Percent individuals with regenerating limbs ..............................203

Appendix 5.6 No. of sex. mature ind. vs. percent ind. with regenerating limbs..203

Appendix 5.7 2-Way ANOVA: proportion ind. with regenerating limbs ...........203

\section{CHAPTER SIX}

General discussion and conclusions

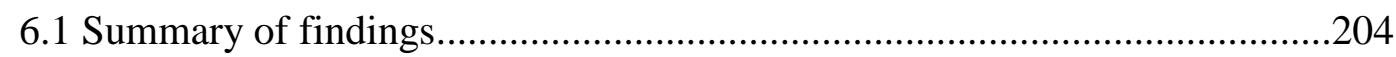

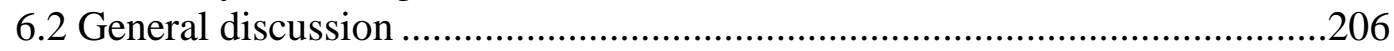

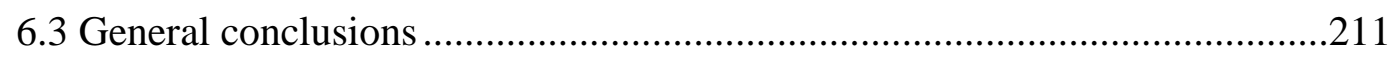

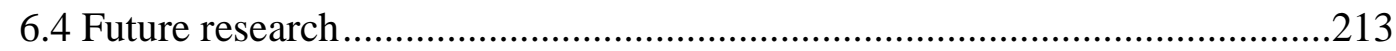

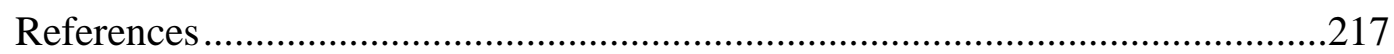




\section{List of Figures}

\section{CHAPTER ONE}

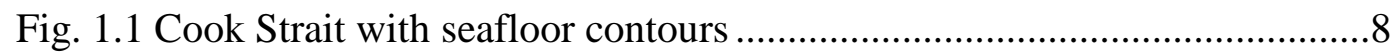

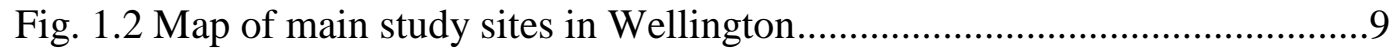

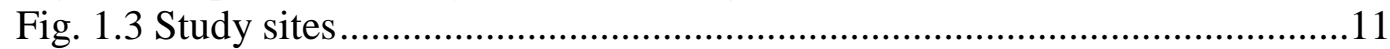

Fig. 1.4 Life cycle of Petrolisthes elongatus ...................................................13

\section{CHAPTER TWO}

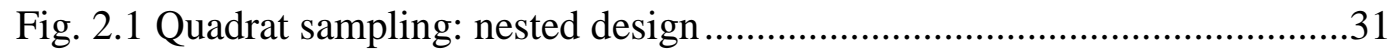

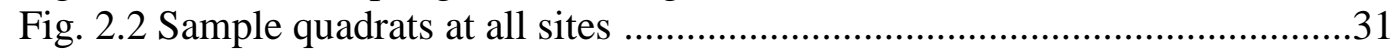

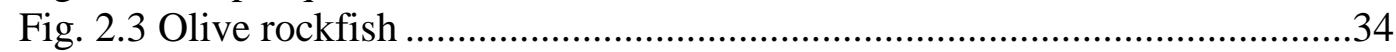

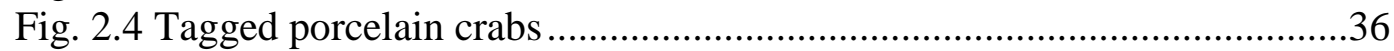

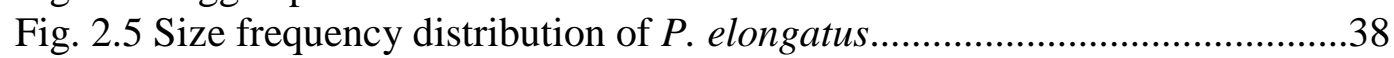

Fig. 2.6 Mean crab density per quadrat within nests ............................................39

Fig. 2.7 Mean CW of adult crabs per quadrat within nests...................................40

Fig. 2.8 Mean rock sizes of occupied rocks within nests.....................................41

Fig. 2.9 Mean and median rock size of occupied rock vs. unoccupied rocks........42

Fig. 2.10 Rock size versus number of individuals under each rock ....................43

Fig. 2.11 Mean carapace width of adult crabs per rock vs. rock size ....................44

Fig. 2.12 Density of $P$. elongatus vs. Hemigrapsus sexdentatus at HRM.............45

Fig. 2.13 Density of $P$. elongatus vs. Heterozius rotundifrons at BRB.................45

Fig. 2.14 Density of $P$. elongatus vs. Heterozius rotundifrons at ISB ..................45

Fig. 2.15 Mean density of $P$. elongatus adults and juveniles ...............................46

Fig. 2.16 Mean body size (CW) of P. elongatus adults ....................................47

Fig. 2.17 Cobble size vs. percent survivors ........................................................48

Fig. 2.18 Size class vs. distance from position of crab to point of release .............50

\section{CHAPTER THREE}

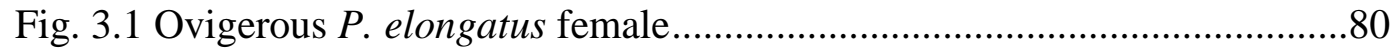

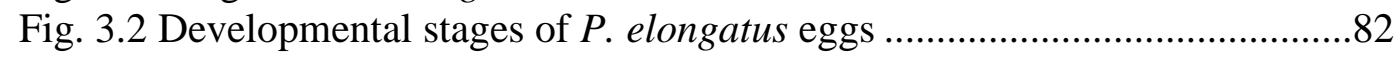

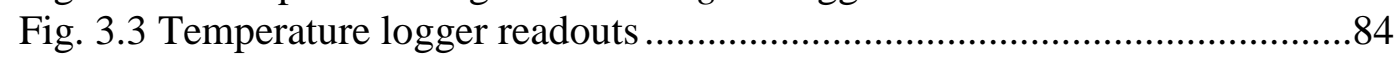

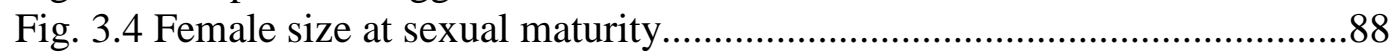

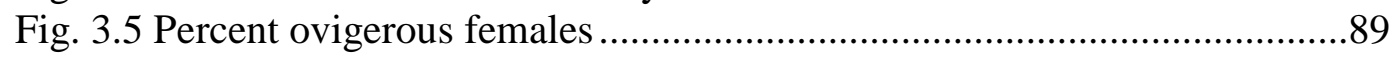

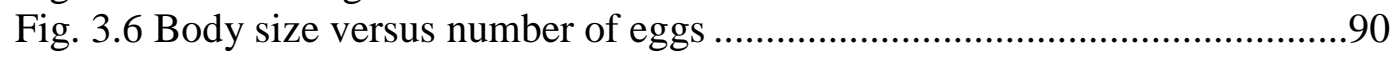

Fig. 3.7 Body weight versus clutch weight...................................................91

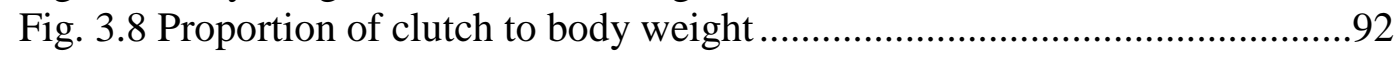

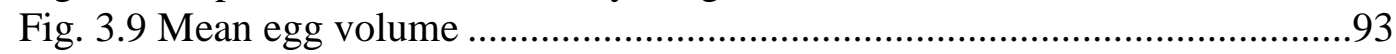

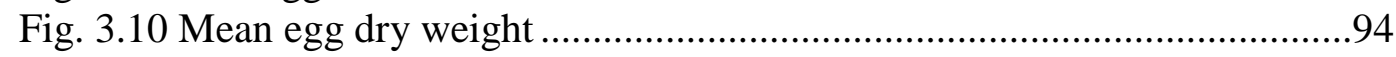

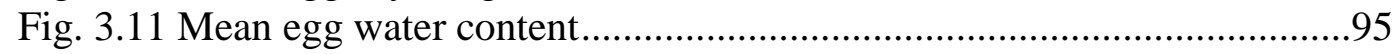

Fig. 3.12 Mean egg wet weight within clutch vs. dev. stage of eggs ...................96

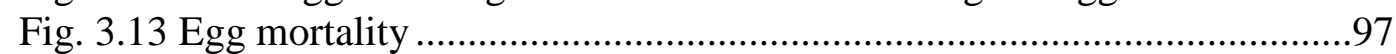

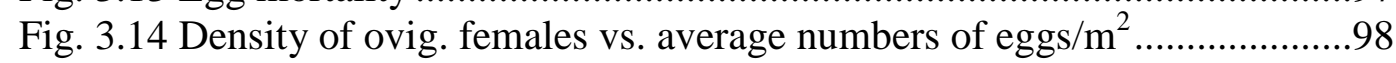




\section{CHAPTER FOUR}

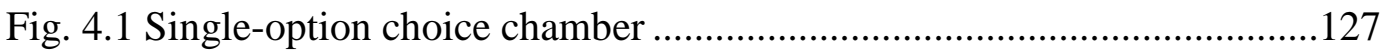

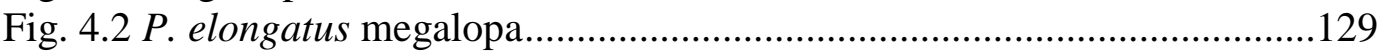

Fig. 4.3 Basket trap in an intertidal boulderfield ...............................................131

Fig. 4.4 Mean position of $P$. elongatus larvae within choice chamber................132

Fig. 4.5 Mean position of $P$. elongatus juveniles within choice chamber ...........133

Fig. 4.6 Percent distribution of responses at the end of observation ...................134

Fig. 4.7 Mean no. of settlers in absence or presence of conspecific adults .........136

\section{CHAPTER FIVE}

Fig. 5.1 Map of sample sites in Wellington Harbour and Cook Strait.................168

Fig. 5.2 Individual growth rate (IGR) by size class, density, and food level ......169

Fig. 5.3 Average mortality over 10 weeks within 4 size classes ........................171

Fig. 5.4 Feeding activity of crabs over $24 \mathrm{~h}$ within 4 size classes.......................172

Fig. 5.5 Change in body mass [\%] over 7 weeks .............................................175

Fig. 5.6 Change in body size $[\mathrm{mm}]$ over 7 weeks........................................175

Fig. 5.7 Early developmental stages of cheliped regeneration in P. elongatus ...176

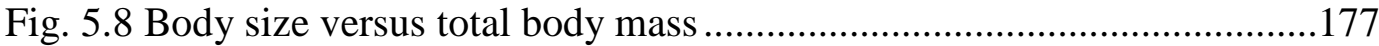

Fig. 5.9 Body mass versus cheliped weight ...................................................177

Fig. 5.10 Number of individuals per basket vs. frequency of limb loss .............178

Fig. 5.11 Reproductive output in females with and without regenerated limbs ..179

\section{CHAPTER SIX}

Fig. 6.1 General conceptual model of mechanisms influencing local population density, demography and reproductivity..........................................211 


\section{List of Tables}

\section{CHAPTER TWO}

Table 2.1 Nested mixed model ANOVA on crab density per rock .......................39

Table 2.2 Nested mixed model ANOVA on crab size..........................................40

Table 2.3 Nested mixed model ANOVA on rock size..........................................41

Table 2.4 One-way ANOVA adult crab density per basket vs. rock size...............46

Table 2.5 One-way ANOVA juvenile crab density per basket vs. rock size.........46

Table 2.6 One-way ANOVA adult carapace width versus rock size....................47

Table 2.7 Survival analysis: rock and crab size..................................................48

Table 2.8 3-Way ANOVA Distance Site + Size cl. + Run + (Site*Size cl. ......49

\section{CHAPTER THREE}

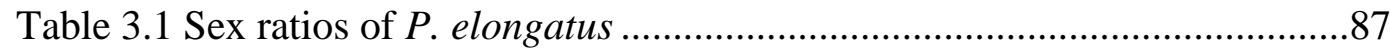

Table 3.2 Binominal logistic regression sex ratio vs. site..................................87

Table 3.3 One-way ANOVA female size at sexual maturity vs. site ...................88

Table 3.4 Logistic regression (Logit no. ovig. females $~$ Site + Size cl.)..............89

Table 3.5 ANCOVA results No. of eggs $\sim$ Site + Body size + (Site * Body size) 90

Table 3.6 ANCOVA results Cl. weight $\sim$ Site + Body wgt. + (Site * Body wgt.) 91

Table 3.7 ANCOVA results $\mathrm{P}_{\mathrm{CB}} \sim$ Site + Body size + (Site * Body size $)$..............93

Table 3.8 ANCOVA results $\mathrm{E}_{\mathrm{V}} \sim$ Site + Body weight $+($ Site $*$ Body weight $) \ldots . . .93$

Table 3.9 One-way ANOVA egg dry weight versus site.....................................94

Table 3.10: One-way ANOVA egg water content .............................................95

Table 3.11: Two-way ANOVA (EW Dev. stage + Site + (Dev. stage * Site) ...96

Table 3.12: One-way ANOVA results egg mortality vs. site .............................97

Table 3.13: One-way ANOVA results RO vs. site ..............................................98

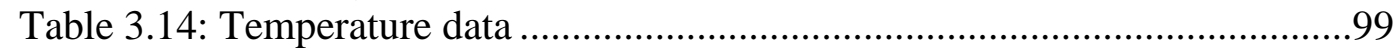

Table 3.15: One-Way ANOVA results on mean temperatures.............................99

\section{CHAPTER FOUR}

Table 4.1 Treatments single-option choice chamber .........................................128

Table 4.2 Contingency table for larval responses ...........................................134

Table 4.3 Significance values for the final positions of larvae (chi squared)......135

Table 4.4 Contingency table for juvenile responses .........................................135

Table 4.5 Significance values for the final positions of juveniles (chi squared) .135 


\section{CHAPTER FIVE}

Table 5.1 GLM results for IGR all size classes of crabs combined...................170

Table 5.2 GLM results for mortality all size classes of crabs combined .............170

Table 5.3 3-Way Repeated Measures ANOVA results (feeding activity)...........172

Table 5.4 Feeding activity of crabs within 4 size classes [\%] ...........................173

Table 5.5 2-Way ANOVA: individual growth rate (IGR ................................173

Table 5.6 2-Way ANOVA: individual body size increase (ISI) .........................173

Table 5.7 ANCOVA reproductive output * limb loss .....................................179 


\section{Chapter 1}

\section{General introduction}

\subsection{Introduction}

Understanding the causes and consequences of spatial patterns of abundance of organisms is a central problem in ecology. For effective management of harvested marine species, for example, spatial patterns of harvest rates, reproductive output, population recruitment and growth rates of individuals must be considered (Hutchings, 2000; Walters \& Kitchell, 2001; Conover \& Munch, 2000; Tapella et al., 2002). In conservation biology, the understanding how spatial structure influences metapopulation dynamics within single- and multispecies systems is crucial, especially for the management of endangered species living in fragmented habitats (Harding \& McNamara, 2002). Much basic evolutionary theory invokes spatially explicit phenomena, e.g. local adaptation and speciation. Despite the central role of spatial patterns in population dynamics, effective resource management, and evolutionary biology, our understanding of mechanisms responsible for spatial patterns is far from complete.

\section{Spatial variability and aggregation in nature}

It is widely acknowledged that ecological communities exhibit heterogeneity and patchiness on a broad range of spatial scales (Kotliar \& Wiens, 1990). The causes of this pattern may be different for different scales (Levin, 1992); hence, it is crucial for the comparison of scientific studies to consider the scale of observation (e.g. Archambault \& Bourget, 1996; Chitarro, 2002). Besides a large number of definitions of patchiness (Blackwell, 2007), a population distribution is regarded as patchy or aggregated if the ratio variance / mean number of individuals in random samples taken in the same habitat area is larger than 1 (Lloyd, 1967; Perry, 1981; reviewed in McArdle et al., 1990; McArdle \& Gaston, 1992; Gaston \& McArdle, 1993; Benedetti-Cecchi, 2003). This ratio is also called "index of dispersion" (see Perry \& Mead, 1979, and calculations in appendix 2.10 of chapter 2). Generally, the observed spatial variability in abundance of animals (i.e. their "patchy" distribution) has been attributed to the heterogeneity in biological and physical factors including the differential availability of resources 
such as food and shelter, as well as variability in predation, competition, disturbance, and recruitment (e.g. Dayton, 1971; Chapman et al., 1995; reviewed in Underwood, 1992, 1996; Caley et al., 1996). Especially in the rocky intertidal zone the resulting mosaic of patches with different sizes, shapes and habitat quality can exhibit high structural complexity with implications for patterns of abundance of species as well as for composition and diversity of communities. Individuals that group in response to resource availability and quality form patterns in which high quality patches have the highest densities (e.g. Fretwell \& Lucas, 1970; Seitz et al., 2003). However, the clumped (i.e. non-random) distribution of individuals does not always arise due to environmental heterogeneity but may also result from species-specific behaviour. Additionally, patterns of aggregation are not necessarily driven by functional purposes and evolutionary benefits and do not always result from the combined actions and interactions of many individuals. Currents, eddies and other hydrodynamic phenomena can result in highly clumped distributions of organisms (Levin \& Segel, 1976; Mackas et al., 1985). Once established, the properties of aggregations (e.g. group size and size frequency distribution) are influenced by biological factors including competition and predation. In addition to random aggregations that form temporarily due to physical effects or those that arise from individuals responding to external cues such as light or food there are "self organizing" aggregations (e.g. fish schools, colonies of bees and termites, as well as bird flocks), in which coordination and integration gives rise to swarm properties that are fundamentally different from properties of the individual (see Parrish et al., 2002; Sumpter, 2012). In these types of aggregations, the benefits typically lead to increased fitness of individuals (i.e. increased survival and/or reproductive success) as well as to increased fitness of the group (i.e. population persistence and/or increased population growth). Generally, the aggregation of animals has been viewed as an evolutionary advantageous state in which individuals may benefit from protection from predators, facilitation, enhanced foraging, mate choice and cooperation, balanced by the costs of limiting resources and increased disturbance risk (Okubo, 1986; Ritz, 1994; Flierl et al., 1999; Parrish \& Edelstein-Keshet, 1999; Floater, 2001). In aggregating species, however, the costs of intraspecific competition are low even at high densities (Donahue, 2006). To understand how aggregations are formed it is important to 
distinguish between the factors that trigger their formation and the effects arising from adaptive advantages (Miller \& Hampton, 1989; Hofmann et al., 2004).

\section{Habitat quality and density dependence}

The physical environmental conditions combined and interacting with biological factors at a particular location form a habitat, that could either be understood as space with relatively homogenous environmental conditions (micro-habitat) or, alternatively, as a certain biotope type that provides resources for its characteristic fauna and flora communities. Spatio-temporal variations in resource availability, resource quality and environmental conditions affect the fitness of individuals either directly or indirectly (Bernstein et al., 1991; Pulliam 2000) and thus generate strong selective pressure for habitat selection (Cody 1985). However, reproduction, survival, and abundance of species may not all be positively correlated with habitat quality (Johnson, 2007) and cannot be assumed without supporting demographic data (VanHorne, 1983). In aggregating species such as $P$. elongatus and $P$. cinctipes, extreme population densities may lead to negative density dependence, affecting individual growth, reproductive output and survival, even though 1) these adverse effects could be outweighed by positive density dependence (i.e. Allee effects) at slightly lower densities and 2) aggregations were initially formed due to high patch quality (compare Donahue, 2004, 2006).

\section{Life history characteristics and reproductive trade-offs}

For any individual, available resources and energy uptake are limited. Hence, the available energy "budget" needs to be balanced by splitting the investment, for example in reproduction and survival. Consequently, higher resource allocation to growth, survival and maintenance often comes at the cost of lower fecundity (i.e. number of offspring per individual). Females facing similar energetic constraints can either have small numbers of large eggs, large numbers of small eggs, or any intermediate combination, provided that the proportion of resources invested in reproduction stays the same relative to the amount of material and energy that is spent for growth, maintenance and survival. Generally, the benefits of performing an ecological function come at a cost of performing another. Stearns $(1989,1992)$ described life history trade-offs as negative functional interactions between reproductive traits. Reproductive patterns in marine invertebrates have been 
shown to be adaptive, in response to environmental conditions that select for maximum offspring survival and, therefore, population stability (Roff, 1992; Stearns, 1992). In decapods, life history traits such as egg size, number of eggs, reproductive output, and female body size may vary with temperature and latitude (Clarke, 1987; Lardies \& Castilla, 2001; Ramirez Llodra, 2002; Lardies et al., 2010). Fecundity, the quality of offspring and offspring survival are directly dependent on the nutritional state of the parent and its allocation of energy to reproduction (Olive, 1985; Eckelbarger, 1986; Jaeckle, 1995, Bertram \& Strathmann, 1998). For the porcelain crab Petrolisthes granulosus, Monaco et al. (2010) demonstrated that maximum body size and reproductive capacity are correlated with latitude; however, food availability and genetic factors may play an important role, as well. Shallow water benthic Crustacea in the polar regions commonly have a larger body size, larger eggs and a non-pelagic development compared to temperate and tropical species with a typically biphasic lifecycle that comprises a planktonic phase lasting several days to several months (Sastry, 1983, and literature therein). A larger maternal investment in individual eggs leads to larger "high quality" eggs and therefore to higher offspring survival (Stearns, 1992; Ramirez Llodra, 2002). However, larger eggs and higher offspring survival result in decreased fecundity and, due to hatching at a more advanced stage in development and shorter planktonic phase, lower dispersal capability. Environmental factors such as food availability and quality, temperature, competition, and predation select for an optimal egg size within certain limits that maximises parental fitness (Olive, 1985; Stearns, 1992; Ramirez Llodra, 2002). Smith \& Fretwell (1974) proposed a model that suggests the selection for a single optimal level of parental investment in offspring for a given species. The variability of egg sizes observed in natural populations may be caused by temporal environmental effects during offspring development, affecting the ability of adults to allocate equal amounts of resources to each egg (McGinley et al., 1987) as well as by morpho-functional constraints and adaptive phenotypic plasticity caused by variability in egg size and resulting offspring fitness (Einum \& Fleming, 2000). The reproductive patterns of decapods are strongly influenced by the trade-off between body size and fecundity (Ramirez Llodra, 2002). Larger females carry higher numbers of eggs (Sastry, 1983; Ramirez Llodra, 2002 and literature therein). Likewise, egg mass weight is positively correlated with female 
body weight (Corey \& Reid, 1991). In addition to energetic and physiological constraints, the physical space for eggs that can be attached to pleopods is limited and depends on body size (Hines, 1982; Somers, 1991; Clarke, 1993). The age or size at first maturity is an important indicator for the life-history strategy of a species and is defined as the age or size at which the female produces the first batch of eggs (Ramirez Llodra, 2002). While early maturing species have shorter life spans and generation times, species with a later onset of sexual maturity live longer, grow larger and therefore have higher initial fecundity. A long lifespan also increases the probability of multiple spawning, thereby increasing lifetime fecundity. However, a delayed maturity also increases the mortality risk before reproductive capability is reached (Bell, 1980; Stearns, 1980, 1992). Additionally, the allocation of resources to reproduction may decrease parental survival and the probability of another reproductive event (Bell, 1980; Stearns, 1992; Gardner, 1999). To understand the demography and population dynamics of a species, the study of its life-history strategy is of great value. As a series of co-adapted and interdependent traits, the life history strategy of a species evolves in response to or in interaction with selective pressures of the biotic and abiotic environment, within limits of genetic, morphological, and physiological constraints.

\section{Consequences of spatial structure on population dynamics and life-history traits}

Spatial structure influences stability and organization of single and multispecies systems, both in nature and in theoretical considerations (Kareiva 1987; Tilman \& Kareiva, 1997; Hanski, 1999). In fragmented landscapes the risk of extinction is usually increased, especially with increasing isolation of habitat patches or decreasing patch size (Burkey \& Reed, 2006). Metapopulation dynamics crucially depend on the form of the relationship between recruitment rate (comprising both immigration and settlement) and the reduction in extinction risk (Levins, 1969; Harding \& McNamara, 2002). However, not all patchy populations are metapopulations (Hanski \& Simberloff, 1997), especially if subpopulations are not spatially separated but rather colonize a continuous or connected habitat with high spatial variability of environmental conditions. Metapopulations inhabiting isolated habitat patches may have extremely complex dynamics (Levins, 1969; Hastings \& Volin 1989; Artzy-Randrup \& Stone, 2010) due to large scale dispersal influenced by wind drift, currents and shoreline properties, leading to a differential connectivity (Pineda et al., 2007; Treml et al., 2008; Carson et al., 
2011; Watson et al., 2012). Additionally, larval settlement and recruitment rates in marine invertebrates are highly variable on several special and temporal scales (reviewed in Rodriguez et al., 1993; Pineda, 2010). As a result of large scale dispersal, costal marine species commonly exist in systems of interconnected subpopulations (e.g. Watson et al., 2011a and b). Because gene flow between geographically isolated populations may increase fitness (Bossuyt, 2007; Vandewoestijne, 2008), pelagic larval development is of particular significance for benthic marine invertebrates, many of which have limited dispersal capabilities as adults. Dispersal also allows the colonization and recolonization of habitat patches (Hanski, 1985; Fahrig \& Paloheimo, 1988; Adler \& Nuernberger, 1994). On the other hand, dispersal effects are balanced by the costs of high losses of individuals due to failure to find suitable habitat and predation. In adaptation to geographically isolated metapopulations, species are more likely to exhibit high frequency of spawning, larger numbers of smaller offspring (due to the trade-off between size and number of offspring), prolonged pelagic larval development, and an ability to detect and respond to settlement cues. Additionally, the evolution of life history traits is influenced by habitat stability, disturbance rate, climate, food conditions, competition, and predation.

\section{Settlement cues and conspecific attraction}

Historically, it has become a paradigm that marine invertebrate larvae are passively transported by advection and diffusion (Johnson, 1939, Abelson \& Denny, 1997), mixed in a "larval pool" (Pineda, 2000), and then randomly recruited to juvenile or adult habitat (Roughgarden et al., 1988; Siegel et al., 2003; Pineda et al., 2007). However, in many species settlement occurs nonrandomly due to the selectivity of larvae that is associated with a range of different settlement cues, many of which are species specific (for reviews, see Meadows \& Campbell, 1972; Crisp, 1974; Burke, 1983, 1986; Pawlik, 1992; Rodriguez et al., 1993; Rittschof et al., 1998; Hadfield \& Paul, 2001; Hay, 2009). A high specificity in detection of and responding to settlement cues in competent larvae may be correlated with their fitness and survival probability because settlement into sub-optimal habitat can be detrimental (reviewed in Levin \& Bridges, 1995; Heyland et al., 2011). Besides a range of physical substratum properties such as surface texture that may act as settlement cues, chemical waterborne cues either originate from substratum components or are released by 
biofilms, coexisting species, predators or conspecifics; however, for most species, biological and chemical characteristics appear to be more important than physical properties (e.g. LeTourneux \& Bourget, 1988). Conspecific cueing has been regarded as an adaptation of benthic marine invertebrates to a fragmented or widespread species distribution that increases the chance for a larva to find suitable habitat, facilitates dispersal, and ensures connectivity between geographically isolated metapopulations (Rodriguez et al., 1993; Pineda et al., 2007).

\subsection{Study location}

\section{Hydrology}

Wellington Harbour (Port Nicholson, Te Whanganui-a-Tara) is of tectonic origin, and a major earthquake fault lies along its western shore. While the entrance at its southern end is only $1.8 \mathrm{~km}$ wide, the Harbour itself measures $11.1 \mathrm{~km}$ at its widest point, has a surface area of approximately $85 \mathrm{~km}^{2}$, and is with an average depth of 20m (31m max.) relatively shallow (Booth, 1975) (Fig. 1.1). The semi-diurnal tides in the Harbour have a range of approximately $0.75 \mathrm{~m}$ on average with a maximum of $1.5 \mathrm{~m}$ during spring tides (Maxwell, 1956). On flood tide, water within the Harbour flows in a clockwise direction and anti-clockwise on ebb tide, leading to a net clockwise flow (Brodie, 1958; Heath, 1977). The major source of freshwater input is the Hutt River with a catchment of $630 \mathrm{~km}^{2}$ (Booth, 1975) and a discharge ranging from $2 \times 10^{6} \mathrm{~m}^{3}$ to $180 \times 10^{6} \mathrm{~m}^{3}$ (Maxwell, 1956). A freshwater lens with a thickness of ca. $1 \mathrm{~m}$ extends out from the Hutt River mouth along the eastern shore and may reach as far south as well past Matiu-Somes Island after prolonged periods of rain (Helson, 2001). Other (minor) sources of freshwater input include three small streams: Kaiwharawhara, Ngauranga and Korokoro.

Cook Strait (Raukawa Moana), the strait between North and South Island of New Zealand, connects the Tasman Sea on the west with the South Pacific Ocean on the east (Fig. 1.2). With 23 kilometers at its narrowest point and an average depth of 128 meters it separates Cape Terawhiti in the North Island from Perano Head on Arapawa Island in the Marlborough Sounds. To the east, between the submarine plateaus of both islands lies the Cook Strait Canyon with steep walls descending eastwards into the Hikurangi Trench. The Narrows Basin to the north- 
west is between 300 and 400 meters deep. The tidal flow through Cook Strait is unusual in that on each side of the strait ebb and high tides are almost exactly out of phase. Strong currents result, with almost zero tidal height change in the centre of the strait. Dependent on weather conditions, the tidal surge can be irregular. The direction of the flow is usually reversed every six hours but strong winds may partly negate reversed surge, resulting in unidirectional flow over longer periods (Carter, 2001; Foster, 2006). Moreover, water flow as well as variations in temperature and salinity within Cook Strait is influenced by three major currents: The Southland Current, moving northward along the east coast of the South Island, the (sub surface) East Cape Current, moving southward along the east coast of the North Island, and the D'Urville Current, travelling northward along the west coast of the South Island, entering Cook Strait from the north due to prevailing northerly winds (see Bowman et al., 1983). These currents mix in Cook Strait in an area called the "Narrows", west of Cape Terawhiti. In this area, flow velocities between 12.5 and $25 \mathrm{~cm} \mathrm{~s}^{-1}$ have been measured (Heath, 1971).

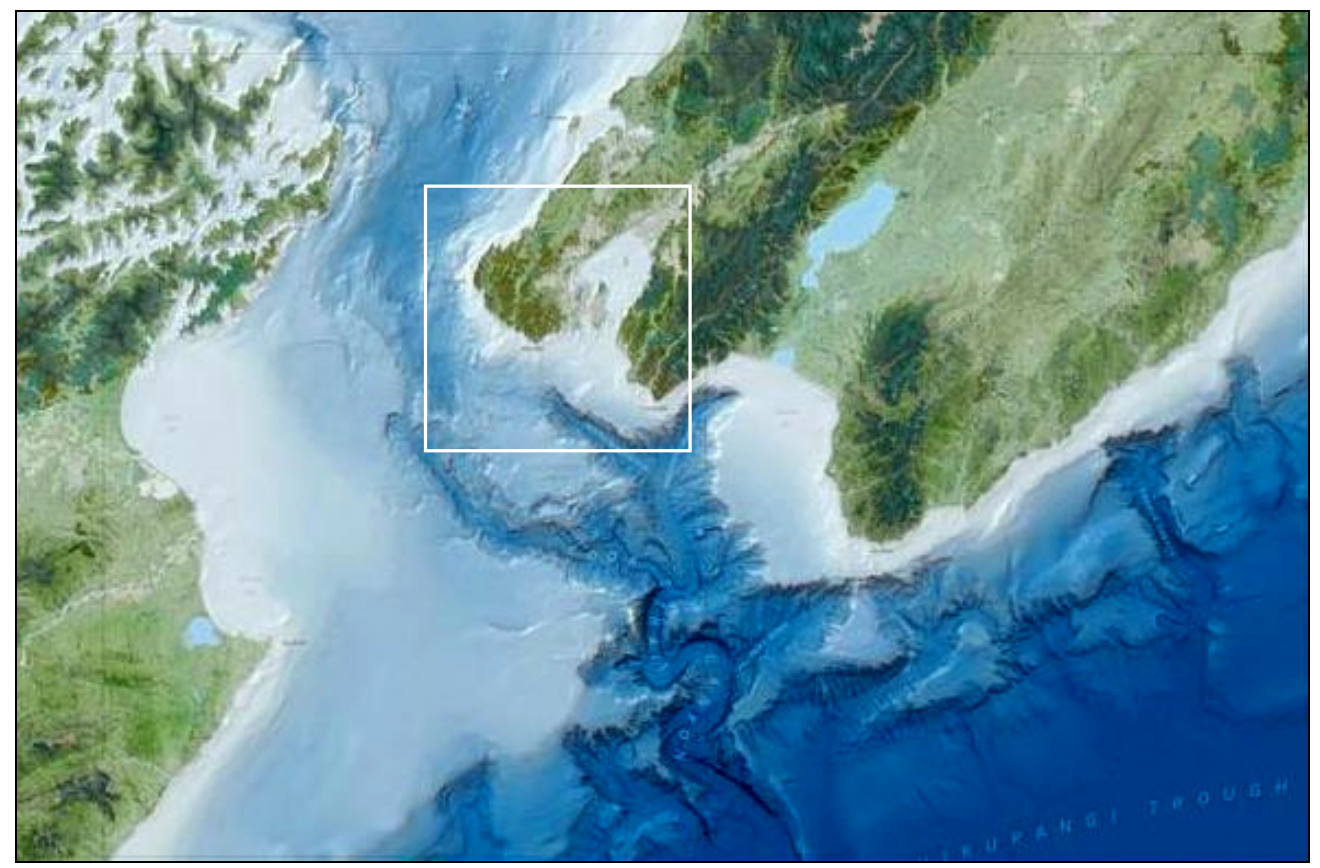

Fig. 1.1: Cook Strait with seafloor contours with Cook Strait Canyon and Hikurangi Trench (image credit: National Institute of Water and Atmospheric Research, NIWA, New Zealand). The boxed area, including Wellington Harbour, is represented in Fig. 1.2. 


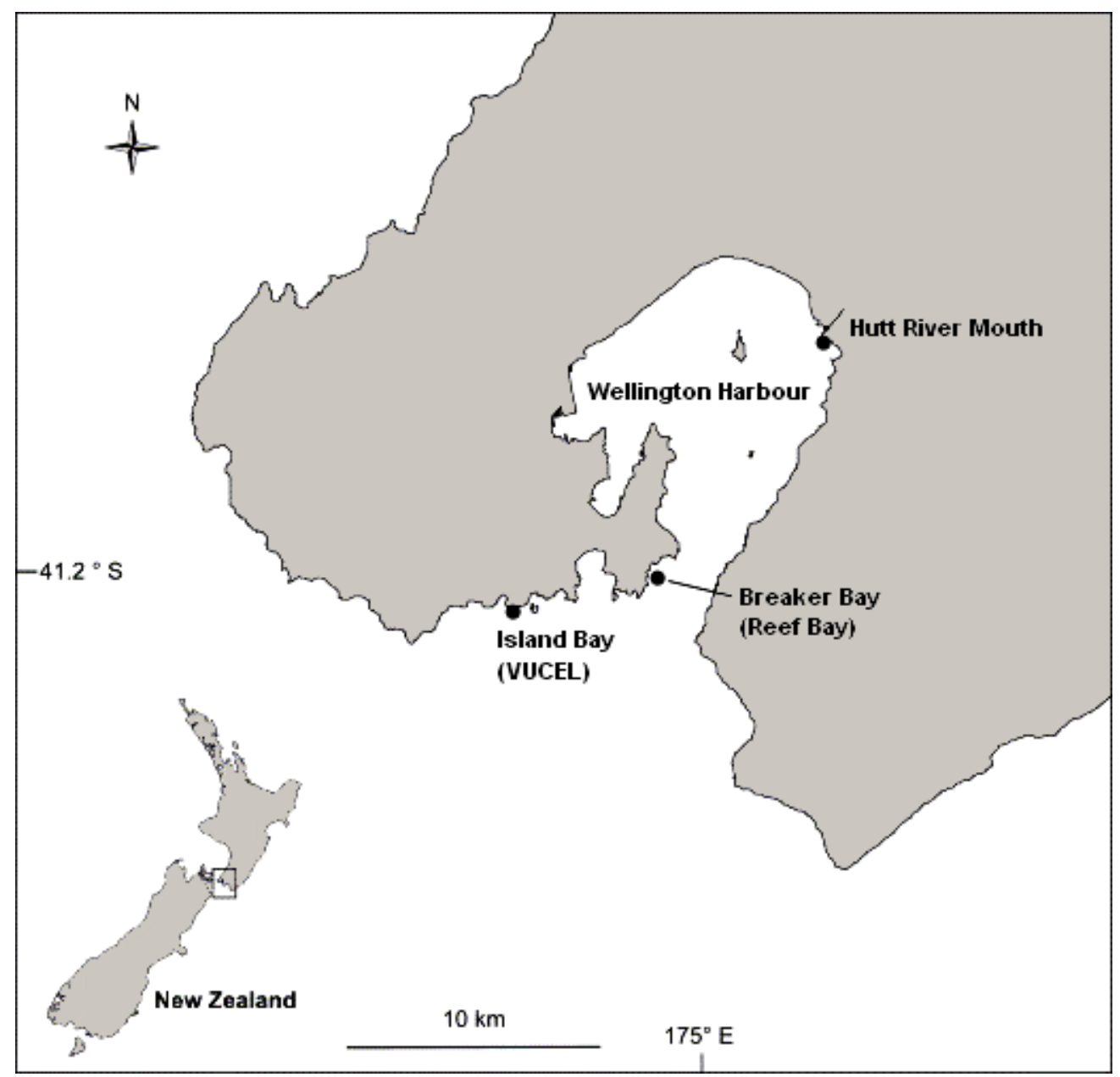

Fig 1.2: Map of main study sites in Wellington region at the southern tip of New Zealand's North Island in Wellington Harbour (Hutt River mouth (HRM), $41^{\circ} 14^{\prime} 49.50^{\prime \prime} \mathrm{S}, 174^{\circ} 53^{\prime} 57.00^{\prime}$ ' E), at the Harbour entrance (Breaker Bay - Reef

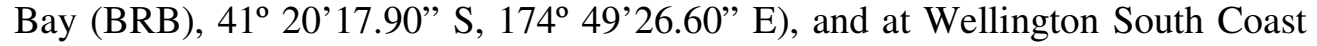
(Island Bay - VUCEL (ISB), 41²0'54.30” S, 174 45'53.20” E).

Wind and wave exposure

Due to the funnel effect of Cook Strait, wind speeds are generally high in the Wellington area. Especially during the winter months Wellington's South Coast is regularly exposed to gale force southerly winds and swell heights of up to $6 \mathrm{~m}$ have been frequently reported by MetService New Zealand (http://metservice.com/marine/coastal/cook). Maximum wave heights off Baring Head (10km south-east of Wellington), measured by buoys, peaked at 7 to $8 \mathrm{~m}$ (http://www.niwa.co.nz/our-science/natural-hazards/research-projects, 2010). The inner Wellington Harbour, by contrast, is a moderate wave energy environment, sheltered from swell from all directions except the narrow entrance to the south. 
As a consequence, the Harbour is mainly subject to low energy waves generated by sea breezes, but is also influenced by ground swell from Cook Strait. On stormy days with southerly winds, wave heights may occasionally exceed $1 \mathrm{~m}$ at the northern end of the Harbour (own observation).

\section{Selection of study sites}

Three intertidal cobble beaches in the Wellington area were selected as study sites, all of which were inhabited by porcelain crabs in high densities. The littoral zone at all three locations consists mainly of rough shingle and cobbles, interspersed with larger rocks. At Island Bay and Breaker Bay, large rocky greywacke outcrops fringe the boulder fields and form a reef-like barrier that partly protects the beaches from heavy surge. While the South Coast site, now situated within the boundaries of Kupe / Kevin Smith Marine Reserve, is characterised by high wave exposure, lower mean water temperatures, and generally smaller cobble sizes, the opposite was found at the Harbour site (Hutt River mouth). With overall intermediate features at the harbour entrance (Breaker Bay), the differential adaptations of $P$. elongatus individuals and populationresponses could be examined within a broad range of environmental conditions. 

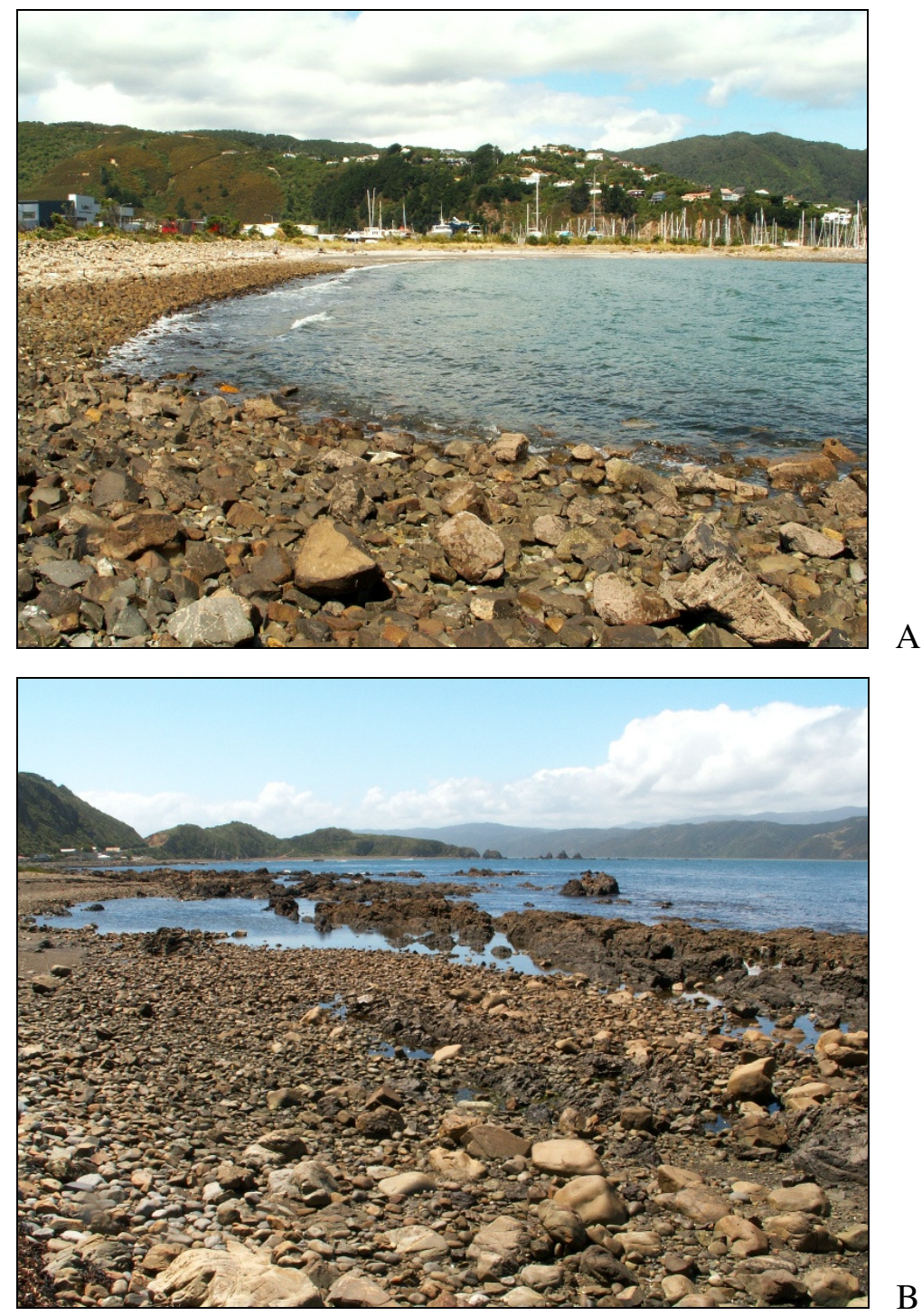

\section{A}

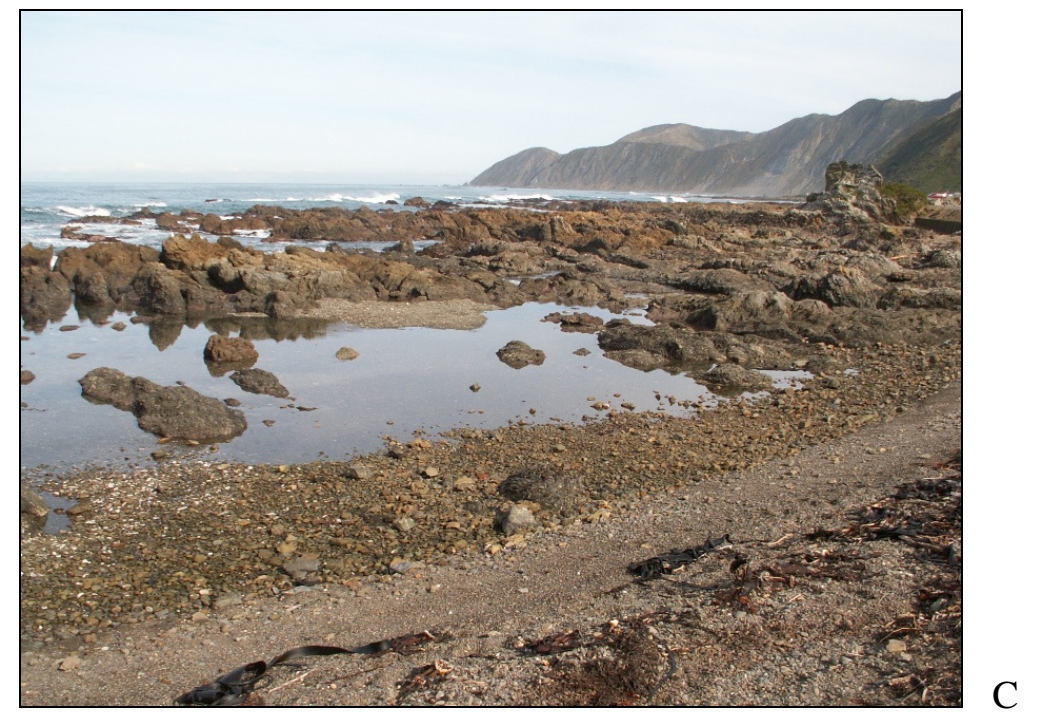

Fig.1.3: Study sites, A) Hutt River mouth, B) Breaker Bay, C) Island Bay - VUCEL 


\subsection{Study species}

The porcelain crab Petrolisthes elongatus (H. Milne Edwards, 1837) is highly abundant on intertidal boulder fields and cobble beaches throughout New Zealand including Auckland Islands as well as in Tasmania, Australia (Pellegrino, 1984). As these crabs appear to be restricted to this habitat type, it forms geomorphologically isolated metapopulations that are separated by uninhabited sandy beaches and stretches of rocky shores by hundreds of meters to several kilometers. Hence, the species exhibit a patchy distribution on a large scale in a naturally fragmented habitat. Field observations prior to this study revealed patchiness in local density also on a medium scale (several meters), as well as on a small scale (tens of centimetres), with high density aggregations under larger boulders. Besides an obvious negative phototaxis (Scott, 1958), Meyer-Rochow \& Meha (1994) found, based on field studies, that during the day P. elongatus has a considerably higher tendency to conceal itself at low tide compared to high tide. Ovigerous females occur from October to March (Jones, 1977). Compared to other decapods occurring in similar latitudes, the eggs are large (Gohar \& AlKholy, 1957), whereby egg numbers are relatively small (Greenwood, 1965). Large females (14mm carapace length) have up to 900 (Jones, 1977), 1100 (Wear, 1965) or 1200 eggs (Greenwood, 1963), respectively. Like many other marine invertebrates, $P$. elongatus has a biphasic life cycle (Fig.1.3), with a planktonic larval phase and benthic juvenile and adult populations. The swimming and feeding larval stages remain in the plankton for several weeks; however, the exact duration of the planktonic phase of Porcellanidae is still unknown. According to laboratory-based rearing of $P$. laevigatus from a similar latitude in Chile (Mascetti \& Wehrtmann, 1996), the larval development in P. elongatus (from hatching until metamorphosis into first instar juvenile) is likely to last for approximately 3-6 weeks and comprises six different stages, one or two of which may be frequently bypassed (Wear, 1964). Lower water temperatures typically result in considerably longer larval intermoult periods (Mascetti \& Wehrtmann, 1996) and consequently in longer planktonic phases. Studies at Christchurch (Scott, 1958), Kaikoura (Jones, 1977), Wellington (Wear, 1965) and Auckland (Greenwood, 1965) suggest that breeding biology of $P$. elongatus varies with latitude. For a more comprehensive species description, see McLay (1988). 


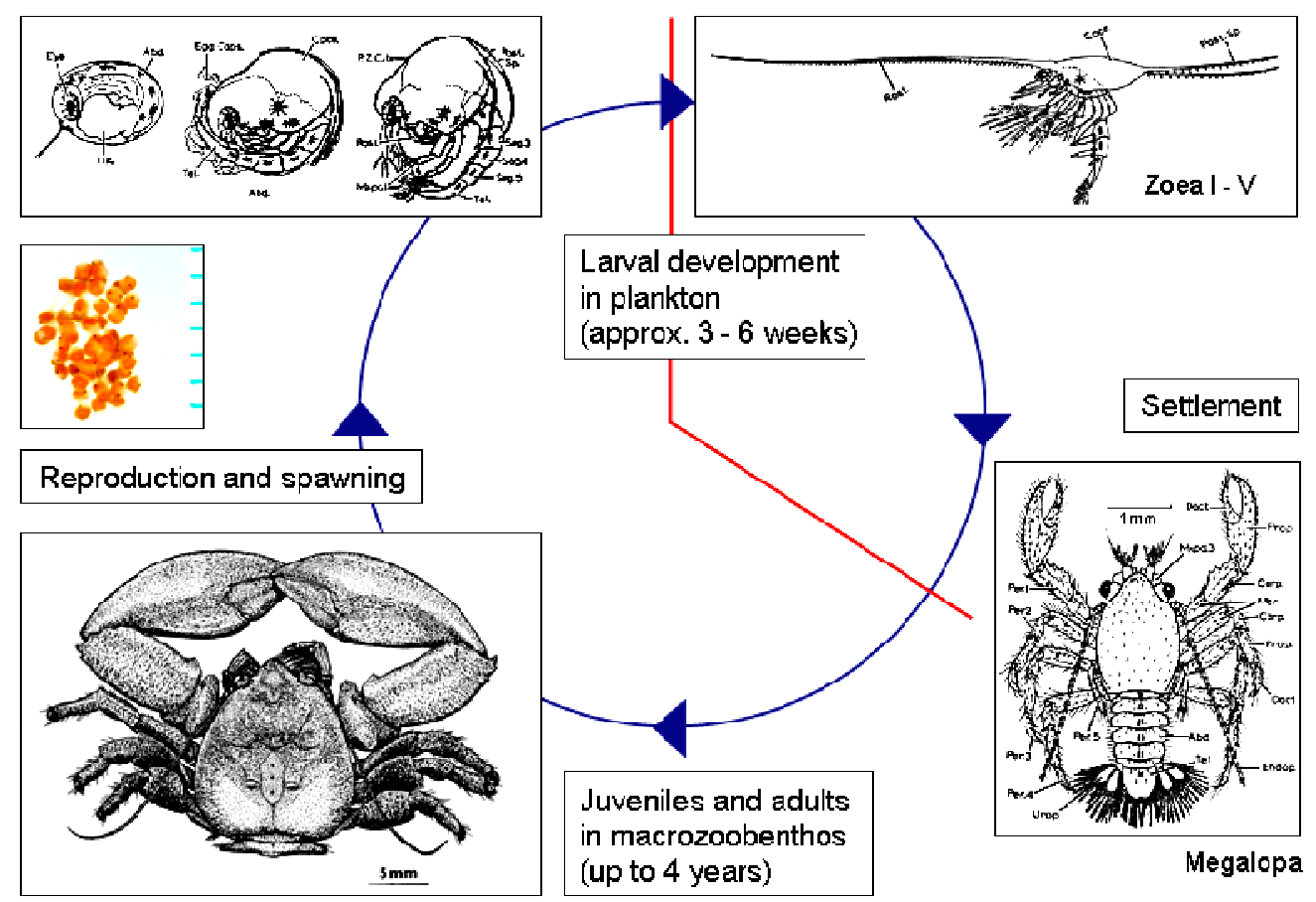

Fig. 1.4: Biphasic life cycle of Petrolisthes elongatus, comprising a pelagic larval and a benthic juvenile-adult phase. Eggs are attached to three pairs of pleopods in female crabs and carried between abdominal flap and sternum until hatching. Larval development via three to five planktotrophic zoea stages; the megalopa forms the last, meroplanktic stage that becomes competent and settles in rocky intertidal, approx. 3-6 weeks after hatching. Drawings of larval stages by Wear (1964); drawing of the adult stage by Jones (1977).

\subsection{Objectives}

Understanding the causes and consequences of population dynamics on various spatial scales and species-specific reproductive traits as adaptations to environmental conditions is crucial for both conservation and sustainable stock management. The identification of relevant habitat quality indicators for a species helps to understand its ecology and specific requirements for survival and fitness maximisation. Due to its high abundance and accessibility in intertidal boulder fields, its gregariousness, as well as its patchy distribution on a range of spatial scales $P$. elongatus was chosen as a suitable model organism to study the underlying mechanisms of observable distributional patterns within benthic populations, including habitat quality, settlement rates, and density dependence. 
In this study, I examine the main drivers of patchiness of abundance in P. elongatus. Since these patterns are commonly influenced by habitat quality and the heterogeneous availability of resources I aim to identify the relevant environmental factors responsible for the patchy distribution of crabs within and between habitats. Because P. elongatus inhabits the interstitial space between boulders the availability of this cavity system serving as shelter and refuge is potentially crucial, providing protection from predation and excessive water movement. Therefore, I test the hypothesis that cobble size is a relevant habitat quality indicator for $P$. elongatus, directly or indirectly affecting patterns of settlement, migration, abundance and survival in this species. If we assume that the differences in shape or "roundness" of boulders are negligible, then the sizefrequency distribution of boulders within a defined area determines the relative size of cavities, physically restricting the size and number of crabs that can inhabit a particular space between them. Hence, I aim to investigate whether rock size is a suitable predictor of local density and average size of crabs. The limiting factor of available interstitial space that may affect the size-frequency distribution of $P$. elongatus could also restrict or allow predation. I therefore aim to examine whether predation rates depend on rock size. Since structural complexity affects mobility, I investigate the impact of rock size on migratory activity. However, besides rock size other environmental factors may also influence local abundance; therefore, I aim to analyse spatio-temporal variations in temperature, food availability and larval supply.

The evolution of life history traits in marine invertebrates and other animals is shaped by environmental conditions that affect fitness. Additionally, reproductive traits, e.g. egg size and egg quality, may be altered by factors such as ambient temperature and food conditions (i.e. exhibit phenotypic plasticity). Against this background, I speculate whether extreme differences in habitat structure, wave exposure, temperature, predator abundance, and food supply between sites in Wellington Harbour and at the south coast influence or select for certain life history characteristics. In order to examine the probable site differences in reproductive traits in relation to environmental conditions, I measure and compare important life history characteristics in females from three geographically isolated metapopulations, e.g. body size versus number of eggs and egg mass weight, 
female size at maturity, and egg mortality, in conjunction with temperature data and site differences in food availability and rock size.

Since conspecific cueing is common among marine invertebrates and P. elongatus is an aggregating species that is likely to settle gregariously (i.e. preferably in the presence of conspecifics) I hypothesize that competent larvae of this species are attracted to conspecific adults, mediated by a waterborne cue. If settlement was dependent on the presence of conspecifics, then higher cue densities due to higher local abundance of adults may be correlated with higher settlement rates. This assumption is tested with various field and laboratory experiments. Additionally, I investigate other potential sources of settlement cues such as crustose coralline algae and diatom biofilms that had been reported to affect swimming direction of other decapod larvae.

Living in aggregations involves a trade-off between fitness gains of in-group individuals and costs due to intraspecific competition for limited resources, especially at density levels close to the carrying capacity of a habitat patch. These costs and benefits depend on both life history and environmental conditions. To investigate how population density, combined with food availability, affects individual growth rates and feeding activity within different size classes of crabs I conduct a series of laboratory experiments similar to the work presented by Donahue $(2002,2004)$ on the density dependence in Petrolisthes cinctipes. Because crabs with autotomized limbs can be frequently found in the field it seems compelling to study the associated costs of limb loss by examining the effects of limb regeneration on individual growth rate and reproductive output. Additionally, I aim to determine whether frequency of limb loss can be predicted by local density (as an indicator for intraspecific competition) or whether autotomy is correlated with site-specific disturbance and predation rates, because shedding a limb is a strategy porcelain crabs utilize to escape predators or physical stress.

In summary, the aim of this study is to identify the main mechanisms and factors shaping the population structure of $P$. elongatus and the observable heterogeneity of abundance in the field. 


\subsection{Thesis layout}

This dissertation comprises six chapters.

Chapter 2 discusses the role of cobble size as habitat quality indicator for $P$. elongatus on various spatial scales, ranging from single rocks within $0.25 \mathrm{~m}^{2}$ sample quadrats to different sites in the Wellington region, several kilometers apart. In a nested design the patterns of abundance as well as the mean carapace width of crabs are analysed in regard to rock size. In further experiments I examine the influence of cobble size on predation rates, migratory activity, and size frequency distribution of crabs in the field.

Chapter 3 investigates if and how the life history characteristics of $P$. elongatus differ between sample sites and discusses the underlying mechanisms driving the observed patterns. At all sample sites, temperature data are taken with data loggers placed among cobbles. Additionally, the analysis of spatio-temporal variations in food and larval supply is attempted, albeit without yielding usable datasets. Combined with conclusions drawn in chapter 2 , the role of habitat quality in mediating life history characteristics is discussed.

Chapter 4 presents a comparative examination of a number of potential settlement inducing waterborne cues, both under laboratory conditions and in the field. With the help of a single option choice chamber the swimming behaviour of competent $P$. elongatus larvae in response to various potential chemical attractants, including those released by conspecific adults, is investigated. Settlement in response to presence or absence of conspecifics is examined using basket traps deployed among intertidal boulder fields.

Chapter 5 investigates the effects of density dependence on survival, individual growth rate, and feeding activity in $P$. elongatus across different size classes under laboratory conditions. Using a fully crossed factorial design combining two food levels and two crab densities, growth and mortality rates are monitored, while densities remain constant by replacing lost individuals. Adopting the same experimental setup and treatments, the effect of density and food level on frequency of filter-feeding is examined. To investigate the effect of limb loss on growth rate, changes in body mass and carapace width under laboratory 
conditions are recorded over several weeks, which are then compared between injured and uninjured crabs across different size classes. Data obtained from a field survey complement these results.

Chapter 6 represents the integrated summary and general discussion of the findings of the various components of this study with regard to the previously formulated thesis aims. 


\section{References}

Adler , F. \& Nuernberger, B., 1994. Persistence in patchy irregular landscapes. Theoretical Population Biology 45: 41-75.

Archambault, P. \& Bourget, E., 1996. Scales of coastal heterogeneity and benthic intertidal species richness, diversity and abundance. Mar. Ecol. Prog. Ser. 136: $111-121$.

Artzy-Randrup, Y. \& Stone, L., 2010. Connectivity, Cycles, and Persistence Thresholds in Metapopulation Networks. PLoS Comput. Biol. 6(8): e1000876. doi:10.1371/journal.pcbi.1000876

Bell, G., 1980. The costs of reproduction and their consequences. Am. Nat. 116: 45-76.

Benedetti-Cecchi, L., 2003. The importance of the variance around the mean effect size of ecological processes. Ecology 84(9): 2335-2346.

Bernstein, C.M.; Krebs, J.R. \& Kacelnik, A., 1991. Distribution of birds amongst habitats: theory and relevance to conservation. Pp. 317-345. In: Bird population studies: relevance to conservation and management. C.M. Perrins; J.D. Lebreton \& G.J.M. Hirons (eds.). Oxford University Press, Oxford, UK.

Bertram, D.F. \& Strathmann, R.R., 1998. Effects of maternal and larval nutrition on growth and form of planktotrophic larvae. Ecology 79: 315-327.

Blackwell, P.G., 2007. Heterogeneity, patchiness and correlation of resources. Ecological Modelling 207 (2-4): 349-355.

Booth, J.D., 1975. Seasonal and tidal variations in the hydrology of Wellington Harbour. New Zealand J. Mar. Fresh. Res. 9(3): 333-354.

Bossuyt, B., 2007. Genetic rescue in an isolated metapopulation of a naturally fragmented plant species, Parnassia palustris. Conserv. Biol. 21(3): 832-41.

Brodie, J.W., 1958. A note on tidal circulation in Port Nicholson, New Zealand. N.Z. J. Geol. Geophys. 1(4): 684-702.

Burkey, T.V. \& Reed, D.H., 2006. The effects of habitat fragmentation on extinction risk. Mechanisms and synthesis. Songkl. J. Sci. Technol. 28(1): 9-37.

Caley, M.J.; Carr, M.H.; Hixon, M.A.; Hughes, T.P.; Jones, G.P. \& Menge, B.A., 1996. Recruitment and the local dynamics of open marine populations. Ann. Review Ecol. Syst. 27: 477-500.

Carson, H.S.; Cook, G.S.; López-Duarte, P.C. \& Levin, L.A., 2011. Evaluating the importance of demographic connectivity in a marine metapopulation. Ecology 92: 1972-1984. 
Carter, L., 2001. Currents of change: the ocean flow in a changing world. National Institute of Water and Atmospheric Research (NIWA) New Zealand: Water \& Atmosphere 9(4): 15-17.

Chapman, M.G., Underwood, A.J. \& Skilleter, G.A., 1995. Variability at different spatial scales between a subtidal assemblage exposed to the discharge of sewage and 2 control assemblages. J. Exp. Mar. Biol. Ecol. 189: 103-122.

Chitarro, P.M., 2002.Species-area relationships for coral reef fish assemblages of St. Croix, US Virgin Islands. Mar. Ecol. Prog. Ser. 233: 253-261.

Clarke, A., 1993. Reproductive trade-offs in caridean shrimps. Funct. Ecol. 7: 411-419.

Clarke, A., 1987. Temperature, latitude and reproductive effort. Mar. Ecol. Prog. Ser. 38:89-99.

Cody, M.L. (ed.), 1985. Habitat selection in birds. Academic Press, Orlando, Fl.

Conover, D.G. \& Munch, S.B, 2002. Sustaining fisheries yields over evolutionary time scales. Science 297: 94-96.

Dayton, P.K. 1971. Competition, disturbance, and community organization: the provision and subsequent utilization of space in a rocky intertidal community. Ecol. Monogr. 41: 351-389.

Donahue, M.J., 2004. Size-dependent competition in a gregarious porcelain crab Petrolisthes cinctipes (Anomura: Porcellanidae). Mar. Ecol. Prog. Ser. 267: 219-231.

Donahue, M.J., 2006. Allee effects and conspecific cueing jointly lead to conspecific attraction. Oecologia 149: 33-43.

Einum, S. \& Fleming, I.A., 2000. Highly fecund mothers sacrifice offspring survival to maximize fitness. Nature 405: 565-567.

Fahrig, L. \& Paloheimo, J., 1988. Effect of spatial arrangement of habitat patches on local population size. Ecology 69: 468-75.

Flierl, G.; Grünbaum, D.; Levin, S. \& Olson, D., 1999. From individuals to aggregations: the interplay between behaviour and physics. J. Theoret. Biol. 196: 397-454.

Floater, G.J., 2001. Habitat complexity, spatial interference, and "minimum risk distribution'": a framework for population stability. Ecology 71: 447-468.

Foster, M.W., 2006. The rise and fall of Cook Strait. ISBN 978-0-473-11956-0. $64 \mathrm{pp}$.

Fretwell, S.D. \& Lucas, H.J., 1970. Ideal free distribution. Acta Biotheor.19: p16. 
Gardner, C., 1999. The larval and reproductive biology of the giant crab Pseudocarcinus gigas. PhD thesis, University of Tasmania, Launceston, Tasmania, Australia. 666 pp.

Gohar, H.A.F \& Al-Kholy, A.A., 1957. The larvae of four decapod crustacea from the Red Sea. Publ. Mar. Biol. Sta. Al Ghardaga (Red Sea) 9: 177-202.

Greenwood, J.G., 1965. The larval development of Petrolisthes elongatus (H. Milne Edwards) and Petrolisthes novaezelandiae Filhol (Anomura, Porcellanidae) with notes on breeding. Crustaceana 8: 285-307.

Hanski, I., 1985. Single-species spatial dynamics may contribute to long-term rarity and commonness. Ecology 66: 335-43.

Hanski, I., 1999. Metapopulation ecology. Oxford University Press, Oxford. $328 \mathrm{pp}$.

Hanski, I. \& Simberloff, D., 1997. The metapopulation approach, its history, conceptual domain, and application to conservation. In: Metapopulation Biology: Ecology, genetics and evolution. I.A. Hanski \& M.E. Gilpin (eds.). Academic Press, San Diego, CA. pp. 5-26.

Harding, K.C. \& McNamara, J., 2002. A unifying framework for metapopulation dynamics. Am. Nat. 160(2): 173-185.

Hastings, A. \& Volin, C., 1989. Within-patch dynamics in a metapopulation. Ecology 70: 1261-1266.

Heath, R.A., 1971. Hydrology and circulation in central and southern Cook Strait, New Zealand. New Zealand J. Mar. Fresh. Res. 5(1): 178-199.

Heath, R.A., 1977. Circulation and hydrology of Wellington Harbour. New Zealand Oceanographic Survey 12, 8pp.

Heyland, A.; Degnan, S. \& Reitzel, A.M., 2011. Emerging patterns in the regulation and evolution of marine invertebrate settlement and metamorphosis. In: Mechanisms of Life History Evolution: The Genetics and Physiology of Life History Evolution. T. Flatt, A. Heyland (eds.). Oxford University Press, New York. Pp. 29-42.

Hines, A.H., 1982. Allometric constraints and variables of reproductive effort in Brachyuran crabs. Mar. Biol. 69: 309-320.

Hofmann, E.E.; Haskell, A.G.E.; Klinck, J.M. \& Lascara, C.M., 2004. Lagrangian modelling studies of Antarctic krill (Euphausia superba) swarm formation. J. Mar. Sci. 61: 617-631.

Hutchings, J.A., 2000. Collapse and recovery of marine fishes. Nature 406: 882-885. 
Jaeckle, W.B., 1995. Variation in size, energy content and biochemical composition of invertebrate eggs: correlates to the mode of larval development. In: Ecology of marine invertebrate larvae. L. McEdward (ed.). CRC Press, Marine Science Series. Pp. 49-77.

Johnson, M.D., 2007. Measuring habitat quality: a review. The Condor 109: 489504.

Jones, M.B., 1977. Breeding and seasonal population changes of Petrolisthes elongatus (Crustacea, Decapoda, Anomura) at Kaikoura, New Zealand. J. Royal Soc. New Zealand 7(3): 259-272.

Kareiva, P.M., 1987. Habitat fragmentation and the stability of predator-prey interactions. Nature 321: 388-391.

Kotliar, N.B. \& Wiens, J.A., 1990. Multiple scales of patchiness and patch structure: a hierarchical framework for the study of heterogeneity. Oikos 59: 253-260.

Lardies, M.A.; Arias, M.B \& Bacigalupe, L.D., 2010. Phenotypic covariance matrix in life history traits along a longitudinal gradient: a study case in a geographically widespread crab on the coast of Chile. Mar. Ecol. Prog. Ser. 412: 179-187.

Lardies, M.A. \& Castilla, J., 2001. Latitudinal variation in the reproductive biology of the commensal crab Pinnaxodes chilensis (Decapoda: Pinnotheridae) along the Chilean coast. Mar. Biol. 139(6): 1125-1133.

LeTourneux, F. \& Bourget, E., 1988. Importance of physical and biological settlement cues used at different spatial scales by the larvae of Semibalanus balanoides. Mar. Biol. 97: 57-66.

Levin, S.A., 1992. The problem of pattern and scale in ecology. Ecology 73(6): 1943-1967.

Levin, S.A., 1974. Dispersion and population interactions. Am. Nat.108: 207-228.

Levin, S.A. \& Bridges, T.S., 1995. Pattern and diversity in reproduction and development. In: Marine Invertebrate Larvae. L. McEdward (Ed.) CRC Press, Oxford. Pp. 1-47.

Levin, S.A.; Morin, A. \& Powell, T.H., 1989. Patterns and processes in the distribution of Antarctic krill. Pp.281-299 In: Scientific Committee for the Conservation of Antarctic Marine Living Resources Selected Scientific Papers, Part 1. SC-CAMLR-SSP/5. Hobart, Tasmania, Australia.

Levin, S.A. \& Segel, L.A., 1976. A hypothesis for the origin of plankton patchiness. Nature 259(5545): 659.

Levins, R., 1969. Some demographic and genetic consequences of environmental heterogeneity for biological control. Bull. Enotomol. Soc. Am. 15: 237-240. 
Lloyd, M., 1967. Mean crowding. J. Anim. Ecol. 36 (1): 1-30

Mackas, D.L.; Denman, K.L. \& Abbott, M.R., 1985. Plankton patchiness: biology in the physical vernacular. Bull. Mar. Sci. 37: 652-674.

Mascetti, P. \& Wehrtmann, I.S., 1996. Aspects of the reproductive biology of Petrolisthes laevigatus (Guerin, 1835) (Decapoda, Anomura, Porcellanidae). Part III: Effects of starvation and different types of diet on larval development under laboratory conditions. Arch. Fish. Mar. Res. 43(2): 159-170.

Maxwell, B.E., 1956. Hydrobiological observations for Wellington Harbour. Transactions Royal Soc. New Zealand 83(3): 493-503.

McArdle, B.H. \& Gaston K.J., 1992. Comparing population variabilities. Oikos 64: 610-612.

McArdle, B.H.; Gaston, K.J. \& Lawton, J.H., 1990. Variation in the size of animal populations: patterns, problems and artefacts. J. Anim. Ecol. 59: 439-454.

Gaston, K.J. \& McArdle, B.H., 1993. Measurement of variation in the size of populations in space and time: some points of clarification. Oikos 68: 357-360.

McGinley, M.A.; Temme, D.H. \& Geber, M.A., 1987. Parental investment in offspring in variable environments: theoretical and empirical considerations. Am. Nat. 130: 370-398.

McLay, C., 1988. Brachyura and crab-like anomura of New Zealand. Leigh Laboratory Bulletin 22. 463 pp.

Meyer-Rochow, V.B. \& Meha, W.P., 1994. Tidal rhythm and the role of vision in shelter-seeking behaviour of the half-crab Petrolisthes elongatus (Crustacea: Anomura: Porcellanidae). J. Royal. Soc. New Zealand 24(4): 423-427.

Miller, D.G.M. \& Hampton, I., 1989. Krill aggregation characteristics: spatial distribution patterns from hydroacoustic observations. Polar Biol. 10: 125-134.

Monaco, C.J.; Brokordt, K.B. \& Gaymer, C.F., 2010. Latitudinal thermal gradient effect on the cost of living of the intertidal porcelain crab Petrolisthes granulosus. Aquatic Biol. 9: 23-33.

Okubo, A., 1986. Dynamical aspects of animal groupings: swarms, schools, flocks and herds. Advances in Biophysics 22: 1-94.

Olive, P.J.W., 1985. Physiological adaptations and the concepts of optimal reproductive strategy and physiological constraint in marine invertebrates. In: Physiological Adaptation of Marine Invertebrates. M.S. Laverack (Ed.) Soc. Exp. Biol., Cambridge. Pp. 268-300. 
Parrish, J.K. \& Edelstein-Keshet, L., 1999. Complexity, pattern, and Evolutionary trade-offs in animal aggregation. Science 284(5411): 99-101.

Parrish, J.K.; Viscido, S.V. \& Grünbaum, D., 2002. Self-organized fish schools: An examination of emergent properties. Biol. Bull. 202: 296-305.

Pellegrino, C.R., 1984. The role of desiccation pressures and surface area/volume relationships on seasonal zonation and size distribution of four intertidal decapod crustacea from New Zealand: implications for adaption to land. Crustaceana 47(3): 251- 268.

Perry, J.N., 1981. Taylor's power law for dependence of variance on mean in animal populations. Applied Statistics 30: 254-263.

Perry, J.N. \& Mead, R., 1979. On the power of the index of dispersion test to detect spatial pattern. Biometrics 35: 613-622.

Pineda, J.; Hare, J.A. \& Sponaugle, S., 2007. Larval transport and dispersal in the coastal ocean and consequences for population connectivity. Oceanography 20(3): 22-39.

Pineda, J.; Porri, F.; Starczak, V. \& Blythe; J., 2010. Causes of decoupling between larval supply and settlement and consequences for understanding recruitment and population connectivity. J. Exp. Mar. Biol. Ecol. 392: 9-21.

Pulliam, H.R. 2000. On the relationship between niche and distribution. Ecology Letters 3: 349-361.

Ramirez Llodra, E., 2002. Fecundity and life-history strategies in marine invertebrates. Adv. Mar. Biol. 43: 87-170.

Ritz, D.A., 1994. Social aggregation in pelagic invertebrates. Adv. Mar. Biol. 30: 155-216.

Rodriguez, S.R.; Ojeda, F.P. \& Inestrosa, N.C., 1993. Settlement of benthic marine invertebrates. Mar. Ecol. Prog. Ser. 97: 193-207.

Roff, D.A., 1992. The evolution of life histories; theory and analysis. Chapman \& Hall, New York. 535 pp.

Sastry, A.N., 1983. Ecological aspects of reproduction. In: Vernberg (Ed.), The biology of crustacea. Vol. 8: Environmental adaptations. Academic Press, New York, pp. 197-270.

Scott, M.S., 1958. Studies on the false crab, Petrolisthes elongatus Milne Edwards. M.Sc.-thesis, Canterbury University, Christchurch, NZ.

Seitz, R.D.; Lipcius, R.N.; Stockhausen, W.T.; Delano, K.A.; Seebo, M.S. \& Gerdes, P.D., 2003. Potential bottom-up control of blue crab distribution at various spatial scales. Bull. Mar. Sci. 72: 471- 490. 
Somers, K.M., 1991. Characterizing size-specific fecundity in crustaceans. Crustacean Issues 7: 357-378.

Stearns, S.C., 1980. A new view of life-history evolution. Oikos 35: 266-281.

Stearns, S.C., 1989. Trade-offs in life-history evolution. Funct. Ecol. 3: 259-268.

Stearns, S.C., 1992. The evolution of life histories. Oxford University Press, Oxford, U.K. 249 pp.

Sumpter, D.J.T., 2012. The principles of collective animal behaviour. Phil. Trans. R. Soc. B 361: 5-22.

Tapella, F.; Lovrich, G.A.; Romero, M.C. \& Thatje, S., 2002. Reproductive biology of the crab Munida subrugosa (Decapoda: Anomura: Galatheidae) in the Beagle Channel, Argentina. J. Mar. Biol. Ass. U.K. 82: 589-595.

Tilman, D. \& Kareiva, P., 1997. Spatial ecology: the role of space in population dynamics and interspecific interactions. Princeton University Press, Princeton, N.J. Pp. 368.

Treml, E.A.; Halpin, P.N.; Urban, D.L. \& Pratson, L.F., 2008. Modelling population connectivity by ocean currents, a graph-theoretic approach for marine conservation. Landscape Ecol. 23:19-36.

Underwood, A.J., 1992. Beyond BACI: the detection of environmental impacts on populations in the real, but variable, world. J. Exp. Mar. Biol. Ecol. 161: 145-178.

Underwood, A.J., 1996. Spatial patterns of variance in density of intertidal populations. In: Frontiers of population ecology. R.B. Floyd; A.W. Sheppard \& P. J. De Barro (eds.) CSIRO Publishing, Melbourne, Victoria, Australia. Pp. 369-389.

Vandewoestijne, S.; Schtickzelle, N. \& Baguette, M., 2008. Positive correlation between genetic diversity and fitness in a large, well-connected metapopulation. BMC Biol. 6: 46.

VanHorne, B., 1983. Density as a misleading indicator of habitat quality. J. Wildl. Managem. 474: 893-901.

Walters, C. \& Kitchell, J.F., 2001. Cultivation / depensation effects on juvenile survival and recruitment: implications for the theory of fishing. Can. J. Fish. Aquat. Sci. 58(1): 39-50.

Wear, R.G., 1964. Larvae of Petrolisthes elongatus (Milne Edwards, 1837). (Crustacea, Decapoda, Anomura). Trans. Royal Soc. New Zealand. Zoology 5(2): 39-53. 
Wear, R.G., 1965. Breeding cycles and pre-zoea larva of Petrolisthes elongatus (Milne Edwards, 1837). (Crustacea, Decapoda). Trans. Royal Soc. New Zealand. Zoology 5(13): 169-175.

Watson, J.R.; Hays, C.; Raimondi, P.; Mitarai, S.; Dong, C.; McWilliams, J.C.; Blanchette, C.A.; Caselle, J.E. \& Siegel, D.A., 2011a. Currents connecting communities: nearshore community similarity and ocean circulation. Ecology 92(6): 1193-1200.

Watson, J.R.; Siegel, D.A.; Kendall, B.E.; Mitarai, S.; Rassweiller, A. \& Gaines., S., 2011b. Identifying critical regions in small-world marine metapopulations. Proc. Nat. Acad. Sci. In press.

Watson, J.R.; Kendall, B.E.; Siegel, D.A. \& Mitarai, S., 2012. Changing seascapes, stochastic connectivity and marine metapopulation dynamics. Am. Nat. In press. 


\section{Chapter 2}

\section{Effects of cobble size on population structure, predation risk and movement of Petrolisthes elongatus.}

\subsection{Introduction}

In the rocky intertidal spatial variability may be found in exceptionally high levels (Hartnoll \& Hawkins, 1980; Miller \& Ambrose, 2000). Intertidal boulder fields are heterogeneous mosaics of bedrock, gravel, pebbles and soft sediment and, therefore, provide a high structural complexity. The spatial and temporal variability of environmental conditions within a (macro-) habitat is linked to the heterogeneity of abundance of species (Sousa, 1979; McGuinness \& Underwood, 1986; Davis \& Wilce, 1987; Rios \& Mutschke, 1999; Takada, 1999). Habitat variation exists at a broad range of spatial scales (Wiens, 1989); correspondingly, the same is true for the heterogeneity and patchiness of ecological communities (Kotliar \& Wiens, 1990). The spatial distribution of krill populations in the Southern Ocean, for example, have been shown to be patchy an almost every scale of description (Levin et al., 1989). The causes of this pattern may be different for different scales: While patches on a large scale are the result of water movement, small scale distribution is influenced by swimming behaviour (Levin, 1992). Hence, the identification of relevant scales is very important, as well as the consideration of the scale of observation when comparing the results of scientific studies (Levin, 1992; Archambault \& Bourget, 1996; Azovsky, 2000; Bishop et al., 2002; Chitarro, 2002).

Generally, the observed spatial and temporal variability in abundance of animals have been attributed to a multitude of ultimate and proximate factors, such as the distribution of suitable habitat, physical habitat structure and shelter availability (Hixon \& Beets, 1993; Drolet et al., 2004a; Shima et al., 2008), food supply (Wildish \& Kristmanson, 1979; Gardner, 2000; Helson et al., 2007), predator abundance (Kneib, 1984; Alonzo \& Mangel, 2001; Knight et al., 2005), episodic disturbances (Dayton, 1971; Dayton \& Oliver, 1980; Paine \& Levin, 1981; 
Dethier, 1984), hydrodynamic conditions (Shepherd \& Partington, 1995; Menge et al., 1997; Lapointe \& Bourget, 1999; Pech et al., 2002; Arkema, 2009), temperature (Stillman \& Somero, 1996), and light (Spanier \& Almogshtayer, 1992; Drolet et al., 2004b), whereby each factor acts differently on a particular spatial scale. Thus, the identification of relevant habitat quality indicators across a range of spatial scales is crucial for the understanding of the differential population density and distribution of a species. Since levels of competition depend on both population density and availability of resources, the specific carrying capacity of a habitat (sensu Le Hir \& Hily, 2005, "spatial area with homogenous environmental parameters on a given observational scale") could be estimated based on habitat characteristics if habitat size and home range are taken into account (e.g. Thompson Hobbs \& Hanley, 1990; Reid et al., 2007; Downs et al., 2008; Griffen \& Drake, 2008). Not only patch quality, but also patch size and landscape context affect local population abundance (and dispersal rate) (Hanski, 1994; Andren, 1994; Ricketts, 2001; Thomas et al., 2001; Haynes \& Cronin, 2003, 2004; Haynes et al., 2007). However, patchiness of abundance is also explainable by differential spatio-temporal larval supply, settlement and recruitment rates, differential mortality and predation, post-settlement migration, as well as aggregation and conspecific attraction.

Spatial structure influences stability and organization of both species and communities (Kareiva, 1987; Tilman \& Kareiva, 1997; Hanski, 1999). Especially with increasing isolation of habitat patches or decreasing patch size, the risk of extinction in fragmented landscapes is usually increased (Burkey \& Reed, 2006). Metapopulation dynamics depend crucially on the form of the relationship between recruitment rate (due to immigration and settlement) and the reduction in extinction risk (Levins, 1969; Harding \& McNamara, 2002). Considerable efforts have been made to model the dynamics of metapopulations, taking into account the size, growth rate, and age structure of each subpopulation (Levins, 1969; Hastings \& Volin 1989, Allen et al. 1993), patch quality (Hanski, 1994), and interactions with predators (Taylor, 1990; Holt, 1997). These and other studies revealed that metapopulations inhabiting isolated habitat patches (e.g. cobble beaches) with a differential connectivity due to large scale dispersal influenced by wind drift, currents and shoreline properties may have extremely complex dynamics. 
Besides the large-scale variation of habitat structure, every habitat patch exhibits variation on a number of small scales. It is well known that habitat complexity strongly influences patterns of abundance of marine invertebrates (McCoy \& Bell, 1991; Firstater et al., 2011) as well as foraging success of predators (e.g. Bartholomew, 2002; Warfe \& Barmuta, 2004). However, the drivers of spatial heterogeneity in population density and structure of a given species may be different on different scales of observation. While on a scale of tens of meters, for example, patterns of abundance of mobile invertebrates could be directly explained by actions and characteristics of the physical environment, the patterns on a smaller scale (e.g. tens of centimeters) could emerge due to behavioural traits. The irregular and structurally complex nature of rocky shores in general and cobble beaches in particular provides a multitude of habitat patches that vary in size and specific physical and biological characteristics that determine their quality for a particular species.

For Petrolisthes spp., cobble size (as a measure of interstitial space as a limiting factor for local population density) may be a relevant factor of habitat quality. Its variability could lead to patchiness on various spatial scales in terms of population density and crab size. Preliminary field observations indicated that high density patches and large individuals can be found mainly among larger boulders. Additionally, P. elongatus is restricted to intertidal cobble beaches and does not occur on sandy patches. Predation rates may also be influenced by rock size due to a varying degree of accessibility of prey. Despite their camouflaging colouration, firm carapaces and efficient defence mechanisms, P. elongatus juveniles and adults frequently fall victim to a variety of predators including fish (see Graham, 1938), birds, mammals and larger invertebrates (McLay, 1988), contributing to an increased post-settlement mortality. Moreover, larger and therefore heavier rocks provide "better" (i.e. more stable) shelters, whereas smaller ones are more prone to be shifted by water movement. Thus, individuals may be more frequently exposed to predators or injured or killed between tumbling rocks in heavy surge (Shanks \& Wright, 1986). Furthermore, smallscale hydrodynamic conditions are influenced by physical habitat structure (Sanders, 1958; Boaden, 1968). Since porcellanids are filter-feeders, current velocity is crucial for filtration efficiency (Trager \& Genin, 1993); Petrolisthes spp. may therefore aggregate at and compete for high quality feeding spots 
(Molenock, 1976; Jensen, 1990). Hence, cobble size could be a relevant habitat quality indicator for $P$. elongatus. However, patterns of abundance and population structure of crabs may also be influenced by shelter-targeting and social behaviour as well as migration.

Mobile benthic crustaceans migrate between adjacent habitat patches for various reasons. Individuals may emigrate out of a patch to avoid high levels of competition in order to make use of substitutable or non-substitutable resources in neighbouring areas (Dunning et al., 1992). Immigration into a habitat patch, on the other hand, could result from conspecific attraction. Other reasons for movement include active shelter seeking, flight behaviour to escape predators or competitors, aggressive pursuit of intruders, foraging behaviour, spatio-temporal variation in resource availability such as food, shelter, and mating partners, source/sink dynamics due to relative differences in patch productivity (e.g. Pulliam, 1988; Pulliam \& Danielson, 1991), or (accidental) passive drift due to wave action.

In this chapter, I investigate the implications of a heterogeneous habitat structure on patterns of abundance and demography in Petrolisthes elongatus, based on the hypothesis that cobble size is an important factor of habitat quality for this species. Specifically, I examine how the spatial variability of rock size (as an approximate measure of the size and availability of interstitial space) affects local density and size-frequency distribution of crabs on a range of spatial scales. Another factor contributing to patterns of abundance in P. elongatus could be a differential predation rate which, in turn, may be related to cobble size. Hence, I examine whether predation rate depends on rock size. Further, I am interested in how migration rate is affected by spatial complexity, measured as size-frequency distribution of rocks. Additionally, crabs of different sizes are likely to be differently affected by predation and may exhibit different migration behaviour. Therefore, the heterogeneous distribution of rock sizes relative to body size could not only mediate the observable patchiness of abundance of crabs, but also influence local variations in population demographics that, traditionally, are primarily explained by spatio-temporal variations in rates of settlement and recruitment. 


\subsection{Materials and Methods}

\subsubsection{Field survey: Petrolisthes elongatus density and size relative to cobble size}

at different spatial scales

To understand how the heterogeneity in cobble size affects abundance and size frequency distribution of $P$. elongatus, local population density and average carapace width on three different spatial scales were measured, along with cobble size. In May 2006, a nested design with randomly chosen patches at three different sites (Hutt River mouth, Island Bay and Breaker Bay) was used, whereby each "nest" consisted of five sample quadrats $(50 \mathrm{~cm}$ side length), spaced between $1 \mathrm{~m}$ and $2 \mathrm{~m}$ apart. At each site (i.e. on the same cobble beach), three nests were sampled with a minimum distance of $10 \mathrm{~m}$ in between (Fig. 2.1). Each sampling quadrat was delimited by a steel frame. Prior to sampling, all rocks within the frame larger than $2 \mathrm{~cm}$ at their widest point were numbered with white crayon and a digital photograph of the sample patch was taken (Fig. 2.2). The image was later used for the calculation of the surface area of each rock using analytic imaging software (Image-Pro v5.1, Media Cybernetics, September 2004). The porcelain crabs were killed in situ with hot water (approx. $70-80^{\circ} \mathrm{C}$ ) poured over the sampling patch. All rocks within the sampling area were removed one by one and the crabs found underneath collected and preserved in $70 \%$ ethanol. If there were several layers of rocks, another photo of the sample area was taken after removal of the top layer and consecutive numbering of rocks. To extract the crabs from these sediment samples, the material was transferred into a double sieve (5mm and $1 \mathrm{~mm}$ mesh size) stacked on top of each other, and thoroughly rinsed with seawater. The residue from each sieve was washed into a shallow, white tray and all crabs where transferred into sample jars and preserved in $70 \%$ ethanol. 


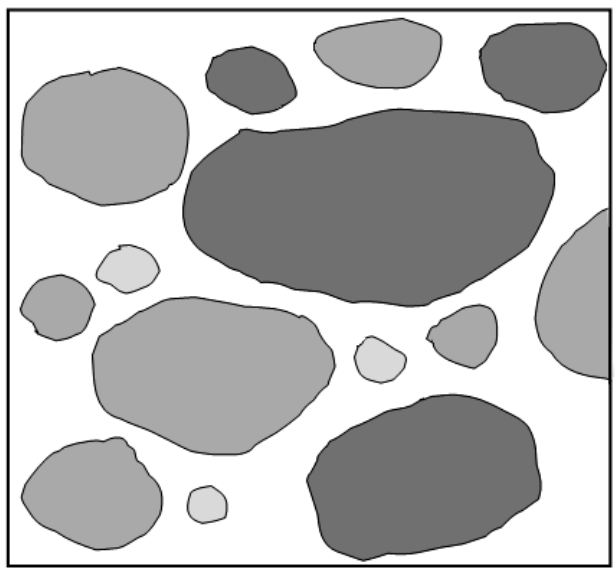

A

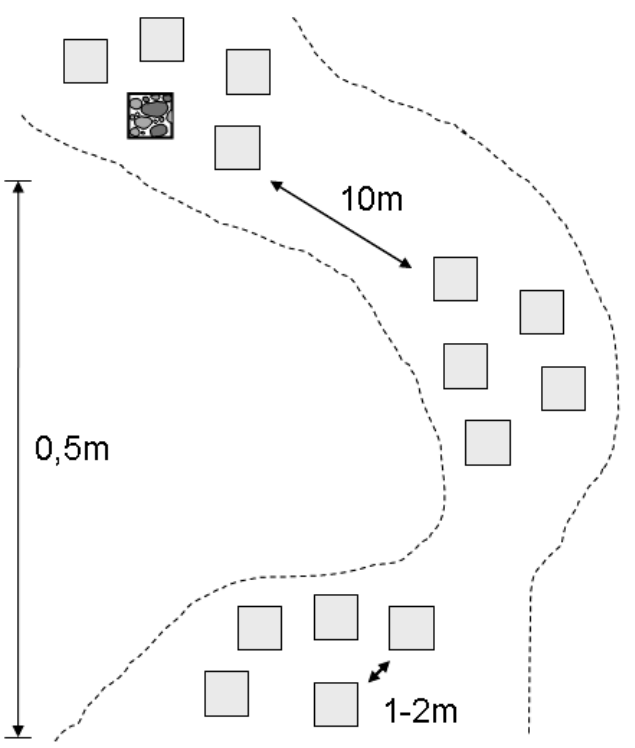

B

Fig. 2.1: Quadrat sampling: nested design. Three sites were sampled. A) Example of individual quadrat with rocks of different sizes and different numbers of crabs underneath, indicated by shades of grey where dark grey stands for higher local crab density. B) Example of 3 "nests" of quadrats at one site. Quadrats within nests were $1-2 \mathrm{~m}$ apart from one another, nests approximately $10 \mathrm{~m}$.

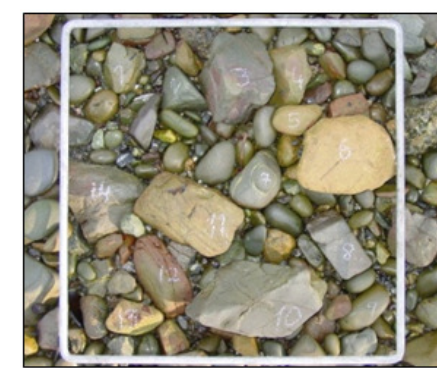

Island Bay

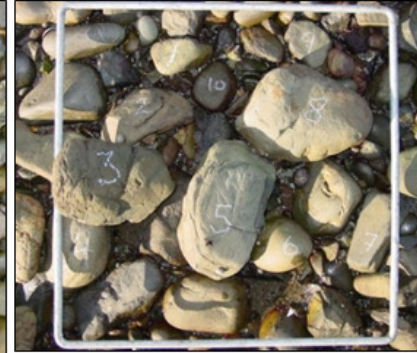

Breaker Bay

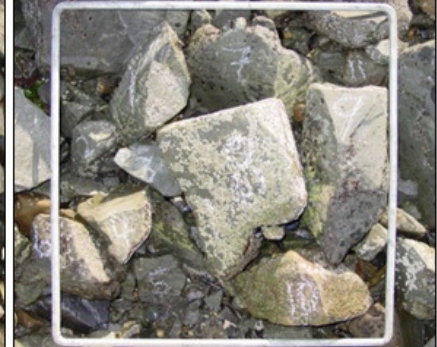

Hutt River mouth

\section{Cobble size}

Wave exposure

Fig. 2.2: Examples of sample quadrats at each site. While site Island Bay has the smallest cobble size and highest wave exposure Hutt River mouth is characterised by large boulders and low wave exposure. Both factors are intermediate at Breaker Bay, located at the entrance of Wellington Harbour.

The patchiness of crab abundance as well as the variability in size frequency distribution of crabs and rock sizes on various spatial scales (i.e. site, nest, sample quadrat, and per single rock) were analysed separately by fully nested mixed model ANOVAs with site as fixed factor and all other levels as random factors. To determine if and how rock size influences the size frequency distribution of crabs as well as their local density, fully nested mixed model ANCOVAs on both 
density and crab size were used with rock size as covariate and site as fixed factor. Additionally, the index of dispersion (ratio of variance in numbers of crabs under each rock to mean number of crabs per quadrat) was calculated as a measure of patchiness (see Appendix 2.9). Because crabs were generally found under larger rocks only, rocks sizes of occupied and unoccupied rocks, pooled across sites, were compared by t-test. Using linear regression, the relationships between rock size (i.e. surface area of occupied rocks) and frequency as well as mean carapace width of crabs found underneath each rock was calculated for each site. To determine whether the relationship between rock size and crab density could be generalized on the scale of the sample quadrat and whether there were differences between adult and juvenile density, mean rock size per quadrat was plotted against mean total crab density as well as against adult density (individuals $/ \mathrm{m}^{2}$ ) for each site.

Apart from Petrolisthes elongatus there were mainly two other crab species found within the sample quadrats: Hemigrapsus sexdentatus (A. Milne Edwards, 1837) and Heterozius rotundifrons A. Milne Edwards, 1867. Because interspecific spatial concurrence may result in negatively correlated abundances of sympatric species, the frequency of $P$. elongatus per quadrat was plotted against the frequency of the second most abundant coexisting species (H. sexdentatus at Hutt River mouth and H. rotundifrons at Breaker Bay and Island Bay).

\subsubsection{Field experiment: cobble size and colonization of P. elongatus}

To examine the effect of rock size and the resulting interstitial space on mean carapace width of crabs inhabiting the cavity system within boulder fields, 30 baskets were deployed in the field in December 2005. The plastic baskets $(30 \mathrm{~cm} \mathrm{x}$ $20 \mathrm{~cm} \times 15 \mathrm{~cm})$ had rectangular openings $(10 \mathrm{~mm} \times 20 \mathrm{~mm})$ on either side, large enough to allow porcelain crabs of all sizes to colonise the cobbles inside. Greywacke rocks with a similar surface roughness were collected in the natural habitat of porcelain crabs, thoroughly rinsed with fresh water and dried on a clean concrete surface outside the laboratory. Three rock sizes $(3-5 \mathrm{~cm}, 5-10 \mathrm{~cm}$, and $10-$ $20 \mathrm{~cm}$ ) were selected as treatments. Baskets were filled with rocks of the appropriate size and coarse PVC mesh (Netlon, 10mm mesh size) attached to the opening of each basket using cable ties to secure the rocks inside the baskets. For each treatment, ten replicates were deployed in a random distribution at Hutt 
River mouth, the site with the highest known abundance of $P$. elongatus in the Wellington region, and anchored with two steel pegs each. The baskets were retrieved after four weeks in January 2006 and brought to VUCEL. For transport and to prevent animals from moving out of the trap as well as to keep them moist for several hours, the baskets were slid into plaited, breathable plastic bags. At the laboratory, the crabs were extracted from the basket traps by thoroughly rinsing the content with running seawater on a double sieve ( $5 \mathrm{~mm}$ and $1 \mathrm{~mm}$ mesh size). The residue from each sieve was washed into a shallow, white tray and all crabs where transferred into sample jars and preserved in 95\% ethanol. Later, the animals were sexed and measured with a dissecting microscope.

Number of crabs per basket as well as crab size (carapace width) in each treatment were analysed by one-way ANOVA with "basket" as random factor nested within treatment. Because there were fishes found in all basket traps (Acanthoclinus fuscus, the same species that was used for predation experiments, see Section 2.2.3), the effect of rock size treatments on mean head-to tail length of fish were also analysed by one-way ANOVA.

\subsubsection{Laboratory experiment: Influence of cobble size on predation rate}

The influence of cobble size on vulnerability to predation (i.e. mortality rate due to predation) was examined by exposing crabs to predators in a laboratory experiment. As described above (Section 2.2.2), three rock sizes were used as treatments with a maximum length of $3-5 \mathrm{~cm}, 5-10 \mathrm{~cm}$, or $10-20 \mathrm{~cm}$. Greywacke rocks a with a similar roundness were collected from the supralittoral zone of a cobble beach in Island Bay, measured and sorted by hand, thoroughly rinsed with fresh water and dried for $24 \mathrm{~h}$ at $50^{\circ} \mathrm{C}$ in a drying oven. $1 \mathrm{~kg}$ of rocks from each of the three cobble size treatments was then placed into a 30L seawater aquarium (eight per treatment) and piled up against one side wall of the tank in at least two layers to simulate the cavity system between rocks on natural boulder fields. Additionally, the rocks (and thus the photonegative porcelain crabs) were shielded from light by a non-transparent PVC sheet that was attached to the front side of each tank. Each aquarium was filled with 15L unfiltered seawater that was replaced every two days and had two air-stones. To reduce mortality related to factors other than predation, porcelain crabs were introduced first and the predatory fish 6-8 days later. 
The olive rockfish, Acanthoclinus fuscus (Plesiopidae) (Fig. 2.3), native to New Zealand, appeared to be an ideal model predator species: these fish (with a maximum head-to-tail length of max. $30 \mathrm{~cm}$ ) live sympatrically amongst porcelain crabs in the intertidal zone and in rock pools at low tide, feeding mostly on small invertebrates, particularly crustaceans and molluscs. Predation of A. fuscus on $P$. elongatus was observed on several occasions in the field as well as in captivity. A specific characteristic of this species is its ability to breathe air when out of water; hence it can be found in the intertidal during low tide, hidden in moist cavities between rocks, often amidst an aggregation of crabs (for species descriptions, see Hardy, 1984; Francis, 2001). For this experiment, 48 fish in two size classes were collected: $3-6 \mathrm{~cm}$ and $8-12 \mathrm{~cm}$ head-to-tail-length $(4.56 \pm$ $0.19 \mathrm{~cm}$, and $10.25 \pm 0.097 \mathrm{~cm}$ ) to match the approximate size distribution found in the wild with large specimen ( $>15 \mathrm{~cm}$ length) being rare. Two fish from each size class were placed into each tank.

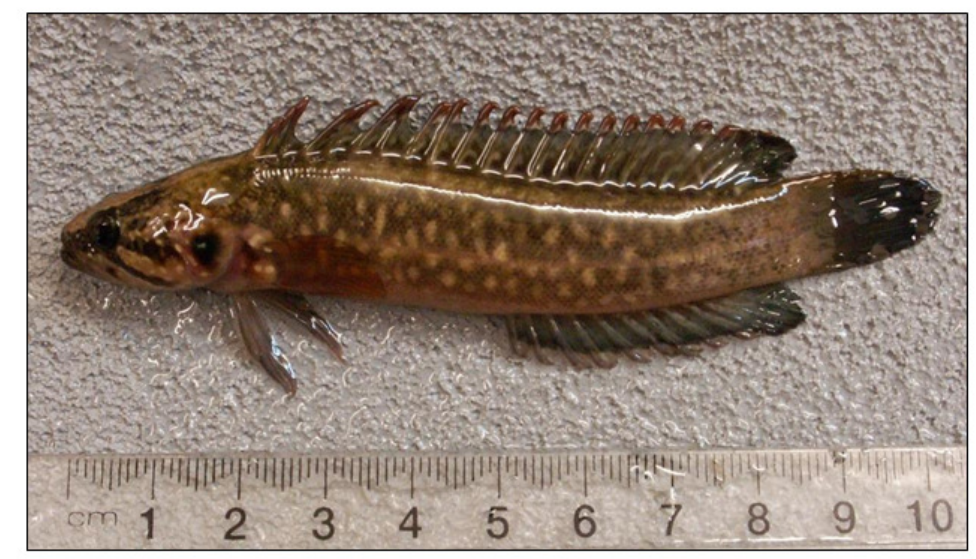

A

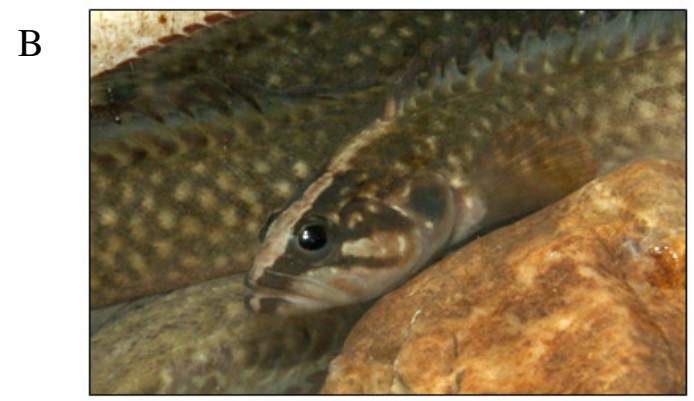

Fig. 2.3: Olive rockfish, Acanthoclinus fuscus, live among boulders in the intertidal where they can be found even at low tide. These fish share their habitat with $P$. elongatus and prey upon smaller sized individuals of this species. A: size class 3 specimen with a head-to-tail-length of approx. $10 \mathrm{~cm}$, and $\mathrm{B}$ : several individuals in an aquarium; note the characteristic fleshy dorsal fin rays and the dorsal/anterior light brown stripe. 
Porcelain crabs were collected at Hutt River mouth during low tide. To each aquarium 30 crabs in four size classes were added, in a ratio of 10:10:5:5 individuals per tank: (size class $1=3.5-4.5 \mathrm{~mm}$ carapace width, size class $2=6.5$ $7.5 \mathrm{~mm}$, size class $3=9-11 \mathrm{~mm}$, and size class $4=12.5-14.5 \mathrm{~mm})$. After the fish were added to each treatment, the numbers of remaining crabs in each tank and size class were counted weekly for a period of 30 days by carefully removing all rocks and animals from the aquaria. Dead crabs were removed and replaced as soon as possible to keep numbers of available prey consistent with numbers of crabs placed into each tank at the beginning of the experiment minus those that had been eaten by fish. The decline of crab individuals due to predation was used to estimate predation rates dependent on cobble size. Treatment differences in the final number of surviving crabs after 30 days within each size class were analysed by two-way ANOVA (No. of survivors $\sim$ Rock size + Crab size $+($ Rock size * Crab size).

\subsubsection{Field experiment: Mobility and migration of P. elongatus among cobbles}

The mobility and migration rate over one day of $P$. elongatus was examined with a mark and recapture survey for different size-classes (compare Jensen, 1989; Jensen \& Armstrong, 1991; Donahue, 2004). 100 uninjured crabs were collected at Hutt River mouth and subdivided into four size classes (same as described above) of 25 individuals each. The animals were tagged with coloured and numbered "Queen Bee" tags (manufacturer: E.H.Thorne Ltd., Beehive Works, Wragby, Market Rasen, Lincolnshire, U.K., http://www.thorne.co.uk/index.htm) glued onto the carapace (one colour per size class, see Fig. 2.4). At three sites (Island Bay, Breaker Bay, and Hutt River mouth), a larger boulder (approx. 20cm $\mathrm{x} 20 \mathrm{~cm}$ ) was chosen as a point of release in the mid intertidal zone with a reasonably homogenous distribution of boulders surrounding it. If such a boulder could not be found, it was moved to a suitable spot from an adjacent area. The patch under the rock was cleared of all crabs and the boulder itself was marked with a small dot of spray paint. Prior to the release of the tagged crabs, wire gauze was put around the boulder to prevent the immediate spread of animals as a result of flight behaviour. After release and a period of calming (2min.) the gauze was carefully removed. The crabs were recaptured after $25 \mathrm{~h}$ in an area with a radius of $10 \mathrm{~m}$ around the point of release. Each recaptured individual was recorded and notes were taken concerning size class, individual tag number, distance from 
point of release and direction of movement (by compass bearing) from the release point. At each site, the mark and recapture survey was conducted three times with at least six weeks between two consecutive runs. Site differences of migration distance within all size classes of crabs were analysed by 3-way ANOVA Distance $\sim$ Site + Size class + Run $+($ Site $*$ Size class $)+($ Site $*$ Run $)+($ Size class * Run $)+($ Site $*$ Size class * Run $)$ with stepwise desaturation.

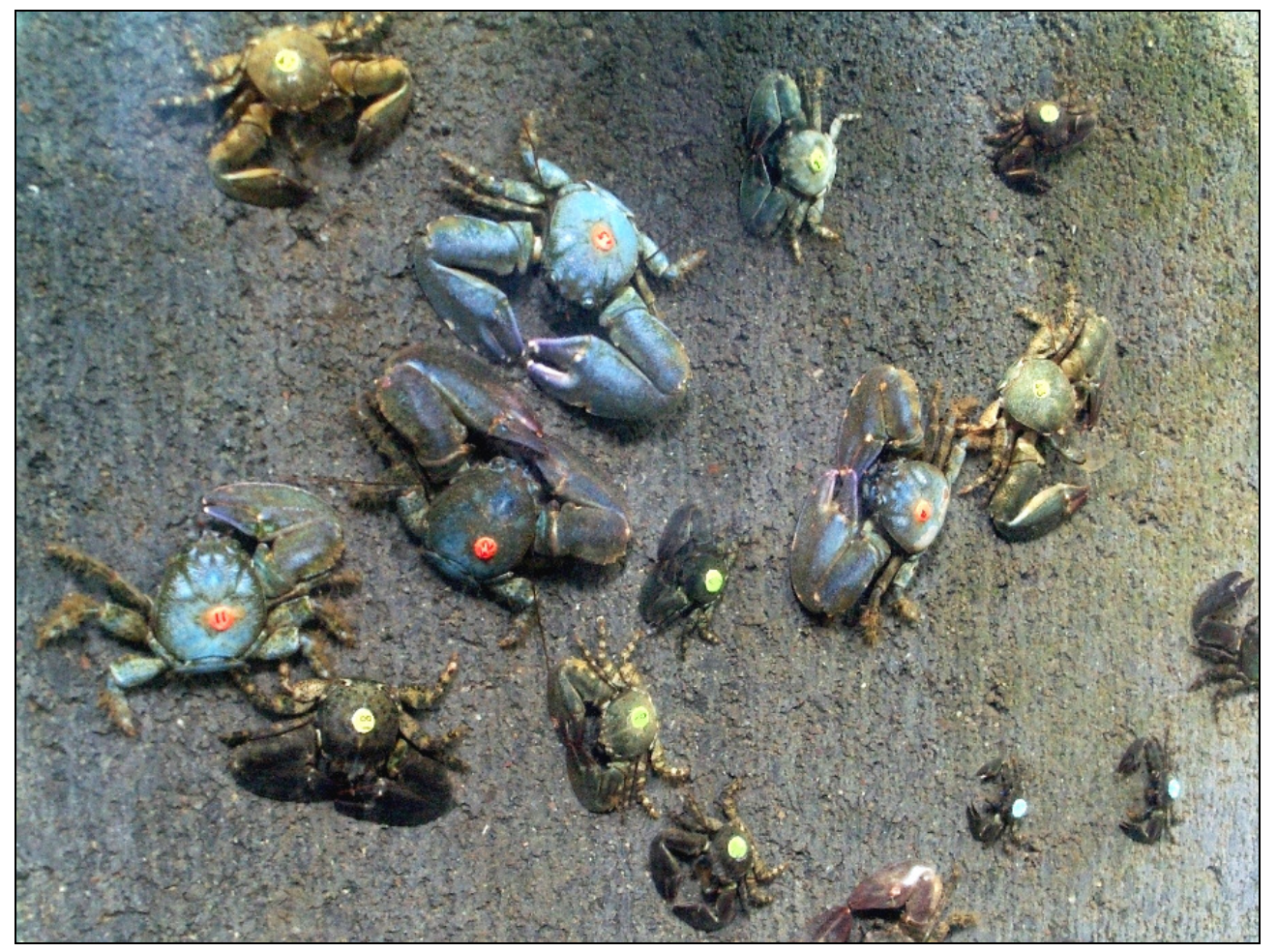

Fig. 2.4: Tagged porcelain crabs in a seawater tank prior to release. Size classes of crabs are marked by differently coloured "queen bee tags", glued onto their carapaces. The tags are numbered in order to distinguish individuals. Only uninjured crabs were used for the mark and recapture survey.

All statistical analyses (ANOVA, ANCOVA) in this chapter were calculated in JMP 4.0.4 (SAS Institute, September 2001). For regressions and graphs, SigmaPlot 10.0.1 (Systat, January 2007) as well as Microsoft Excel (2003) was used. 


\subsection{Results}

2.3.1 Field survey: P. elongatus density and size relative to cobble size at different spatial scales

The size frequency distributions of P. elongatus at the three sample sites (Fig. 2.5) show a distinctive peak of smaller crabs between $1.5 \mathrm{~mm}$ and $4.5 \mathrm{~mm}$ carapace width (CW), especially at Hutt River mouth (HRM). These crabs largely represent settlers (Megalopa larvae, approx. 1.5-2.0mm CW) and recruits (juveniles, approx. 2.0-3.5mm CW) from the latest reproductive season. Another, much lower maximum comprises adult crabs from previous years between $6.0 \mathrm{~mm}$ and 9.0mm CW at HRM, between $4.5 \mathrm{~mm}$ and $8.0 \mathrm{~mm} \mathrm{CW}$ at Breaker Bay (BRB), and between $4.0 \mathrm{~mm}$ and $7.0 \mathrm{~mm} \mathrm{CW}$ at Island Bay (ISB). Additionally, there were more large crabs at HRM compared to the other two sites. Despite a higher total number of crabs at ISB, there were more large crabs at BRB. According to the size frequency distributions of crabs split by size class of rocks (Appendix 2.1, 2.2, and 2.3), rock size did not influence size frequency distributions at HRM and $\mathrm{BRB}$, but clearly has an effect on the relative frequencies of size classes of crabs at ISB. While there were (relatively and absolutely) more small crabs $(0.5 \mathrm{~mm}$ $3.5 \mathrm{~mm} \mathrm{CW})$ under small rocks $\left(<100 \mathrm{~cm}^{2}\right.$ surface area), there where more larger crabs $(6.0 \mathrm{~mm}-7.0 \mathrm{~mm} \mathrm{CW})$ under larger rocks (200-300 $\mathrm{cm} 2$ surface area).

Crab densities were significantly higher at HRM (on average, approximately 6fold) compared to the BRB and ISB (Fig. 2.6). This was confirmed by the nested mixed model ANOVA on crab density per rock (Table 2.1) and post-hoc tests. The overall differences between densities within nests were non-significant (Table 2.1); however, at all sites the mean densities within one nest (nest 3 at HRM, nest 1 at BRB, and nest 1 at ISB, respectively) were lower than within the other two (Fig. 2.6). Differences between quadrats within nests and sites were highly significant (Table 2.1 and Appendix 2.4), whereas differences between rocks, nested within quadrats, nests and sites where non-significant (Table 2.1). 

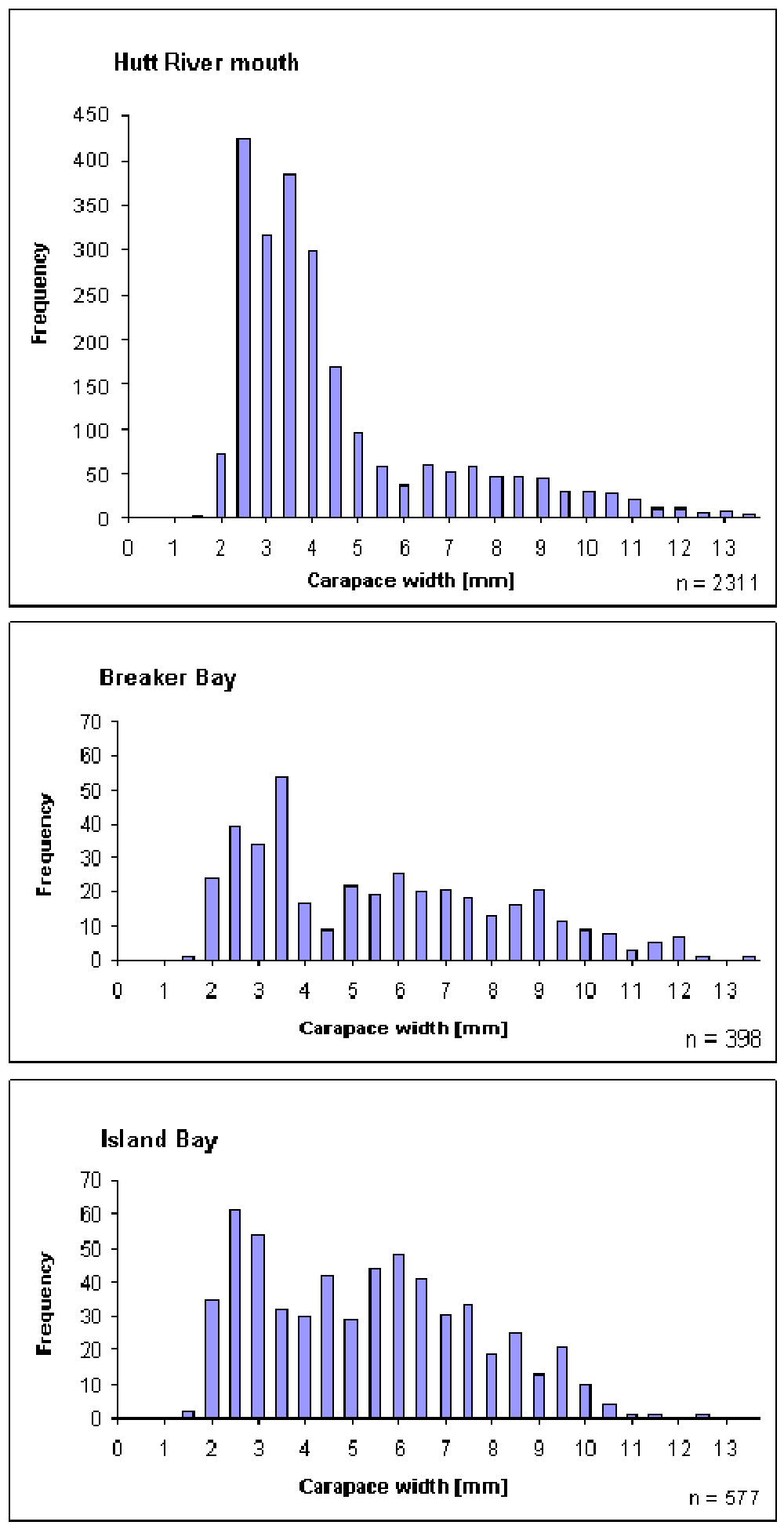

Fig. 2.5: Size frequency distribution of $P$. elongatus (numbers of individuals) at all sites in May 2006. The high frequency of smaller sized crabs (1.5-4.5mm) largely represents settlers (Megalopa larvae, approx. 1.5-2.0mm) and recruits (juveniles, approx. $2.0-3.5 \mathrm{~mm}$ ) from the latest reproductive season. Numbers of settlers, recruits, and resident adult population were much higher at Hutt River mouth. Female crabs reach sexual maturity at a size of $3.4 \pm 0.1 \mathrm{~mm} \mathrm{CW}$ at all sites (see section 3.3). 


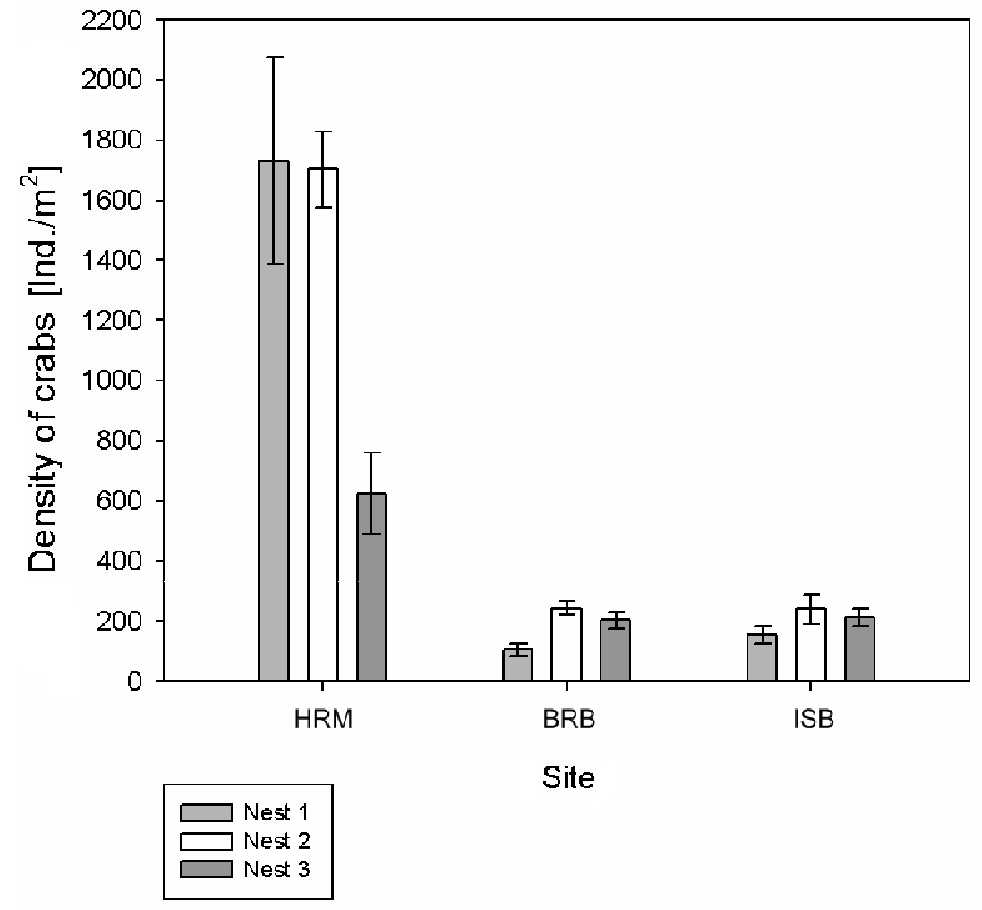

Fig 2.6: Mean crab density per quadrat within nests at all sites (HRM = Hutt River mouth, BRB = Breaker Bay, and ISB = Island Bay) in May 2006. On average, total densities (including juveniles) were approx. 6-fold higher at HRM than at the other two sites. Error bars represent $95 \%$ confidence intervals.

Table 2.1: Fully nested mixed model ANOVA on crab density per rock, where site is a fixed factor and all others random factors. Crab density significantly varied with site and sample quadrat, but did not on the scale of nests and single rocks. This result indicates patchiness of abundance on the 1-5m scale and reflects site differences as shown in Fig. 2.6.

\begin{tabular}{|l|rrrl|}
\hline Source & \multicolumn{1}{l}{ SS } & df & F & p \\
\hline Site & 371.68 & 2 & 7.4141 & $<\mathbf{0 . 0 2 3 9}$ \\
Nest [Site] & 325.08 & 6 & 2.1615 & $<0.6990$ \\
Quadrat [Site,Nest] & 2080.64 & 36 & 2.3057 & $<\mathbf{0 . 0 0 0 1}$ \\
Rock [Site,Nest,Qu.] & 142408.27 & 301 & 18.8750 & $<0.1819$ \\
Error & 312716.85 & 345 & & \\
\hline
\end{tabular}


Mean carapace width $(\mathrm{CW})$ of adult crabs was significantly higher at BRB compared to the other two sites (Fig. 2.7, and Table 2.2). The overall differences between nests within sites were non-significant (Table 2.2), whereas the differences between quadrats within nests and sites (Table 2.2 and Appendix 2.5) and between rocks within quadrats, nests and sites (Table 2.2) were significant.

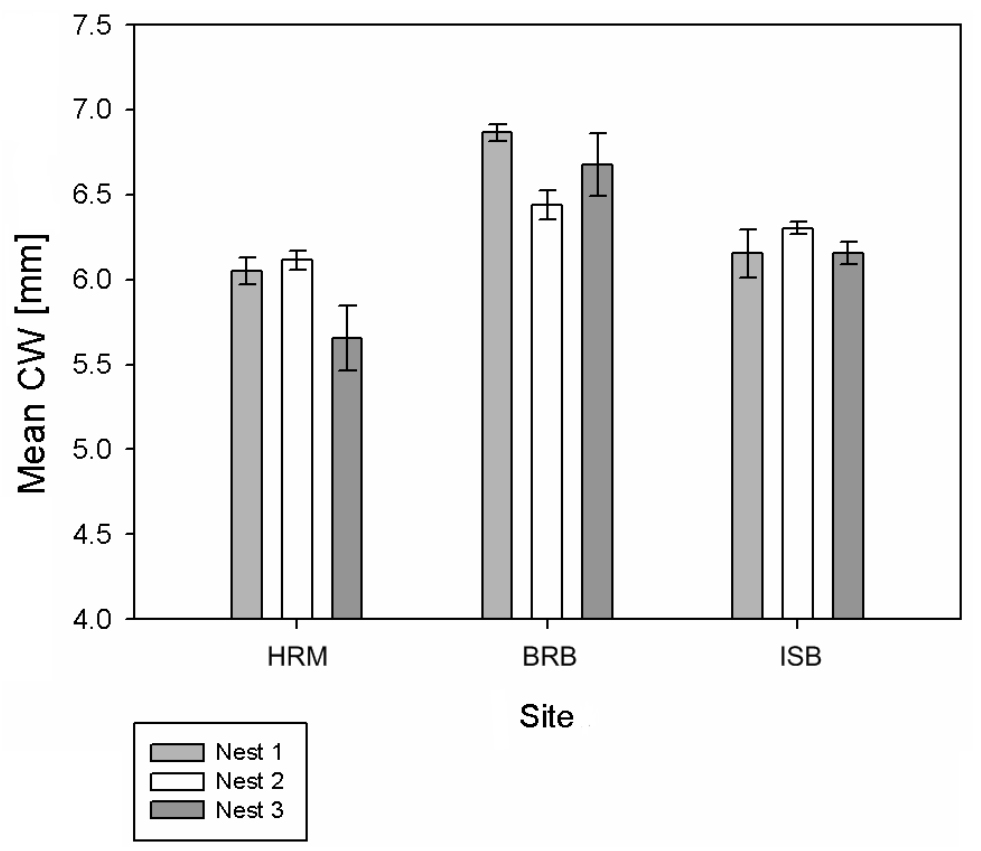

Fig 2.7: Mean carapace width of adult crabs per quadrat within nests at all sites. Error bars represent $95 \%$ confidence intervals. There were significant differences in mean crab size between sites and sample quadrats.

Table 2.2: Fully nested mixed model ANOVA on crab size, where site is a fixed factor and all others random factors. Crab size significantly varied with site, sample quadrat and rock, suggesting that population structure was heterogeneous on the small $(5-50 \mathrm{~cm})$ and on the large scale (several $\mathrm{kms})$.

\begin{tabular}{|l|rrrl|}
\hline Source & \multicolumn{1}{l}{ SS } & \multicolumn{1}{l}{ df } & F & p \\
\hline Site & 440.148 & 2 & 16.4891 & $<\mathbf{0 . 0 0 1 7}$ \\
Nest [Site] & 106.575 & 6 & 0.7971 & $<0.5775$ \\
Quadrat [Site,Nest] & 1271.69 & 36 & 5.2246 & $<\mathbf{0 . 0 0 0 1}$ \\
Rock [Site,Nest,Qu.] & 2708.69 & 301 & 2.0830 & $<\mathbf{0 . 0 0 0 1}$ \\
Error & 25264.795 & 5848 & & \\
\hline
\end{tabular}


The mean sizes of rocks occupied by crabs were significantly higher at HRM compared to BRB and ISB (due to larger rocks at HRM), whereas there was no difference between mean rock sizes at BRB and ISB (Fig. 2.8 and Table 2.3). The differences between nests within sites were non-significant (Table 2.3) but the differences between quadrats within nests and sites were significant (Table 2.3 and Appendix 2.6).

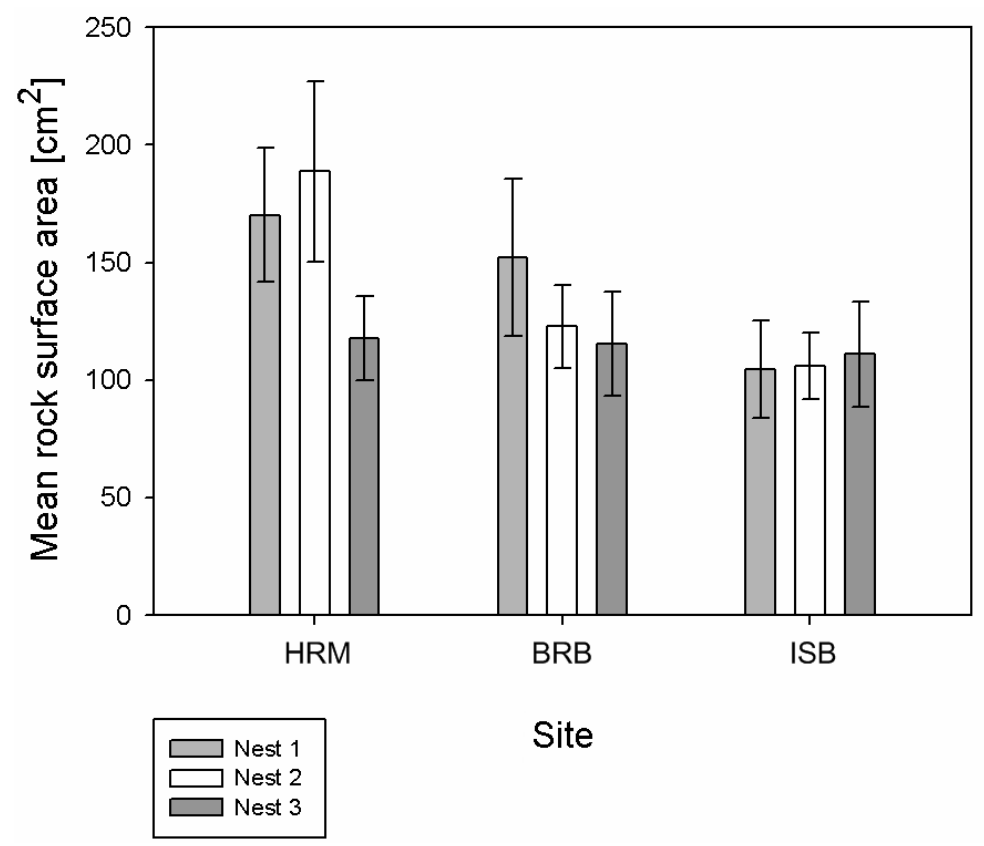

Fig. 2.8: Mean rock sizes (measured as rock surface area) of occupied rocks within nests at all sites. Error bars represent $95 \%$ confidence intervals. Rock sizes were, on average, largest at HRM, intermediate at BRB and smallest at ISB; however, overall differences between nests are non-significant.

Table 2.3: Nested mixed model ANOVA on rock size where site is a fixed factor, nest and quadrat random factors. Rock size significantly varied with sample quadrat and site.

\begin{tabular}{|l|lrrl|}
\hline Source & SS & df & F & p \\
\hline Site & 204138.01 & 2 & 19.1703 & $<\mathbf{0 . 0 0 0 1}$ \\
Nest [Site] & 363839.04 & 6 & 1.1286 & $<0.0726<$ \\
Quadrat [Site,Nest] & 334680.11 & 36 & 2.7461 & $<\mathbf{0 . 0 0 6 9}$ \\
Error & 1607949.0 & 302 & & \\
\hline
\end{tabular}


Crabs preferred larger boulders as shelters over smaller ones (Fig. 2.9) and occurred under boulders with a minimum surface area of approximately $30 \mathrm{~cm}^{2}$. Smaller rocks were hence unoccupied.

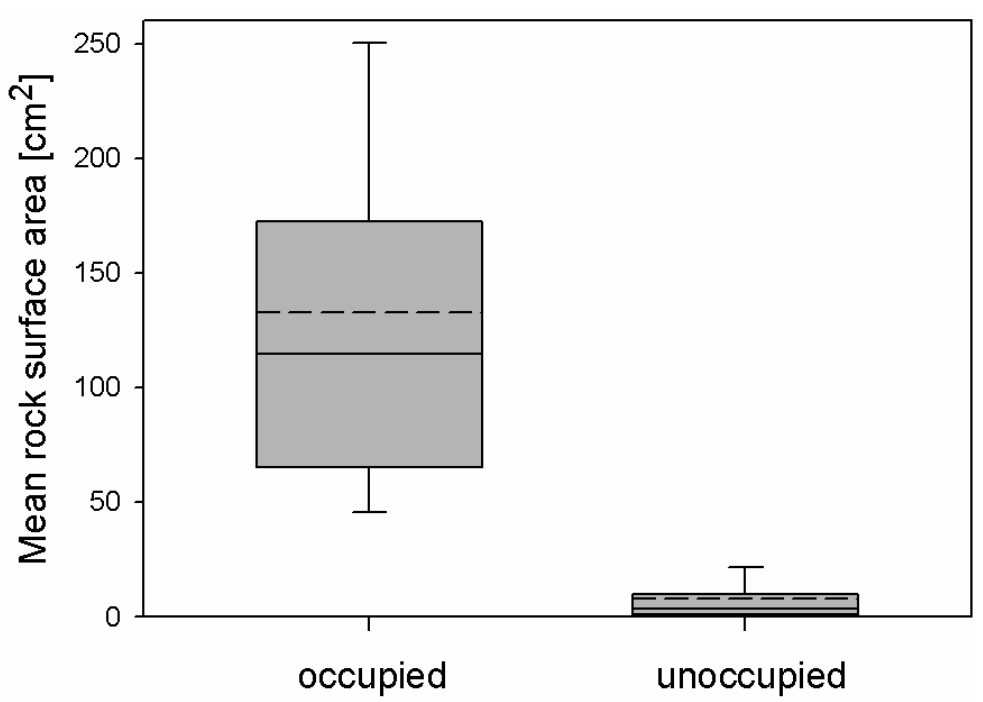

Fig. 2.9: Mean (dashed line) and median (solid line) rock size of occupied versus unoccupied rocks, pooled across sites. Whisker caps represent $2.5 \%$ and $97.5 \%$ quantiles. T-test: $\mathrm{p}<\mathbf{0 . 0 0 0 1} ; \mathrm{T}=72.399 ; \mathrm{df}=2481$. Crabs chose larger boulders as shelters with a minimum surface area of approx. $30 \mathrm{~cm}^{2}$. Crabs were be found under all larger rocks (unless their bottom side was buried in fine sediments), whereas small rocks and pebbles were not used as shelters.

Individual rock size explained $20-43 \%$ of the variation in the number of crabs per rock at all sites (Fig. 2.10). However, mean rock size was not significantly related to mean total crab density (Appendix 2.7) or mean adult density (Appendix 2.8).

Rock size was significantly positively related to mean carapace width of adult crabs per rock at HRM and ISB, but not at BRB (Fig 2.11). However, the amount of variation in carapace width explained by rock size was very low (5-7\%) indicating this relationship, although significant, was weak.

The densities of $P$. elongatus were positively correlated with those of Hemigrapsus sexdentatus (A. Milne Edwards, 1837) at HRM (Fig. 2.12) and Heterozius rotundifrons A. Milne Edwards, at BRB (Fig. 2.13) and ISB (Fig. 2.14). 


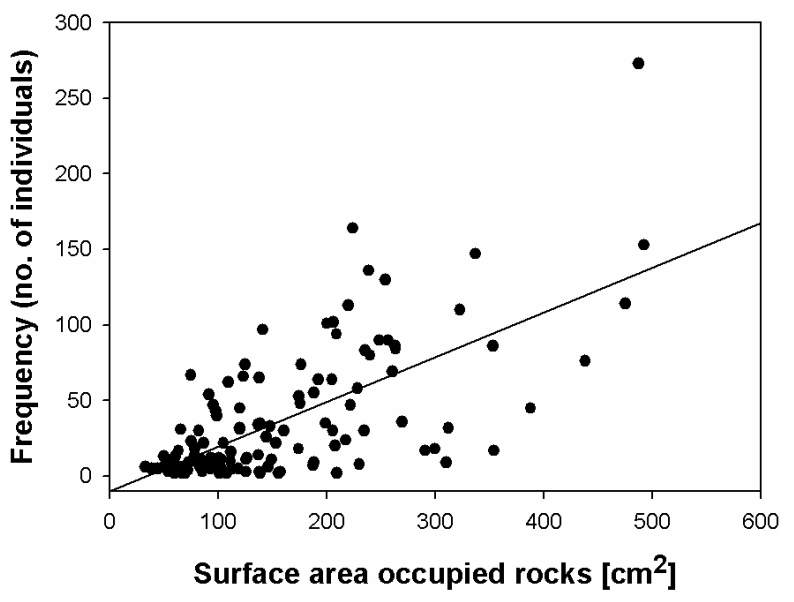

A) Hutt River mouth $\left(R^{2}=0.4395 ; F=94.0847 ; p<0.0001 ; y=-9.6861+0.2956 x\right)$

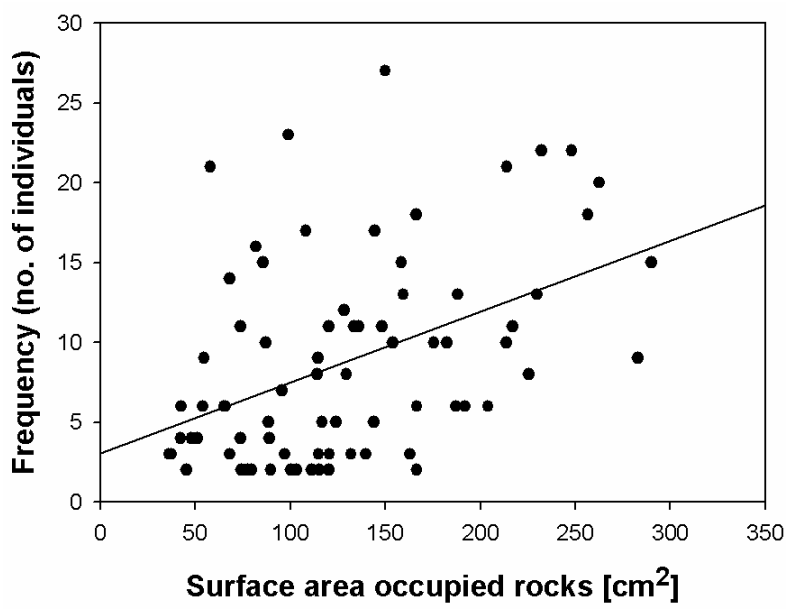

B) Breaker Bay $\left(R^{2}=0.1968 ; F=17.8817 ; p<0.0001 ; y=3.0885+0.0443 x\right)$

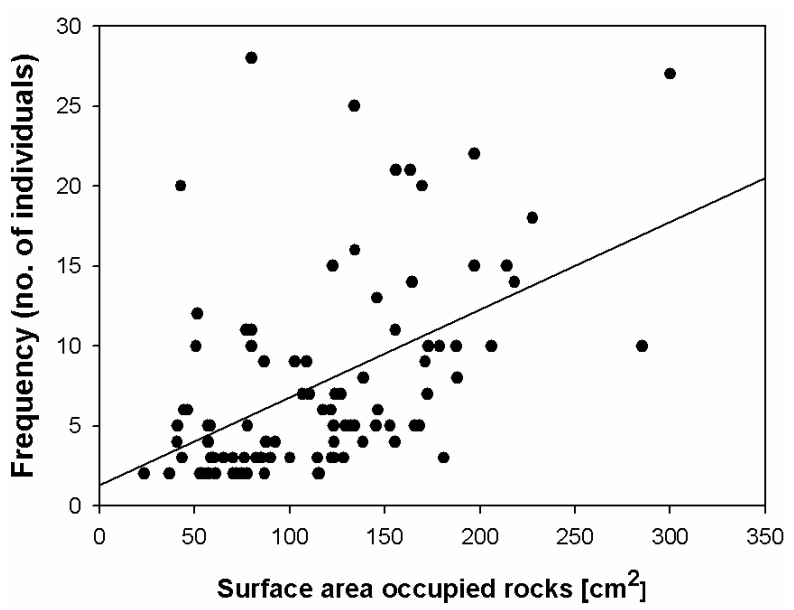

C) Island Bay $\left(\mathrm{R}^{2}=0.2476 ; \mathrm{F}=30.2689 ; \mathrm{p}<\mathbf{0 . 0 0 0 1} ; \mathrm{y}=1.29+0.055 \mathrm{x}\right)$

Fig. 2.10: Rock size (i.e. surface area) versus number of individuals under each rock at a) HMR, b) BRB, and c) ISB. Larger rocks offer more shelter space for more individuals. Please note the different scales on $\mathrm{X}$ - and $\mathrm{Y}$-axis for site a) (HRM). 


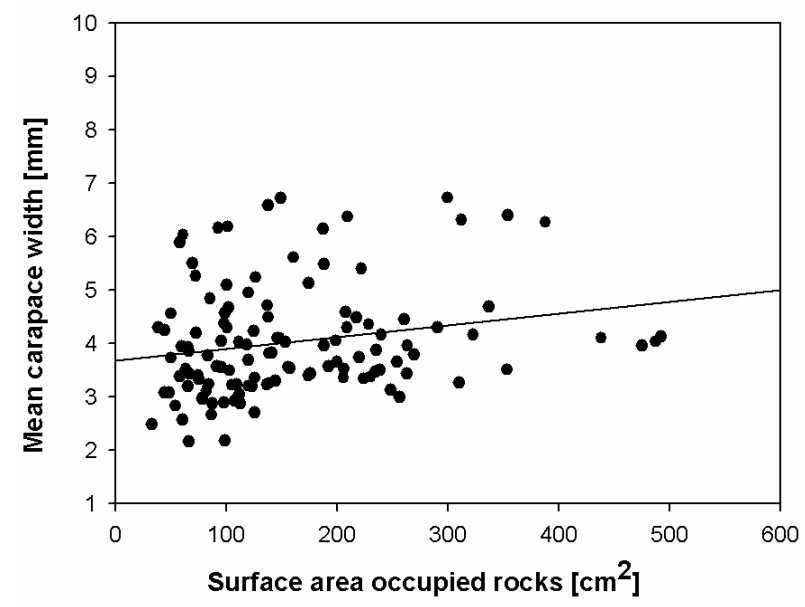

A) Hutt River mouth $\left(R^{2}=0.0448 ; F=5.5776 ; p=0.0198 ; y=3.6795+0.0022 x\right)$

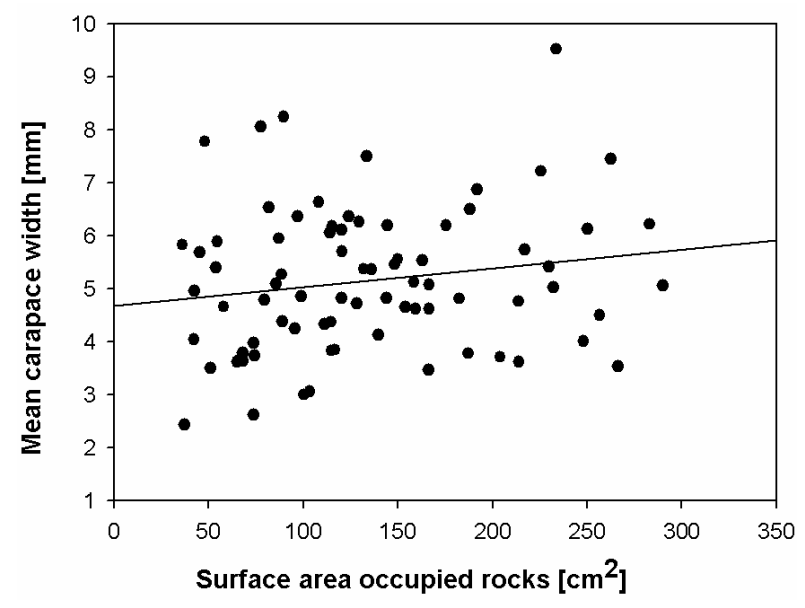

B) Breaker Bay $\left(R^{2}=0.03 ; F=2.3519 ; p=0.1293 ; y=4.6734+0.0036 x\right)$

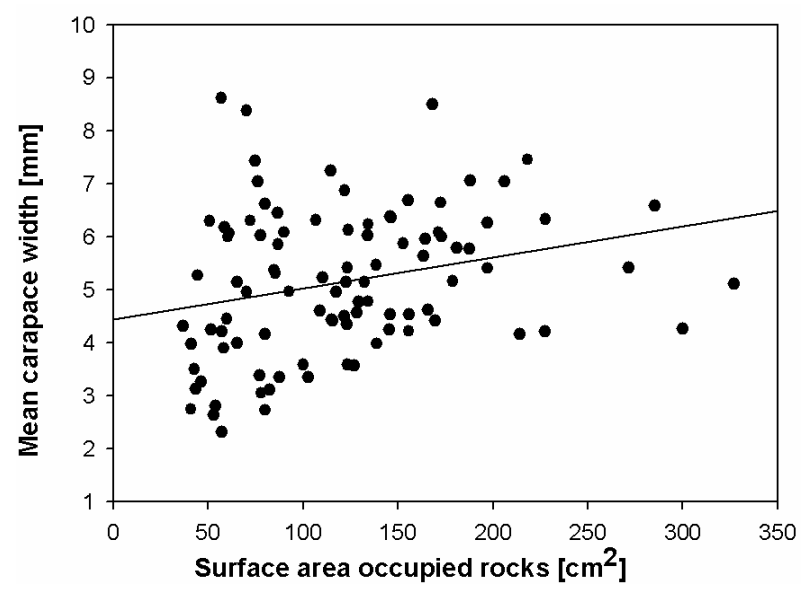

C) Island Bay $\left(R^{2}=0.0686 ; F=6.9271 ; p=0.0099 ; y=4.4461+0.0059 x\right)$

Fig. 2.11: Mean carapace width of adult crabs per rock versus rock size at a) HMR, b) BRB, and c) ISB. The average crab size was larger under larger rocks. Please note the different scales on the X-axis for site a) (HRM). 

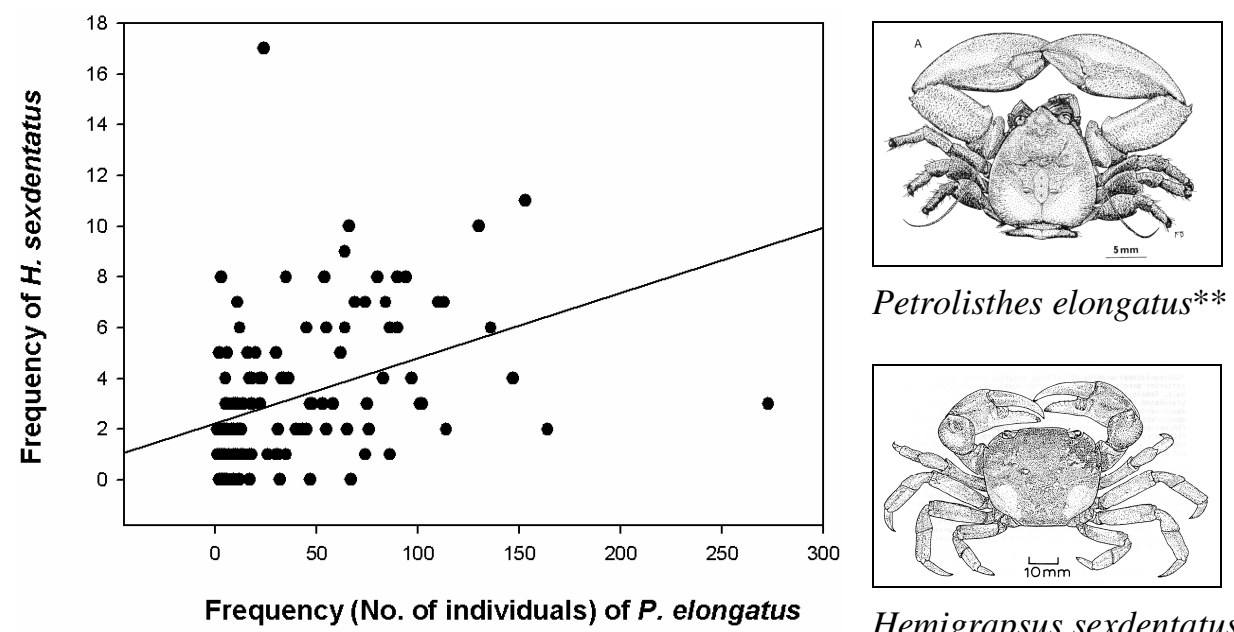

Petrolisthes elongatus**

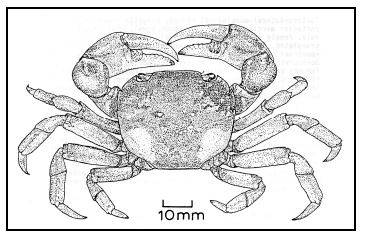

Hemigrapsus sexdentatus*

Fig. 2.12: Density of P. elongatus versus Hemigrapsus sexdentatus (A. Milne Edwards, $1837)$ per quadrat $(0.25 \mathrm{~m} 2)$ at Hutt River mouth $(\mathrm{r}=0.3943 ; \mathrm{F}=23.1982 ; \mathrm{p}<\mathbf{0 . 0 0 0 1})$
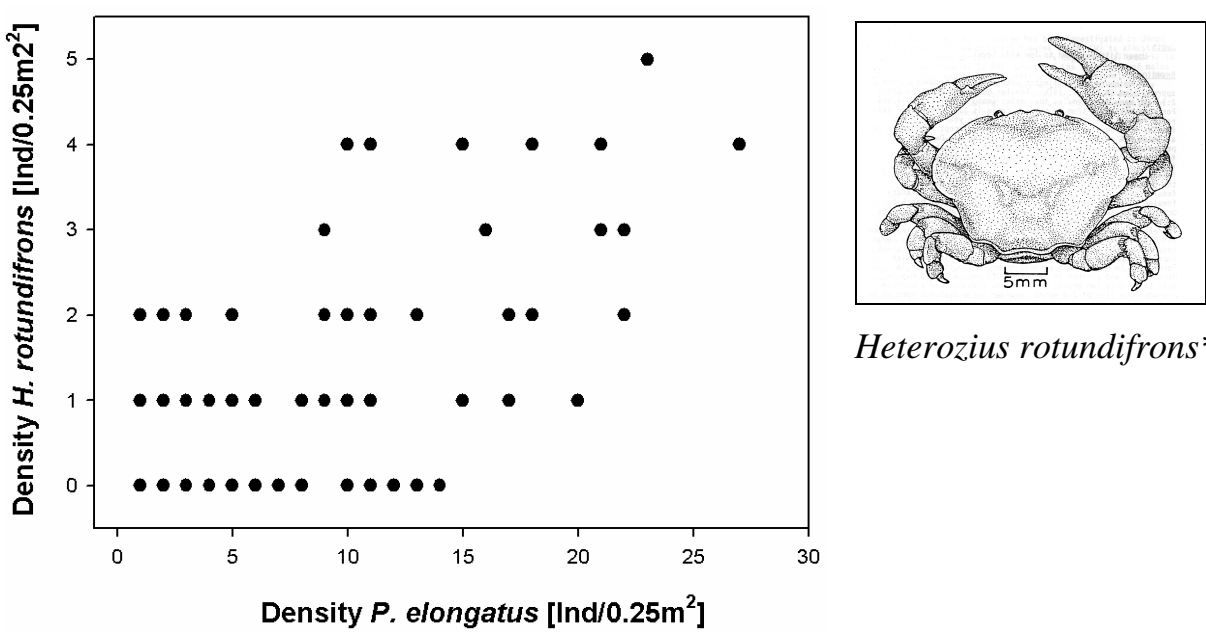

Heterozius rotundifrons*

Fig. 2.13: Density of $P$. elongatus versus Heterozius rotundifrons A. Milne Edwards, 1867 per quadrat $\left(0.25 \mathrm{~m}^{2}\right)$ at Breaker Bay $(\mathrm{r}=0.6424 ; \mathrm{F}=63.9552 ; \mathrm{p}<\mathbf{0 . 0 0 0 1})$
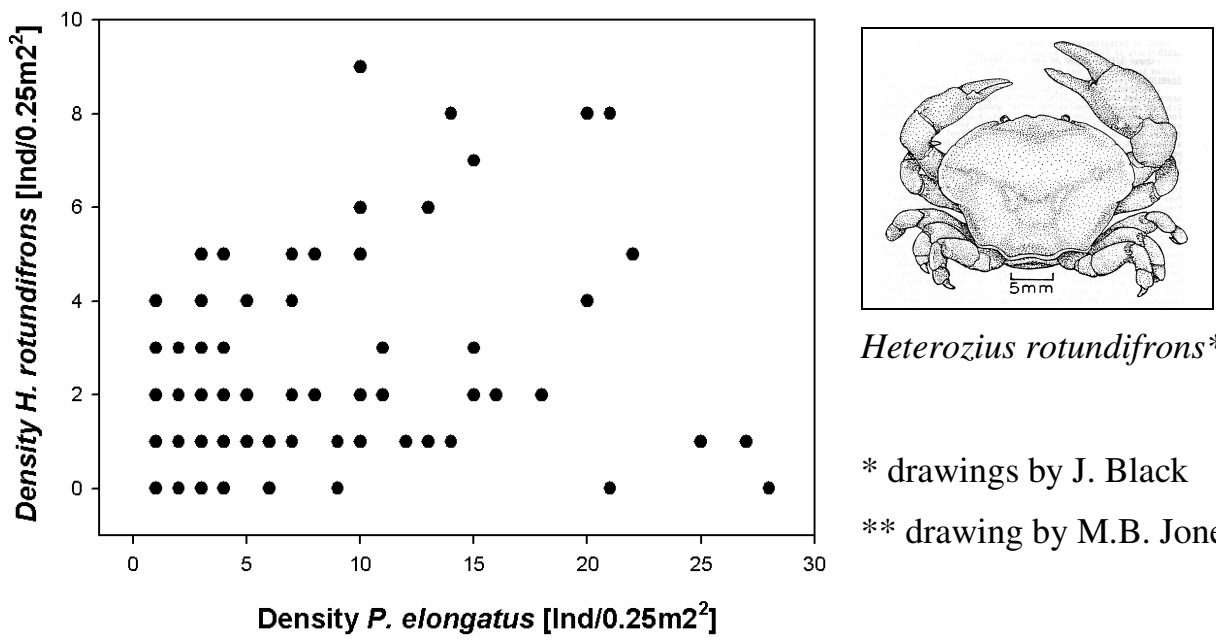

Heterozius rotundifrons*

* drawings by J. Black

** drawing by M.B. Jones

Fig. 2.14: Density of $P$. elongatus versus Heterozius rotundifrons A. Milne Edwards, 1867 per quadrat $\left(0.25 \mathrm{~m}^{2}\right)$ at Island Bay $(\mathrm{r}=0.4028 ; \mathrm{F}=23.6217 ; \mathrm{p}<\mathbf{0 . 0 0 0 1})$ 


\subsubsection{Field experiment: cobble size and colonization of P. elongatus}

Mean density of adults that colonized experimental baskets was significantly different in all rock size treatments (Table 2.4 and post-hoc tests). Adult densities were highest in baskets with small rocks, intermediate among medium-sized rocks, and lowest among large rocks (Fig. 2.15). The relationship for juvenile densities was similar (Table 2.5 and Fig. 2.15), except there was no significant difference between small and medium-sized rocks according to Tukey's HSD. For juveniles and adults there were no significant differences between baskets nested within treatments.

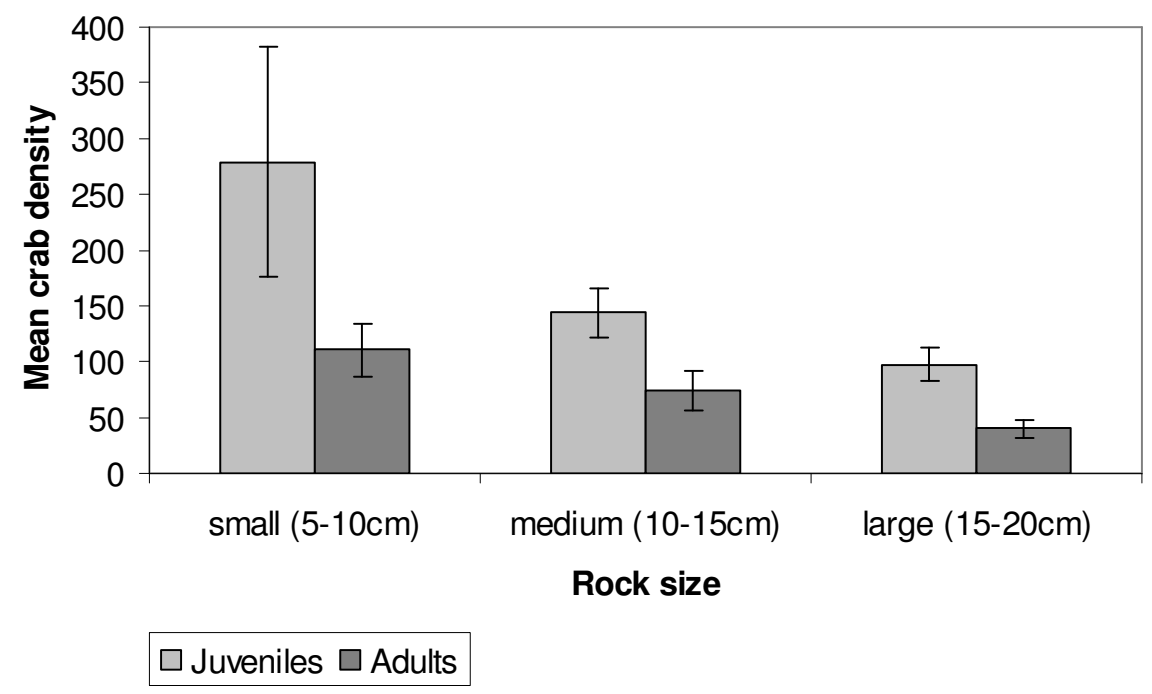

Fig. 2.15: Mean density of $P$. elongatus adults ( $\mathrm{n}=2005$, dark grey) and juveniles $(n=3955$, light grey) as average number of individuals per basket trap within all treatments (i.e. three size classes of rocks: small: $5-10 \mathrm{~cm}$, medium: $10-15 \mathrm{~cm}$, and large: $15-20 \mathrm{~cm}$ maximum length). Error bars represent $95 \%$ confidence intervals.

Table 2.4: One-way ANOVA results adult crab density per basket vs. rock size with basket as random factor, nested within treatment (rock size)

\begin{tabular}{|l|lrrl|}
\hline Source & SS & df & F & p \\
\hline Rock size & 19956.25 & 2 & 15.4826 & $<\mathbf{0 . 0 0 0 1}$ \\
Basket no. [Rock size] & 2211.726 & 3 & 1.1439 & $<0.3582$ \\
Error & 11600.524 & 18 & & \\
\hline
\end{tabular}

Table 2.5: One-way ANOVA results juvenile crab density per basket vs. rock size with basket as random factor, nested within treatment (rock size)

\begin{tabular}{|l|lrrl|}
\hline Source & \multicolumn{1}{|l}{ SS } & df & F & p \\
\hline Rock size & 142660.75 & 2 & 7.8948 & $<\mathbf{0 . 0 0 3 5}$ \\
Basket no. [Rock size] & 2133.70 & 3 & 0.0787 & $<0.9707$ \\
Error & 162631.55 & 18 & & \\
\hline
\end{tabular}


Mean body size of adults depended on rock size with significant differences between treatments (Fig. 2.16 and Table 2.6) with significantly smaller crab sizes among small rocks compared to the other treatments (Fig. 2.16). The differences in body size of crabs between baskets nested within treatments were nonsignificant (Table 2.6).

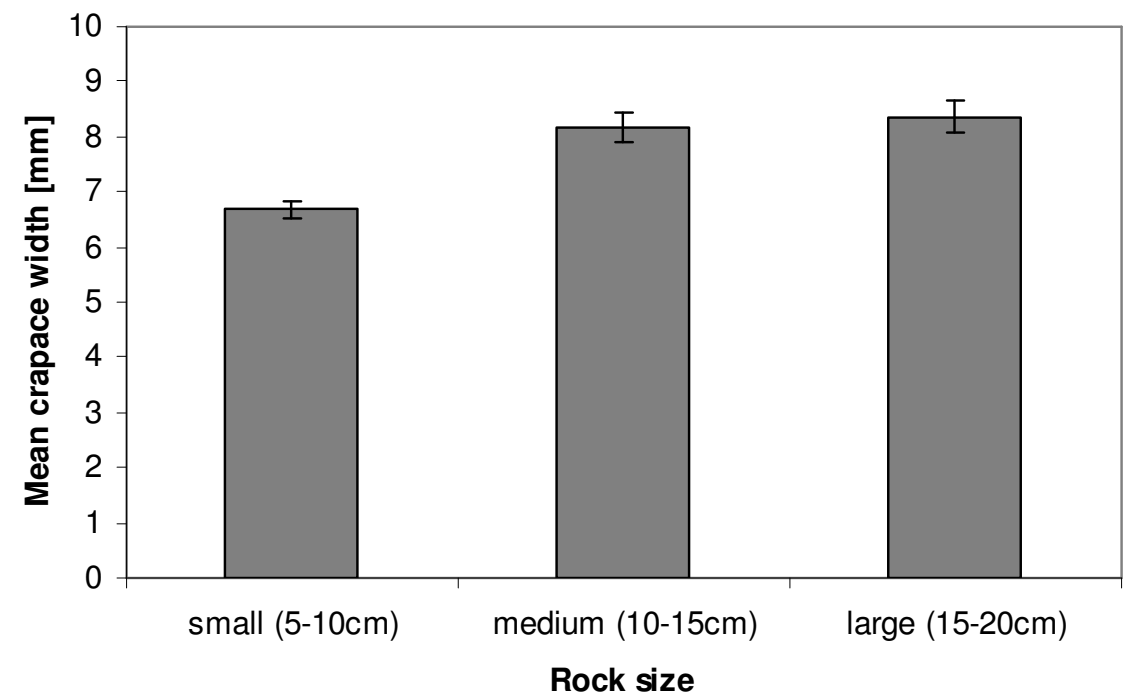

Fig. 2.16: Mean body size (carapace width, CW) of $P$. elongatus adults (n=2005) within all treatments (i.e. three size classes of rocks: small: $5-10 \mathrm{~cm}$, medium: $10-$ $15 \mathrm{~cm}$, and large: $15-20 \mathrm{~cm}$ maximum length). Juveniles were excluded due to identical carapace widths. Error bars represent $95 \%$ confidence intervals.

Table 2.6: One-way ANOVA results adult carapace width versus rock size with basket as random factor, nested within treatment (rock size)

\begin{tabular}{|l|lrrr|}
\hline Source & SS & df & F & p \\
\hline Rock size & 2.4677274 & 2 & 171.5264 & $<\mathbf{0 . 0 0 0 1}$ \\
Basket no. [Rock size] & 0.0086967 & 3 & 0.4030 & $<0.7509$ \\
Error & 10.617183 & 1521 & & \\
\hline
\end{tabular}

\subsubsection{Laboratory experiment: Influence of cobble size on predation rate}

Cobble size significantly influenced predation rates (i.e. number of survivors)

(Table 2.7) with highest predation and, accordingly, lowest survival for the smallest 1 crabs among small rocks (Fig. 2.17). Predation rate also varied 
significantly with crab size (Table 2.7 and Fig 2.17). Small crabs had much higher survival rates among medium and large rocks. Size class 2 crabs had intermediate survival, similar for all rock sizes, whereas large crabs (size class 3 and 4) were rarely to never preyed upon, regardless of rock size (Fig. 2.17).
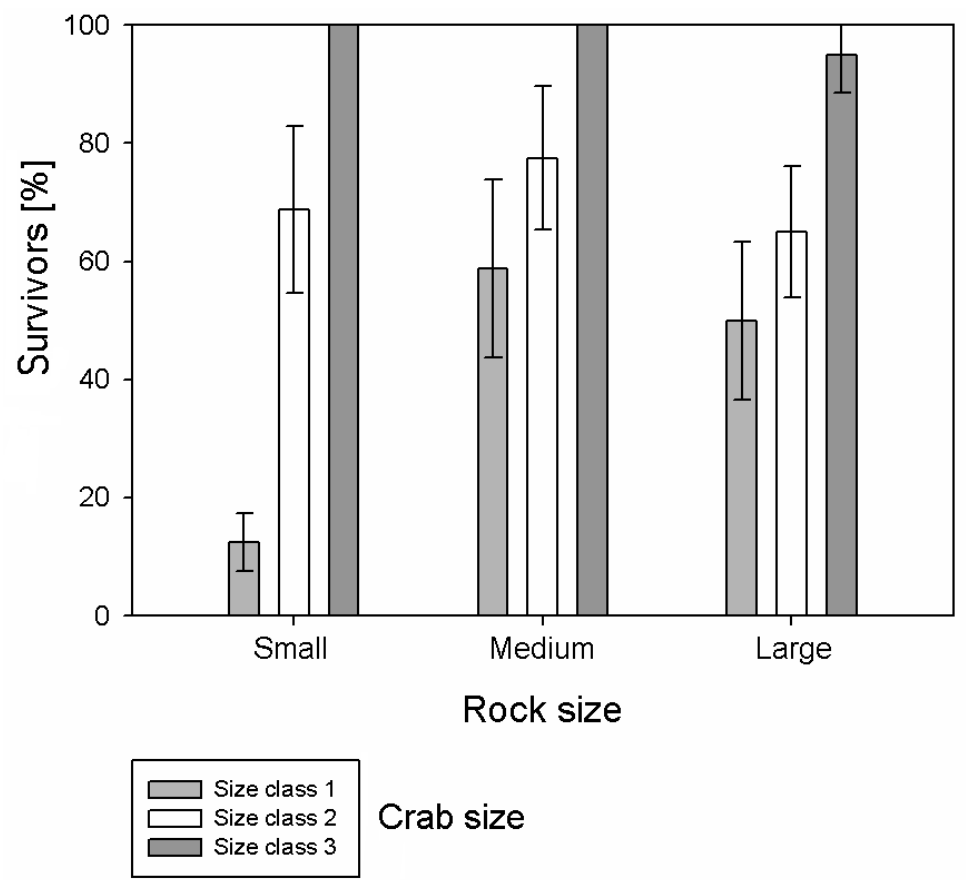

Fig. 2.17: Cobble size $($ small $=2.5-5.0 \mathrm{~cm} ;$ medium $=5-10 \mathrm{~cm} ;$ large $=10-$ $20 \mathrm{~cm}$ maximum length) versus mean percent survivors within three size classes of crabs at the end of the predation experiment (exposure to Acanthoclinus fuscus for three weeks). Size class 4 crabs are not shown due to $100 \%$ survival in all treatments. Error bars represent $95 \%$ confidence intervals. In all treatments, smaller crabs were preyed upon more frequently than larger ones. For small crabs, predation rates were higher among small rocks compared to predation in the other treatments.

Table 2.7: Survival analysis (Cox's Proportional Hazard; nominal logistic fit) No. of crabs per census* $\sim$ Rock size + Crab size. Tank as random factor was excluded from the model as it proved to be non-significant. Size class four (largest crab size) was excluded due to no predation over time. SE = Standard Error; $\mathrm{CI}=$ Confidence Interval. $*$ Weekly count of survivors in each size class over 3 weeks.

\begin{tabular}{|l|lcccr|}
\hline Variable & df & Coefficient (SE) & CI (upper) & (lower) & P $\left(\mathbf{C h i}^{2}\right)$ \\
\hline Rock size & 20 & $1.0995(0.4673)$ & 2.0036 & 0.1651 & $\mathbf{0 . 0 1 0 3}$ \\
Crab size & 20 & $-0.9163(0.2929)$ & -1.5176 & -0.3616 & $<\mathbf{0 . 0 0 0 1}$ \\
\hline
\end{tabular}




\subsubsection{Field experiment: Mobility and migration among cobbles of P. elongatus}

The interaction between site and size class was non-significant (Table 2.8). However, the distance the crabs had moved over $25 \mathrm{~h}$ was significantly different among sites (Table 2.8). Post-hoc tests revealed that the mean distances at HRM were significantly different from those at BRB and ISB, but there was no significant difference between BRB and ISB. These results are reflected in Fig. 2.18: All size classes of crabs at HRM had moved significantly smaller distances compared to those at the other two sites. The differences among size classes were also significant (Table 2.8). Small crabs (size class 1) had moved significantly less than all larger crabs and size class 2 crabs moved significantly smaller distances than size class 3 and 4 crabs (post-hoc tests and Fig. 2.18). Tukey's HSD showed that the differences among all size classes were significant apart from size class 3 versus size class 4 . Differences between runs were nonsignificant (Table 2.8 and post-hoc tests). In the fully saturated model (Appendix 2.10), all interactions with "run" were also non-significant and were thus removed from the final model.

Table 2.8 : 3-Way ANOVA results Distance $\sim$ Site + Size class + Run + (Site * Size class). Migration rate significantly varied with crab size and site, whereas there were no differences between runs at each site.

\begin{tabular}{|l|lrrl|}
\hline Source & SS & df & F & p \\
\hline Site & 2.0045169 & 2 & 11.3423 & $<\mathbf{0 . 0 0 0 1}$ \\
Size class & 5.8203202 & 3 & 21.9557 & $<\mathbf{0 . 0 0 0 1}$ \\
Run & 0.0355214 & 2 & 0.2010 & $<0.8180$ \\
Site $*$ Size class & 0.4812757 & 6 & 0.9077 & $<0.4896$ \\
Error & 25.183901 & 263 & & \\
\hline
\end{tabular}




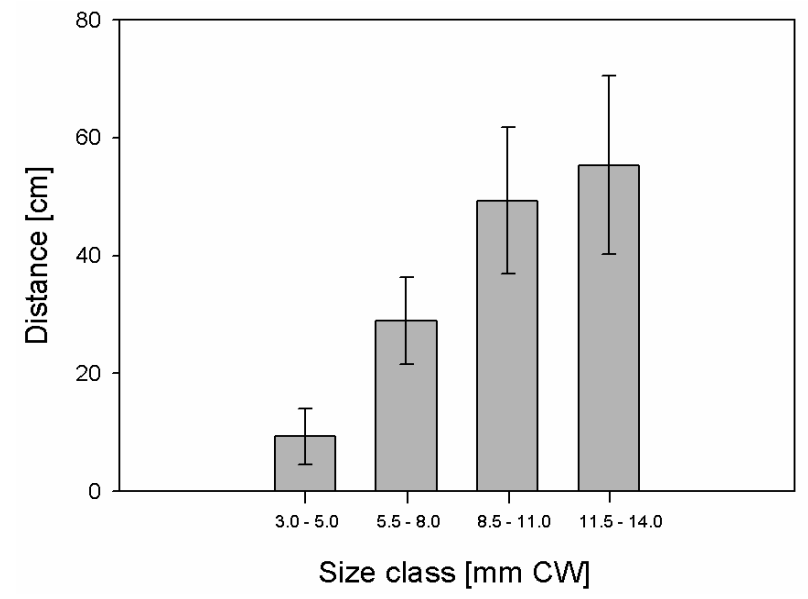

A) Hutt River mouth (HRM)

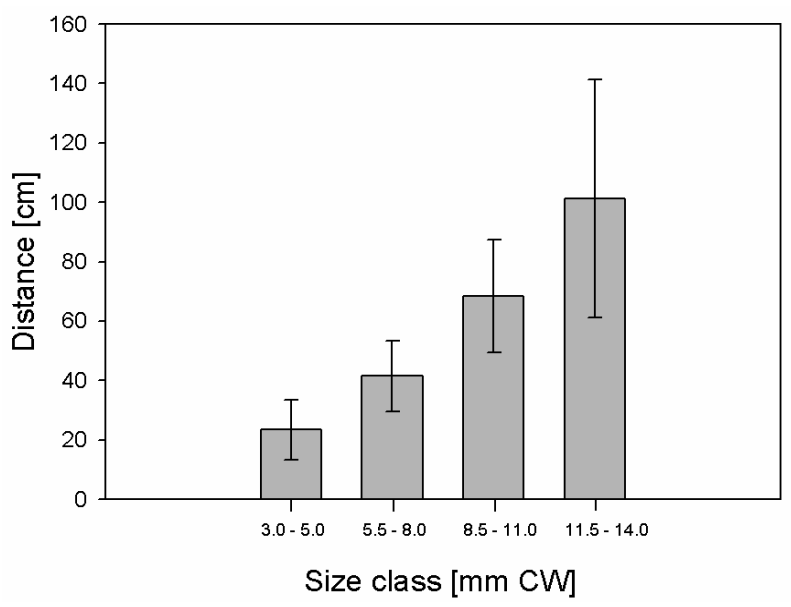

B) Breaker Bay (BRB)

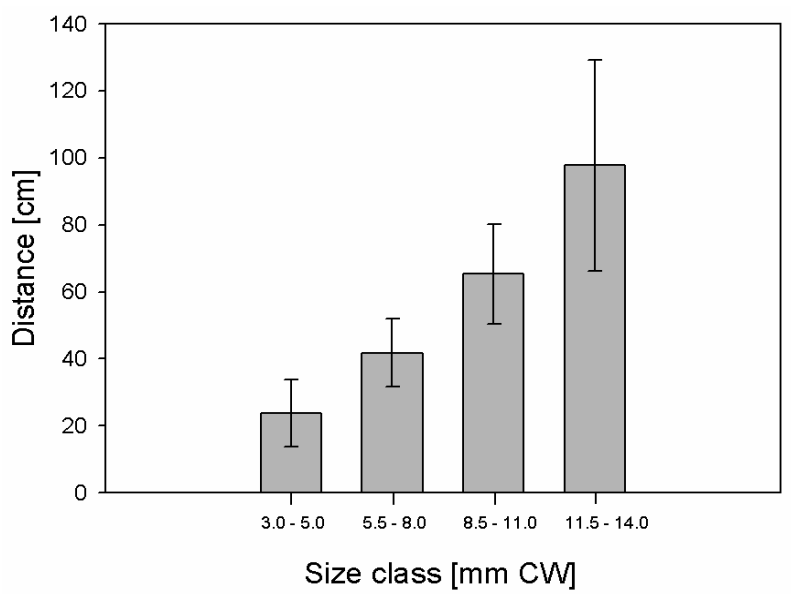

C) Island Bay (ISB)

Fig. 2.18: Mark and recapture survey: Size class (carapace width) versus distance from position of crab to point of release after $25 \mathrm{~h}$ at all sites. Carapace width is positively correlated with migration rate. Error bars represent $95 \%$ confidence intervals. Please note that scale of Y-axis varies among subfigures A-C. 


\subsection{Discussion}

Population density and structure of porcelain crabs living in intertidal boulder fields are affected by a variety of factors such as larval supply, settlement and recruitment, predation, individual growth rates, migration in response to intraspecific competition, light conditions and desiccation stress, etc.; however, substratum characteristics and habitat structure appear to be highly relevant in shaping the observable patterns of abundance and size frequency distributions of crabs on different special scales.

\section{Patterns of abundance}

A patchy distribution of $P$. elongatus was found on the scale of 1-5 meters (between quadrats) as well as on the scale of several kilometres (between sites). On these scales of observation cobble size was a good predictor of local abundance of porcelain crabs. Similarly, Gebauer et al. (2007) observed that the high spatial variability in population density of Petrolisthes laevigatus in southern Chile may be attributed to the size and shape of rocks. In the present study, rock size was positively correlated with numbers of crabs found underneath since larger rocks, on average, provide more shelter space. Additionally, P. elongatus

prefers larger rocks (min. surface area of approx. $30 \mathrm{~cm}^{2}$ ) as shelters over smaller ones. This preference could be explained by visually guided shelter targeting behaviour (Meyer-Rochow \& Meha, 1994) in conjunction with negative phototaxis (Scott, 1958). Generally, larger rocks provide better protection from predation (see discussion below), temperature stress, and desiccation (Stillman, 2002; Emperanza, 2007). In intertidal boulder fields in northern Chile, Emparanza (2007) showed that distribution patterns as well as mean size of Petrolisthes granulosus, P. violaceus and Allopetrolisthes angulosus is strongly affected by temperature and emersion gradients. Pellegrino (1984) reported that the vertical distribution of $P$. elongatus is mainly driven by increasing desiccation pressure with increasing height, combined with species specific levels of adaptation to water loss (compare Stillman \& Somero, 1996), whereby small individuals are more vulnerable than larger ones (Jones \& Greenwood, 1982). In addition to the responses to environmental factors such as light conditions and desiccation stress, the selection of shelters may be influenced by the sediment type below boulders. 
In a randomized field experiment, Akins (2003) found that adult $P$. cinctipes strongly preferred rocks set on cobbles and pebbles, rather than rocks on sand or on a combination of sand and pebbles. The same appears to be true for $P$. elongatus (own observation).

Generally, mean crab density was significantly higher at HRM compared to BRB and ISB, presumably due to factors such as differences in larval supply and retention, recruitment and survival rates, food supply, availability of shelter space, and wave exposure. At HRM, local densities of up to $6,500 \mathrm{ind} . / \mathrm{m}^{2}$ per boulder and up to 843 individuals per quadrat $\left(=3372 \mathrm{ind} . / \mathrm{m}^{2}\right)$ were estimated or counted. To my knowledge, these are the second-highest recorded densities of porcelain crabs, surpassed only by Petrolisthes cinctipes living in the interstices of Mytilus californianus beds, reaching densities of up to $3933 \mathrm{ind} . / \mathrm{m}^{2}$ in the cool temperate north-eastern Pacific (Jensen 1990).

\section{Population structure}

Rock size does not only affect local abundance in $P$. elongatus, but also influences population structure with significant differences in mean carapace width $(\mathrm{CW})$ between sites as well as on the scale of quadrats and single rocks. At two sites (HRM and ISB), mean CW was positively correlated with rock size: larger crabs were found under larger rocks, which is consistent with the mean $\mathrm{CW}$ of adults extracted from basket traps. While at ISB factors such as wave exposure and differential predation may have contributed to this pattern, a dominance hierarchy among $P$. elongatus in competition for the most suitable microhabitats could have been the main driver at HRM. Such hierarchical systems based on body size and agonistic interaction have been observed in P. elongatus (own observation), P. cinctipes (Molenock, 1976; Donahue, 2004; Rypien \& Palmer, 2007), P. cabrilloi, P. eriomerus and P. manimaculis (Molenock, 1976), Allopetrolisthes spinifrons (Baeza et al., 2002), as well as in the hermit crab Pagurus longicarpus (Winston \& Jacobson, 1978) and other anumuran crustaceans. Additionally, the physical space between boulders can delimit the body size of occupants. Populations of many crustacean species appear to be constrained by the availability of appropriately sized refuges in the substratum (Wahle \& Steneck, 1992; Beck, 1995; Casariego et al., 2004; Briones-Fourzán et al., 2007) or in artificial substrates (Bartholomew \& Shine, 2008). Juveniles of the 
southern rock lobster Jasus edwardsii, for example, exhibit a close association with shelters that are conform to their body dimensions (Booth \& Ayers 2005), as do other panulirid species (Jernakoff 1990; Eggleston \& Lipcius, 1992; Dennis et al., 1997). Shelter size also sets an upper limit to the body size of American lobsters, Homarus americanus, occupying the interstitial spaces among cobbles (Wahle, 1992). Hixon \& Beets (1993) and Drolet et al. (2004a) demonstrated that the physical structure of subtidal reefs, particularly through the provision of refuges from predation, profoundly affects associated communities of fish and invertebrates. Willis \& Anderson (2003) detected positive correlations between reef surface rugosity and the density and diversity of cryptic fish communities in and adjacent to the Cape Rodney-Okakari Point Marine Reserve in north-eastern New Zealand. By contrast, Alexander et al., (2009) found reef structure (i.e. rugosity) to be a relatively poor predictor of invertebrate abundance and species richness on all spatial scales examined (5m, 50m, and 200m).

The size frequency distributions of crabs that were obtained by quantitative sampling in May 2006 (well after the reproductive season, lasting from July/August until March in the Wellington region, see Wear, 1965), clearly show frequency peaks for small crabs $(1.5 \mathrm{~mm}-4.5 \mathrm{~mm})$ which result from seasonal larval supply and recruitment into the benthic population. This pattern was especially pronounced at HRM, suggesting higher recruitment rates (and possibly larval supply) at this site.

\section{Predation}

Predation on $P$. elongatus varied with both crab size and rock size when exposed to Acanthoclinus fuscus under laboratory conditions. Small crabs were significantly more susceptible to predation than larger ones with higher predation rates among small rocks $(2.5-5.0 \mathrm{~cm}$ max. length) relative to larger rocks $(5-10 \mathrm{~cm}$ and $10-20 \mathrm{~cm})$. In juvenile blue crabs, Callinectes sapidus, the smallest crabs were eaten at a higher rate than larger crabs if algal cover was absent and therefore shelters unavailable (Wilson et al., 1990). Rock size, available shelter space, and predation risk are related for a number of reasons. At wave exposed shores, pebbles roll and shift more frequently than larger boulders due to water movement, thereby increasing disturbance (see Shanks \& Wright, 1986) as well as predation risk of small crabs among small rocks, whereas small crabs are more 
easily dislodged by high current velocities than larger individuals. Larger predators are capable of moving smaller rocks. Larger individuals of A. fuscus, for example, wiggle into loose gravel to seek cover or prey on small crabs (own observation). However, larger cavities among large boulders may be more accessible for predators, whereas smaller rocks in the more stable ground layer of boulder fields provide physical refuge, possibly explaining the significantly higher densities of (on average) smaller crabs in basket traps with small rocks compared to densities and size frequency distributions among larger rock sizes. In addition to the importance of physical shelter, Jensen \& Armstrong (1991) showed that adults of $P$. cinctipes protected settlers and juveniles from predation by intertidal fishes.

The effectiveness of autotomy in Petrolisthes spp. as an escape strategy has been demonstrated by Wasson et al. (2002); however, the crabs show a context dependent response and only employ the costly strategy of autotomizing a limb as a last resort if the success of struggle or flight is low (Wasson \& Lyon, 2005). Furthermore, $P$. elongatus exhibits differential behavioural responses to food and alarm odours that are profoundly affected by autotomy of limbs (Hazlett, 2004).

The variability of coloration in P. elongatus adults appears to be an adaptation to the diversity of microhabitats (own observation) in order to be optimally camouflaged on differently coloured substrates such as rocks, biofilms and shingle (i.e. mollusc shells). By contrast, larvae (including the Megalopa stage) are unpigmented and thus appear transparent, almost invisible for predators in the water column and on most surfaces (e.g. Felder et al., 1985). Future research may elucidate whether site-specific differences in colouration of adult crabs could be explained by differential visual predation, thereby selecting for better camouflaged phenotypes, or whether other environmental factors such as local variations in diet composition influence these patterns (see chapter 6).

\section{Sympatric species}

The positively correlated densities of $P$. elongatus and two relatively abundant sympatric crustacean species, Heterozius rotundifrons and Hemigrapsus sexdentatus, indicate that the level of interspecific competition is low and has consequently no effect on their local abundance. However, Hazlett \& McLay 
(2005) presented evidence for chemical communication (i.e. the perception of interspecific waterborne alarm odours) between $P$. elongatus and $H$. rotundifrons. Despite the fact that these species share the same habitat (i.e. the interstitial space among boulders), each of them occupies a different niche in terms of shelter use as well as regarding exploitation of food resources. While P. elongatus is a suspension feeder and seeks shelter in small cavities and crevices under and among cobbles, $H$. rotundifrons can be commonly found buried in the sediment under boulders (Bennet, 1964, and own observation), and is feeding on seaweed (McLay, 1988). H. sexdentatus, by contrast, is much larger and more mobile than the other two species, preys upon drift algae as well as molluscs (McLay, 1988), and is far less susceptible to desiccation (Pellegrino, 1984). These crabs do not live exclusively in the upper intertidal, but also in the supralittoral among large boulders.

\section{Migration}

Migrated distances did not exceed $100 \mathrm{~cm}$ over $25 \mathrm{~h}$ even for larger crabs and where up to 10 times smaller compared to those of other decapods, such as Carcinus maenas (Moksnes, 2002), Cancer magister (Holsmann et al., 2006), and Callinectes sapidus (Johnson \& Eggleston, 2010). In a mark-recapture survey Donahue (2004) conducted examining the mobility of $P$. cinctipes, most individuals moved very little $(<0.5 \mathrm{~m})$ in $24 \mathrm{~h}$. At HRM, the mean travelled distances of crabs in all size classes where significantly smaller compared to the other sites. While a larger variation in (larger) rock sizes increases structural complexity, a higher complexity should decrease migration rate. Additionally, mean population density was significantly higher at HRM relative to BRB and ISB, presumably indicating higher patch quality and/or higher levels of intraspecific competition that may, in turn, influence migration rate. Donahue (2006) argues that conspecific density in Petrolisthes spp. is likely to reflect underlying microhabitat quality due to differential mortality of crabs in different quality patches, but also through immigration of resident conspecifics into highquality patches. However, Hugie \& Grant (1998) emphasize that animals will occasionally move between patches for reasons other than to simply maximize their resource payoffs. Both movement and aggregation of porcellanidae with intertidal distribution is probably related to the tidal cycle, similar to hermit crabs (Snyder-Conn, 1980; Gherardi \& Vanini, 1992; Turra \& Leite, 1999), even 
though in P. elongatus and other porcellanidae no evidence was detected for vertical migration following the tidal rhythm. While clusters of mostly inactive individuals form primarily during low tide in response to environmental factors such as habitat heterogeneity, light, and desiccation, animals disperse more readily when submerged (own observation), e.g. adjusting their position to suitable locations and current velocities optimal for filter feeding.

In the present study, small crabs exhibited significantly lower migration rates than larger crabs, which is consistent with observations of size-dependent flight behaviour in P. elongatus (own observation) and in P. cinctipes (Jensen, 1990; Donahue, 2004). Adult crabs quickly escape after turning over a rock, whereas recruits do not move at all. Generally, $P$. elongatus as well as $P$. cinctipes appear to move more with increasing disturbance (Jensen, 1990; Jensen \& Armstrong, 1991; Donahue, 2004, and own observation).

\section{Sampling methods}

A major drawback of methods using rock surface area (i.e. the area of a horizontal cross section of each rock as seen from above) as an indicator for shelter size and habitat complexity is that the surface area of rocks does not necessarily represent the amount of available interstitial shelter space, because shelter space depends not only on rock size but also on the shape (i.e. "roundness") and packing density of rocks (for suggestions of a three dimensional measure, see Chapter 6). In some patches rocks were stacked in multiple layers, whereas in other areas boulders rested on bedrock and/or soft sediment, some of which were partially or entirely buried. However, in contrast to the standard method of measuring grain-size using the Wentworth scale (see Buchanan, 1984) based on the maximum diameter of particle fractions, I opted for a two-dimensional measure as a closer approximation to shelter space or cover area, almost identical to digital photography assisted quadrat sampling techniques applied by Warrick et al. (2009). A similar approach to the method chosen in the present study has been proposed by Bartholomew et al. (2000) who suggest to apply the ratio total area of cover within a habitat divided by the total area of the habitat $(\mathrm{Ct} / \mathrm{At})$ as a dimensionless index of habitat complexity (i.e. the amount of cover or shelter space available within a defined area). However, Bartholomew et al. (2000) propose a second index which measures the extent to which the structural 
complexity interferes with a predator's ability to search or pursue prey, calculated as the average 'inter-structural space size' (i.e. the randomly chosen gap width between structures) divided by the size of the predator $(\mathrm{Sp} / \mathrm{Pr})$, e.g. the gill to gill width of a fish.

\section{Conclusions}

Because interstitial space among boulders is crucial for the presence of $P$. elongatus and directly or indirectly affects predation rate, local population densities and population structure, cobble size is an important indicator of habitat quality for this species that largely explained patchiness of abundance on a macro(several kms) and microscale $(5-50 \mathrm{~cm})$. By contrast, it remained elusive whether migration rate is affected by the size frequency distribution of rocks or whether movement is mainly driven by factors such as habitat quality, intraspecific competition, and disturbance. The underlying mechanisms of how habitat quality is influenced by rock size were difficult to quantify in detail (except for predation on P. elongatus by Acanthoclinus fuscus) and presumably acted differently in different habitat patches and at the sites examined in the present study. The effect of predation, for example, is far more complex in the field than the observed patterns in aquaria, where other predator species as well as abiotic factors such as wave exposure were excluded for simplification. The aim to identify relevant habitat quality indicators for mobile marine invertebrates living on intertidal boulder fields was only partially met. While patterns of abundance of $P$. elongatus are strongly affected by cobble size, future research should take a broad range of potentially relevant environmental factors (e.g. larval supply, differential mortality among and within habitats, predator abundance, and food availability) into account, as well, to better understand and predict patterns of abundance and demography in nature. 


\section{References}

Akins, L.J., 2003. The relative effects of top-down and bottom-up processes and abiotic factors on the abundance of shore crabs around a headland. M.Sc. thesis, University of California.

Alexander, T.J.; Barrett, N.; Haddon, M. \& Edgar G., 2009. Relationships between mobile macroinvertebrates and reef structure in a temperate marine reserve. Mar. Ecol. Prog. Ser. 389: 31-44.

Allen, J.C.; Schaffer, W.M. \& Rosko, D. 1993. Chaos reduces species extinction by amplifying local population noise. Nature 364: 229-232.

Alonzo, Z.H. \& Mangel, M., 2001 Survival strategies and growth of krill: avoiding predators in space and time. Mar. Ecol. Prog. Ser. 209: 203-217.

Andren, H., 1994. Effects of habitat fragmentation on birds and mammals in landscapes with different proportions of suitable habitat: a review. Oikos 71: 355-366.

Archambault, P. \& Bourget, E., 1996. Scales of coastal heterogeneity and benthic intertidal species richness, diversity and abundance. Mar. Ecol. Prog. Ser. 136: 111-121.

Arkema, K.K., 2009. Flow-mediated feeding in the field: consequences for the performance and abundance of a sessile marine invertebrate. Mar. Ecol. Prog. Ser. 388: 207-220.

Azovsky, A.I., 2000. Concept of scale in marine ecology: linking the words or the worlds? Web Ecology 1: 28-34.

Baeza, J.A.; Stotz, W. \& Thiel, M., 2002. Agonistic behaviour and development of territoriality during ontogeny of the sea anemone dwelling crab Allopetrolithes spinifrons (H. Milne Edwards, 1837) (Decapoda: Anomura: Porcellanidae). Mar. Fresh. Behav. Physiol. 35(40): 189-202.

Bartholomew, A., 2002. Total cover and cover quality: predicted and actual effects on a predator's foraging success. Mar. Ecol. Prog. Ser. 227: 1- 9.

Bartholomew, A. \& Shine, R.L., 2008. Space size relative to prey width (Sp/Py) influences macrofaunal colonization of artificial structures. Mar. Ecol. Prog. Ser. 358: 95-102.

Beck, M.W., 1995. Size-specific shelter limitation in stone crabs - a test of the demographic bottleneck hypothesis. Ecology 76: 968-980.

Bennet, E.W., 1964. The marine fauna of New Zealand: Crustacea, Brachyura. New Zealand Department of Scientific and Industrial Research, Bulletin 153. Pp.119. 
Bishop, M.J.; Underwood, A.J. \& Archambault, P., 2002. Sewage and environmental impacts on rocky shores: a necessity of identifying relevant spatial scales. Mar. Ecol. Prog. Ser. 236: 121-128.

Boaden, P.J.S., 1968. Water movement - a dominant factor in interstitial ecology. Sarsia 34: 125-136.

Briones-Fourzán, P.; Lozano-Álvarez, E.; Negrete-Soto, F. \& Barradas-Ortiz, C., 2007. Enhancement of juvenile Caribbean spiny lobsters: an evaluation of changes in multiple response variables with the addition of large artificial shelters. Oecologia 151: 401-416.

Buchanan, J.B., 1984. Sediment analysis. In: Methods for the study of marine benthos. N.A. Holme and A.D. McIntyre (eds.). IBP Handbook, 2nd edition. Blackwell Scientific Publications, Oxford, London. Pp 41-65.

Burkey, T.V. \& Reed, D.H., 2006. The effects of habitat fragmentation on extinction risk. Mechanisms and synthesis. Songklanakarin J. Sci. Technol. 28(1): 9-37.

Casariego, A.M.; Schwindt, E. \& Iribarne, O., 2004. Evidence of habitat structure generated bottleneck in the recruitment process of the SW Atlantic crab Cyrtograpsus angulatus. Mar. Biol. 145: 259-264.

Chitarro, P.M., 2002.Species-area relationships for coral reef fish assemblages of St. Croix, US Virgin Islands. Mar. Ecol. Prog. Ser. 233: 253-261.

Davis, A.N. \& Wilce, R.T., 1987. Algal diversity in relation to physical disturbance: a mosaic of successional stages in a subtidal cobble habitat. Mar. Ecol. Prog. Ser. 37: 229-237.

Dayton, P.K., 1971. Competition, disturbance and community organization: the provision and subsequent utilization of space in a rocky intertidal community. Ecol. Monogr. 41: 351-389.

Dayton, P.K. \& Oliver, J.S., 1980. An evaluation of experimental analyses of population and community patterns in benthic marine environments. Pp. 93120. In: Marine Benthic Dynamics. K.R. Tenore \& B.C. Coull (eds.). University of South Carolina Press, Columbia.

Dennis, D.M.; Skewes, T.D. \& Pitcher, C.R., 1997. Habitat use and growth of juvenile ornate rock lobsters, Panulirus ornatus (Fabricus, 1798), in Torres Strait, Australia. Mar. Freshw. Res. 48: 663-670.

Dethier, M.N., 1984. Disturbance and recovery in intertidal pools: maintenance of mosaic patterns. Ecol. Monogr. 54(1): 99-118.

Donahue, M.J., 2004. Size-dependent competition in a gregarious porcelain crab, Petrolisthes cinctipes Randall (Anomura: Porcellanidae). Mar. Ecol. Prog. Ser. 267: 195-207. 
Donahue, M.J., 2006. Allee effects and conspecific cueing jointly lead to conspecific attraction. Oecologia 149: 33-43.

Downs, J.A.; Gates, R.J. \& Murray, A.T., 2008. Estimating carrying capacity for sandhill cranes using habitat suitability and spatial optimization models. Ecol. Modelling 214: 284-292.

Drolet, D.; Himmelman, J.H. \& Rochette, R., 2004a. Use of refuges by the ophiuroid Ophiopholis aculeata: contrasting effects of substratum complexity on predation risk from two predators. Mar. Ecol. Prog. Ser. 284: 173-183.

Drolet, D.; Himmelman, J.H. \& Rochette, R., 2004b. Effect of light and substratum complexity on microhabitat selection and activity of the ophiuroid Ophiopholis aculeata. J. Exp. Mar. Biol. Ecol. 313: 139-154.

Dunning, J.B., Danielson, B.J. \& Pulliam, H.R., 1992. Ecological processes that affect populations in complex landscapes. Oikos 65: 169-175.

Eggleston, D.B. \& Lipcius, R.N., 1992. Shelter selection by spiny lobster under variable predation risk, social conditions, and shelter size. Ecology 73: 9921011.

Emaparanza, E.J.M., 2007. Patterns of distribution of dominant porcelain crabs (Decapoda: Porcellanidae) under boulders in the intertidal of northern Chile. J. Mar. Biol. Assoc. U.K. 87: 523-531.

Felder, D.L.; Martin, J.W. \& Goy, J.W., 1985. Patterns in early postlarval development of decapods. In: Crustacean growth: Larval growth. A.M. Wenner (ed.). Crustacean issues 2. A.A. Balkema, Rotterdam/Boston. Pp 248.

Firstater, F.N.; Hidalgo, F.J.; Lomovasky, B.J.; Ramos, E.; Gamero, P. \& Iribarne, O.O., 2011. Habitat structure is more important than nutrient supply in modifying mussel bed assemblage in an upwelling area of the Peruvian coast. Helgol. Mar. Res. 65(2): 187-196.

Gardner, J.P.A., 2000. Where are the mussels on Cook Strait (New Zealand) shores? Low seston quality as a possible factor limiting multi-species distributions. Mar. Ecol. Prog. Ser. 194: 123-132.

Gebauer, P., Paschke, K. \& Moreno, C.A., 2007. Reproductive biology and population parameters of Petrolisthes laevigatus (Anomura: Porcellanidae) in southern Chile: consequences on recruitment. J. Mar. Biol. Assoc. UK 87: 729-734.

Gherardi, F. \& Vanini, M., 1992. Hypotheses on ultimate and proximate factors influencing clustering in tropical hermit crab Clibanarius laevimanus. Ethol. Ecol. Evol. Special Issue 2: 17-22.

Graham, D.H., 1938. Food of the fishes of Otago Harbour and adjacent sea. Trans. Proc. Royal Soc. New Zealand 68(3): 399-419. 
Griffen, B.D. \& Drake, J.M., 2008. Effects of habitat quality and size on extinction in experimental populations. Proc. R. Soc. B 275: 2251-2256.

Hanski, I., 1991. Single-species metapopulations dynamics: concepts, models, and observations. Biol. J. Linnean Soc. 42: 17-38.

Hanski, I., 1994. A practical model of metapopulation dynamics. J. Anim. Ecol. 63: 151-162.

Hanski, I. 1999. Metapopulation ecology. Oxford University Press, Oxford.

Harding, K. \& McNamara, K.C., 2002. A unifying framework for metapopulation dynamics. Am. Nat. 160 (2): 173-185.

Hardy, G. S., 1984. Revision of the Acanthoclinidae (Pisces: Perciformes) with descriptions of a new genus and five new species. NZ J. Zool. 11: 357-393.

Hartnoll, R.G. \& Hawkins, S.J., 1980. Monitoring rocky-shorecommunities: a critical look at spatial and temporal variation. Helgol. Meeresunters. 33: 484-494.

Hastings, A. \& Volin, C., 1989. Within-patch dynamics in a metapopulation. Ecology 70: 1261-1266.

Haynes, K.; Dillemuth, F.; Anderson, B.; Hakes, A.; Jackson, H.; Jackson, E.S. \& Cronin, J., 2007. Landscape context outweighs local habitat quality in its effects on herbivore dispersal and distribution. Oecologia 151(3): 431-441.

Haynes K.J. \& Cronin J.T., 2003. Matrix composition affects the spatial ecology of a prairie planthopper. Ecology 84: 2856-2866.

Haynes K.J. \& Cronin J.T., 2004. Confounding of patch quality and matrix effects in herbivore movement studies. Lands. Ecol. 19: 119-124.

Hazlett, B.A., 2004. Alternative tactics and responses to conflicting inputs in the porcellanid crab Petrolisthes elongatus. Mar. Fresh. Behav. Physiol. 37(3): 173-177.

Hazlett, B.A. \& McLay, C., 2005. Responses of the crab Heterozius rotundifrons to heterospecific chemical alarm cues: phylogeny vs. ecological overlap. J. Chem. Ecol. 31(3): 671-7.

Helson, J.G.; Pledger, S. \& Gardner, J.P.A., 2007. Does differential particulate food supply explain the presence of mussels in Wellington Harbour (New Zealand) and their absence on neighbouring Cook Strait shores? Estuar. Coast. Shelf Sci. 72(1-2): 223-234.

Hixon, M.A. \& Beets, J.P., 1993. Predation, prey refuges and the structure of coral reef fish assemblages. Ecol. Monogr. 63: 77-101. 
Holsman, K.K.; McDonald, S.P. \& Armstrong, D.A., 2006. Intertidal migration and habitat use by subadult Dungeness crab Cancer magister in a NE Pacific estuary. Mar. Ecol. Prog. Ser. 308: 183-195.

Holt, D.R., 1997. From metapopulation dynamics to community structure. Pp. 149-164. In: Metapopulation biology. Hanski \& Gilpin (eds). Academic Press, San Diego, USA.

Hugie D.M. \& Grand, T.C., 1998. Movement between patches, unequal competitors and the ideal free distribution. Evol. Ecol. 12, 1-19.

Jensen, G.C., 1989. Gregarious settlement by megalopae of the porcelain crab Petrolisthes cinctipes (Randall) and P. eriomerus Stimpson. J. Exp. Mar. Biol. Ecol. 131: 223-231.

Jensen, G.C., 1990. Intertidal zonation of porcelain crabs: Resource partitioning and the role of selective settlement. Washington, Seattle.

Jensen, G.C. \& Armstrong, D.A., 1991. Intertidal zonation among congeners: factors regulating distribution of porcelain crabs Petrolisthes spp. (Anomura: Porcellanidae) Mar. Ecol. Prog. Ser. 73: 47-60.

Jernakoff, P., 1990. Distribution of newly settled western rock lobsters Panulirus cygnus. Mar. Ecol. Prog. Ser. 66: 63-74.

Johnson, E.G. \& Eggleston, D.B., 2010. Population density, survival and movement of blue crabs in estuarine salt marsh nurseries. Mar. Ecol. Prog. Ser. 407: 135-147.

Jones, M.B., 1976. Limiting factors in the distribution of intertidal crabs (Crustacea: Decapoda) in the Avon-Heathcote estuary, Christchurch. NZ J. Mar. Fresh. Res. 10(4): 577-587.

Jones, W.E. \& Greenwood, J.G., 1982. Water loss of a porcelain crab Petrolisthes elongatus (Milne Edwards, 1837) (Decapoda, Anomura) during atmospheric exposure. Comp. Biochem. Physiol. A: Physiology 72(4): 631-636.

Kareiva, P.M., 1987. Habitat fragmentation and the stability of predator-prey interactions. Nature 321: 388-391.

Kneib, R.T., 1984. Patterns of invertebrate distribution and abundance in the intertidal salt marsh: Causes and questions. Estuaries 7(4A): 392-412.

Knight, T.M; McCoy, M.W.; Chase, J.M.; McCoy, K.A. \& Holt, R.D., 2005. Trophic cascades across ecosystems. Nature 437(6): 880-883.

Kotliar, N.B \& Wiens, J.A., 1990. Multiple scales of patchiness and patch structure: a hierarchical framework for the study of heterogeneity. Oikos 59: 253-260. 
Lapointe, L. \& Bourget, E., 1999. Influence of substratum heterogeneity scales and complexity on a temperate epibenthic marine community. Mar. Ecol. Prog. Ser. 189: 159-170.

Le Hir, M. \& Hily, C., 2005. Macrofaunal diversity and habitat structure in intertidal boulder fields. Biodiversity and Conservation 14: 233-250.

Levin, S.A., 1992. The problem of pattern and scale in ecology. Ecology 73(6): 1943-1967.

Levin, S.A.; Morin, A. \& Powell, T.H., 1989. Patterns and processes in the distribution of Antarctic krill. Pp. 281-299 In: Scientific Committee for the Conservation of Antarctic Marine Living Resources Selected Scientific Papers, Part 1. SC-CAMLR-SSP/5. Hobart, Tasmania, Australia.

Levins, R., 1969. Some demographic and genetic consequences of environmental heterogeneity for biological control. Bull. Enotomol. Soc. Am. 15: 237-240.

McCoy, E.D.\& Bell, S.S., 1991. Habitat structure: the evolution and diversification of a complex topic. In: Habitat Structure: the physical arrangement of objects in space. S.S. Bell, E.D. McCoy \& H.R. Mushinsky (eds.), Chapman and Hall, London. Pp 3-27.

McGuinness, K.A. \& Underwood, A.J., 1986. Habitat structure and the nature of communities on intertidal boulders. J. Exp. Mar. Biol. Ecol. 104: 97-123.

McLay, C., 1988. Brachyura and crab-like anomura of New Zealand. Leigh Laboratory Bulletin 22. Pp. 463.

Menge, B.; Daley, B.A.; Wheeler, P.A.; Dahlhoff, E.; Sanford, E. \& Strub, P.T., 1997. Benthic-pelagic links and rocky intertidal communities: Bottom-up effects on top-down control? PNAS 94(26): 14530-14535.

Meyer-Rochow, V.B. \& Meha, W.P., 1994. Tidal rhythm and the role of vision in shelter-seeking behaviour of the half-crab Petrolisthes elongatus (Crustacea; Anomura; Porcellanidae). J. Royal Soc. New Zealand 24(4): 423-427.

Miller, A.W. \& Ambrose, R.F., 2000. Sampling patchy distributions: comparison of sampling designs in rocky intertidal habitats. Mar. Ecol. Prog. Ser. 196: $1-14$.

Moksnes, P.O., 2002. The relative importance of habitat specific settlement, predation and juvenile dispersal for distribution and abundance of young juvenile shore crabs Carcinus maenas L. J. Exp. Mar. Biol. Ecol. 271: 41-73.

Molenock, J., 1976. Agonistic interactions of the crab Petrolisthes (Crustacea, Anomura). Zeitschr. Tierpsychol. 41: 277-294.

Paine, R.T. \& Levin, S.A., 1981. Intertidal landscapes: disturbance and the dynamics of pattern. Ecol. Monogr. 51(2): 145-178. 
Pech, D.; Ardisson, P.L. \& Bourget, E., 2002. Settlement of a tropical marine epibenthic assemblage on artificial panels: influence of substratum heterogeneity and complexity scales. Estuar. Coast. Shelf Sci. 55: 743-750.

Pellegrino, C.R., 1984. The role of desiccation pressures and surface area / volume relationships in seasonal zonation and size distribution of four intertidal decapod crustaceans from New Zealand: implications for adaptations to land. Crustaceana 47(3): 251-268.

Pulliam, H.R., 1988. Sources, sinks, and population regulation. Am. Nat. 132: 652-661.

Pulliam, H.R. \& Danielson, B.J., 1991. Sources, sinks, and habitat selection: a landscape perspective on population dynamics. Am. Nat. 137: 50-66.

Reid, C.; Slotow, R.; Howison, O. \& Balfour, D., 2007. Habitat changes reduce the carrying capacity of Hluhluwe-Umfolozi Park, South Africa, for critically endangered black rhinoceros Diceros bicornis. Oryx 41(2): 247-254.

Ricketts, T.H., 2001. The matrix matters: effective isolation in fragmented landscapes. Am. Nat. 158: 87-99.

Rios, C. \& Mutschke, E., 1999. Community structure of intertidal boulder-cobble fields in the Straits of Magellan, Chile. Sciencia Marina 63: 193-201.

Rypien, K.L. \& Palmer, A.R., 2007. The effect of sex, size and habitat on the incidence of puncture wounds in the claws of the porcelain crab Petrolisthes cinctipes (Anomura: Porcellanidae). J. Crust. Biol. 27(1): 59-64.

Sanders, H.L.,1958. Benthic studies in Buzzards Bay. 1. Animal-sediment relationships. Limnol. Oceanogr. 3: 245-258.

Scott, M.S., 1958. Studies on the false crab, Petrolisthes elongatus Milne Edwards. M.Sc. thesis, Canterbury University, Christchurch, NZ.

Shanks, A.L. \& Wright, W.G., 1986. Adding teeth to wave action: the destructive effects of wave-borne rocks on intertidal organisms. Oecologia 69: 420-428.

Shepherd, S.A. \& Partington, D., 1995. Studies on southern Australian abalone (genus Haliotis). XVI. Recruitment, habitat and stock relations. Mar. Freshw. Res. 46: 669-680.

Silvertown, J.; Cook, L.; Cameron, R., Dodd, M.; McConway, K.; Worthington, J.; Skelton, P.; Anton, C.; Bossdorf, O.; Baur, B.; Schilthuizen, M.; Fontaine, B.; Sattmann, H.; Bertorelle, G.; Correia, M.; Oliveira, C.; Pokryszko, B.; Ożgo, M.; Stalažs, A.; Gill, E.; Rammul, Ü.; Sólymos, P.; Féher, Z.; \& Juan, X., 2011. Citizen science reveals unexpected continental-scale evolutionary change in a model organism. PLoS One, 6(4): e18927.

Snyder-Conn, E., 1980. Tidal clustering and dispersal of the hermit crab Clibanarius digueti. Mar. Behav. Physiol. 7: 135-154. 
Sousa, W.P., 1979. Disturbance in marine intertidal boulder fields: the nonequilibrium maintenance of species diversity. Ecology 60: 1225-1239.

Spanier, E. \& Almogshtayer, G., 1992. Shelter preferences in the Mediterranean slipper lobster-effects of physical properties. J. Exp. Mar. Biol. Ecol. 164: 103-116.

Stillman, J.H., 2002. Causes and consequences of thermal tolerance limits in rocky intertidal porcelain crabs, genus Petrolisthes. Integ. Comp. Biol. 42: 790-796.

Stillman, J. \& Somero, G., 1996. Adaptation to temperature stress and aerial exposure in congeneric species of intertidal porcelain crabs (genus Petrolisthes): correlation of physiology, biochemistry and morphology with vertical distribution. J. Exp. Biol. 199(8): 1845-1855.

Takada, Y., 1999. Influence of shade and number of boulder layers on mobile organisms on a warm temperate boulder shore. Mar. Ecol. Prog. Ser. 189: 171-179.

Taylor, A.D., 1990. Metapopulations, dispersal and predator-prey dynamics: an overview. Ecology 71: 429-433.

Thomas, J.A.; Bourn, N.A.D.; Clarke, R.T.; Stewart, K.E.; Simcox, D.J.; Pearman G.S.; Curtis, R. \& Goodger, B., 2001. The quality and isolation of habitat patches both determine where butterflies persist in fragmented landscapes. Proc. R. Soc. Lon. Ser. B 268: 1791-1796.

Thompson Hobbs, N. \& Hanley, T.A., 1990. Habitat evaluation: Do use/availability data reflect carrying capacity? J. Wildlife Management 54(4): 515-522.

Tilman, D. \& Kareiva,P., 1997. Spatial ecology: the role of space in population dynamics and interspecific interactions. Princeton University Press, Princeton, N.J.

Trager, G.C. \& Genin, A., 1993. Flow velocity induces a switch from active to passive suspension feeding in the porcelain crab Petrolisthes leptocheles (Heller). Biol. Bull. 185: 20-27.

Turra, A. \& Leite, F.P.P., 1999. Clustering behaviour of hermit crabs (Decapoda, Anomura) in an intertidal rocky shore at São Sebastião, southeastern Brazil. Rev. Brasil. Biol. 60(1): 39-44.

Wahle, R.A., 1992. Substratum constraints on body size and the behavioural scope of shelter use in the American lobster. J. Exp. Mar. Biol. Ecol. 159: $59-75$. 
Wahle, R.A. \& Steneck, R.S., 1992. Habitat restrictions in early benthic life: experiments on habitat selection and in situ predation with the American lobster. J. Exp. Mar. Biol. Ecol. 157: 91-114.

Warfe, D.M. \& Barmuta, L.A., 2004. Habitat structural complexity mediates the foraging success of multiple predator species. Oecologia 141: 171-178.

Warrick, J.A.; Rubin, D.M.; Ruggiero, P.; Harney, J.N.; Draut, A.E. \& Buscombe, D. 2009. Cobble cam: grain-size measurements of sand to boulder from digital photographs and autocorrelation analyses. Earth Surf. Process. Landforms 34: 1811-1821.

Wasson, K.; Lyon, B.E. \& Knope, M., 2002. Hair-trigger autotomy in porcelain crabs is a highly effective escape strategy. Behav. Ecol. 13: 481-486.

Wasson, K. \& Lyon, B.E., 2005. Flight or fight: flexible antipredatory strategies in porcelain crabs. Behav. Ecol. 16: 1037-1041.

Wear, R.G., 1965. Breeding cycles and pre-zoea larva of Petrolisthes elongatus (Milne Edwards, 1837). (Crustacea, Decapoda). Trans. Royal Soc. New Zealand, Zoology 5(13): 169-175.

Wiens, J.A., 1989. Spatial scaling in ecology. Funct. Ecol. 3: 385-397.

Willis, T.J. \& Anderson, M.J., 2003. Structure of cryptic reef fish assemblages: relationships with habitat characteristics and predator density. Mar. Ecol. Prog. Ser. 257: 209-221.

Wilson, K.A.; Able, K.W. \& Heck, K.L., 1990. Predation rates on juvenile blue crabs in estuarine nursery habitats: evidence for the importance of macroalgae (Ulva lactuca). Mar. Ecol. Prog. Ser. 243-251.

Winston, M.L. \& Jacobson, S., 1978. Dominance and effects of strange conspecifics on aggressive interactions in the hermit crab Pagurus longicarpus (Say). Animal Behav. 26(1): 184-191. 


\section{Appendix 2}
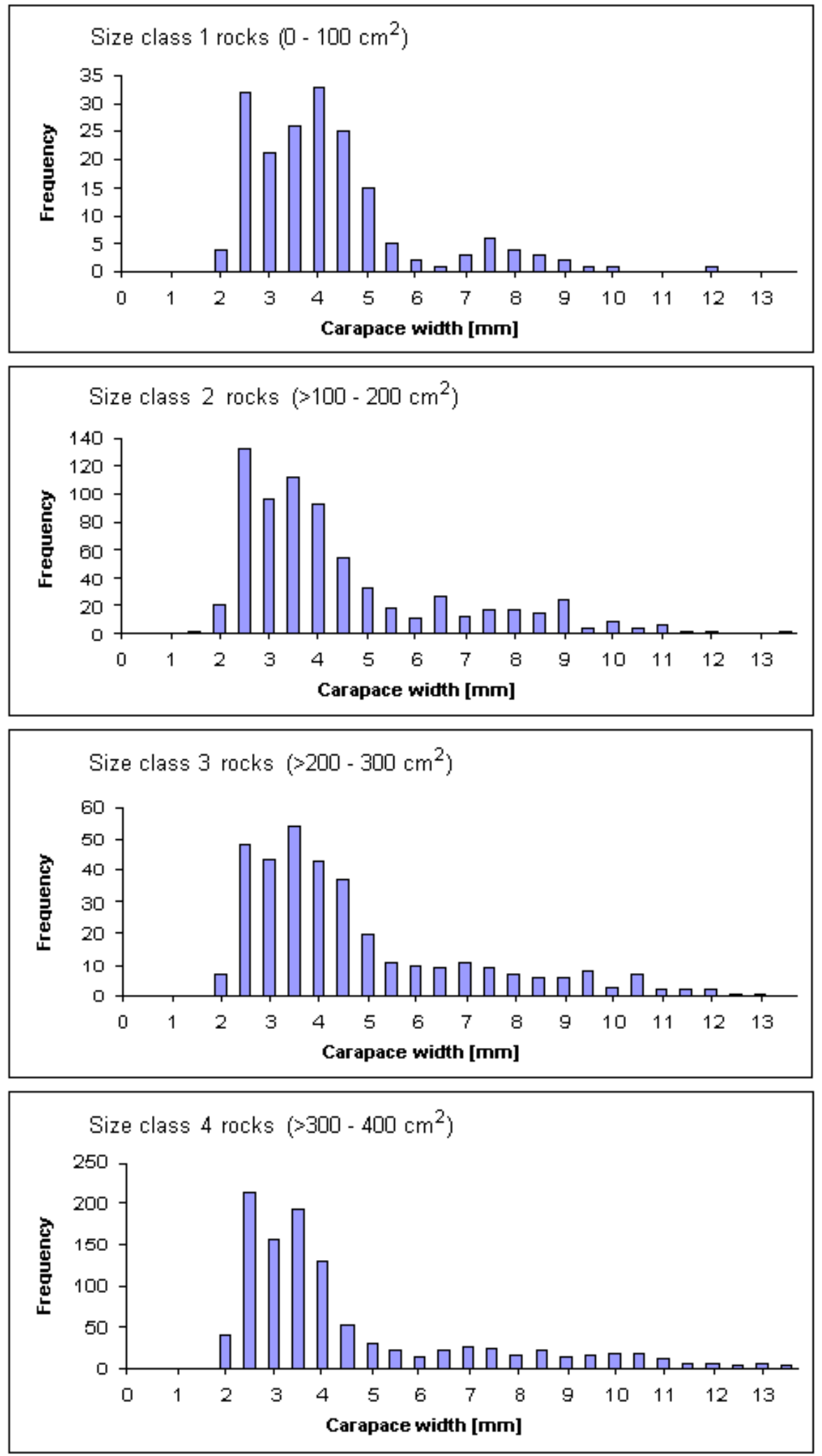

Appendix 2.1: Size frequency distribution of crabs at Hutt River mouth (numbers of individuals), split by size class of rocks 

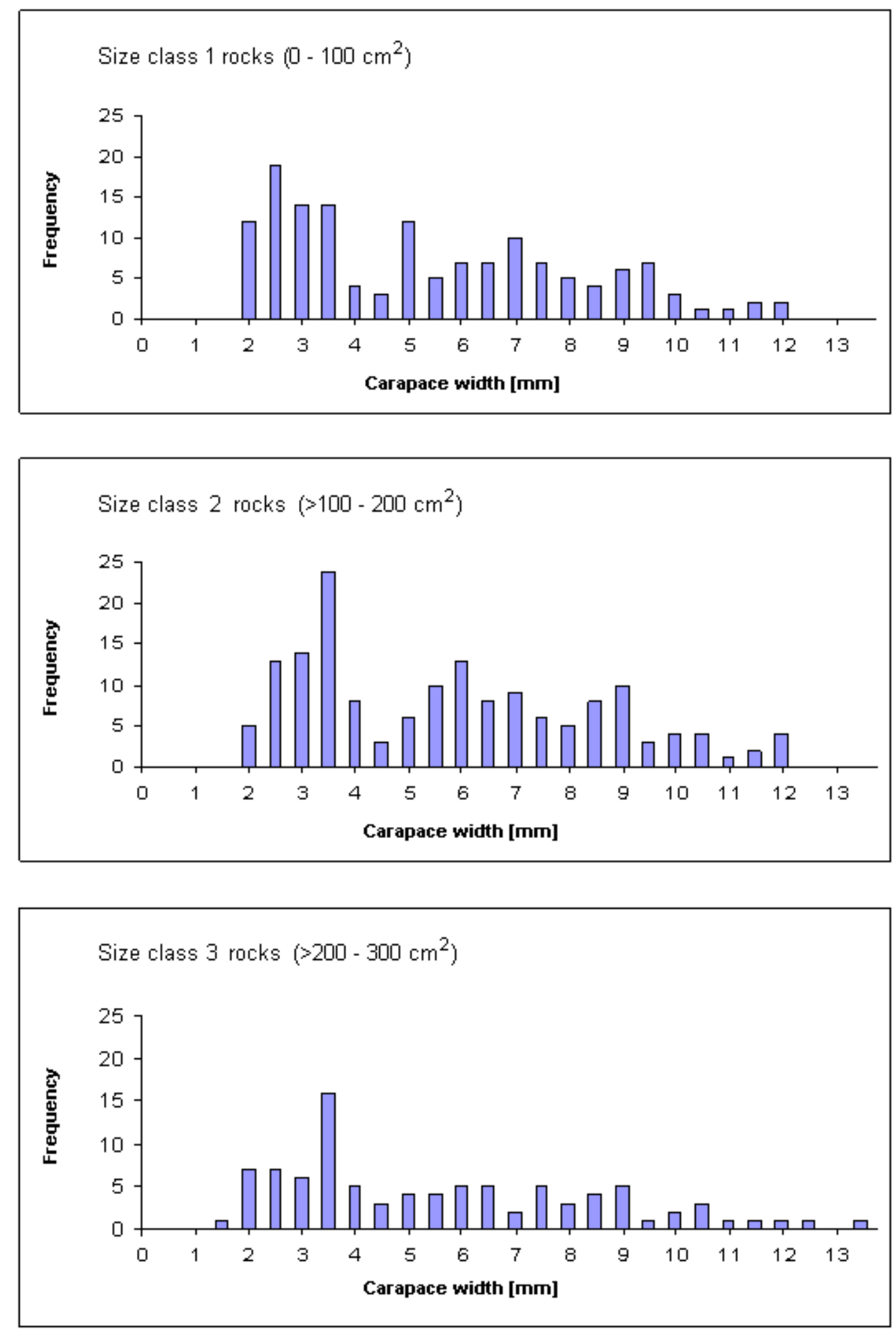

Appendix 2.2: Size frequency distribution of crabs at Breaker Bay (numbers of individuals), split by size class of rocks 

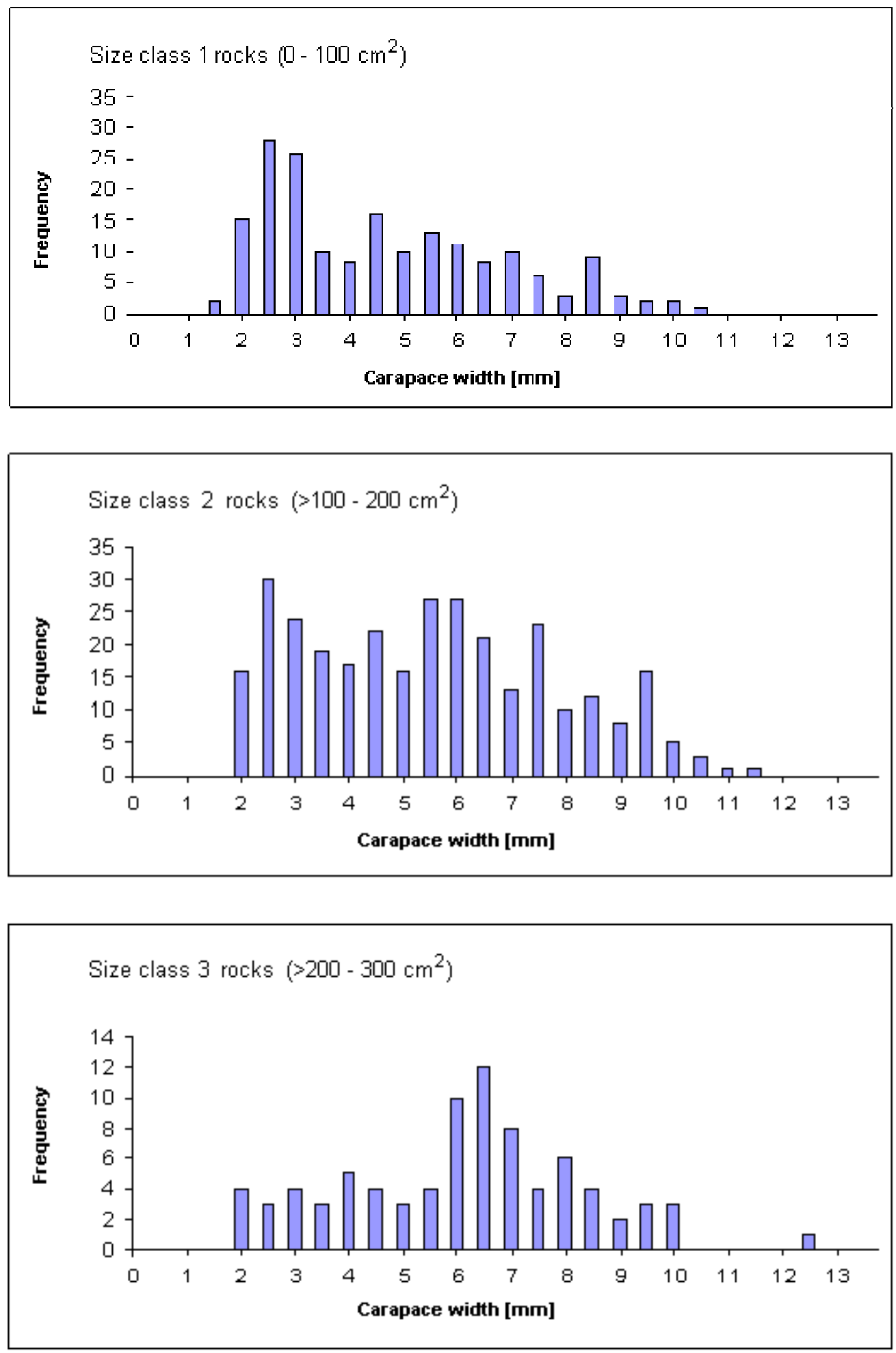

Appendix 2.3: Size frequency distribution of crabs at Island Bay (numbers of individuals), split by size class of rocks 

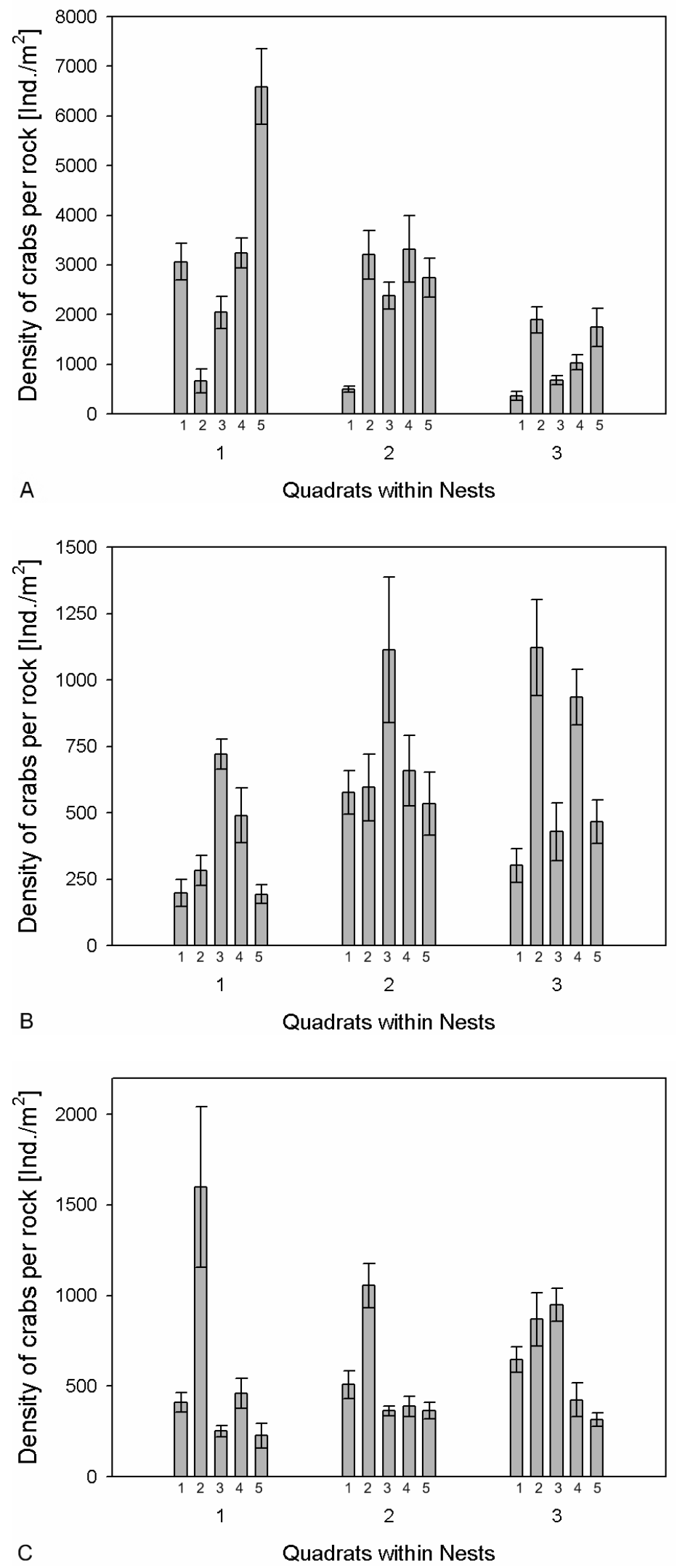

Appendix 2.4: Mean crab density per rock within quadrats at A: Hutt River mouth, B: Breaker Bay, and C: Island Bay. Error bars represent 95\% confidence intervals. 

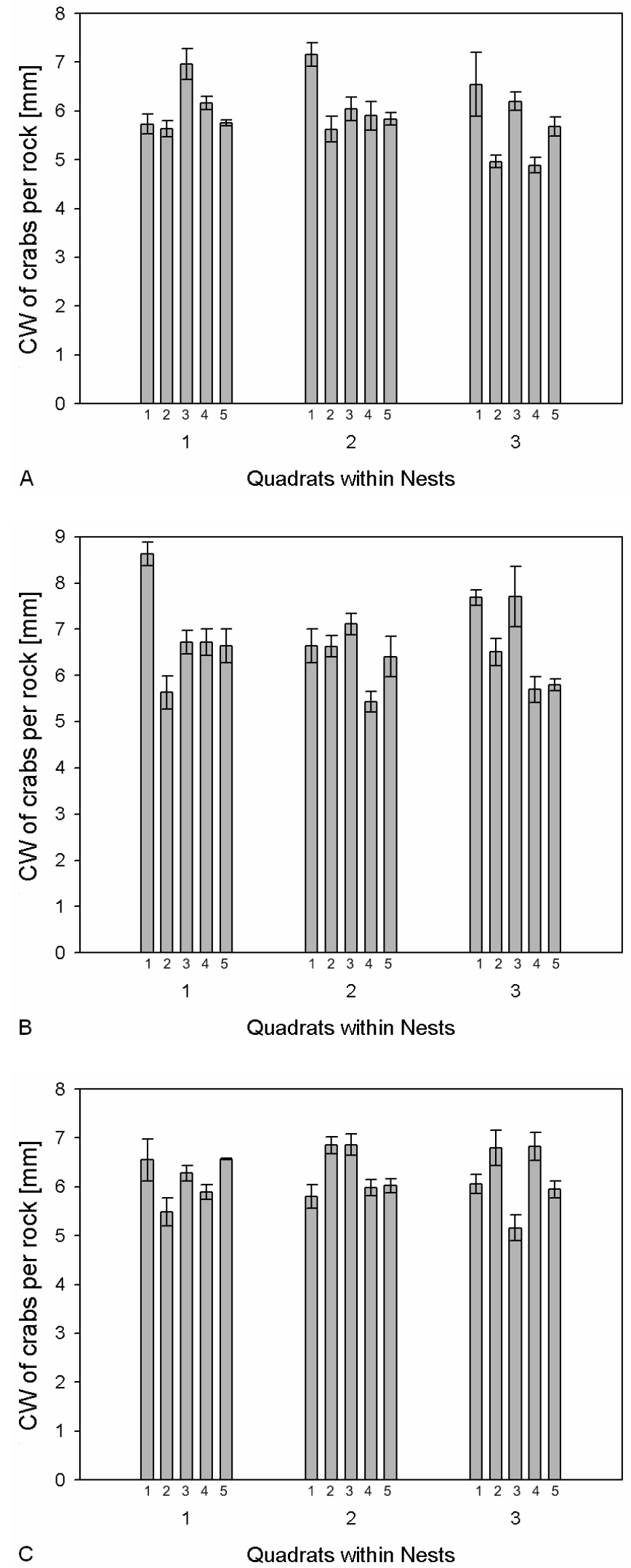

Appendix 2.5: Mean carapace width $(\mathrm{CW})$ of adult crabs per rock within quadrats at A: Hutt River mouth, B: Breaker Bay, and C: Island Bay. Error bars represent $95 \%$ confidence intervals. 

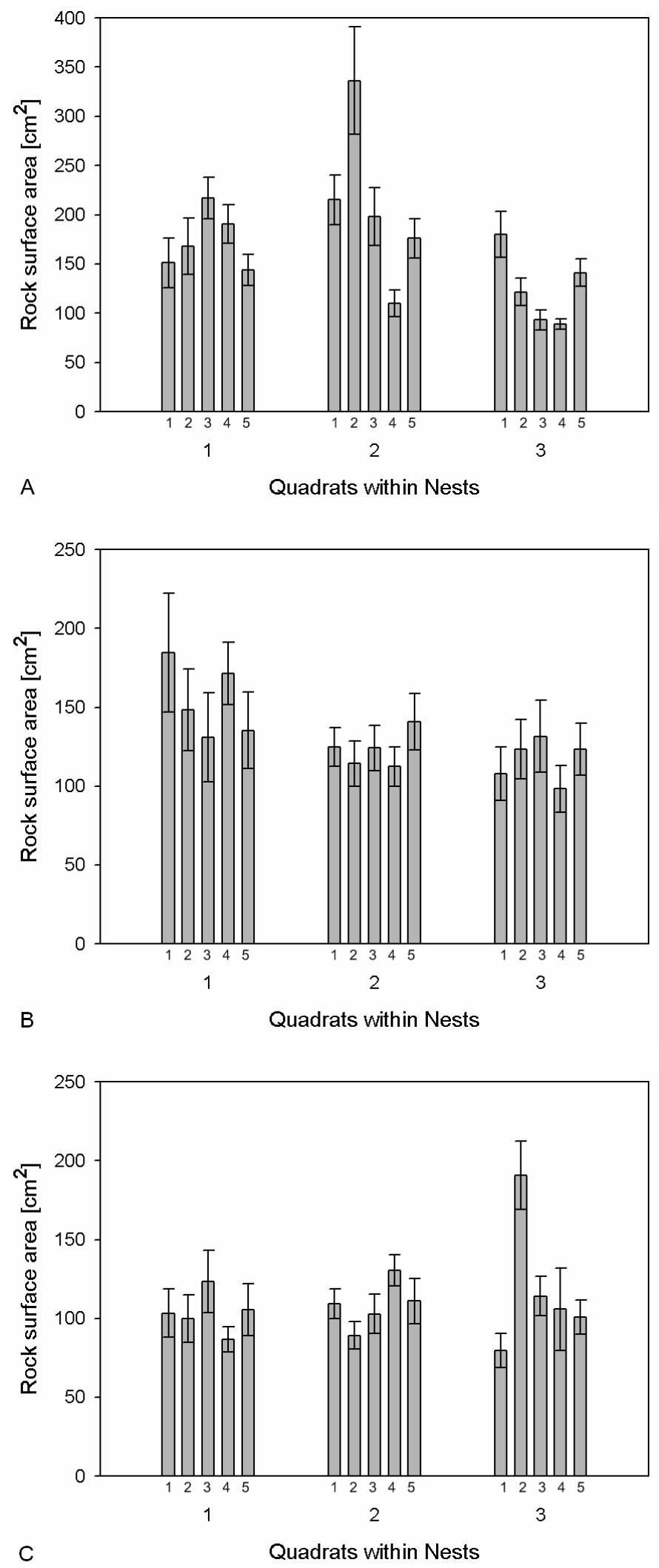

Appendix 2.6: Mean rock sizes of occupied rocks within quadrats at A: Hutt River mouth, B: Breaker Bay, and C: Island Bay. Error bars represent 95\% confidence intervals. 


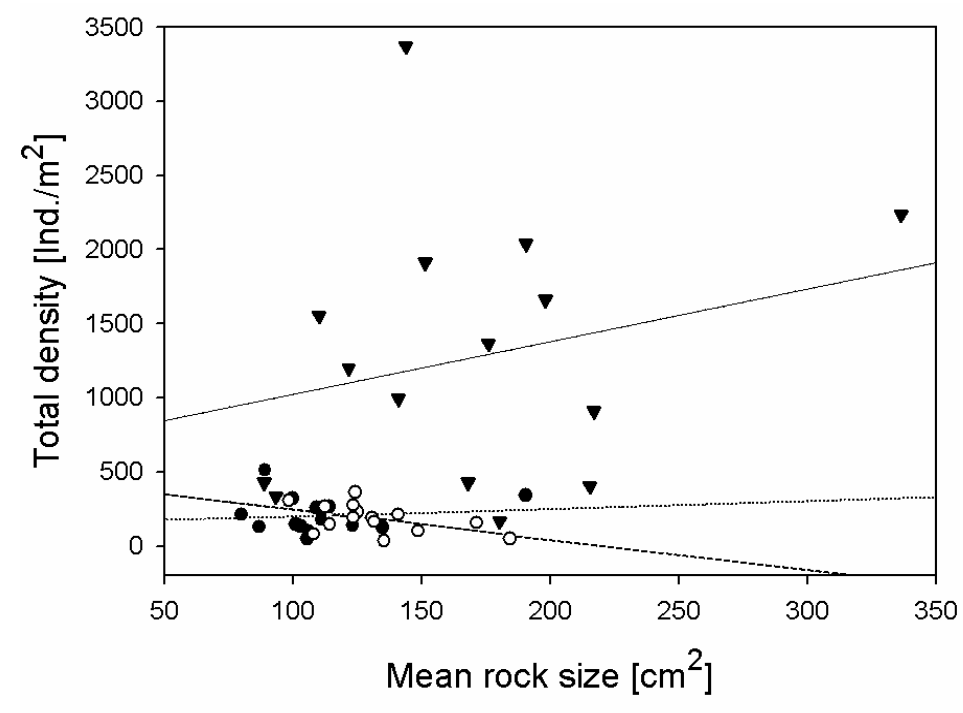

- Island Bay

Breaker Bay

$\nabla$ Hutt River mouth

Appendix 2.7: Mean rock size within each sample quadrat versus mean total crab density (individuals $/ \mathrm{m}^{2}$ ), calculated from the number of crabs per quadrat.

(ISB: $\quad \mathrm{R}^{2}=0.0124 ; \mathrm{F}=0.163 ; \mathrm{p}=0.693 ; \mathrm{y}=145.8606+0.25094 \mathrm{x}$ )

(BRB: $\quad \mathrm{R}^{2}=0.2434 ; \mathrm{F}=4.1813 ; \mathrm{p}=0.0617 ; \mathrm{y}=451.6296-2.0357 \mathrm{x}$ )

(HRM: $\quad R^{2}=0.0609 ; F=0.8425 ; p=0.3754 ; y=667.2818+3.5459 x$ )

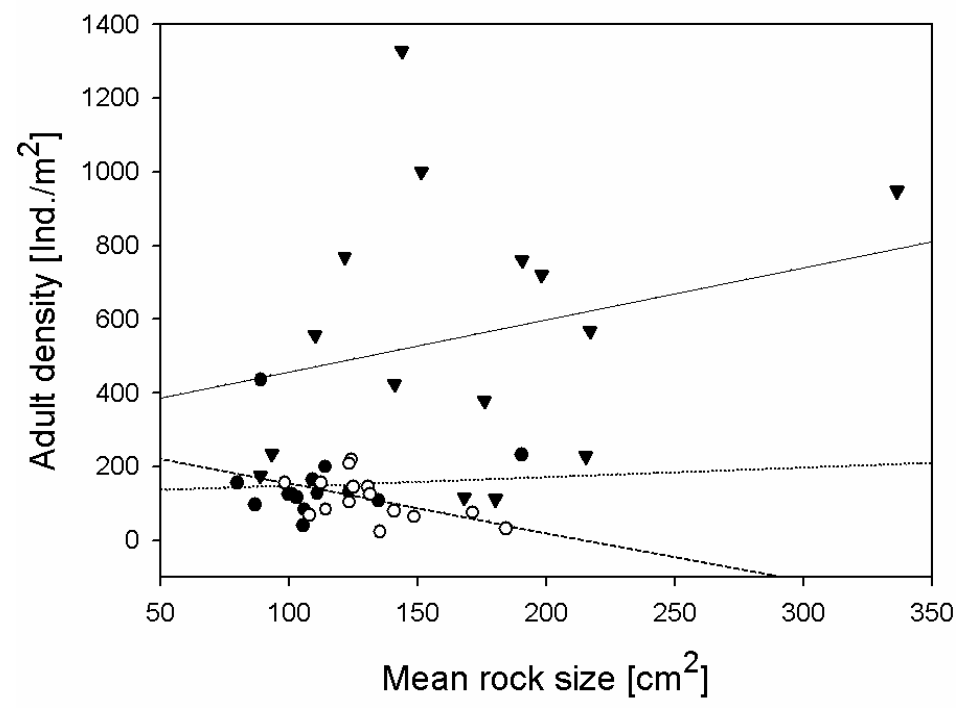

- Island Bay

Breaker Bay

- Hutt River mouth

Appendix 2.8: Mean rock size within each sample quadrat versus mean adult crab density (individuals $/ \mathrm{m}^{2}$ ), calculated from the number of crabs per quadrat.

(ISB: $\quad \mathrm{R}^{2}=0.0049 ; \mathrm{F}=0.0634 ; \mathrm{p}=0.8052 ; \mathrm{y}=123.4031+0.2444 \mathrm{x}$ )

(BRB: $\quad R^{2}=0.2616 ; \mathrm{F}=4.6050 ; \mathrm{p}=0.0513 ; \mathrm{y}=285.0049-1.3139 \mathrm{x}$ )

(HRM: $\quad R^{2}=0.0574 ; F=0.7916 ; p=0.3898 ; y=316.7689+1.4092 x$ ) 


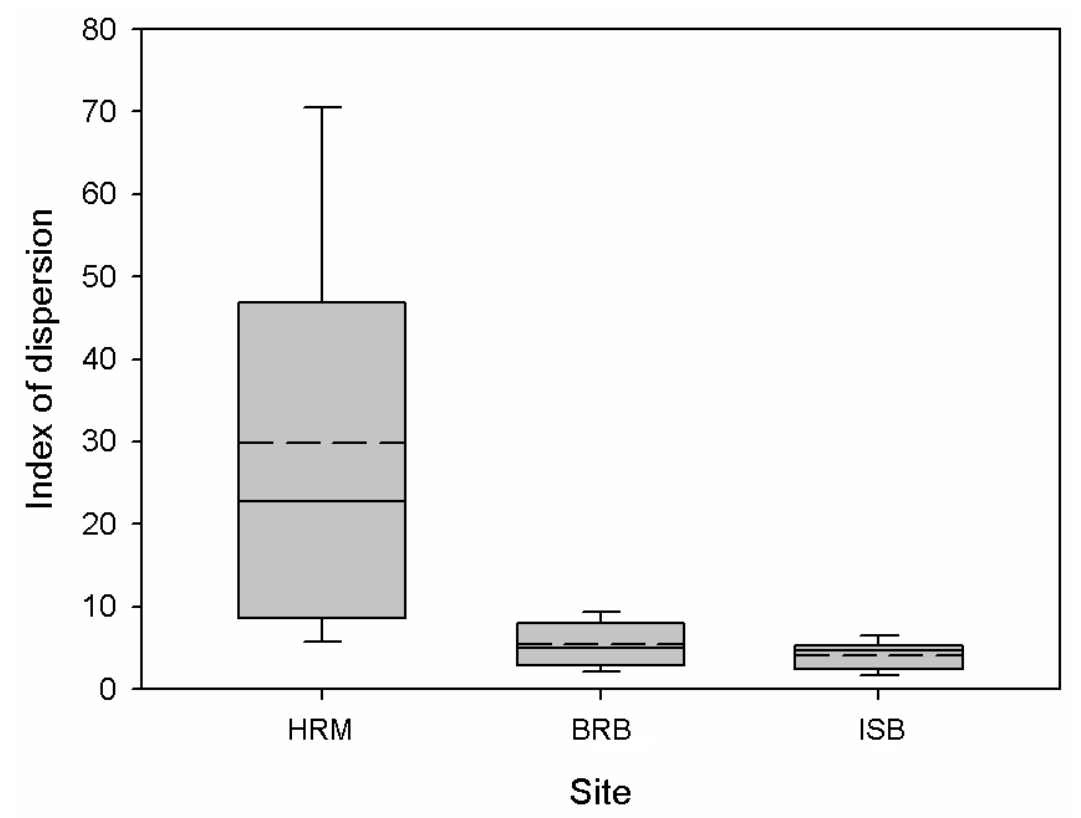

Appendix 2.9: Mean (dashed line) and median (solid line) index of dispersion (ratio between the variance in numbers of crabs under each rock and the mean number of crabs per quadrat) at sample sites Island Bay (IsB), Breaker Bay (BrB), and Hutt River mouth (HRM). Whisker caps represent $2.5 \%$ and $97.5 \%$ quantiles. Because all indices were $>1$, patchiness can be assumed on a between-quadrats level as well as between sites and is especially high at HRM, mainly due to a larger range of rock sizes and larger boulders. This reflects the results shown in table 2.1.

Appendix 2.10: 3-Way ANOVA results of the mark and recapture survey (fully saturated model $):$ Distance $\sim$ Site + Size class + Run $+($ Site $*$ Size class $)+($ Site $*$ Run $)+($ Size class * Run $)+($ Site $*$ Size class * Run $)$

\begin{tabular}{|l|lrrl|}
\hline Source & SS & df & F & p \\
\hline Site & 1.9920476 & 2 & 10.5034 & $<\mathbf{0 . 0 0 0 1}$ \\
Size class & 5.8164635 & 3 & 20.4455 & $<\mathbf{0 . 0 0 0 1}$ \\
Run & 0.0283584 & 2 & 0.1495 & $<0.8612$ \\
Site * Size class & 0.4829144 & 6 & 0.8487 & $<0.5333$ \\
Site * Run & 0.0411504 & 4 & 0.1085 & $<0.9795$ \\
Size class * Run & 0.0973556 & 6 & 0.1711 & $<0.9844$ \\
Site * Size class * Run & 0.1192880 & 12 & 0.1048 & $<0.9999$ \\
Error & 24.940004 & 263 & & \\
\hline
\end{tabular}




\section{Chapter 3}

\section{Effects of habitat quality on life history traits}

\subsection{Introduction}

Understanding the ecological factors that favour different life history strategies is a central goal in the study of life history evolution (e.g. Williams, 1966; Partridge \& Harvey, 1988). Animal populations often exhibit considerable variation in life history traits due to their exposure to different environmental conditions within their natural range (reviewed in Roff, 1992; Stearns, 1992). Specifically, parental investment within a species varies with environmental factors (e.g. Morris, 1987; Roff, 1992; Stearns, 1992), largely attributed to phenotypic plasticity. Natural selection, on the other hand, rarely affects single life history traits but rather acts on suites of traits that respond to selection in a correlated manner (e.g. Endler, 1995; Badyaev \& Ghalambor, 2001). The life history traits of a species such as size at sexual maturity, number of offspring and level of parental investment are interdependent, with differential resource allocations of an organism to reproduction, growth, maintenance metabolism and survivorship (e.g. Calow, 1979; Townsend \& Calow, 1981). Due to energetic constraints as a result of limited availability of resources, the benefits of performing an ecological function come at a cost of performing another. Classic examples of life history trade-offs, generally defined as negative functional interactions between traits (Stearns, 1989a, 1992; Zera \& Harshman, 2001) include 1) energy allocation to reproduction versus energy allocation to growth and maintenance (or relationship between body size and fecundity, respectively), 2) egg size and -quality versus numbers of eggs per female (or offspring survival versus dispersal potential, respectively), and 3) offspring fitness versus fitness of parent (or life span versus reproductive output and frequency of spawning, respectively).

Variations in life histories of marine invertebrates have attracted considerable research interest (e.g. Palmer \& Strathmann, 1981; Grahame \& Branch, 1985; Hines, 1986; Strathmann, 1986; Scheltema, 1998). The variability of life history strategies among and within species is commonly understood as adaptations to 
specific physical and biotic environmental conditions, constrained by phylogenetic effects (e.g. Herrera, 1998; Niewiarowski et al., 2004; Dudycha \& Lynch, 2005). Phenotypic plasticity, as a within-lifespan response of organisms associated with environmental change, can be crucial for the persistence of animal populations (Gabriel et al., 2005; Helmuth et al., 2005) and is defined as the interaction of an individual's genotype with environmental factors (GxE interaction) in the sense of an individual's inherent, albeit limited, ability to change behaviour, physiology, morphology, or life history characteristics (e.g. Edgell \& Hollander, 2011). Phenotypic plasticity is considered heritable, favoured by high environmental variability or unpredictability, and in certain conditions adaptive because induced phenotypes may increase individual fitness (reviewed in Stearns, 1989b; Via et al., 1995; Ghalambor et al., 2007). Life history evolution, by contrast, comprises the mechanisms that select for certain suites of interdependent life history characteristics (via fitness of the individual in relation to environmental factors and their stability or unpredictability) and how these characteristics manifest themselves, or fluctuate, within populations over time. While reduced adult survival, for example, will select for early maturation and increased reproductive effort, the increase in juvenile mortality will favour the opposite pattern (e.g. Reznick \& Endler, 1982; Reznick et al., 1990). "K" and "r" selection are extremes in a spectrum of possible patterns of life history adaptations to the degree of environmental stability or disturbance, that generally involve trade-offs between the costs and benefits of particular strategies of survival and reproduction (for reviews, see Pianka, 1970, 1972; Stearns, 1977; Parry, 1981; Getz, 1993). Coexistence within communities and niche differentiation between species, on the other hand, are frequently explained by trade-offs in species performances of different ecological functions (reviewed in Laland et al., 1999; Kneitel \& Chase, 2004). The existence of a larval phase in many aquatic organisms has been attributed to avoidance of intraspecific competition due to resource partitioning (i.e. of food sources and space) in larvae and adults (e.g. Felder et al., 1985). Therefore, larval stages differ from juvenile and adult phases in characteristics such as morphology, nutrient requirements, behaviour, and habitat, whereby these differences can be subtle or more pronounced. 
Approximately $80 \%$ of marine organisms, both vertebrate and invertebrate, have a biphasic life-cycle. The planktonic larvae spend a variable amount of time developing in the water column, ranging from minutes to months, before they settle into the benthos and metamorphose into the adult life-form (Thorson 1964). Since many benthic invertebrates are either sessile or have very limited dispersal capabilities as adults, the planktonic larval stages are of particular significance. In geographically isolated metapopulations, such as those of $P$. elongatus, the planktonic phase does not only facilitate dispersal, but also connectivity and hence gene flow, between patches. Moreover, meroplanktonic larvae are considered as principal components of benthic-pelagic coupling processes (Anger, 2006). The transition between planktonic and benthic phase implies a radical change of life style, typically involving metamorphosis of competent larvae into the benthic life form.

Petrolisthes elongatus is highly specific concerning their habitat choice (Jones, 1976) and is virtually absent on sandy beaches, mudflats and at rocky shores (own observation). Consequently, their suitable habitat is naturally fragmented, leading to relatively isolated benthic metapopulations that are separated from other patches of suitable habitat by hundreds of meters to tens of kilometers. For a successful colonisation of more distant sites and maintenance of persisting metapopulations, the geographic isolation, associated with higher extinction risk, has to be compensated by dispersal strategies (i.e. planktonic larvae with high dispersal potential), larval behaviour (i.e. ability to swim and respond to settlement cues), larval features that enable drift, improve buoyancy, and reduce sink speed (i.e. long rostral and posterior spines and oil droplets), as well as reproductive traits such as high egg numbers and high frequency of spawning. Due to the trade-off between size and number of offspring, however, the adaptation to geographically isolated metapopulations and/or recruitment limitation is likely to result in larger numbers of smaller offspring.

In Porcellanidae as well as in other decapods, growth rate and body size strongly varies with latitude, and therefore with temperature (Stillman \& Somero, 2000; Stillman, 2002; Wehrtmann, 2005; but see Rivadeneira et al., 2010). Locally, adult body size decreases towards the upper intertidal zone, where average temperatures are higher and desiccation risk more intense (Emparanza, 2007). 
Reproductive effort depends on both body size and temperature (Clarke, 1987), and is commonly affected by food supply.

In this chapter, I compare life history characteristics of $P$. elongatus from three geographically isolated metapopulations and aim to identify the relevant environmental factors and habitat quality indicators mediating phenotypic plasticity. Specifically, I test whether there are site-differences in reproductive output, egg size, egg numbers, size at maturity, sex ratio, and percentage of ovigerous females. As discussed in the previous chapter, the chosen study sites differ largely in available refuge, and presumably in larval supply and food levels, which I aim to examine. 


\subsection{Materials and Methods}

\subsubsection{Sex ratio}

In January and February 2006, P. elongatus adults were randomly sampled using $1550 \times 50 \mathrm{~cm}$ quadrats to standardize sample area at each of three sites: Hutt River

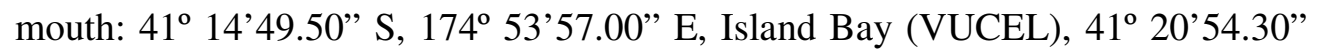
S, 174 45'53.20” E, Breaker Bay (Reef Bay), 41²0'17.90” S, 174 49'26.60” E (chapter 1, Fig. 1.1). All individuals were sexed (for morphological differences between genders see Fig. 3.1) and the numbers of males and females recorded. The sex ratios for all samples at all sites were calculated; site differences were tested by binominal logistic regression.

\subsubsection{Female size at sexual maturity}

For the size at sexual maturity estimate, only females were used (compare Annala et al., 1980; Fransozo et al., 2003; Xiao \& Kumar, 2003) as their morphological characteristics visibly change over the transition between juvenile and adult phase. These characteristics comprise in females 1) three pairs of ramified pleopods (on abdominal segments three to five) which may be present but incompletely developed (i.e. unramified) in late stage juveniles or sexually immature females, respectively, and 2) oval shaped genital openings on both coxae of the third pereiopods (Fig. 3.1). At the laboratory, particularly late stage juveniles and young females $(3.0 \mathrm{~mm}-5.0 \mathrm{~mm}$ carapace width, $\mathrm{CW}$ ) were examined under a dissecting microscope with $25 \mathrm{x}$ magnification and divided in immature or mature individuals. Size at maturity was estimated for each quadrat as the mean of the 20 largest immature and the 20 smallest mature individuals. Using the carapace widths of these selected animals, site differences in female size of sexual maturity were tested by ANOVA. 


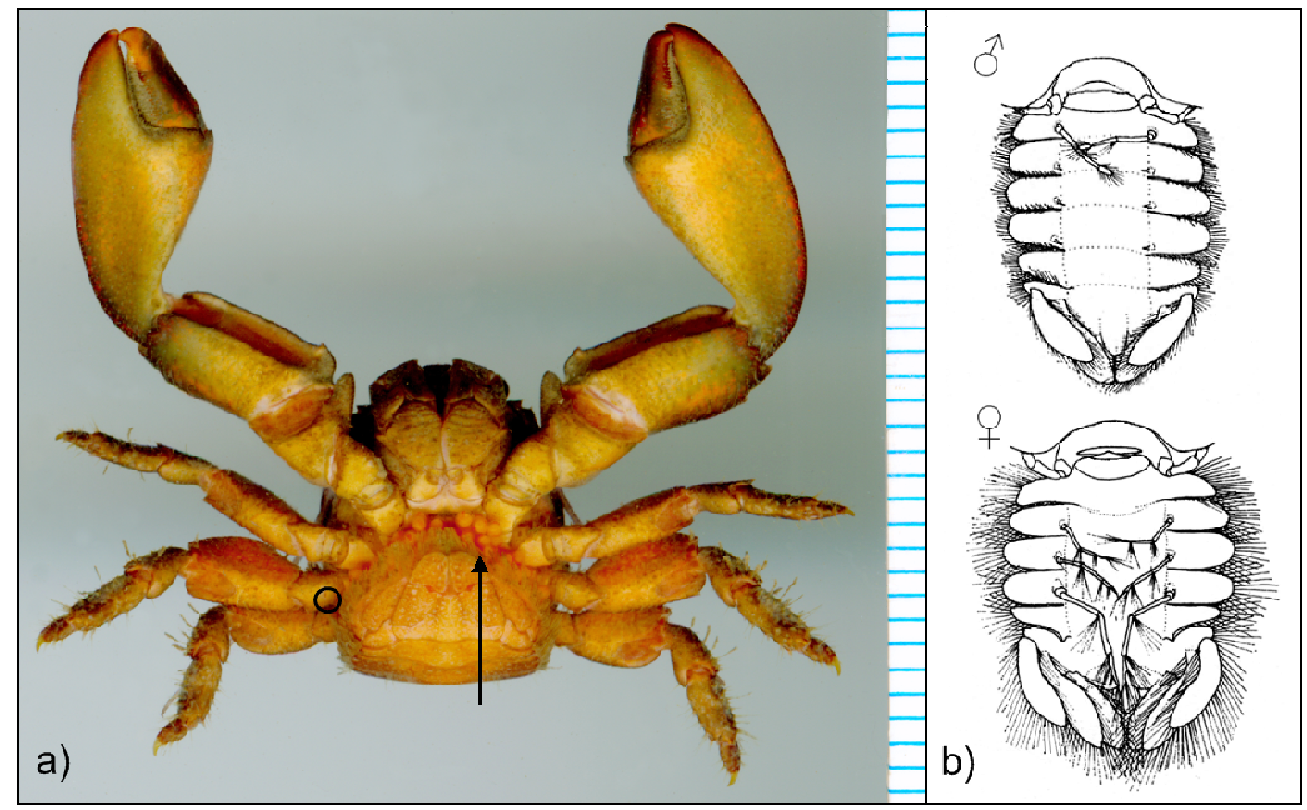

Fig. 3.1: a) Ovigerous Petrolisthes elongatus female, ventral view. Several eggs can be seen between sternum and abdominal flap (arrow); the genital openings are not visible (position marked by black circle). Scale in mm. b) Arrangement of pleopods in male (top) and female (bottom) (modified, after M.B. Jones, 1976).

\subsubsection{Female life-history traits}

\section{a) Sampling}

From February until March 2008, 100 - 150 P. elongatus females were collected fortnightly (five times) at each of three sites: Hutt River mouth, Island Bay (VUCEL), and Breaker Bay (Reef Bay) (Fig. 1.1). Both ovigerous and nonovigerous females were randomly collected, if 1) all limbs were present and 2) the carapace width, measured with digital callipers in the field, was between $5.0 \mathrm{~mm}$ and $12.5 \mathrm{~mm}$ at its widest point. For subsequent processing, the animals were kept in separate tanks (one tank per site), filled with filtered seawater $(10 \mu \mathrm{m}$ mesh size) at the National Institute of Water and Atmospheric Research (NIWA) facility in Wellington, New Zealand.

\section{b) Percentage of ovigerous females}

At the laboratory, each female was checked for eggs by folding over the abdomen with a pair of fine tweezers. The females were subdivided into 3 size classes $(1=5.0-7.5 \mathrm{~mm} ; 2=7.6-10.0 \mathrm{~mm} ; 3=10.1-12.5 \mathrm{~mm} \mathrm{CW})$. For each size class, each sample and each site, the mean percentage of ovigerous females was calculated. 
The error for each site and size class results from combining the values obtained for each sample. A binary logistic regression was used to test differences between sites and size classes (Logit no. ovig. females $\sim$ Site + Size class).

\section{c) Body size, clutch weight and proportion of clutch to body weight}

Every individual was weighed on an electronic balance (wet weight, $\mathrm{B}_{\mathrm{ww}}$ ), and the carapace width $(\mathrm{CW})$ measured with digital callipers. Ovigerous females were weighed after the removal of eggs. Before the clutch wet weight $\left(\mathrm{C}_{\mathrm{Ww}}\right)$ was determined, removed egg masses were placed on a dry paper towel for approx. five seconds to drain excessive interstitial water. To examine whether body weight predicts clutch weight, linear regressions on data from each site were used. Site differences were analysed by ANCOVA with body weight as covariate and site as categorical factor. Similar to the gonadosomatic index, the proportion of clutch to body weight $\left(\mathrm{P}_{\mathrm{CB}}\right)$ was calculated by dividing clutch weight by body weight, multiplied by $100\left(\mathrm{P}_{\mathrm{CB}}=\left(\mathrm{C}_{\mathrm{WW}} / \mathrm{B}_{\mathrm{WW}}\right)^{* 100}\right)$. The relationship between body size and $\mathrm{P}_{\mathrm{CB}}$ was tested by linear regression. Site differences in $\mathrm{P}_{\mathrm{CB}}$, and interactions between site and body size were analysed by ANCOVA with body size as covariate and site as categorical factor.

\section{d) Number of eggs per female and egg volume}

Under a dissecting microscope with $25 \mathrm{x}$ magnification the eggs of each clutch were counted and measured in three dimensions. The egg volume $\left(\mathrm{E}_{\mathrm{V}}\right)$ was calculated by using the formula for an ellipsoid $\left(E_{V}=4 / 3 \pi a b c\right.$ where $a=$ egg length, $b=$ width, $c=$ height). Egg numbers per female were regressed against individual body size $(\mathrm{CW})$, pooled across sites. The effect of body weight and site on egg volume was analysed as ANCOVA, with body weight as covariate and site as categorical factor.

\section{e) Egg dry weight}

For the estimate of clutch dry weight $\left(\mathrm{C}_{\mathrm{DW}}\right)$, the clutches from 20 females from each sample site were dried separately in a drying oven at $75^{\circ} \mathrm{C}$ for $24 \mathrm{~h}$. The $C_{D W}$ was then weighed on an electronic balance. Egg dry weight $\left(\mathrm{E}_{\mathrm{W}}\right)$ was calculated as $E_{W}=C_{D W} /$ no. of eggs. To minimise variance, eggs of developmental stages 1 and 2 (see below) were used only. Site differences in egg dry weight were tested by one-way ANOVA. The water content of eggs $\left(\mathrm{C}_{\mathrm{WC}}\right.$, Appendix 3.1) was 
calculated as the difference (D) between clutch wet weight and dry weight ( $\mathrm{D}=$ $\left.C_{W W}-C_{D W}\right)$, expressed as percent wet weight $\left(C_{W C}=D * 100 / C_{W w}\right)$.

\section{f) Developmental stage of eggs, and egg mortality}

Despite continuous development, the eggs of each clutch were assigned the following defined developmental stages (see Fig. 3.2):

Stage 1: newly deposited eggs, oval, no cleavage, dark red yolk in healthy eggs

Stage 2: Early cleavage, white tissue cap present

Stage 3: Small black eyespots present, yolk still present but reduced

Stage 4: Eyes large, yolk limited, red chromatophores and pre-hatch larva visible

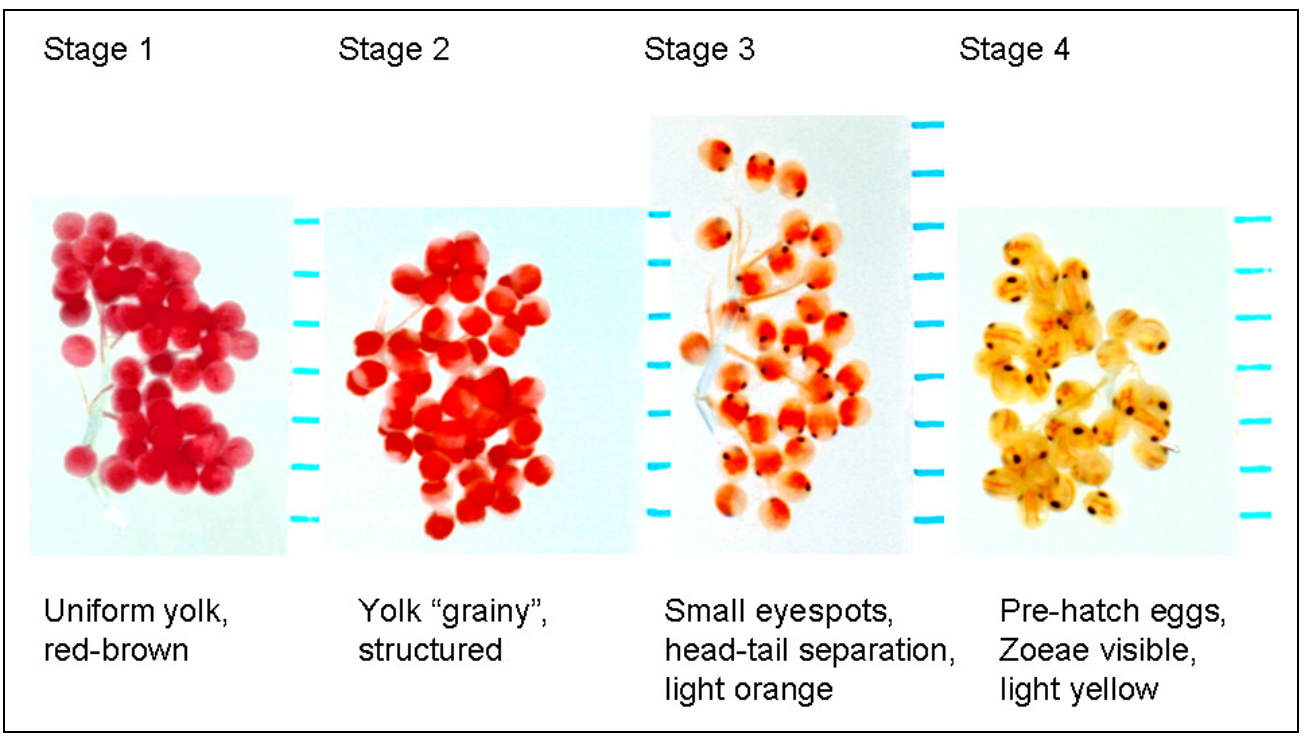

Fig. 3.2: Developmental stages of $P$. elongatus eggs, still attached to neartransparent pleopods. Note the changes in colouration, yolk structure as well as the development and enlargement of eyespots. The scales represent $\mathrm{mm}$.

To account for possible size differences, only females with a carapace width between $7.5 \mathrm{~mm}$ and $10.0 \mathrm{~mm}$ were sampled for this analysis ( $\mathrm{n}=60$ per site). The eggs per clutch were counted and assigned to one of the four developmental stages shown in Fig. 3.2. For each site, the mean number of eggs was calculated for pooled developmental stages $3+4$ (eggs with eye pigment; i.e. further developed) as well as for stages $1+2$ (eggs lacking eye pigment; i.e. newly deposited). Based on decreasing egg numbers with increasing development (due to mortality and dead eggs being actively or passively removed from the clutch) 
the initial mean egg number (stages $1+2$ ) was set to $100 \%$, whereas the percentage of the difference between newly deposited and older, remaining eggs $(\mathrm{D}=(1+2)-$ $(3+4))$ represents the egg mortality $\left(D^{*} 100 /(\right.$ mean stage $1+2)$ ) (compare Jones, 1977). Site differences were tested by one-way ANOVA.

\subsubsection{Female density and reproductive output per area unit}

In order to describe the differences in reproductive output not only per individual female but also per area unit (square meter) at each site at a given time within the reproductive season, the density of ovigerous females $\left(\mathrm{D}_{\mathrm{OF}}\right)$ was calculated from a subset of data obtained by quadrat sampling (described in chapter 2, see 2.2.2). Taking the size frequency distribution of females into account, the average number of eggs per female $\left(E_{F}\right)$ was calculated for each sample quadrat and site. The average number of eggs per square meter (i.e. the reproductive output per square meter, RO) was then calculated by multiplying the average density of ovigerous females by the average egg number per female $\left(\mathrm{RO}=\mathrm{D}_{\mathrm{OF}} * \mathrm{E}_{\mathrm{F}}\right)$. The variability within each site was estimated by calculating $95 \%$ confidence intervals by comparison of densities and egg numbers from 15 sample quadrats per site. Site differences in RO were tested by one-way ANOVA. To visualise the significance of site differences, $\mathrm{D}_{\mathrm{OF}}$ was plotted against $\mathrm{RO}$ for all sites with corresponding errors.

\subsubsection{Temperature-Loggers}

At each sample site for ovigerous females, two "StowAway® TidbiT®" temperature loggers (Onset Computer Corporation, 470 MacArthur Blvd., Bourne, MA 02532, USA) were deployed in the field from February until May 2008 , covering the second half of the reproductive season of $P$. elongatus and the time ovigerous females were sampled. The loggers were programmed to record the temperature every $5 \mathrm{~min}$. Each device was attached to a cobble filled plastic basket that was anchored with steel pegs in the intertidal zone (near the low and high water mark); dug in to the extent that the top of the basket was level with the surrounding rocks. To measure the temperature between cobbles (i.e. the temperatures the crabs are exposed to in their natural habitat) the loggers were covered by 1-2 layers of medium-sized cobbles $(8-16 \mathrm{~cm}$ length) inside each basket. The time series plots are shown in Fig. 3.3. 


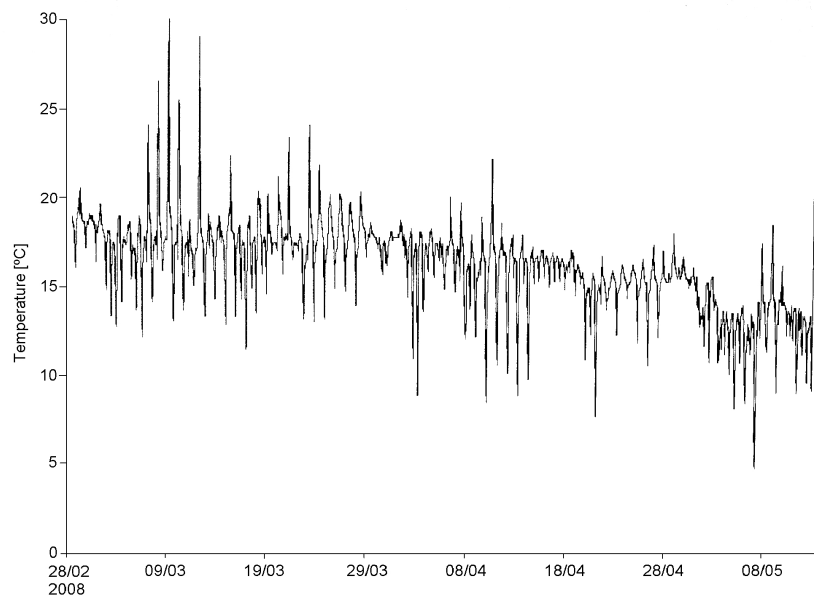

a) HRM

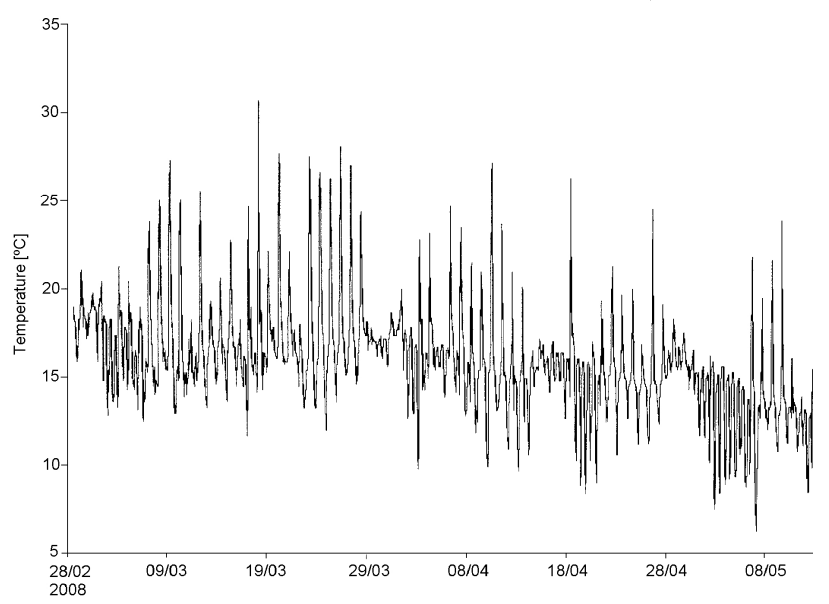

b) $\mathrm{BRB}$

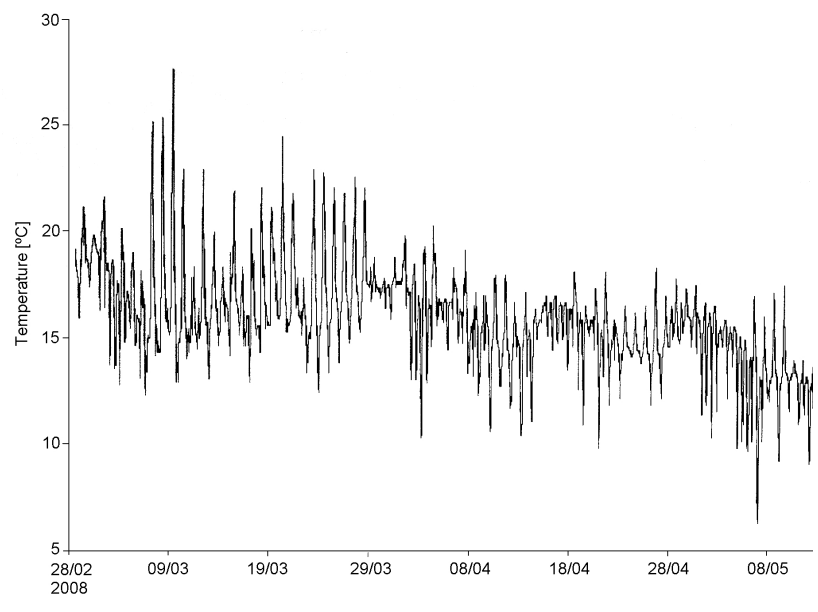

c) ISB

Fig 3.3: Temperature logger readouts as time series plot for each site with the date of sampling on the x-axis. Shown are the data measured at the high water mark, only, for a) Hutt River mouth, b) Breaker Bay, and c) Island Bay. Note the steep rise in temperature during low tide and the change in amplitude influenced by weather conditions, coherent across sites. 


\subsubsection{Food supply}

Water samples were taken weekly over a period of 4 months (from September until December 2009). At each of the study locations (Island Bay, Breaker Bay, and Hutt River mouth), five samples were taken 1-2h after high tide at the water line by filling 11 dark bottles with seawater just below the surface and at intervals of approx. $5 \mathrm{~m}$. To preserve active chlorophyll and phaeophytin, the samples were cooled on ice immediately in insulated containers (i.e. a Styrofoam boxes with lid) and transported to the laboratory. Not longer than $3 \mathrm{hrs}$ after sampling, in subdued light conditions, the water was filtered using $25 \mathrm{~mm}$ GF/F Whatman ash free filters. After placing a filter onto the $25 \mathrm{~mm}$ sieve base of a plastic filter funnel, 2x100ml well shaken sample water was poured into the funnel (three runs / filters per bottle). An electric suction pump, connected with a conical flask under the funnel, was used to create a vacuum pressure $(<2 \mathrm{psi})$ to suck the water through the filter. The pump was switched off as soon as the water level inside the funnel reached the $20 \mathrm{ml}$ mark. Each filter was removed with fine tweezers and put into a labelled plastic zip-lock bag that was stored in a $-80^{\circ} \mathrm{C}$ freezer. It was planned to spectrophotometrically determine levels of chlorophyll a, b, c and pheophytin (EPA Method 446.0, see Arar, 1997; Arar \& Collins, 1997) in filtration residues.

\subsubsection{Larval supply}

To estimate settlement and recruitment rates as well as their spatial variability, three different types of larval collectors were used in the field: tube traps, donutshaped nylon mesh pan scrubbers and basket traps. The design of the tube traps was based on the principle of sediment traps (see Yund et al., 1991) and consisted of a series of PVC pipes ( $5 \mathrm{~cm}$ diameter, $60 \mathrm{~cm}$ length each) with a glued-on cap at the bottom end. 5 truck tyres were fitted with two U-shaped reinforcing iron rods each (in a cross pattern, forming two interlaced perpendicular loops) and filled with concrete, providing robust, heavy base frames. To the reinforced iron loops of each base 4 upright standing tube traps were lashed with strong $1 \mathrm{~cm}$ wide and $30 \mathrm{~cm}$ long cable ties, approximately $20-30 \mathrm{~cm}$ apart from one another. To kill and preserve larvae, the tube traps were filled with buffered formalin-seawater solution while submerged in seawater. Theoretically, the formalin remains inside the tube due to its heavier specific weight. These plankton collectors were 
deployed in approximately 10m depth at Evans Bay, Shelly Bay, Petone Wharf, Island Bay, and Breaker Bay in April 2006.

Nylon mesh pan scrubbers ("Tuffies") had been successfully used to estimate larval supply of bivalves (Menge et al., 1994, 1999; Phillips \& Gaines, 2001; Rilov \& Schiel, 2006), and amphipods (Rule \& Smith, 2005). These artificial substrates were bolted to rocks at the lowest possible level in the intertidal, using a nested design similar to the one used for quadrat sampling (see section 2.2.1) with 5 sampling units per nest, 3 nests per site, at 3 sites (Island Bay, Breaker Bay, and Hutt River mouth). After an exposure of 1 week the traps were retrieved and replaced, put into labelled plastic bags and processed at the laboratory by carefully disentangling the nylon mesh of pan scrubbers, rinsing them in filtered seawater and systematically searching the residue with a dissecting microscope and a Petri dish with grid lines.

Further, 2 types of basket traps were tested; a larger trap $(30 \mathrm{~cm}$ x $20 \mathrm{~cm} \times 15 \mathrm{~cm})$ and a smaller and shallower version $(15 \times 15 \times 10 \mathrm{~cm})$, filled with bare cobbles from the supralittoral zone $(10 \mathrm{~cm}$ to $15 \mathrm{~cm}$ maximum length). At each site, five traps of each type were deployed between February and April 2007.

All statistical analyses in this chapter were calculated in JMP 4.0.4 (SAS Institute, September 2001). For regressions and graphs, SigmaPlot 10.0.1 (Systat, January 2007) was used. 


\subsection{Results}

\subsubsection{Sex ratio}

Sex ratios varied among sites (Table 3.1 and 3.2) but no differences between sample quadrats and nests of quadrats were detected; hence, these factors were excluded from the model. According to the parameter estimates, difference between BRB and ISB were significant, with a higher proportion of females at BRB (Table 3.1).

Table 3.1: Mean percentage and sex ratios of $P$. elongatus with standard error at sites HRM $=$ Hutt River mouth $\left(\mathrm{n}_{\text {total }}=2080\right)$; BRB = Breaker Bay $\left(\mathrm{n}_{\text {total }}=421\right)$, and ISB = Island Bay $\left(\mathrm{n}_{\text {total }}=564\right)$, based on 15 samples per site taken at one time. There was a higher percentage of females at Breaker Bay relative to the other two sites.

\begin{tabular}{|l|c|c|c|}
\hline Site & Males [\%] & Females [\%] & Sex ratio (m:f) \\
\hline & & & \\
HRM & $50.3 \pm 1.7$ & $49.7 \pm 1.7$ & $1.15 \pm 0.07$ \\
BRB & $46.0 \pm 2.0$ & $54.0 \pm 2.0$ & $0.88 \pm 0.06$ \\
ISB & $55.9 \pm 2.1$ & $44.1 \pm 2.1$ & $1.36 \pm 0.15$ \\
\hline
\end{tabular}

Table 3.2: Binominal logistic regression results site versus sex ratio. There was a significant difference in sex ratio between sites.

\begin{tabular}{|l|lllll|}
\hline Source & $\mathbf{R}^{\mathbf{2}}$ & df & $-\log$ likelihood (diff.) & $\mathbf{C h i}^{\mathbf{2}}$ & $\mathbf{p}\left(\mathbf{C h i}^{\mathbf{2}}\right)$ \\
\hline Site & 0.0015 & 2 & 3.1300 & 80.76196 & $\mathbf{0 . 0 4 3 7}$ \\
\hline
\end{tabular}




\subsubsection{Female size at sexual maturity}

Female size at sexual maturity $(3.40 \pm 0.09 \mathrm{~mm}$, standard error) was similar at all sites (Fig. 3.4); all differences were non-significant (Table 3.3).

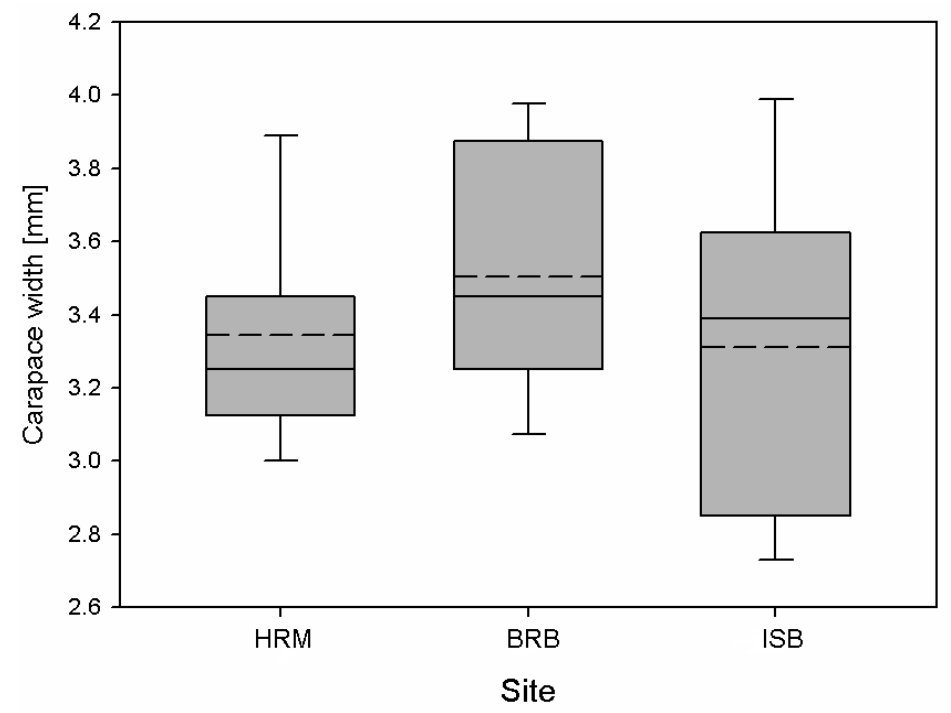

Fig. 3.4 Female size at sexual maturity at all sites. The median is indicated as solid line; the mean as dashed line. Across sites, female size at sexual maturity is similar at $3.40 \pm 0.09 \mathrm{~mm}$. Whisker caps represent $2.5 \%$ and $97.5 \%$ quantiles.

Table 3.3: One-way ANOVA results female size at sexual maturity versus site. No significant differences between sites were detected.

\begin{tabular}{|l|llll|}
\hline Source & SS & df & F & p \\
\hline Site & 0.427554 & 2 & 0.8939 & 0.4167 \\
Error & 10.044637 & 42 & & \\
\hline
\end{tabular}




\subsubsection{Percent ovigerous females}

There was no clear pattern of percent ovigerous females among size classes between sites (Fig. 3.5) with non-significant differences between size classes (Table 3.4). However, there were significant differences between sites (Table 3.4) with significantly higher percentages of ovigerous females at ISB relative to HRM and BRB (Fig. 3.5 and post hoc tests).

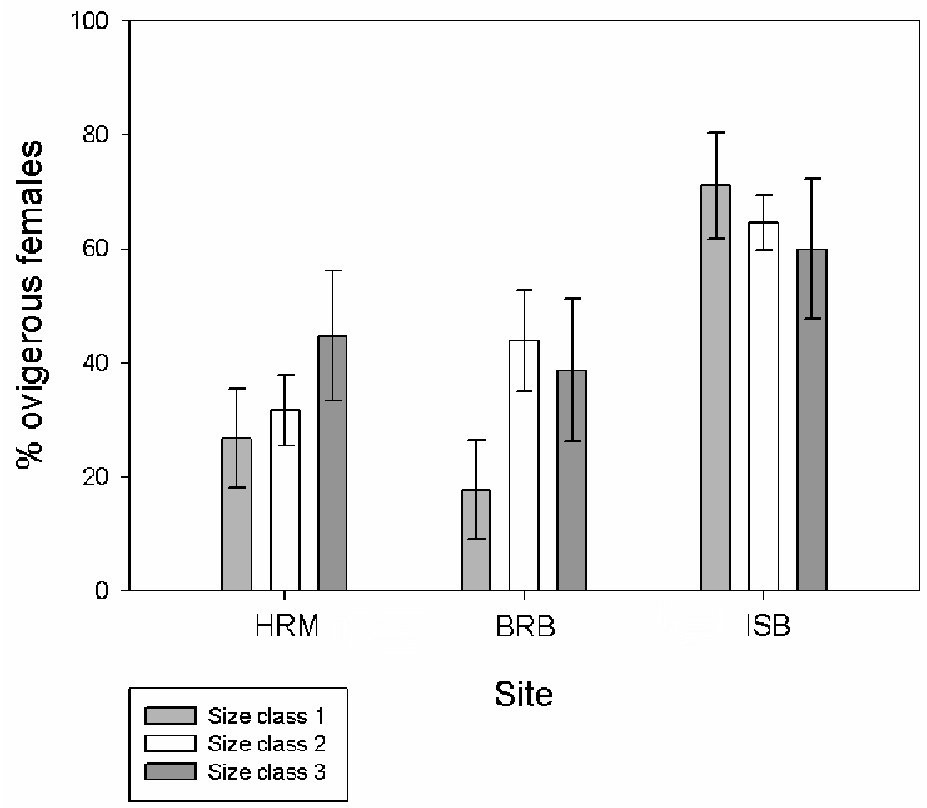

Fig. 3.5: Percent ovigerous females (in relation to total number of females) at all sites within three size classes $(1: 5.0-7.5 \mathrm{~mm} \mathrm{CW} ; 2:>7.5-10.0 \mathrm{~mm} \mathrm{CW} ; 3:>10.0-$ $12.5 \mathrm{~mm} \mathrm{CW}$ ). The percentage of ovigerous females varies with sites, but no conclusive pattern emerges when comparing size classes within sites. Error bars represent $95 \%$ confidence intervals.

Table 3.4: Logistic regression results (Logit no. ovig. females $\sim$ Site + Size cl.). There is significant variation between sites, but not between size classes within sites.

\begin{tabular}{|l|llll|}
\hline Source & $\mathbf{R}^{2}$ & df & $\mathbf{C h i}^{\mathbf{2}}$ & $\mathbf{p}$ \\
\hline Site & 0.0538 & 2 & 80.76196 & $<\mathbf{0 . 0 0 0 1}$ \\
Size class & 0.0019 & 1 & 2.755193 & $<0.0969$ \\
\hline
\end{tabular}




\subsubsection{Body size versus number of eggs}

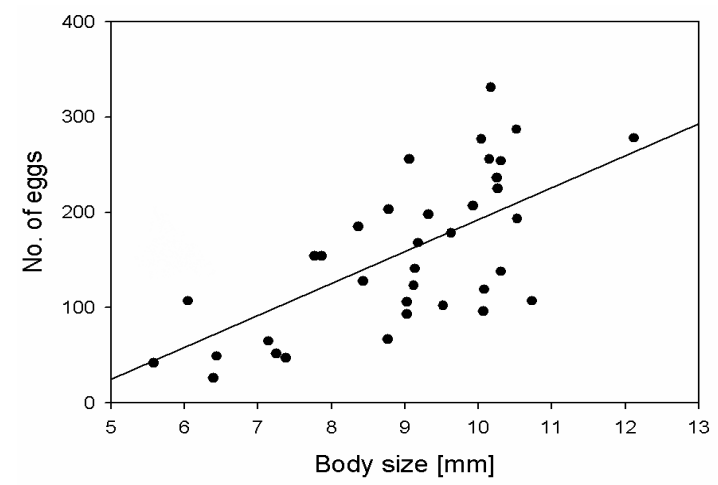

a) Hutt River mouth $\left(R^{2}=0.43 ; F=26.2130 ; p<0.0001 ; y=-143.132+33.558 x\right)$

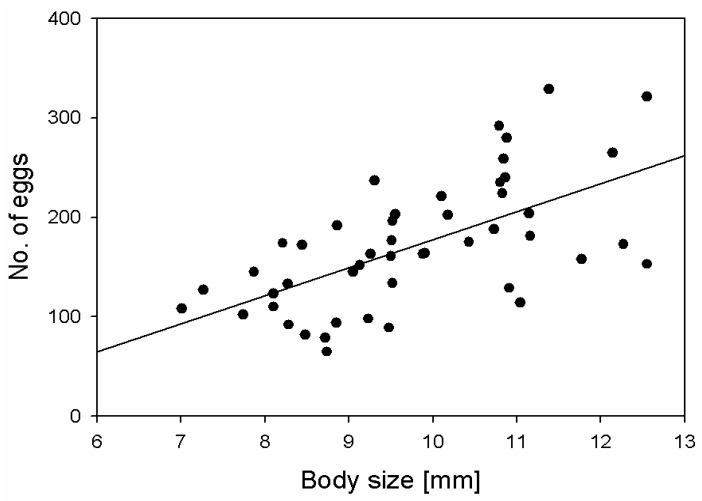

b) Breaker Bay $\left(\mathrm{R}^{2}=0.4172 ; \mathrm{F}=28.3161 ; \mathrm{p}<\mathbf{0 . 0 0 0 1} ; \mathrm{y}=-103.841+28.152 \mathrm{x}\right)$

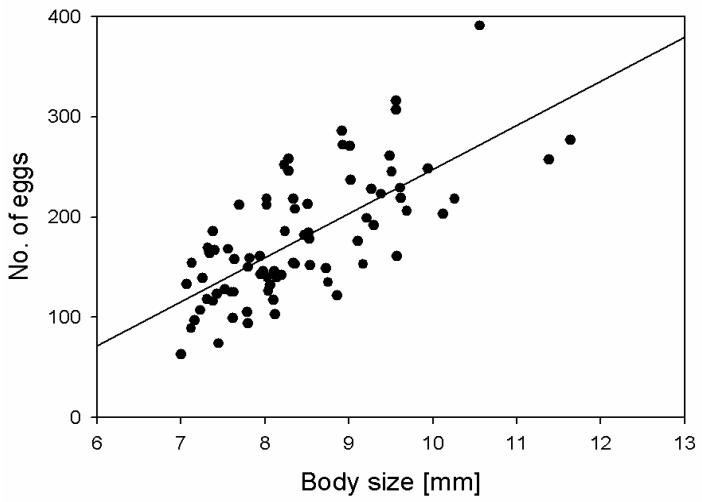

c) Island Bay $\left(\mathrm{R}^{2}=0.6724 ; \mathrm{F}=76.0672 ; \mathrm{p}<\mathbf{0 . 0 0 0 1} ; \mathrm{y}=-191.764+43.982 \mathrm{x}\right)$

Fig 3.6: Body size versus number of eggs at all sites; the body size is given as carapace width. At all sites egg number was strongly correlated with female body size with a steeper slope at Island Bay.

Table 3.5: ANCOVA results No. of eggs $\sim$ Site + Body size $+($ Site $*$ Body size $)$ Egg number varied with both site and body size.

\begin{tabular}{|l|lrrl|}
\hline Source & SS & df & F & p \\
\hline Site & 85472.61 & 2 & 17.1726 & $<\mathbf{0 . 0 0 0 1}$ \\
Body size & 327552.56 & 1 & 131.6191 & $<\mathbf{0 . 0 0 0 1}<$ \\
Site * Body size & 10742.61 & 2 & 2.1583 & $<0.1189$ \\
Error & 390716.36 & 157 & & \\
\hline
\end{tabular}




\subsubsection{Body weight versus clutch weight}

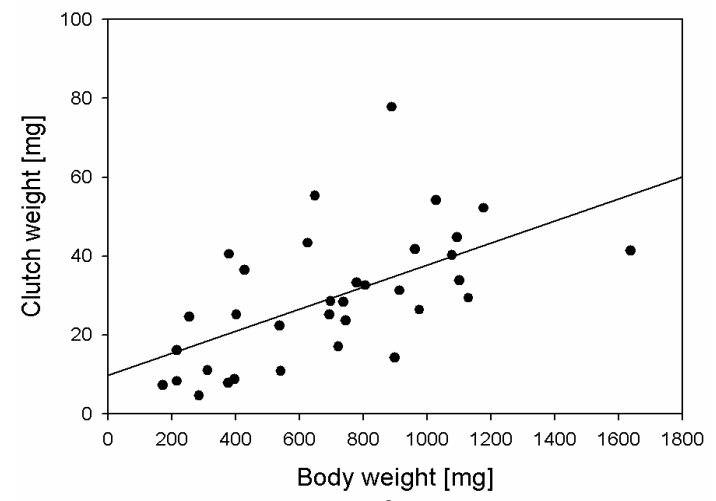

a) Hutt River mouth $\left(R^{2}=0.3391 ; F=16.4173 ; p=0.0003 ; y=9.783+0.028 x\right)$

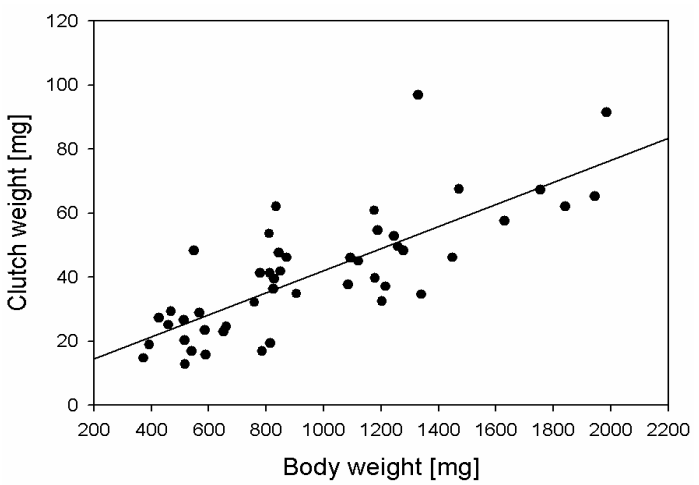

b) Breaker Bay $\left(\mathrm{R}^{2}=0.6018 ; \mathrm{F}=69.5130 ; \mathrm{p}<\mathbf{0 . 0 0 0 1} ; \mathrm{y}=7.574+0.035 \mathrm{x}\right)$

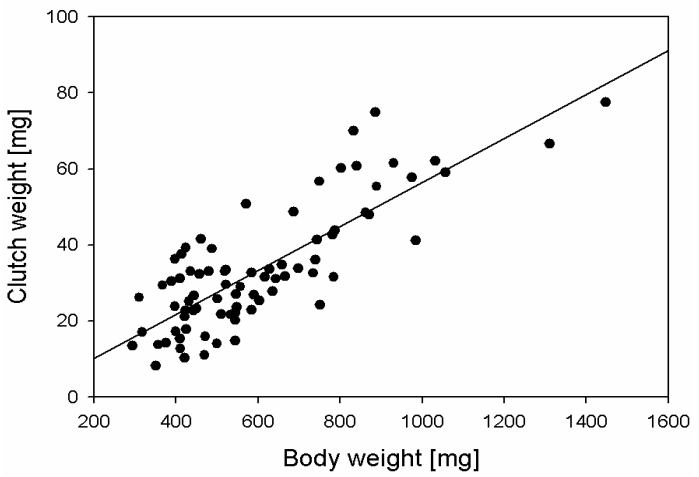

c) Island Bay $\left(\mathrm{R}^{2}=0.6577 ; \mathrm{F}=147.9410 ; \mathrm{p}<\mathbf{0 . 0 0 0 1} ; \mathrm{y}=-1.456+0.058 \mathrm{x}\right)$

Fig. 3.7: Body weight versus clutch weight at all sites. At all sites clutch weight was strongly correlated with female body size with a steeper slope at Island Bay. Note that the $\mathrm{X}$-axis (body weight) differs among subfigures a) to c).

Table 3.6: ANCOVA results Cl. weight $\sim$ Site + Body wgt. + (Site * Body wgt.) Clutch weight varied with site and body weight; however, body weight differs between sites.

\begin{tabular}{|l|lrrl|}
\hline Source & SS & df & F & p \\
\hline Site & 3421.820 & 2 & 16.5066 & $<\mathbf{0 . 0 0 0 1}$ \\
Body wgt. & 21041.245 & 1 & 203.0022 & $<\mathbf{0 . 0 0 0 1}$ \\
Site * Body wgt. & 2431.019 & 2 & 11.7270 & $<\mathbf{0 . 0 0 0 1}$ \\
Error & 15547.546 & 157 & & \\
\hline
\end{tabular}


Body size was an excellent predictor of egg number per female; predicting $42-67 \%$ of the variation in number of eggs per female (Fig. 3.6). There were significant differences between sites, with females from ISB having on average a higher number of eggs than the other sites (post hoc Tukey test, $\mathrm{p}<0.05$ ). Expectedly, body weight was significantly positively related to clutch weight (Fig. 3.7) and clutch weight varied with site (Table 3.6). However, the ANCOVA revealed that body weight also varied with site (Table 3.6) with heavier females at BRB compared to ISB, despite no significant differences in body size (Table 3.5). Additionally, the slope of the regression line for both body size versus number of eggs and body weight versus clutch weight at ISB was steeper compared to the other two sites, indicating higher individual reproductive output. At ISB, females had on average heavier clutches than at HRM or BRB (post hoc Tukey test, $\mathrm{p}<0.05)$.

\subsubsection{Proportion of clutch to body weight}

The proportion of clutch to body weight did not vary by body size, but did vary with site (Table 3.7). Post hoc tests confirmed that the proportion of clutch to body weight was significantly higher at ISB than at the other two sites (Fig 3.8), which is consistent with results of the regressions body size versus number of eggs and body weight versus clutch weight shown above (Figs. 3.6 and 3.7).

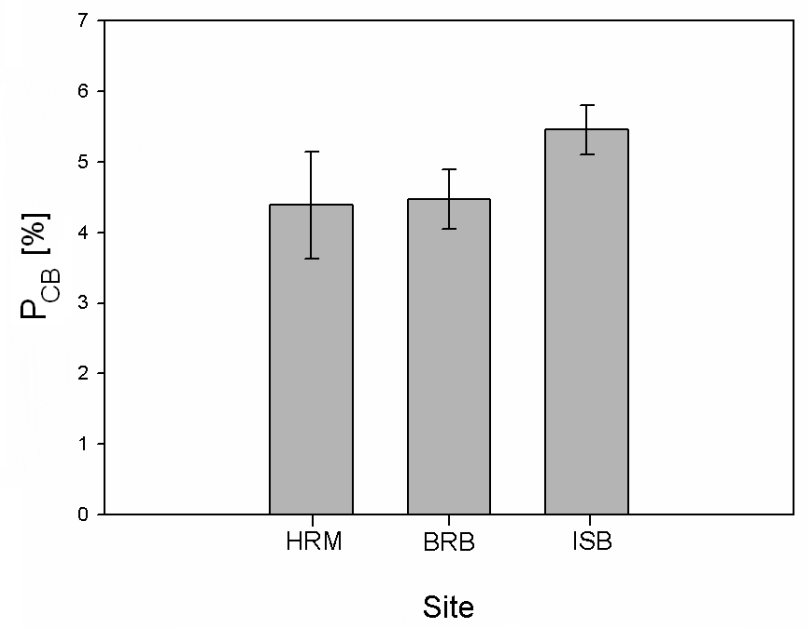

Fig. 3.8: Mean proportion of clutch to body weight $\left(\mathrm{P}_{\mathrm{CB}}\right)$ in percent body weight at all sites with a higher mean value at Island Bay compared to HRM and BRB. Error bars represent $95 \%$ confidence intervals. 
Table 3.7: ANCOVA results $\mathrm{P}_{\mathrm{CB}} \sim$ Site + Body size $+($ Site $*$ Body size) While the mean proportion of clutch to body weight varied with site, there is no relation to body size.

\begin{tabular}{|l|rrll|}
\hline Source & \multicolumn{1}{l}{ SS } & df & F & p \\
\hline Site & 46.645486 & 2 & 7.7279 & $\mathbf{0 . 0 0 0 6}$ \\
Body size & 7.184003 & 1 & 2.3804 & 0.1249 \\
Site * Body size & 5.364997 & 2 & 0.8888 & 0.1432 \\
Error & 473.822440 & 157 & & \\
\hline
\end{tabular}

\subsubsection{Mean egg volume}

The mean egg volume did not vary with female body weight but was significantly different between sites (Table 3.8). There were smaller eggs at ISB compared to HRM and BRB (Fig. 3.9, Tukey's HSD p < 0.05).

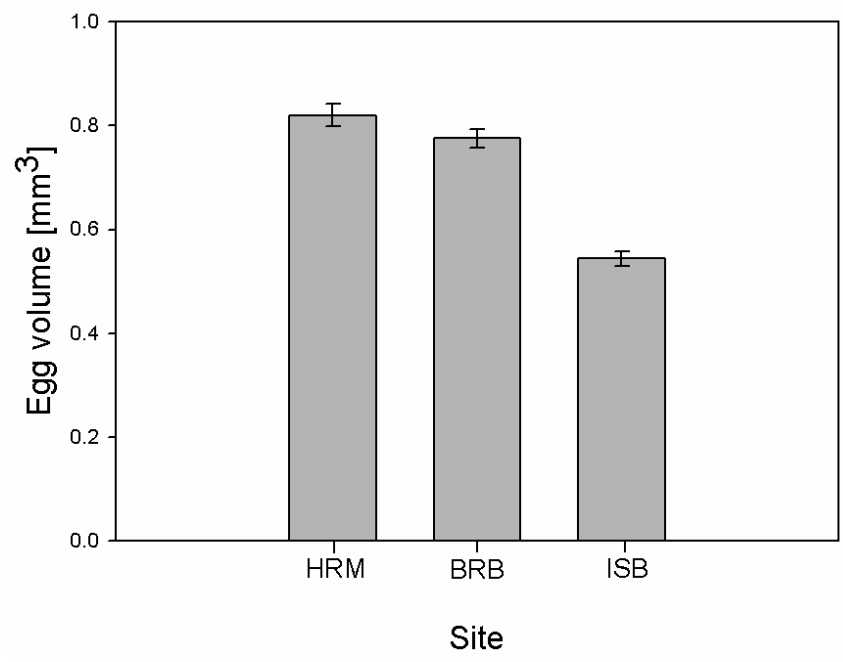

Fig. 3.9: Mean egg volume at all sites (developmental stages 1 and 2 only). At Island Bay, egg volume is significantly lower than at Hutt River mouth and Breaker Bay. Error bars represent $95 \%$ confidence intervals.

Table 3.8: ANCOVA results $\mathrm{E}_{\mathrm{V}} \sim$ Site + Body weight + (Site * Body weight $)$ Mean egg volume strongly varies with site, but not with body weight.

\begin{tabular}{|l|lrrl|}
\hline Source & SS & df & F & p \\
\hline Site & 1.3575472 & 2 & 12.3209 & $<\mathbf{0 . 0 0 0 1}$ \\
Body wgt. & 0.0107136 & 1 & 0.1945 & $<0.6604$ \\
Site * Body wgt. & 0.0161298 & 2 & 0.1464 & $<0.8641$ \\
Error & 4.6276526 & 84 & & \\
\hline
\end{tabular}




\subsubsection{Mean egg dry weight}

The mean egg dry weight was significantly different between sites (Table 3.9) with the highest value at Hutt River mouth compared to the other two sites (Fig. 3.10), largely related to egg volume (Fig. 3.9). While mean egg dry weight at HRM is significantly different from values at the other two sites, those for Breaker Bay and Island Bay were not significantly different from each other (Tukey's HSD p <0.05).

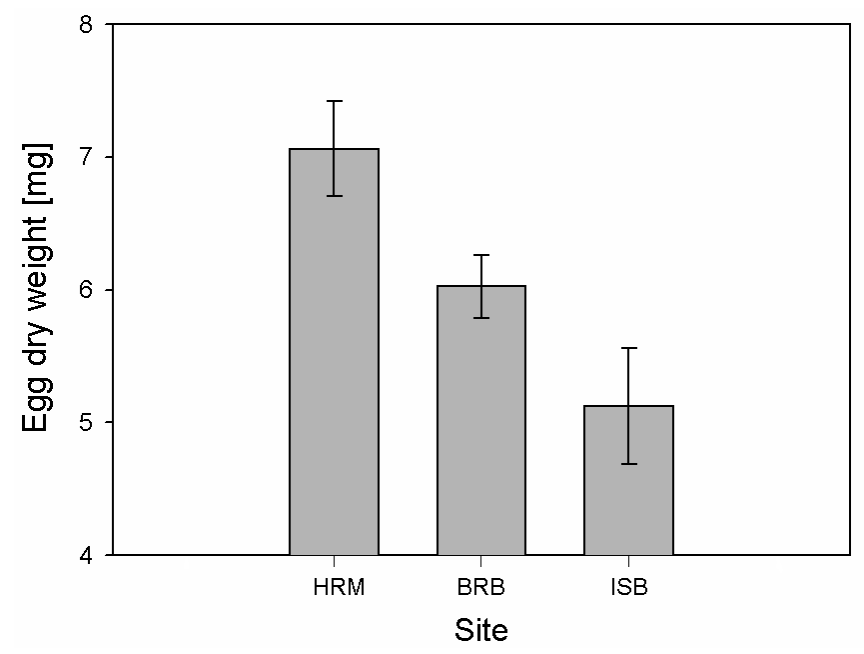

Fig. 3.10: Mean egg dry weight of 100 eggs at all sites (developmental stages 1 and 2 only). At Hutt River mouth, mean egg dry weight is significantly higher compared to the other two sites. Error bars represent $95 \%$ confidence intervals.

Table 3.9: One-way ANOVA results egg dry weight versus site. Egg dry weight is significantly different between sites.

\begin{tabular}{|l|lrll|}
\hline & SS & df & F & p \\
\hline Site & 0.00360944 & 2 & 144.9852 & $<\mathbf{0 . 0 0 0 1}$ \\
Error & 0.00070951 & 57 & & \\
\hline
\end{tabular}




\subsubsection{Mean egg water content}

Site differences in mean egg water content were significant (Table 3.10); however, Tukey's HSD revealed that only site differences between Hutt River mouth and Island Bay were significant with highest values at HRM (Fig. 3.11).

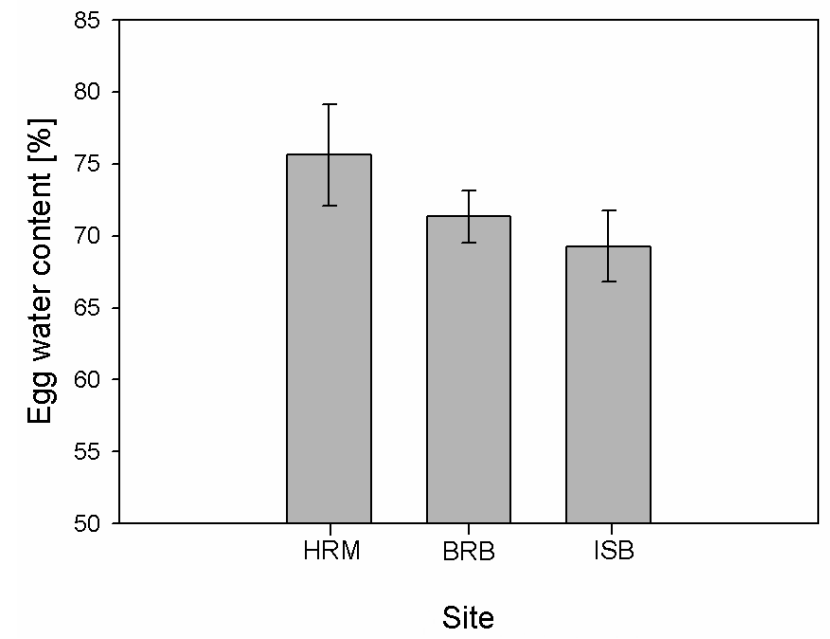

Fig. 3.11: Water content of eggs at all sites (developmental stages 1 and 2 only). Mean egg water content was highest at Hutt River mouth and lowest at Island Bay. Error bars represent $95 \%$ confidence intervals.

Table 3.10: One-way ANOVA results water content of eggs vs. site. Egg water content varied with site.

\begin{tabular}{|l|rrll|}
\hline & \multicolumn{1}{|l}{ SS } & df & F & p \\
\hline Site & 318.42237 & 2 & 5.0502 & $<\mathbf{0 . 0 0 9 6}$ \\
Error & 1796.94960 & 57 & & \\
\hline
\end{tabular}




\subsubsection{Egg wet weight versus developmental stage of eggs}

The average egg wet weight increased with progressing egg development (Fig. 3.12) with significant differences between developmental stages (Table 3.11). According to post hoc tests, eggs in the earliest two developmental stages were significantly lower in weight than those in the more advanced two developmental stages (Tukey's HSD p < 0.05, Fig 3.12). While there was no interaction between site and developmental stage, differences between sites were significant similar to the above analysis where egg weights were higher at ISB than the other two sites (Table 3.11).

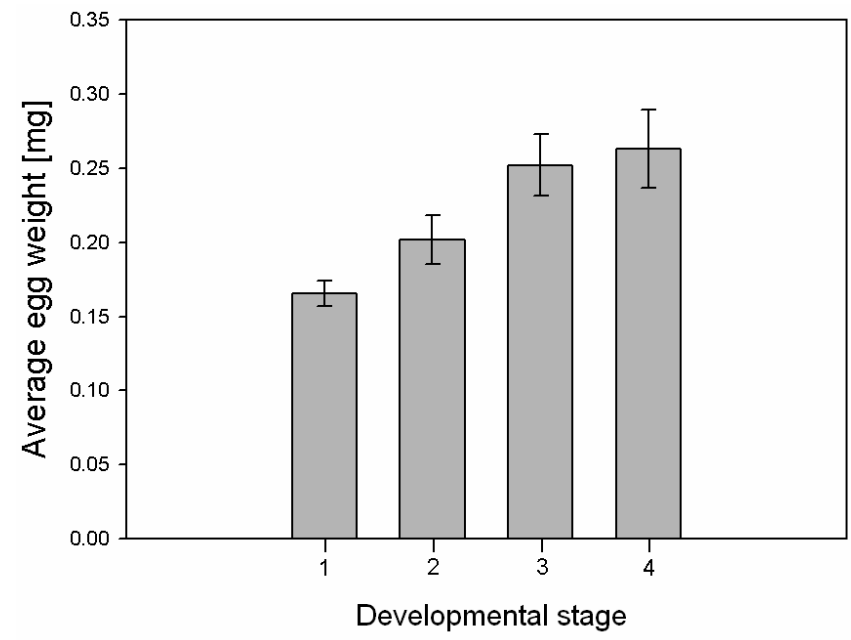

Fig. 3.12: Mean egg wet weight within clutch (single egg) versus developmental stage of eggs (see Fig. 3.2), pooled across sites. Egg wet weight increases with the development of the egg. Error bars represent $95 \%$ confidence intervals.

Table 3.11: ANCOVA results $\left(E_{\mathrm{W}} \sim\right.$ Dev. stage + Site $+($ Dev. stage $*$ Site $)$ Mean egg wet weight varied with developmental stage and there were site differences, as well.

\begin{tabular}{|l|lrrl|}
\hline & SS & df & F & p \\
\hline Site & 0.03132505 & 2 & 5.7602 & $<\mathbf{0 . 0 0 3 9}$ \\
Dev. stage & 0.14135772 & 3 & 17.3291 & $<\mathbf{0 . 0 0 0 1}$ \\
Site * Dev. stage & 0.00450868 & 6 & 0.2764 & $<0.9473$ \\
Error & 0.40514301 & 150 & & \\
\hline
\end{tabular}




\subsubsection{Egg mortality}

Egg mortality in females with a carapace width between $7.5 \mathrm{~mm}$ and $10.0 \mathrm{~mm}$ was significantly different between sites (Table 3.12) with mortality at BRB significantly higher (approx. twice as high) as that of the HRM (Tukey's HSD, p $<0.05$; Fig. 3.13). However, there were no significant differences between BRB and ISB, and HRM and ISB.

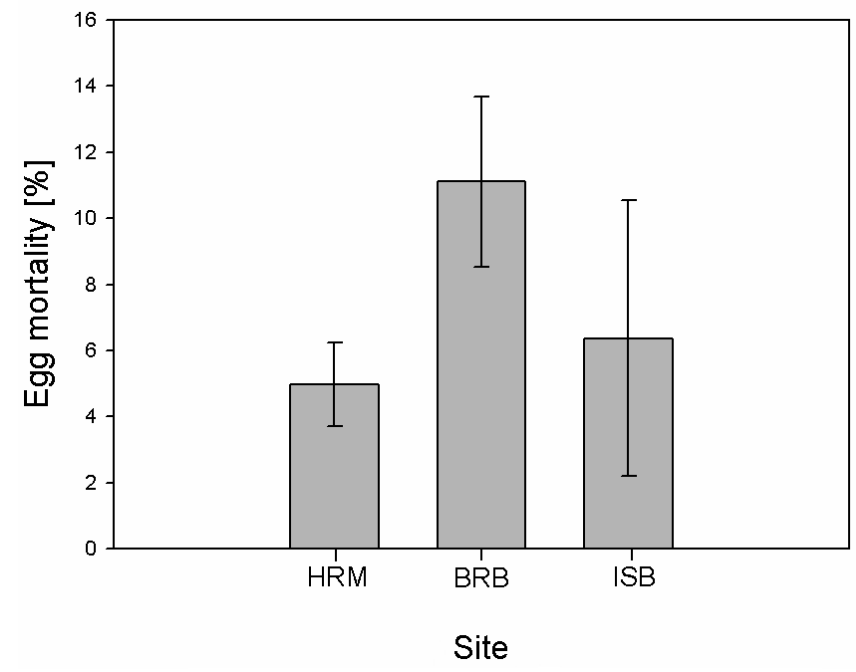

Fig. 3.13: Egg mortality in crabs with $7.5 \mathrm{~mm}-10.0 \mathrm{~mm} \mathrm{CW}$ varied with site and was with approx. 5\% at HRM significantly lower than at BRB (approx. 11\%). Error bars represent $95 \%$ confidence intervals.

Table 3.12: One-way ANOVA results egg mortality vs. site. There were significant differences in egg mortality between sites.

\begin{tabular}{|l|llll|}
\hline & SS & df & F & p \\
\hline Site & 103.60496 & 2 & 6.0040 & $\mathbf{0 . 0 1 5 6}$ \\
Error & 103.53559 & 12 & & \\
\hline
\end{tabular}




\subsubsection{Density of ovigerous females versus reproductive output per unit area}

The average numbers of eggs per square meter were significantly different at the different sites (Table 3.13). Post hoc Tukey tests revealed that all sites were significantly different from one another, with highest RO at Hutt River mouth, intermediate at Island Bay and lowest at Breaker Bay (Fig 3.14, Tukey's HSD $\mathrm{p}<0.05$ ). Fig 3.14 shows that this pattern is linearly related to the density of ovigerous females at each site.

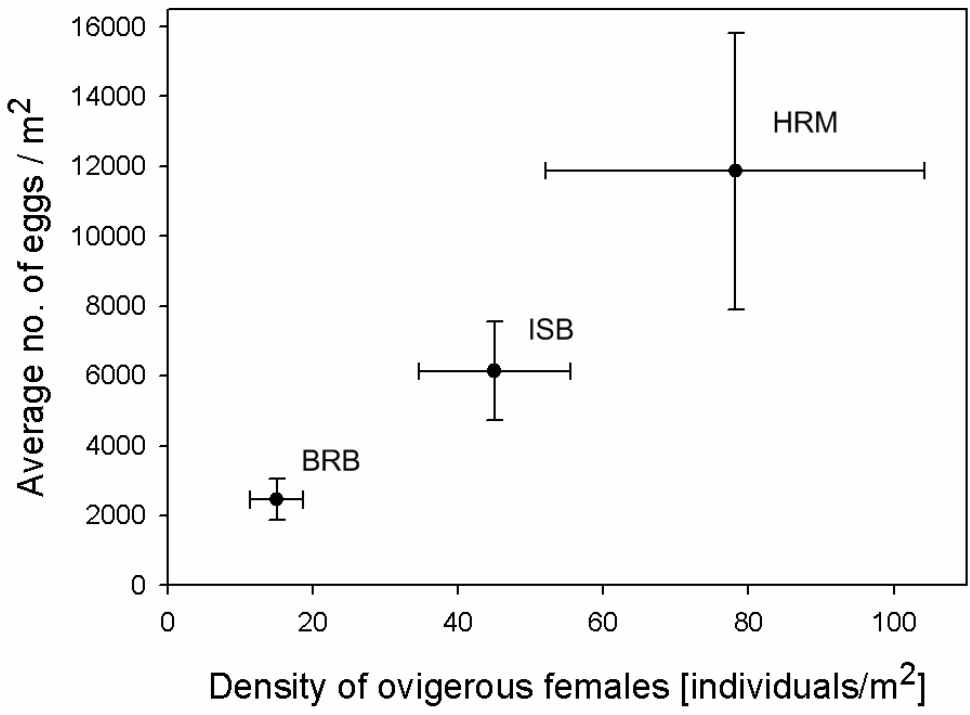

Fig. 3.14: Density of ovigerous females versus average numbers of eggs per square meter (reproductive output per area unit, RO) at all sites in January and February 2006. Female density (ovigerous only) was linearly positively correlated with mean number of eggs per square meter, which, in turn is dependent on female density. However, if intraspecific competition would affect individual egg numbers within the sampled density range, then the relationship would have resembled a saturation curve rather than being linear. Error bars for both factors represent $95 \%$ confidence intervals.

Table 3.13: One-way ANOVA results RO vs. site. Reproductive output per area unit strongly varied with site, as visualized in Fig. 3.14.

\begin{tabular}{|l|lrll|}
\hline & SS & df & F & p \\
\hline Site & $465,356,684$ & 2 & 15.6920 & $<\mathbf{0 . 0 0 0 1}$ \\
Error & $578,285,704$ & 42 & & \\
\hline
\end{tabular}




\subsubsection{Temperature data}

Mean temperature varied significantly with site (Table 3.15) with a significantly higher mean temperature at BRB relative to HRM and ISB (Table 3.14 and post hoc Tukey test). Fig 3.3 shows the high temperature fluctuations due to tidal rhythm and periodic submersion (up to $17^{\circ} \mathrm{C}$ max. amplitude at HRM). Additionally, influences of weather changes are visible with generally warmer interstitial air temperatures at $\mathrm{BRB}$, as well as the overall cooling with the shortening day-lengths in early autumn.

Table 3.14: Temperature data from all sites $(\mathrm{HRM}=$ Hutt River mouth, $\mathrm{BRB}=$ Breaker Bay, ISB = Island Bay; 1 = near high water mark; 2 = near low water mark), between 28/02 and 10/05/2008 ( $\mathrm{SE}=$ standard error; sample size per temperature logger $n=18,919$ ). While mean temperature at ISB is lower compared to BRB and HRM, the amplitude (between temperature maxima and minima) is lower at ISB, as well. Both mean temperature as well as amplitude is generally lower at the low water mark compared to locations higher up on the beach due to differences in submersion time and exposure during low tide.

\begin{tabular}{|l|l|l|l|}
\hline Site & Min. & Max. & Mean \pm SE \\
\hline HRM1 & 4.85 & 29.96 & $16.35 \pm 0.05$ \\
HRM2 & 5.11 & 27.32 & $14.87 \pm 0.04$ \\
BRB1 & 6.26 & 30.55 & $17.63 \pm 0.08$ \\
BRB2 & 8.32 & 26.37 & $15.39 \pm 0.06$ \\
ISB1 & 6.30 & 27.58 & $15.44 \pm 0.03$ \\
ISB2 & 8.23 & 26.37 & $14.32 \pm 0.03$ \\
\hline
\end{tabular}

Table 3.15: One-Way ANOVA results on mean temperatures (subsets 1\&2 combined) at all sites revealed highly significant differences between sites.

\begin{tabular}{|l|lrll|}
\hline Source & SS & df & F & p \\
\hline Site & 575.20639 & 2 & 61.8701 & $<\mathbf{0 . 0 0 0 1}$ \\
Error & 13931.563 & 2997 & & \\
\hline
\end{tabular}

\subsubsection{Food supply}

Both water sampling and filtration was completed for all samples and study sites; however, mainly due to time constraints the photometric analysis of filtration residues was not carried out and, therefore, yielded no results.

In addition to the analyses of water samples, continuous sampling with CTD instruments (Conductivity-Temperature-Depth recorder) and other sensors 
deployed in the field may yield more detailed information on spatio-temporal variations of salinity, temperature, turbidity and phytoplankton densities (measured as fluorescence). Also, GIS assisted remote-sensing techniques have proven useful, although costly, for estimating plankton distribution (see Harding \& Miller, 2009) and providing information on food supply for decapods (Salam \& Ross, 2000; Salam et al., 2003).

\subsubsection{Larval supply}

After 2-4 weeks of exposure, SCUBA diving revealed that both trap-base units of the sediment traps at Island Bay and Breaker Bay had disappeared or were destroyed by wave action. From sites within the harbour only the plankton collector at Petone wharf could be retrieved but contained large amounts of silt and almost no plankton. Despite repeated dives the remaining sample collectors could not be found due to low visibility, dense algal canopies, and no GPS coordinates to indicate the exact location.

Because most nylon mesh traps were found empty and only occasionally 1-5 P. elongatus megalopae were encountered, this experiment was terminated after 3 months, lasting from September until December 2006.

Basket traps were generally suitable (see settlement experiment, section 4.2.2) but very large in comparison to the tiny $(1.5 \mathrm{~mm}-2.0 \mathrm{~mm} \mathrm{CW})$, near-transparent larvae. The extraction of larvae from traps proved to be more difficult and time consuming than presumed, since the very fragile megalopae are naturally very good at clinging to the surface of rocks, frequently in small cracks and nooks, only to be dislodged by a high pressure water-jet or exposure to ethanol or formalin-seawater solution. Even though steel pegs and cable ties were used to anchor the traps, most of them were either removed by curious or environmentally conscious people (personal communication; this problem was resolved by tags stating their purpose and origin in later experiments) or swept away after the first storm.

Yan et al. (2004) introduced a promising type of filter-cup trap that can be easily and cost-effectively assembled as a simplified version of a plankton trap designed and used by Castilla \& Varas (1998) and Castilla et al. (2001). Deploying a similar trap, bolted to bedrock and placed among boulders, may be a useful method to estimate spatio-temporal variations in settlement of $P$. elongatus larvae. 


\subsection{Discussion}

The reproductive traits of $P$. elongatus strongly varied with site. While at ISB the percentage of ovigerous females, as well as the proportion of clutch to body weight was significantly higher relative to females from HRM and BRB, mean egg volume mean as well as egg dry weight were significantly smaller at this site. Additionally, when comparing numbers of eggs per female with a similar body size across sites, egg numbers were significantly higher at ISB, especially among large individuals. Apart from the exception of elevated egg mortality at BRB, site specific characteristics of reproductive traits were generally similar at HRM and BRB. This high variability is consistent with large scale phenotypic differences in reproductive traits in Petrolisthes armatus, reported by Wehrtmann et al., 2012.

Due to the close proximity of the study sites and prevailing current patterns (see chapter 1) it can be assumed that connectivity is high between metapopulations, maintained by larval transport and a pelagic phase lasting several weeks. Consequently, the observed pattern largely reflects phenotypic plasticity of crabs in response to the different environmental conditions at these sites. Roff (1992) argues that reproductive patterns in marine invertebrates are adaptive, related to environmental conditions, in order to maximise offspring fitness and, hence, population stability. Phenotypic plasticity in water fleas Daphnia spp. (i.e. their change in head morphology to reduce predation risk in response to waterborne cues) is not necessarily associated with high metabolic costs (Oda et al., 2007). Generally, short-term phenotypic plasticity is one of the most significant responses of organisms to environmental change (West-Eberhard, 2003; Berrigan \& Scheiner, 2004), and may determine whether a population will persist following an alteration in its conditions (Gabriel et al., 2005; Helmuth et al., 2005). Differences in phenotypic plasticity between introduced and indigenous species are likely to be particularly important in mediating responses to climate change (Walther et al., 2002; Stillman, 2003; Chown, 2007).

\section{Effects of temperature on reproductive traits}

Generally, gonad growth and development are strongly affected by temperature in marine organisms (Nelson et al., 1988). While total clutch production is commonly correlated with lifespan, clutch size and the timing of clutch 
production varies with water temperature (Dickinson et al., 2006, Darnell et al., 2009). However, even though mean temperature was significantly higher at BRB relative to HRM and ISB during sampling (section 3.13), neither mean egg volume nor mean egg dry weight appeared to be positively affected by the generally higher rates of metabolism at higher temperatures (e.g. Gillooly et al., 2001). However, elevated temperature could have been responsible for higher egg mortality at BRB. In P. granulosus, reproductive output is negatively correlated with environmental temperature and egg volume as well as body size and reproductive capacity increase with latitude (Monaco et al., 2010). There is no evidence for a latitudinal gradient in egg size in P. elongatus (Jones, 1977).

The length of the reproductive season in Petrolisthes spp. depends on water temperature, and consequently varies with latitude (Wehrtmann, 2005; Gebauer et al., 2007). While ovigerous P. elongatus females can be found over 12 months in Hauraki Gulf (Greenwood, 1965), and over 9 months between July and March in Wellington (Wear, 1965, and own observation), Jones (1976) reported that in the Christchurch area ovigerous females were found over 6 months between October and March, limited by the cyclic variations in water temperature (Jillett, 1971). Alternatively or additionally, Booloothian (1959) suggested that species with annual breeding cycles have adapted to the seasonal differences in food availability for larval stages, whereas Ahmed \& Mustaquim (1974) presented evidence that in decapods with tropical distribution timing of the breeding period may depend on food supply for adult crabs. Gebauer et al. (2007) reported that in Petrolisthes laevigatus from warm-temperate waters of southern Chile ovigerous females were present during 11 months, whereas species with tropical distribution, such as Petrolisthes armatus (Gibbes), usually exhibit continuous reproduction (Oliveira \& Masunari, 1995).

P. elongatus female can have several broods during her lifespan (Jones, 1977). Most females with well developed eggs (i.e. developmental stages 3 and 4) carried a new batch of eggs in their ovaries. Therefore, it is likely that in the Wellington region most females carry at least two broods per reproductive season (Wear, 1965, and own observation). This is consistent with the findings of Scott (1958) in Kaikoura. 
Stillmann (2002, 2004) suggested that the thermal acclimatisation capacity in Petrolisthes spp. involves an evolutionary and/or functional trade-off between the maintenance of plasticity in thermal tolerance and the achievement of extreme tolerance limits. Due to high variation in temperature (and desiccation stress) between high and low tide intertidal organisms generally exhibit adaptations to a wider range of temperatures compared to subtidal species, including specific life history characteristics.

\section{Food conditions}

The aim to estimate spatio-temporal variations in food supply as an important environmental factor influencing reproductive characteristics was not met in the present study. However, various authors (Gardner, 2000, 2002; Gardner \& Thompson, 2001; Helson, 2001; Helson et al., 2007) reported higher food levels (i.e. phytoplankton and particulate organic matter) within Wellington Harbour compared to south coast sites. Despite presumably much higher food supply at HRM, reproductive output per female of equal size is lower compared to ISB. The extremely high population densities found at HRM are likely to lead to high levels of intraspecific competition (see chapter 5) that may outweigh positive effects of high food levels (Donahue, 2004).

\section{Density dependence and carry-over effects}

Density dependent fitness loss to offspring may favour high variability in offspring size (McGinley et al., 1987). If smaller egg size results in lower larval quality and performance that could be carried over into the benthic phase, then fitness (i.e. fecundity) of the adult may be reduced, as well (Williams, 1966; VanNoordwijk \& DeJong, 1986), with further implications on offspring fitness in the following generation. If egg size affects the length of the larval phase, then dispersal potential would be altered, as well. However, Marshall \& Keough (2005) indicated that small offspring may not necessarily exhibit lower performance and survival rates than larger offspring as suggested by many authors (reviewed in Moran \& Emlet, 2001).

\section{Salinity, turbidity, and parasite loads}

Reduced salinity near the Hutt River mouth (Lachowicz, 2005) as well as high fluctuations in salinity (Maxwell, 1956; Hicks, 1973; Booth, 1975) should not 
greatly affect $P$. elongatus because this species can tolerate salinities as low as $50 \%$ seawater over several days (Jones, 1976). However, egg size may be negatively correlated with salinity (Giménez \& Anger, 2001), which could partly explain larger egg sizes and higher egg water content within the Harbour compared to south coast sites. Further, temporarily elevated turbidity after heavy rain, especially at HRM (own observation), may negatively affect filtration efficiency (and therefore energy uptake) of $P$. elongatus if the concentration of suspended sediment exceeds $100 \mathrm{mg} / \mathrm{L}$ (Steger \& Gardner, 2007). Parasite loads were generally negligible and in all samples taken within the scope of this study, only two individual $P$. elongatus females were found with bopyrid infestations.

\section{Larval supply}

All attempts to estimate larval supply at the study sites were unsuccessful. For larvae of the mussels Aulacomya maoriana, Mytilus galloprovincialis and Perna canaliculus, Helson \& Gardner (2004) found that planktonic larval densities were almost an order of magnitude greater within Wellington Harbour than at coastal sites and larval recruitment was also significantly greater at harbour sites. Hence, I speculate that the distributional patterns and settlement rates for $P$. elongatus larvae could be similar, even though fine scale settlement is strongly influenced by settlement cue density (chapter 4 ). The production of higher egg numbers as well as higher individual reproductive output at Cook Strait sites could be a strategy to compensate for the recruitment limitation reported by Helson \& Gardner (2004). Higher larval retention rates, by contrast, that are likely to occur within the harbour (e.g. Wing et al., 1995, Archambault \& Bourget, 1999), combined with high densities of reproducing females at HRM, do not require, or allow, high individual reproductive output.

\section{Reproductive output}

Generally, reproductive output in decapods varies with age (Pianka \& Parker, 1975), body size (MacDiarmid, 1989), temperature (Calow, 1979), and food supply (Calow \& Woolhead, 1977). Even though the per-capita reproductive output appeared to be highest at ISB, the reproductive output per area unit, largely dependent on population density, was on average approximately twice as high at HRM. At BRB, the numbers of eggs per square meter were significantly lower than at the other sites (approx. $2300 \mathrm{eggs} / \mathrm{m}^{2}$ at BRB as opposed to $6000 \mathrm{eggs} / \mathrm{m}^{2}$ 
at ISB and 12,000 eggs $/ \mathrm{m}^{2}$ at HRM). The number of eggs per square meter were positively correlated with density of ovigerous females and with total female density (not shown), but not with absolute density (compare section 2.3.1, Fig. 2.6), mainly due to variable relative densities of juveniles across sites. Because the relationship between number of eggs per square meter and female density appeared to be linear, intraspecific competition does not seem to affect individual fecundity within the sampled density range.

\section{Egg number and size}

Large P. elongatus females (14mm carapace length, CL) may have up to 400 eggs (own unpublished data for Wellington region), 900 eggs (Jones, 1977, for Kaikoura), 1100 eggs (Wear, 1965, for Wellington Harbour) or 1200 eggs (Greenwood, 1965, for Hauraki Gulf). Jones (1977) pointed out that larger ovigerous females from Kaikoura ( $>11.5 \mathrm{~mm} \mathrm{CL}$ ) carried fewer eggs compared to other areas. However, egg numbers in Petrolisthes spp. do not seem to mainly depend on temperature, but rather vary with carapace width $(\mathrm{CW})$, species, and location. Ogawa \& Rocha (1976) report a maximum egg number of 260 eggs for P. armatus from Brazil (11mm CW), whereas Reid \& Corey (1991a) counted 1050 eggs in a female of the same species from Florida $(9.2 \mathrm{~mm} \mathrm{CW})$. While P. haigae females (7mm CW) may have 711eggs (Reid \& Corey, 1991a), $P$. zacae females (7mm CW) carry up to 455eggs (Reid \& Corey, 1991a). For the porcelain crab Pisidia longicornis Tapella et al. (2001) reported egg numbers of $265 \pm 225$ at $4.9 \mathrm{~mm} \mathrm{CW}$ and $600 \pm 373$ at $6.1 \mathrm{~mm} \mathrm{CW}$. Wehrtmann (2005) compared the reproductive ecology of several Porcellanidae species from Costa Rica and Chile and found that species from the tropics had slightly elevated egg numbers but smaller eggs relative to those from temperate waters, resulting in a similar reproductive output in crabs from both locations. This indicates that crabs allocate a similar proportion of their body mass to egg production (Wehrtmann, 2005).

The eggs of $P$. elongatus are large in comparison with other decapods (Gohar \& Al-Kholy, 1957) and the egg number per clutch is correspondingly small (Greenwood, 1965). In the galatheid crab Munida subrugosa sampled in Beagle Channel, Argentinia, freshly released eggs had a mean diameter of $0.69 \mathrm{~mm}$ (Tapella et al., 2001). In the porcelain crab Pisidia longicornis, sampled in 
Galicia, Spain, egg volume ranged between $0.025 \pm 0.005 \mathrm{~mm}^{3}$ and $0.023 \pm 0.005$ $\mathrm{mm}^{3}$, and varied with site and depth (Sampedro et al., 1997).

In reproduction of crustacea egg size is one of the main factors affecting fecundity (Corey, 1991; Steele \& Steele, 1991). Due to resource constraints it is a common phenomenon among decapod species that small females with low egg numbers exhibit larger eggs compared to larger females of the same species (Mason, 1978, but see Huner \& Lindqvist, 1991). Mauchline (1980), Corey (1987), Corey \& Reid (1991) and Reid \& Corey (1991b) reported strong linear relationships between carapace volume and volume of the egg mass for different crab species. López et al. (1997) showed that in Petrolisthes granulosus (Guérin, 1835), numbers of eggs and carapace length were positively linearly correlated. In sexually mature individuals, net growth is determined by resource allocation for adaptive survival and reproduction strategies (Stearns, 1989a). However, egg size might be highly variable among females of the same species with a similar size (Clarke, 1993). Additionally, egg size may vary with site (Mashiko, 1990) as well as across spawning events and can show seasonal fluctuations (Jones \& Simons, 1983; George, 1990). Seasonal variations in egg size have been reported for some amphipods (Skadsheim, 1984) and isopods (Brody \& Lawlor, 1984; Willows, 1987).

Whether egg size is a useful measure of egg quality has been hotly debated for many years (Jaeckle, 1995). For many decapods, the energy content and biochemical composition of eggs, rather than egg size, are highly correlated with larval development (Jaeckle, 1995), including Petrolisthes laevigatus (Lardies \& Wehrtmann, 1995), distributed at the west coast of South America. Consequently, Jaeckle (1995) concluded that comparisons of the mean egg size within populations and species should be completed by the measurement of energy content and biochemical composition for a more solid estimation of the differences in reproductive effort and corresponding resource allocation.

\section{Egg mortality}

When estimating egg mortality by comparison of egg numbers with different developmental stages in similar sized crabs, a significant proportion of observed egg mortality (i.e. net loss) could occur due to a weak attachment of eggs to pleopods and, therefore, their dislodgement over time. Additionally, porcelain 
crabs actively remove moribund eggs and clean their clutches with a pair of modified fifth pereiopods (Förster \& Baeza, 2001). Jones (1977) reported 15\% mean egg mortality for the $P$. elongatus population at Kaikoura, using a similar method, compared to approx. $11 \%$ and $5 \%$ in the present study. The higher egg mortality at BRB relative to the other sites may be partly explainable by higher desiccation stress at elevated temperatures during low tide and potentially by extreme temporary increases of water temperature and salinity in shallow rock pools. Pinheiro \& Fransozo (1995) presented evidence that in the porcellanid Pachycheles haigae Da Costa, 1960, exposure to higher water temperature may result in reduced fecundity.

\section{Sex ratio}

Despite the highest proportion of ovigerous females at ISB, there were more males than females at this site, as opposed to lower male to female ratios at BRB and HRM. Wear (1965) reported a seasonal fluctuation of sex-ratios with higher percentages of female crabs during the reproductive season, whereas in late autumn and during winter months (i.e. between April and June) sex ratios were approximately $1: 1$. This pattern may emerge due to the migration of females into the upper limit of the intertidal zone in order to expose their eggs to longer periods of warmer atmospheric temperatures (Wear, 1965; Lardies et al., 2004). However, Gebauer et al. (2007) did not observe such migrations and argue that seasonal variations in sex ratio in P. leavigatus could arise from recruitment into the benthic population.

\section{Size at maturity}

Differences in female size at sexual maturity $(3.42 \pm 0.09 \mathrm{~mm} \mathrm{CW})$ were nonsignificant across sites. However, there is evidence for a latitudinal gradient, since smaller females $(5.5 \mathrm{~mm}$ carapace length, CL) became ovigerous at Kaikoura (Jones, 1977) compared to Wellington (8.5mm CL) (Wear, 1965) or 7.5mm CL, respectively (own unpublished data), and Hauraki Gulf (8.5mm CL) (Greenwood, 1965). Similar to the findings of many authors describing egg development in Porcellanidae (e.g. Jones, 1977, for P. elongatus, López et al., 1997, for P. granulosus, and Hernaez \& Palma, 2003, for P. granulosus and $P$. tuberculatus), mean egg wet weight increased with progressing egg development with significantly lower values for stages 1 and 2 compared to stages 3 and 4 . 
Hernaez \& Palma (2003) suggested that size increase of eggs may be important especially for Porcellanidae species distributed in the lower intertidal with less desiccation pressure. For the porcellanid Pisidia longicornis Smaldon (1972) reported that females from the sublittoral are smaller and carry more eggs over shorter periods compared to females from the littoral.

\section{Hatching process and larval development}

Instead of 4 developmental stages, Lardies et al. (2004) and Gebauer et al. (2007) classified three categories for egg development in P. laevigatus: I) initial: redpurple colour, homogenous yolk, and no visible eyespot; II) intermediate: between $1 / 4$ and $1 / 2$ of the yolk consumed and slightly visible ocular spot; and III) final: $3 / 4$ of the yolk consumed and a well-developed ocular spot of prezoea. A detailed description of the hatching process in $P$. armatus has been given by Davis (1966). The swimming and feeding larval stages remain in the plankton for several weeks; however, the exact duration of the planktonic phase of Porcellanidae in the natural environment is still unknown, despite being critical in regard to connectivity between metapopulations. Larval development in Porcellanidae (hatching until metamorphosis of last larval stage) under laboratory conditions takes between 15-20 days in Neopisosoma neglectum (Werding \& Müller, 1990), 22-40 days in Petrolisthes laevigatus (Mascetti \& Wehrtmann, 1996), significantly dependent on water temperature (Albornoz \& Wehrtmann, 1996; Mascetti \& Wehrtmann, 1996).

\section{Conclusions}

The significant variation between sites in nearly all reproductive characteristics examined suggests that $P$. elongatus exhibits high phenotypic plasticity. However, the responsible underlying mechanisms driving this pattern may be complex and remain unclear because the aim of this study to identify and characterise the relevant environmental factors has only been met in part. While temperature affects metabolic rate and may be positively correlated with egg mortality, other factors such as food supply, turbidity and salinity may play an important role in shaping site-specific reproductive traits, as well. Intraspecific competition could lead to a decreased fecundity and may be responsible for the lower individual reproductive output at HRM where the highest population densities were recorded (see Chapter 2), presumably due to available shelter space, related to rock size, 
and abundant food. In ISB on the other hand, food levels could be a limiting factor, also affecting the amount of energy allocated to a single egg. This could explain the smaller egg volumes and lower egg dry weights measured at this site. Additionally, the production of higher egg numbers (compared to BRB and HRM) is traded off with smaller egg size.

Future research may shed light on the adaptive value of phenotypic plasticity in $P$. elongatus in the context of the natural fragmentation of its habitat and highly variable environmental conditions. It remains a challenge to explain how much local environmental conditions directly induce phenotypic variations in reproductive traits or, alternatively, how much of the observable individual phenotypic plasticity is related to gene expression. 


\section{References}

Ahmed, M. \& Mustaquim, J., 1974. Population structure of four species of porcellanid crabs (Decapoda: Anomura) occurring on the coast of Karachi. Mar. Biol. 26: 173-182.

Albornoz, L. \& Wehrtmann, I.S., 1996. Aspects of the reproductive biology of Petrolisthes laevigatus (Guerin, 1835) (Decapoda, Anomura, Porcellanidae). Part II: Description of the larval development, including the first crab stage, cultivated under laboratory conditions. Arch. Fish. Mar. Res. 43(2): 137-157.

Anger, K., 2006. Contributions of larval biology to crustacean research: a review. Invert. Reprod. Dev. 49(3): 175-205.

Annala, J.H.; McKoy, J.L.; Booth, J.D. \& Pike, R.B., 1980. Size at the onset of sexual maturity in female Jasus edwardsii (Decapoda: Palinuridae) in New Zealand. J. Mar. Fresh. Res. 14(3): 217-227.

Arar, E.J., 1997. Method 446.0. In vitro determination of chlorophylls a, b, c1 + c2 and pheopigments in marine and freshwater algae by visible spectrophotometry. National Exposure Research Laboratory Office of Research and Development. US Environmental Protection Agency. 22 pp.

Arar, E.J. \& Collins, G.B., 1997. Method 445.0: In vitro determination of chlorophyll a and pheophytin a in marine and freshwater algae by fluorescence. National Exposure Research Laboratory Office of Research and Development. US Environmental Protection Agency. 26 pp.

Archambault, P. \& Bourget, E., 1999. Influence of shoreline configuration on spatial variation of meroplanktonic larvae, recruitment and diversity of benthic subtidal communities. J. Exp. Mar. Biol. Ecol. 238: 161-184.

Badyaev, A.V. \& Ghalambor, C.K., 2001. Evolution of life histories along elevational gradients: trade-off between parental care and fecundity. Ecology 82(10): 2948-2960.

Berrigan, D.M. \& Scheiner, S.M., 2004. Modelling the evolution of phenotypic plasticity. In: Phenotypic plasticity. Functional and conceptual approaches. T.J. DeWitt \& S.M. Scheiner (eds.). Pp. 82-97. Oxford University Press, Oxford, UK.

Booloothian, R.A.; Giese, A.C.; Farmanfarmaian, A. \& Tucker, J., 1959. Reproductive cycles of five west coast crabs. Physiol. Zool. 32: 213-220.

Booth, J.D., 1975. Seasonal and tidal variations in the hydrology of Wellington Harbour. NZ J. Mar. Fresh. Res. 9(3): 333-354.

Brody, M.S. \& Lawlor, L.R., 1984. Adaptive variation in offspring size in the terrestrial isopod Armillidium vulgare. Oecologia 61: 55-59. 
Calow, P., 1979. The cost of reproduction - a physiological approach. Biol. Rev. 54: 23-40.

Calow, P. \& Woolhead, A.S., 1977. The relationship between ration, reproductive effort and age-specific mortality in the evolution of life history strategies some observations on freshwater triclads. J. Anim. Ecol. 46: 765-781.

Castilla, J.C. \& Varas, M.A., 1998. A plankton trap for exposed rocky intertidal shores. Mar. Ecol. Prog. Ser. 175: 299-305.

Castilla, J.C.; Pacheco, C.; Varas, M.; Ortiz, V., 2001. The rocky intertidal plankton trap RIPT2: a modified device. Sarsia $86: 37-41$.

Chown, S.L.; Slabber, S.; McGeoch, M.A.; Janion, C. \& H.P.Leinaas, H.P., 2007. Phenotypic plasticity mediates climate change responses among invasive and indigenous arthropods. Proc. R. Soc. B 274: 2531-2537.

Clarke, A., 1987. Temperature, latitude and reproductive effort. Mar. Ecol. Prog. Ser. 38:89-99.

Clarke, A., 1993. Egg size and egg composition in polar shrimps (Caridea; Decapoda). J. Exp. Mar. Biol. Ecol. 168: 189-203.

Corey, S., 1987. Comparative fecundity of four species of crayfish in Ontario. Crustaceana 52: 276-282.

Corey, S., 1991. Comparative potential reproduction and actual production in several species of North American crayfish. In: Crustacean Egg Production, Vol. 7. A. Wenner \& A. Kuris (eds.) Crustacean Issues, A.A. Balkema, Rotterdam, Neatherlands. Pp. 69-76.

Corey, S \& Reid, D.M., 1991. Comparative fecundity of decapod crustaceans. The fecundity of thirty three species of nine families of caridean shrimps. Crustaceana 60: 270-294.

Darnell, M.Z.; Rittschof, D.; Darnell, K.M. \& McDowell, R.E., 2009. Lifetime reproductive potential of female blue crabs Callinectes sapidus in North Carolina, USA. Mar. Ecol. Prog. Ser. 394: 153-163.

Davis, C.C., 1966. A study of the hatching process in Aquatic invertebrates. XXIII. Eclosion in Petrolisthes armatus (Gibbes) (Anomura, Porcellanidae). Int. Revue Ges. Hydrobiol. 51(5): 791-796.

Dickinson, G.H.; Rittschof, D. \& Latanich, C., 2006. Spawning biology of the blue crab, Callinectes sapidus, in North Carolina. Bull. Mar. Sci. 79: 273-285.

Donahue, M.J., 2004. Size-dependent competition in a gregarious porcelain crab Petrolisthes cinctipes (Anomura: Porcellanidae). Mar. Ecol. Prog. Ser. 267: 219-231. 
Dudycha, J.L. \& Lynch, M., 2005. Conserved ontogeny and allometric scaling of resource acquisition and allocation in the Daphniidae. Int. J. Org. Evol. 59(3): 565-76.

Edgell, T.C. \& Hollander, J., 2011. The evolutionary ecology of European Green Crab, Carcinus maenas, in North America. In: In the wrong place - Alien Marine Crustaceans: Distribution, Biology and Impacts. B.S. Galil; P.F. Clark \& Carlton, J.T. (Eds.). $1^{\text {st }}$ Edition, Springer Series in Invasion Ecology 6. 716pp.

Emparanza, E.J.M. (2007) Patterns of distribution of dominant porcelain crabs (Decapoda: Porcellanidae) under boulders in the intertidal of northern Chile. J. Mar. Biol. Assoc. U.K. 87, 523-531.

Endler, J.A., 1995. Multiple-trait coevolution and environmental gradients in guppies. Trends Ecol. Evol. 10: 22-29.

Felder, D.L.; Martin, J.W. \& Goy, J.W., 1985. Patterns in early postlarval development of decapods. In: Crustacean growth: Larval growth. A.M. Wenner (ed.). Crustacean issues 2. A.A. Balkema, Rotterdam/Boston. Pp 248.

Förster, C. \& Baeza, J.A., 2001. Active brood care in the anomuran crab Petrolisthes violaceus (Decapoda: Anomura: Porcellanidae): grooming of brooded embryos by the fifth pereiopods. J. Crust. Biol. 21(3): 606-615.

Fransozo, A.; Garcia, R.B. \& Mantelatto, F.L.M., 2003. Morphometry and sexual maturity of the tropical hermit crab Calcinus tibicen (Crustacea, Anomura) from Brazil. J. Nat. Hist. 37: 297-304.

Gabriel, W.; Luttbeg, B.; Sih, A. \& Tollroan, R., 2005. Environmental tolerance, heterogeneity, and the evolution of reversible plastic responses. Am. Nat. 166: 339-353.

Gardner, J.P.A., 2000. Where are the mussels on Cook Strait (New Zealand) shores? Low seston quality as a possible factor limiting multi-species distributions. Mar. Ecol. Prog. Ser. 194: 123-132.

Gardner, J.P.A., 2002. Effects of seston variability on the clearance rate and absorption efficiency of the mussels Aulacomya maoriana, Mytilus galloprovincialis and Perna canaliculus from New Zealand. J. Exp. Mar. Biol. Ecol. 268: 83-101.

Gardner, J.P.A. \& Thompson, R.J., 2001. Naturally low seston concentration and the net energy balance of the greenshell mussel, (Perna canaliculus) at Island Bay, Cook Strait, New Zealand. NZ J. Mar. Fresh. Res. 35: 457-468.

Gebauer, P., Paschke, K. \& Moreno, C.A., 2007. Reproductive biology and population parameters of Petrolisthes laevigatus (Anomura: Porcellanidae) in southern Chile: consequences on recruitment. J. Mar. Biol. Assoc. UK 87: 729-734. 
George, S.B., 1990. Population and seasonal differences in egg quality of Arbacia lixula (Echinodermata: Echinoidea): proximate composition of eggs and larval development. J. Exp. Mar. Biol. Ecol. 141: 107-118.

Getz, W.M., 1993. Metaphysiological and evolutionary dynamics of populations exploiting constant and interactive resources - r-K selection revisited. Evol. Ecol. 7, 287-305.

Ghalambor, C.K.; McKay, J.K.; Carroll, S.P. \& Reznick, D.N., 2007. Adaptive versus non-adaptive phenotypic plasticity and the potential for contemporary adaptation in new environments. Funct. Ecol. 21: 394-407

Gillooly, J.F.; Brown, J.H.; West, G.B.; Savage, V.M. \& Charnov, E.L., 2001. Effects of size and temperature on metabolic rate. Science 293(5538): 2248 2251.

Giménez, L. \& Anger, K., 2001. Relationships among egg size, embryonic development, and larval biomass in the estuarine crab Chasmagnathus granulata Dana, 1851. J. Exp. Mar. Biol. Ecol. 260: 241-257.

Gohar, H.A.F. \& Al-Kholy, A.A., 1957. The larvae of some brachyuran Crustacea. Publications of the Marine Biological Station, Al-Ghardaqa, Egypt 9: $145-176$.

Grahame, J. \& Branch, G.M., 1985. reproductive patterns of marine invertebrates. Oceanogr. Mar. Biol. Annu. Rev. 73: 373-398.

Greenwood, J.G., 1965. The larval development of Petrolisthes elongatus (H. Milne Edwards) and Petrolisthes novaezelandiae Filhol (Anomura, Porcellanidae) with notes on breeding. Crustaceana 8: 285-307.

Harding, L. \& Miller, W.D., 2009. Airborne remote sensing of chlorophyll in Chesapeake Bay, USA. In: X. Yang (ed). Remote Sensing and Spatial Information Technologies for Coastal Ecosystem Assessment and Management: Principles and Applications, Springer Berlin Germany. Pp. 115138.

Helmuth, B.; Kingsolver, J.G. \& Carrington, E., 2005. Biophysics, physiological ecology, and climate change: does mechanism matter? Annu. Rev. Physiol. 67: 177-201.

Helson, J.G., 2001. An investigation into the absence of mussels (Perna canaliculus, Aulacomya maoriana \& Mytilus galloprovincialis) from the south coast of Wellington, New Zealand. PhD thesis, Victoria University of Wellington, New Zealand. Pp.183.

Helson, J.G. \& Gardner, J.P.A., 2004. Contrasting patterns of mussel abundance at neighbouring sites: does recruitment limitation explain the absence of mussels on Cook Strait (New Zealand) shores? J. Exp. Mar. Biol. Ecol. 312(2): 285-298. 
Helson, J.G.; Pledger, S. \& Gardner, J.P.A., 2007. Does differential particulate food supply explain the presence of mussels in Wellington Harbour (New Zealand) and their absence on neighbouring Cook Strait shores? Estuar. Coast. Shelf Sci. 72(1-2): 223-234.

Herrera, C.M. 1989. Frugivory and seed dispersal by carnivorous mammals, and associated fruit characteristics, in undisturbed Mediterranean habitats. Oikos 55: 250-262.

Hernaez, P. \& Palma, S., 2003. Fecundidad, volumen del huevo y rendimiento reproductivo de cinco especies de porcelánidos intermareales del norte de Chile (Decapoda, Porcellanidae). Invest. Mar., Valparaiso, 31(2): 35-46.

Hicks, G.R.F., 1973. Combined effects of temperature and salinity on Hemigrapsus edwardsi (Hilgendorf) and H. Crenulatus (Milne Edwards) from Wellington Harbour, New Zealand. J. Exp. Mar. Biol. Ecol. 13: 1-14.

Hines, A.H., 1986. Larval problems and perspectives in life histories in marine invertebrates. Bull. Mar. Sci. 39: 506-525.

Huner, J.V. and Lindqvist, O.V., 1991. Special problems in freshwater crayfish egg production. In: Crustacean Egg Production, Vol. 7. A. Wenner \& A. Kuris (eds.). Crustacean Issues, A.A. Balkema, Rotterdam, Netherlands.Pp.235-246.

Jaeckle, W.B., 1995. Variation in size, energy content and biochemical composition of invertebrate eggs: correlates to the mode of larval development. In: Ecology of marine invertebrate larvae. L. McEdward (ed.). CRC Press, Marine Science Series. Pp. 49-77.

Jillett, J.B., 1971. Zooplankton and hydrology of Hauraki Gulf in New Zealand. N.Z. Oceanogr. Mem. 53: 1-103.

Jones, M.B., 1976. Limiting factors in the distribution of intertidal crabs (Crustacea: Decapoda) in the Avon-Heathcote estuary, Christchurch. NZ J. Mar. Fresh. Res. 10(4): 577-587.

Jones, M.B., 1977. Breeding and seasonal population changes of Petrolisthes elongatus (Crustacea, Decapoda, Anomura) at Kaikoura, NZ J. Royal Soc. 7(3): 259-272.

Jones, M.B. \& Simons, M.J., 1983. Latitudinal variation in reproductive characteristics of a mud crab, Helice crassa (Grapsidae). Bull. Mar. Sci. 33: 656-670.

Kneitel, J.M. \& Chase, J.M., 2004. Trade-offs in community ecology: linking spatial scales and species coexistence. Ecology Letters 7: 69-80.

Lachowicz, L.S., 2005. Population biology of mussels (Aulacomya maoriana, Mytilus galloprovincialis and Perna canaliculus) from rocky intertidal shores in Wellington Harbour, New Zealand. PhD thesis, Victoria University of Wellington, Wellington, New Zealand. Pp. 245. 
Laland, K.N.; Odling-Smee, F.J. \& Feldman, M.W., 1999. Evolutionary consequences of niche construction and their implications for ecology. Proc. Natl. Acad. Sci. 96: 10242-10247.

Lardies, M.A.: Rojas. J.M. \& Wehrtmann, I.S., 2004. Breeding biology and population structure of the intertidal crab Petrolisthes laevigatus (Anomura: Porcellanidae) in central-southern Chile. J. Nat. Hist. 38: 375-388.

Lardies, M.A. \& Wehrtmann, I.S., 1995. Aspects of reproductive biology of Petrolisthes laevigatus (Guerin, 1835) (Decapoda: Anomura: Porcellanidae) I. Reproductive output and chemical composition of eggs during the embryonic development. Instituto de Biología marina y Instituto de Zoología, Universidad Austral de Chile. Pp18.

López, L.; Jeri, T.; González, C. \& Rodriguez, S., 1997. Fecundidad y esfuerzo reproductivo de Petrolisthes granulosus (Guérin, 1835) en Iquique, Chile (Decapoda, Anomura, Porcellanidae). Invest. Mar., Valparaiso, 25: 159-165.

MacDiarmid, A.B., 1989. Size at onset of maturity and size dependent reproductive output of female and male spiny lobsters Jasus edwardsii (Hutton) (Decapoda, Palinuridae) in northern New Zealand. J. Exp. Mar. Biol. Ecol. 127: 229-243.

Marshall, D.J. \& Keough, M.J., 2005. Offspring size effects in the marine environment: a field test for a colonial invertebrate. Austral Ecology 30: 275280.

Mascetti, P. \& Wehrtmann, I.S., 1996. Aspects of the reproductive biology of Petrolisthes laevigatus (Guerin, 1835) (Decapoda, Anomura, Porcellanidae). Part III: Effect of starvation and different types of diet on larval development under laboratory conditions. Arch. Fish. Mar. Res. 43(2): 159-170.

Mashiko, K., 1990. Diversified egg and clutch sizes among local populations of the freshwater prawn Macrobrachium nipponense (de Haan). J. Crustac. Biol. 10: 306-314.

Mason, J.C., 1978. Significance of egg size in the freshwater crayfish, Pacifastacus leniusculus (Dana). Freshwater Crayfish 4, 83-92.

Mauchline, J., 1980. The biology of mysids and euphausiids. Part I. The biology of mysids. Adv. Mar. Biol. 18: 1-369.

Maxwell, B.E., 1956. Hydrobiological observations for Wellington Harbour. Transactions Royal Soc. NZ 83(3): 493-503.

McGinley, M.A.; Temme, D.H. \& Geber, M.A., 1987. Parental investment in offspring in variable environments: theoretical and empirical considerations. Am. Nat. 130(3): 370-398. 
Menge, B.A.; Berlow, E.L.; Blanchette, C.A.; Navarrete; S.A.; Yamada, S.B., 1994. The keystone species concept: variation in interaction strength in a rocky intertidal habitat. Ecol. Monogr. 64: 249-286.

Menge, B.A.; Daley, B.A.; Lubchenco, J.; Sanford, E.; Dahlhoff, E.; Halpin, P.M.; Hudson, G.; Burnaford, J.L., 1999. Top-down and bottom-up regulation of New Zealand rocky intertidal communities. Ecol. Monogr. 69: 297-330.

Monaco, C.J.; Brokordt, K.B. \& Gaymer, C.F., 2010. Latitudinal thermal gradient effect on the cost of living of the intertidal porcelain crab Petrolisthes granulosus. Aquatic Biol. 9: 23-33.

Moran, A.L. \& Emlet, R.B., 2001. Offspring size and performance in variable environments: field studies on a marine snail. Ecology 82: 1597-1612.

Morris, D.W., 1987. Optimal allocation of parental investment. Oikos 49: 332-339.

Nelson, K.; Hedgecock, D. \& Borgeson, W., 1988. Factors influencing egg extrusion in the American lobster (Homarus americanus). Can. J. Fish. Aquat. Sci. 45: 797-804.

Niewiarowski, P.H.; Angilletta, M.J. \& Leache, A.D., 2004. Phylogenetic comparative analysis of life-history variation among populations of the lizard Sceloporus undulatus: an example and prognosis. Int. J. Org. Evol. 58(3): 619-33.

Oda, S.; Hanazato, T. \& Fujii, K., 2007. Change in phenotypic plasticity of a morphological defence in Daphnia galeata (Crustacea: Cladocera) in a selection experiment. J. Limnol. 66(2): 142-152.

Ogawa, E.F. \& Rocha, C.A.S., 1976. Sobre a fecundidade de crustaceos decapodos marinhos do Estado do Ceará, Brasil. Arq. Cien. Mar. 16: 101-104.

Oliveira, E. \& Masunari, S., 1995. Estrutura populacional de Petrolisthes armatus (Gibbes) (Decapoda, Anomura, Porcellanidae) da Ilha do Farol, Martinhos, Paraná, Brasil. Revta. Brasil. Zool. 12(2): 355-371.

Palmer, A.R. \& Strathmann, R.R., 1981. Scale of dispersal in varying environments and its implications for life histories of marine invertebrates. Oecologia 48: 308-318.

Parry, G.D., 1981. The meaning of r- and K-selection. Oecologia 48: 260-264.

Partridge, L. \& Harvey, P.H., 1988. The ecological context of life history evolution. Science 241: 1449-1455.

Phillips, N.E. \& Gaines, S.D., 2001. Spatial and temporal variability in size at settlement of intertidal mytilid mussels from around Pt. Conception, California. Invertebrate Reproduction and Development 41(1-3): 171-177. 
Pianka, E.R., 1970. On r and K selection. Am. Nat. 104, 592-597.

Pianka, E.R., 1972. $\mathrm{r}$ and K selection or b and d selection? Am. Nat. 106 (951), 581-588.

Pinheiro, M.A. \& Fransozo, A., 1995. Fecundidade de Pachycheles haigae Rodrigues Da Costa, 1960 (Crustacea, Anomura, Porcellanidae) em Ubatuba, Brasil. Rev. Brasil. Biol. 55(4): 623-631.

Reid, D.M. \& Corey, S., 1991a. Comparative fecundity of decapod crustaceans, II.The fecundity of fifteen species of anomuran and brachyuran crabs. Crustaceana 61(3): 175-189.

Reid, D.M. \& Corey, S., 1991b. Comparative fecundity of decapod crustaceans, III. The fecundity of fifty-three species of Decapoda from tropical, subtropical, and boreal waters. Crustaceana 61(3): 308-316.

Reznick, D.A.; Bryga, H. \& Endler, J.A.; 1990. Experimentally induced life history evolution in a natural population. Nature 346: 357-359.

Reznick, D.N. \& Endler, J.A., 1982. The impact of predation on life history evolution in Trindadian guppies (Poecilia reticulata). Evolution 36: 160-177.

Rilov, G. \& Schiel, D.R., 2006. Seascape-dependent subtidal-intertidal trophic linkages. Ecology 87(3): 731-744.

Rivadeneira, M.M.; Hernáez, P.; Baeza, J.A.; Boltaña, S.; Cifuentes, M.; Correa, C.; Cuevas, A.; Valle, E. del; Hinojosa, I.; Ulrich, N.; Valdivia, N.; Vásquez, N.; Zander, A. \& Thiel, M., 2010. Testing the abundant-center hypothesis using intertidal porcelain crabs along the Chilean coast: linking abundance and distribution to life history variation. J. Biogeogr. 37(3): 486-498.

Roff, D.A., 1992. The evolution of life histories; theory and analysis. Chapman \& Hall, New York.

Rule, M.J. \& Smith, S.D.A., 2005. Spatial variation in recruitment to artificial substrata. Mar. Ecol. Prog. Ser. 290: 67-78.

Salam, M.A. \& Ross, L.G., 2000. Optimising site selection for development of shrimp (Penaeus monodon) and mud crab (Scylla serrata) culture in Southwestern Bangladesh. GIS 2000 Conference Proceedings, March 13-16, Toronto, Canada. CD Proceedings.

Salam, M.A.; Rossa, L.G. \& Beveridge, C.M.M., 2003. A comparison of development opportunities for crab and shrimp aquaculture in southwestern Bangladesh, using GIS modelling. Aquaculture 220: 477-494.

Sampedro, M.P.; Fernández, L.; Freire, J.; González-Gurriarán, E., 1997. Fecundity and Reproductive Output of Pisidia longicornis (Decapoda, Anomura) in the Ría de Arousa (Galicia, NW Spain). Crustaceana 70(1): 95-110. 
Scheltema, R.S., 1998. Planktonic and non-planktonic development among prosobranch gastropods and its relationship to the geographic range of species. In: Reproduction, Genetics and Distributions of Marine Organisms. J.S. Ryland \& P.A. Tyler, (eds.) Olsen \& Olsen, Fredensborg, Denmark. 183-188pp.

Scott, M.S., 1958. Studies on the false crab, Petrolisthes elongatus Milne Edwards. M.Sc. thesis, Canterbury University, Christchurch, NZ.

Skadsheim, A., 1984. Coexistence and reproductive adaptations of amphipods: the role of environmental heterogeneity. Oikos 43: 94-103.

Stearns, S.C., 1977. Evolution of life-history traits - critique of theory and a review of data. Ann. Rev. Ecol. System. 8: 145-171.

Stearns, S.C., 1989a. Trade-offs in life-history evolution. Funct. Ecol. 3: 259-268.

Stearns, S.C. 1989b. The evolutionary sigificance of phenotypic plasticity. Bioscience 39: 436-445.

Stearns, S.C., 1992. The evolution of life histories. Oxford University Press, Oxford, U.K. 249 pp.

Steele, D.H. \& Steele, V.J., 1991. Morphological and environmental restraints on egg production in amphipods. In: Crustacean Egg Production, Vol. 7. A. Wenner \& A. Kuris (eds.). Crustacean Issues, A.A. Balkema, Rotterdam, Netherlands. Pp. 157-170.

Steger, K.K. \& Gardner, J.P.A., 2007. The effects of variable suspended sediment load on the ecophysiology of the porcelain crab Petrolisthes elongatus (Milne Edwards 1837). J. Exp. Mar. Biol. Ecol. 344: 181-192.

Stillman, J.H., 2002. Causes and consequences of thermal tolerance limits in rocky intertidal porcelain crabs, genus Petrolisthes. Integ. Comp. Biol. 42: 790-796.

Stillman, J.H., 2003. Acclimation capacity underlies susceptibility to climate change. Science 301: 65.

Stillman, J.H., 2004. A comparative analysis of plasticity of thermal limits in porcellain crabs across latitudinal and intertidal zone clines. Internat. Congr. Ser. 1275: 267-274.

Stillman, J.H. \& Somero, G.N., 2000. A comparative analysis of the upper thermal tolerance limits of eastern Pacific porcelain crabs, genus Petrolisthes: influences of latitude, vertical zonation, acclimation, and phylogeny. Physiol. Biochem. Zool. 73, 200-208.

Strathmann, R.R., 1986. What controls the type of larval development? Summary statement for the evolution session. Bull. Mar. Sci. 39: 616-622. 
Tapella, F.; Lovrich, G.A.; Romero, M.C.; Thatje, S., 2002. Reproductive biology of the crab Munida subrugosa (Decapoda: Anomura: Galatheidae) in the Beagle Channel, Argentina. J. Mar. Biol. Ass. U.K. 82: 589-595.

Thorson, G., 1964. Light as an ecological factor in the dispersal and settlement of larvae of marine bottom invertebrates. Ophelia 1: 167-208.

Townsend, C.R. \& Calow, P., 1981. Physiological ecology. An evolutionary approach to resource use. Blackwell Sci., Oxford, NY. Pp. 393.

VanNoordwijk, A.J. \& DeJong, G., 1986. Acquisition and allocation of resources: their influence on variation in life history tactics. Am. Nat. 128: 137-142.

Via, S.; Gomulkiewicz, R.; De Jong, G.; Scheiner, S.M.; Schlichting, C.D. \& Van Tienderen, P.H., 1995. Adaptive phenotypic plasticity: consensus and controversy. Trends Ecol. Evol. 10(5): 212-217.

Walther, G.-R.; Post, E.; Convey, P.; Menzel, A.; Parmesan, C.; Beebee, T.J.C.; Fromentin, J.-M.; Hoegh-Guldberg, O. \& Bairlein, F., 2002. Ecological responses to recent climate change. Nature 416: 389-395.

Wear, R., 1964. Larvae of Petrolisthes elongatus (Milne Edwards, 1837). (Crustacea, Decapoda, Anomura). Trans. Royal Soc. NZ Zool. 5(2): 39-53.

Wear, R.G., 1965. Breeding cycles and pre-zoea larva of Petrolisthes elongatus (Milne Edwards, 1837). (Crustacea, Decapoda). Trans. Royal Soc. NZ Zool. 5(13): 169-175.

Wehrtmann, I.S., 2005. Egg production in porcellanid crabs: a comparison between Chile and Costa Rica, Central America. Ber. Polar- und Meeresforsch. 507: 103-105.

Wehrtmann, I.S.; Miranda, I.; Lizana-Moreno, C.A.; Hernáez, P.; BarrantesEchandi, V. \& Mantelatto, F.L., 2012. Reproductive plasticity in Petrolisthes armatus (Anomura, Porcellanidae): a comparison between a Pacific and an Atlantic population. Helgol. Mar. Res. 66(1): 87-96.

Werding, B. \& Müller, H.-G., 1990. Larval development of Neopisosoma neglectum Werding, 1986 (Decapoda: Anomura: Porcellanidae) under laboratory conditions. Helgoländer Meeresunters. 44: 363-374.

West-Eberhard, M.J., 2003. Developmental plasticity and evolution. New York, NY: Oxford University Press.

Williams, G.C., 1966. Natural selection, the cost of reproduction and a refinement of Lack's principle. Am. Nat. 100: 687-690.

Willows, R. I., 1987. Intra pulation variation in the reproductive characteristics of two populations of Ligia oceanica (Crustacea: Oniscidea). J. Animal Ecol. 56: 331-340. 
Wing, S.R.; Botsford, L.W.; Largier, J.L. \& Morgan, L.E., 1995. Spatial structure of relaxation events and crab settlement in the northern California upwelling system. Mar. Ecol. Prog. Ser. 128: 199-211.

Xiao, Y. \& Kumar, M., 2003. Sex ratio, and probability of sexualmaturity of females at size, of the blue swimmer crab, Portunus pelagicus Linneaus, off southern Australia. Fisheries Research 68 (1-3): 271-282.

Yan, Y.; Chan, B.K.K.; Williams, G.A., 2004. An improved and simplefied trap for quantifying the distribution and supply of planktonic larvae to rocky shores. J. Plankt. Res. 26(2): 247-253.

Yund, P.O.; Gaines, S.D.; Bertness, M.D., 1991. Cylindrical tube traps for larval sampling. Limnol. Oceanogr., 36: 1167-1177.

Zera, A.J. \& Harshman, L.G., 2001. Physiology of life history trade-offs in animals Ann. Rev. Ecol. System. 32: 95-106. 


\section{Chapter 4}

\section{Larval response to settlement cues}

\subsection{Introduction}

The importance of larval settlement patterns and the effects of variable larval recruitment on community development and structure in marine systems are widely acknowledged (e.g. Raimondi, 1988b, 1991; Menge, 1991; Gaines \& Bertness, 1993). While larval supply at a given site is determined by the number of larvae in the offshore "larval pool" and larval transport, the factors controlling settlement on a smaller scale closer to shore also include larval behaviour (i.e. response to settlement cues), micro-hydrodynamic processes, and substrate availability (Wethey, 1983; Raimondi, 1990; Pineda, 2000). While approaching the shoreline and substratum, density-dependent factors as well as larval behaviour increasingly affect local settlement rate, survival, and the success of finding a suitable habitat.

For many species settlement occurs non-randomly and the selectivity of larvae is associated with a range of different settlement cues, some of which are speciesspecific (for reviews, see Pawlik, 1992; Rodriguez et al., 1993; Rittschof et al., 1998; Hadfield \& Paul, 2001; Hay, 2009). When larvae become capable of responding to settlement cues, they are referred to as "competent" (Crisp, 1984). The zoea and megalopa stages of decapods generally correspond to the developmental (pre-competent) and searching (competent) phases of invertebrate larvae (Meadows \& Campbell, 1972; Sulkin \& Van Heukelum, 1982); the megalopa is transitional between the planktonic and benthic phase, in terms of both behaviour and morphology. After settlement, megalopae and juveniles may be subject to differential mortality or migration. Consequently, not only differential larval supply and settlement, but also post-settlement processes alter recruitment patterns and the often patchily distributed adult population (Keough \& Downes, 1982; Osmann et al., 1989). 
Settling larvae often respond to chemical cues emitted from substratum and coexisting species (e.g. Crisp, 1974; Welch et al., 1997; Forward et al., 2003; Hadfield \& Koehl, 2004), prey species (e.g. Barnes \& Gonor, 1973; Morse et al., 1979; Morse \& Morse, 1984; Salierno et al., 2003), hosts (Boone et al., 2003), as well as conspecific adults (e.g. Knight-Jones 1953; Pawlik, 1986; Raimondi, 1988b, 1991; Boudreau et al., 1993; Toonen \& Pawlik, 2001a, b; Zito-Livingston, \& Childress, 2009, but see Lecchini et al., 2010). Cues originating from competitors and predators tend to repel competent larvae ("kairomones") (Johnson \& Strathmann, 1989; Boudreau et al., 1993; Anger, 2006) but may work as settlement inducers if those cues are associated with enhanced fitness in the benthos and if the ability of dispersers to detect low-quality habitats is increased (Stamps \& Krishnan, 2005).

Additionally, settlement preferences have been demonstrated for a variety of substratum characteristics such as surface texture (e.g. Meadows \& Campbell, 1972; Keough \& Downes, 1982; Raimondi, 1988a; Keough, 1986; Pawlik et al., 1991; Hills \& Thomason, 1996; Walters \& Wethey, 1996; Berntsson et al., 2004), surface orientation (Gotelli, 1987), grain size of sediments (Gray, 1974), sediment cover (Hodgson, 1990), microbial films (e.g. Morse \& Morse, 1984; Le Tourneux \& Bourget, 1988; Todd, 1998; Tamburri, et al., 1992; Keough \& Raimondi, 1995), chemical cues from seagrass (Montfrans et al., 2003), macroalgae (Botero \& Atema, 1982; Krug \& Manzi, 1999; Swanson et al., 2007), water flow next to the substratum (Crisp, 1984; Wethey et al., 1988), sound of breaking waves (Phillips \& Penrose 1985; Jeffs et al. 2003; Montgomery et al., 2006), and visual cues (Thorson, 1964; Botero \& Atema, 1982; Forward \& Rittschof, 1994; Lecchini et al., 2010). For most species, however, biological and chemical characteristics of the substratum appear to be more important than physical properties (e.g. LeTourneux \& Bourget, 1988).

Specific substratum selection due to chemical settlement cues or surface properties may lead to aggregated ("gregarious") settlement and can determine recruitment patterns (Gaines \& Roughgarden, 1985; Minchinton \& Scheibling, 1991; Hills \& Thomason, 1996; Vermeij, 2005). It has been proposed that larvae respond to these cues differently, dependent on daytime: While moving offshore during the day to avoid reef-associated predators, onshore movement and 
settlement predominantly occurs at night (Leis \& Carson-Ewart, 1998). In many cases, larvae settle preferentially on substrata that provide high chances of survival (Knight-Jones et al., 1971; Young \& Chia, 1984; Davis, 1987; Jensen, 1989).

Conspecific attraction, the preferential settlement in habitat patches with individuals of the same species relative to equivalent patches without (Pawlik, 1992; Donahue, 2006), is common among marine invertebrates (reviewed in Burke, 1986; Pawlik, 1992; Rodriguez et al., 1993; Kingsford et al., 2002). This strategy, combined with a complex lifecycle including a pelagic, planktonic larval phase, has been viewed as an adaptation of benthic marine invertebrates to a fragmented distribution of adult habitats and metapopulations that facilitates or enhances dispersal, connectivity and gene-flow (e.g. Sastry, 1983; Young, 1990; Pawlik, 1992; Anger, 2006; Pineda et al., 2006; Cowen \& Sponaugle, 2009). Settlement cues do not only indicate the presence of conspecifics, but also the location of suitable habitat patches, as these patches have proved suitable for those individuals inhabiting them. The obvious benefit of this strategy is increased fitness, e.g. due to conspecifics that may provide benefits directly via positive density dependence (i.e. Allee effects) (Donahue, 2006), such as lower per capita predation rate when surrounded by conspecifics (Bertness \& Grosholz 1985; Jensen \& Armstrong 1991; Ray \& Stoner 1994), higher post-settlement survival (Welch et al., 1997), decreased environmental stress near conspecifics (Bertness 1989), and/or enhanced reproductive success after sexual maturity due to increased access to mates (Toonen \& Pawlik, 1994). On the other hand, settlement into occupied habitat patches results in local populations of very high density (Jensen, 1989; Donahue, 2004), accompanied by costs of density dependence such as higher conspecific competition, e.g. for food (Crisp, 1979; Donahue, 2004) and/or space (Minchinton \& Scheibling, 1993). In mobile organisms, the immediate costs of aggregation may be mitigated by migration. Juveniles and adults of $P$. elongatus, however, remain in high-density aggregations. Generally, post-settlement mortality may be particularly high if settlement rates are high (Hurlbut, 1991). Due to the prevalence of gregariousness in marine hard substratum communities it can be assumed that fitness gains in gregariously settling species must outweigh the costs of higher conspecific densities (Pawlik, 1992; Donahue, 2006). 
Chemical cues from habitats and conspecifics have been shown to induce the metamorphosis of crustacean postlarvae (e.g., Gebauer et al., 1997; Gebauer et al., 2003b; O’Connor, 2007; Krimsby \& Epifanio, 2008). In the absence of such cues, crab megalopae are capable of delaying metamorphosis until a suitable signal is detected (Cole \& Knight-Jones, 1939; Thorson, 1950; Scheltema, 1961; Jensen \& Morse, 1984; Gebauer et al., 2003). This metamorphic plasticity increases their time spent in the plankton and thus the chance of finding a suitable habitat (for reviews, see Pechenik, 1990, 1999; Pawlik, 1992). Even though several authors (e.g. Scheltema, 1974; Butman, 1987; Fenaux \& Pedrotti, 1988) reported that metamorphosis may occur before reaching the benthos, these findings are comparatively rare (Rodriguez et al., 1993). Generally, larvae of different species have different degrees of dependence on and specificity to attractants that trigger their settlement and metamorphosis (Morse 1990).

In this chapter I investigate the conspecific attraction in $P$. elongatus between larvae and adults of both sexes, both in the field and under laboratory conditions. Specifically, I examine whether these cues influence swimming direction in a single option choice chamber and settlement preference (i.e. settlement rate in presence or absence of adult conspecifics) in the field. Additionally, I test a range of potential non-conspecific settlement cues, such as biofilms, crustose coralline red algae and two sympatric species of crabs. To examine whether crabs lose their ability to detect waterborne conspecific cues with metamorphosis (i.e. moult from swimming megalopa larva to benthic juvenile stage) I observe the behavioural response of juveniles of two different size classes, using the same experimental design and setup as for larvae. Generally, the response to settlement cues can have profound implications on the spatial distribution and demography of a benthic population, especially if individual migration rates are low. 


\subsection{Materials and Methods}

4.2.1 Attraction effects on larvae and juveniles caused by conspecific adults and other potential sources of settlement cues in a laboratory experiment

A small and shallow seawater tank $(28 \mathrm{~cm} \times 10 \mathrm{~cm} \times 3 \mathrm{~cm})$ made of grey, nontransparent PVC sheets joined together with a watertight sealant, served as singleoption choice chamber (Fig. 4.1). Divided into two compartments by a finemeshed transparent nylon gauze with a mesh size of $0.5 \mathrm{~mm}$ by $0.5 \mathrm{~mm}$, a potential source of a waterborne cue (e.g. conspecific adults) could be placed into the smaller section of the choice chamber $(3 \mathrm{~cm} \times 10 \mathrm{~cm} \times 3 \mathrm{~cm})$, a larva into the larger one. The gauze prevented the larvae from moving into the "source" compartment and adult individuals from moving into the "observation" compartment. The observation compartment was further subdivided into 10 numbered sections by thin black lines drawn on the bottom of the chamber every $2.5 \mathrm{~cm}$. The section adjacent to the "source" chamber was assigned a " +5 "; the one at the opposite end a "-5" and the line exactly in between (i.e. the point of release of the larvae) was labelled " 0 ". In contrast to the typical setup of such experiments, such as wind tunnels used to test insect responses to pheromones (e.g. Stelinski et al., 2004) or laminar flow choice chamber experiments with marine invertebrate larvae (e.g. Boudreau et al., 1993; Diaz et al., 2003) I used a still water choice chamber (compare Snelgrove et al., 1998) because flow is bidirectional and turbulent in coastal environments due to wave action and is highly variable. By recording the swimming behaviour of the larvae, which can be directed or undirected, the hypothesis of an attraction effect on larvae caused by conspecific adults or other potential sources of waterborne cues was examined.

Competent $P$. elongatus larvae (megalopae) as well as juveniles were tested in the experiment. The animals were collected from the field (an intertidal cobble beach directly in front of VUCEL, 41 $\left.20^{\prime} 54.30^{\prime \prime} \mathrm{S}, 174^{\circ} 45^{\prime} 53.20^{\prime \prime} \mathrm{E}\right)$. At low tide near the low water mark boulders were turned over quickly and larvae and juveniles were washed into a bucket with seawater. All animals were used for the experiment immediately after sampling within 5 hours. The developmental stage of the specimens was verified with a dissecting microscope at $25 \mathrm{x}$ magnification. Megalopae differ from juveniles in that they still have four pairs of fully functional pleopods, arising from the ventral side of the second, third, fourth and 
fifth abdominal segment (see Wear, 1965a), enabling the larvae to swim efficiently. Even though the pleopods are degenerated after the moult into the first postlarval stage, juvenile and adult porcelain crabs are still capable of swimming using their abdominal flap as a paddle.

Conspecific males and females as well as Heterozius rotundifrons of both sexes were collected in the mid and upper intertidal (for a species description see McLay, 1988) at the same site as the P. elongatus larvae and juveniles. Larger boulders were lifted up and put aside; the animals were then gathered by hand and put into buckets half-filled with seawater. At the lab, the adults of both species were transferred into separate tanks with filtered seawater (FSW; $10 \mu \mathrm{m}$ mesh size) and kept for at least 30min. Before any individuals were chosen for the experiment they were sexed, measured with a digital calliper (carapace width, CW), and weighed on an electronic balance (wet weight, WW, see table 4.1) after drying off excess water on a paper tissue. Disposable gloves were worn at all times.

Pebbles of a defined size (see table 4.1) were also collected in the intertidal and upper subtidal directly in front of VUCEL. Two types of pebbles were selected: 1) those entirely covered with green micro algae and diatoms (which was later confirmed with a dissecting microscope) and 2) those that had at least $60 \%$ crust cover. All pebbles were measured with a digital calliper in all three dimensions. Using the formula for the surface area of ellipsoids (see below), the area of the biofilm and/or algal cover was calculated for each pebble.

Surface area ellipsoid $\quad \approx 4 \pi\left(\frac{a^{p} b^{p}+a^{p} c^{p}+b^{p} c^{p}}{3}\right)^{1 / p}$

Where $p \approx 1.6075$ yields a relative error of at most $1.061 \%$ (Knud Thomsen's formula)

Thirty runs were conducted per treatment, with individuals and water replaced each time. After filling the choice chamber with 200ml filtered seawater (FSW; $10 \mu \mathrm{m}$ mesh size), a gradient of dissolved cues was allowed to build up for $20 \mathrm{~min}$. With a custom made Pasteur pipette a larva was then placed exactly into the 
middle of the "observation" compartment (on the middle of line "0"), and after a calming time of $20 \mathrm{sec}$. the $4 \mathrm{~min}$. observation was started. Every $4 \mathrm{sec}$, the position of the larva (i.e. the section number) was recorded. Between runs larvae were removed, the choice chamber was thoroughly rinsed, first with tap water, then with FSW. Finally it was filled again with FSW and a new source of waterborne cues was placed into the "source" compartment. To avoid systematic errors due to a potential effect of negative phototaxis, the chamber was rotated clockwise for $22.5^{\circ}$ to $45^{\circ}$ after each run. Between different treatments, the choice chamber was submerged in seawater in a ventilated flow-through tank for at least $12 \mathrm{~h}$ to remove any remaining traces of chemical cues from the previous treatment.

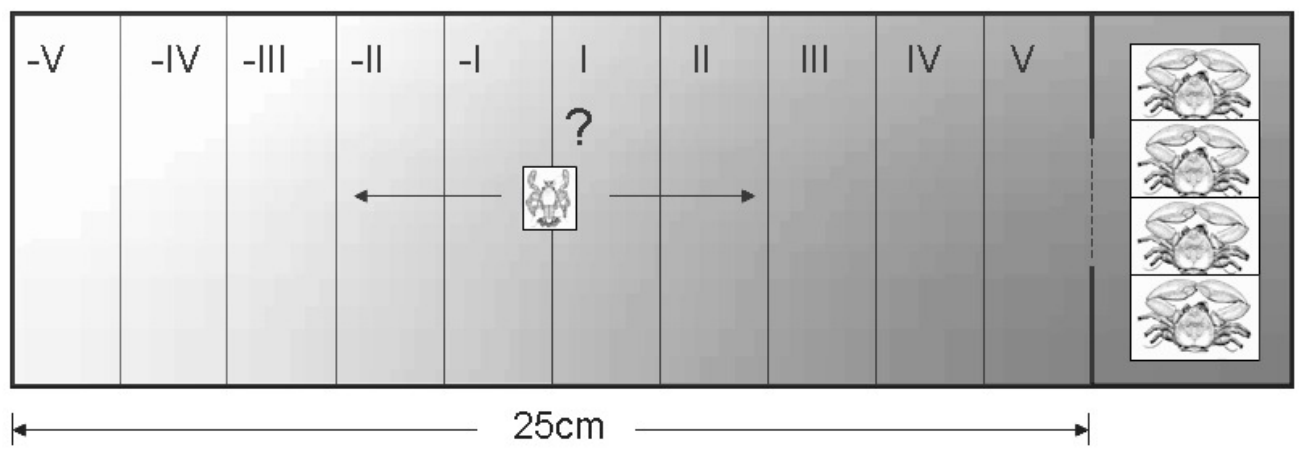

Fig. 4.1: Single-option choice chamber. The small compartment on the right served as "source" compartment, containing the tested potential source of a waterborne settlement cue, e.g. conspecific adults. The larva was placed into the middle of the larger compartment and its swimming direction within the concentration gradient recorded. Nylon gauze prevented the animals from moving into the adjacent compartment.

For each treatment, the probable location of the larva or juvenile, respectively, at the end of the observation $\left(\mathrm{t}_{240}\right)$ was calculated as the mean value of the recorded locations in all 30 runs. These were then plotted according to the subdivision of the choice chamber (X-axis), where " 0 " is the point of release of larvae at $t_{0}$, " 5 ", is directly adjacent to the compartment containing the source of a potential settlement cue, and "-5" marks the opposite side of the choice chamber (Figs.4.4 $\& 4.5$ ), combined with the standard deviation. Additionally, the mean values for all time points recorded were plotted over time (Y-axis) and according to the subdivision of the choice chamber (X-axis) (see Appendix $4.1 \& 4.2$ ). 


\title{
1) Pre-settlement behaviour
}

\section{a) Conspecific waterborne cues:}

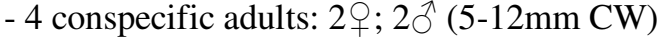 \\ : : $8.44 \pm 1.32 \mathrm{~mm} \mathrm{CW} ; 589.07 \pm 279.71 \mathrm{mg} \mathrm{WW}$ \\ స: $8.61 \pm 1.63 \mathrm{~mm} \mathrm{CW} ; 732.90 \pm 470.51 \mathrm{mg} \mathrm{WW}$ \\ - 4 conspecific adults: 4 ㅇ $(5-12 \mathrm{~mm} \mathrm{CW})$ \\ ㅇ: $8.60 \pm 1.35 \mathrm{~mm} \mathrm{CW} ; 606.69 \pm 278.77 \mathrm{mg} \mathrm{WW}$ \\ - 4 conspecific adults: $4 \widehat{\jmath}(5-12 \mathrm{~mm} \mathrm{CW})$ \\ ô: $8.76 \pm 1.64 \mathrm{~mm} \mathrm{CW} ; 761.73 \pm 479.51 \mathrm{mg} \mathrm{WW}$
}

\section{b) Potential non-conspecific settlement cues:}

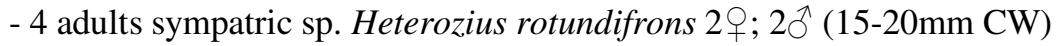

우: $17.87 \pm 1.71 \mathrm{~mm} \mathrm{CW} ; 1563.23 \pm 439.22 \mathrm{mg} \mathrm{WW}$

ô: $16.34 \pm 1.86 \mathrm{~mm} \mathrm{CW} ; 1518.63 \pm 693.67 \mathrm{mg} \mathrm{WW}$

- 4 pebbles with biofilm (max. 30mm length)

Mean total surface area of all pebbles used per run: $162.38 \pm 42.28 \mathrm{~cm}^{2}$

- 4 pebbles with biofilm and coralline crust (max. 30mm length, $>60 \%$ crust cover) Mean total surface area of all pebbles used per run: $126.43 \pm 49.81 \mathrm{~cm}^{2}$

\section{2) Post-settlement behaviour:}

- 10 conspecific larvae (megalopae, $2.09 \pm 0.25 \mathrm{~mm} \mathrm{CW}$ ) on larvae

- 4 conspecific adults: 2 ; $2 \widehat{\bigcirc}(5-12 \mathrm{~mm} \mathrm{CW})$ on juveniles size cl. $1:(3.0-5.0 \mathrm{~mm} \mathrm{CW})$ ㅇ: $8.71 \pm 1.43 \mathrm{~mm} \mathrm{CW} ; 637.51 \pm 313.38 \mathrm{mg} \mathrm{WW}$

o: $8.47 \pm 1.54 \mathrm{~mm} \mathrm{CW} ; 684.71 \pm 427.95 \mathrm{mg} \mathrm{WW}$

Juveniles: $2.37 \pm 0.36 \mathrm{~mm}^{*} \mathrm{CW}$

- 4 conspecific adults: 2 ; $; 2 \widehat{\bigcirc}(5-12 \mathrm{~mm} \mathrm{CW})$ on juveniles size cl. $2:(5.0-7.0 \mathrm{~mm} \mathrm{CW})$ : : $8.48 \pm 1.27 \mathrm{~mm} \mathrm{CW} ; 550.43 \pm 236.43 \mathrm{mg} \mathrm{WW}$

万: $8.23 \pm 1.32 \mathrm{~mm} \mathrm{CW} ; 589.09 \pm 465.27 \mathrm{mg} \mathrm{WW}$

Juveniles: $3.58 \pm 0.40 \mathrm{~mm} \mathrm{CW}$

- Control 1 empty chamber vs. larvae

- Control 2 empty chamber vs. juveniles

Table 4.1: Treatments used in the single-option choice chamber experiment, subdivided in cues relevant in pre- and post settlement behaviour. Settlement could be affected by a) conspecific cues and b) non-conspecific cues. The error is given as standard deviation. 
The sets of responses to each chemical cue (i.e. the final position values) were subdivided in positive, neutral and negative response: A positive response corresponds to a position of the larva or juvenile directly adjacent to the source compartment of the choice chamber (section +5 ), and a negative response, when the larva or the juvenile had moved to the opposite end of the choice chamber (section -5). All positions in between (sections +4 to -4 ) were labelled as neutral response. The percent distribution of responses of larvae and juveniles at the end of the observation $\left(\mathrm{t}_{240}\right)$ was calculated for each treatment (Fig. 4.6). Additionally, the durations larvae spent in all sections of the choice chamber were calculated and presented as percent of total time ( $30 \times 240 \mathrm{sec}$. for each treatment) for three outcomes (negative, neutral, and positive; Appendix 4.3). Contingency tables display the frequency distribution of total counts of the responses within all treatments (the categorical variables) as well as the expected values (post hoc). Pearson's chi square statistic was used for pair wise comparisons between treatment and control, for both larvae (Tables $4.2 \& 4.3$ ) and juveniles (Tables 4.4 $\& 4.5)$.

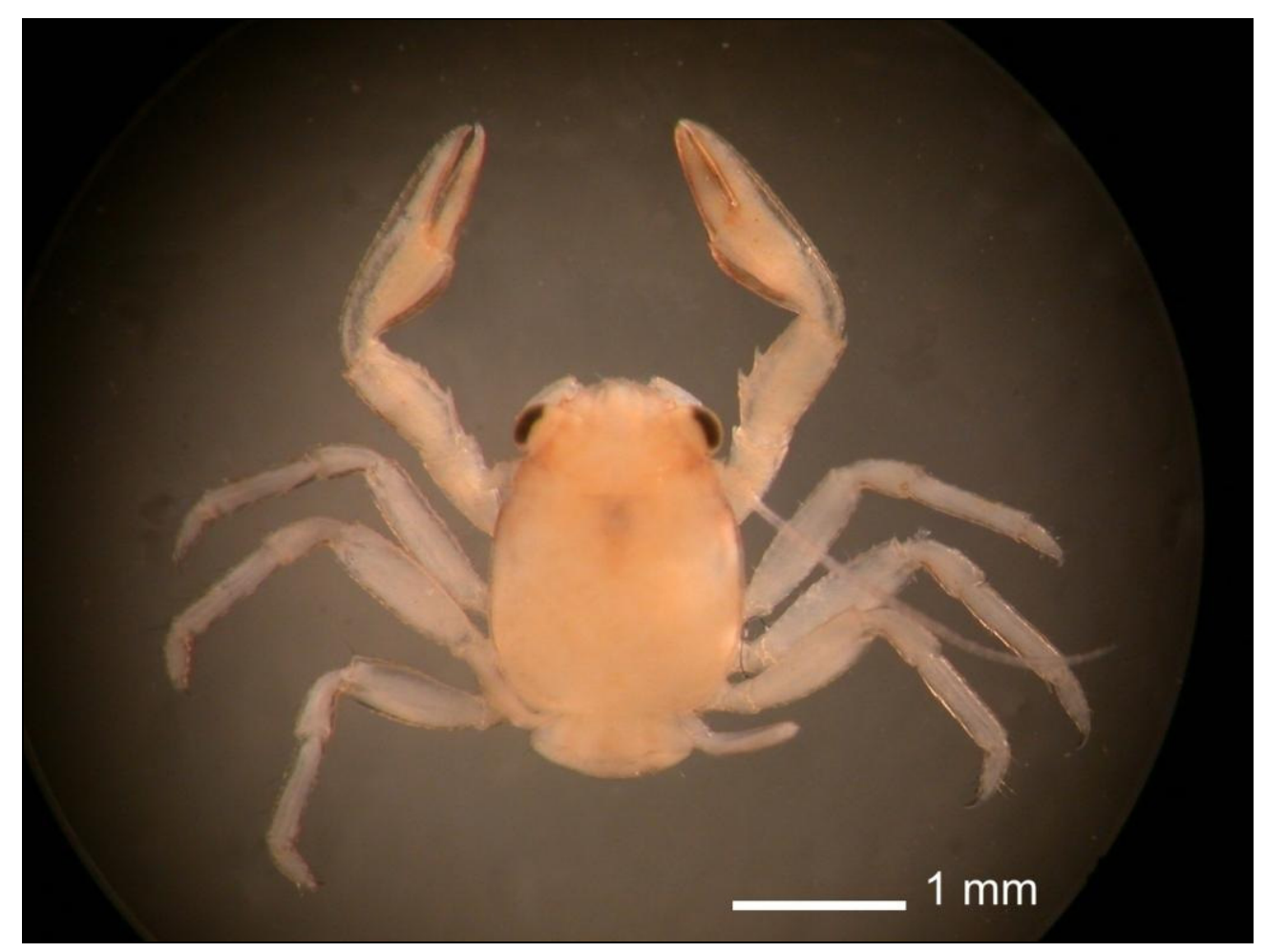

Fig. 4.2: Petrolisthes elongatus megalopa, distinguishable from first instar juvenile only by four pairs of fully developed and functional pleopods on the ventral side of the abdomen. Note: fifth pereiopods small, used as highly flexible "cleaning legs" in porcellanids. 


\subsubsection{Attraction effects on larvae caused by conspecific adults in the field}

To confirm the results from the laboratory experiment, 16 basket traps were deployed in the field at the Hutt River mouth site $\left(41^{\circ} 14^{\prime} 49.50^{\prime} \mathrm{S}, 174^{\circ}\right.$ 53'57.00” E) spaced at intervals of at least $3 \mathrm{~m}$ along the mean low water mark and with a random distribution of treatments. All baskets $(30 \mathrm{~cm} \times 20 \mathrm{~cm} \times 15 \mathrm{~cm})$ were filled with bare cobbles from the supralittoral zone of $10 \mathrm{~cm}$ to $15 \mathrm{~cm}$ length and were fitted with a mesh inlay ( $2 \mathrm{~mm}$ by $4 \mathrm{~mm}$ mesh size) that allowed settlement of larvae but prevented migration of juveniles and adults (Fig. $4.3 \&$ 4.7). Furthermore, death of settlers by predation before sampling was unlikely because the enclosures excluded fish and crab predators. 8 baskets contained 30 adult crabs each (15 males, 15 females, $5 \mathrm{~mm} \mathrm{CW}$ minimum), resembling natural densities observed at this particular site (see chapter 2). For the other treatment, 8 baskets were left empty, the mesh preventing any juveniles and adults from colonizing the trap. After 4 weeks of exposure in the intertidal, the traps were retrieved and the contents carefully transferred into two sieves stacked on top of each other, a coarse ( $5 \mathrm{~mm}$ mesh size) and a fine sieve ( $1 \mathrm{~mm}$ mesh size). The rocks and other accumulated material were thoroughly rinsed with running seawater and the residue from each sieve was washed into a shallow tray. All crabs where transferred into sample jars and preserved in $95 \%$ ethanol on the same day. Later, settlers (megalopae and first instar juveniles) of $P$. elongatus in each basket were counted. The significance level of the difference between numbers of settlers in both treatments was determined by chi square statistic. 


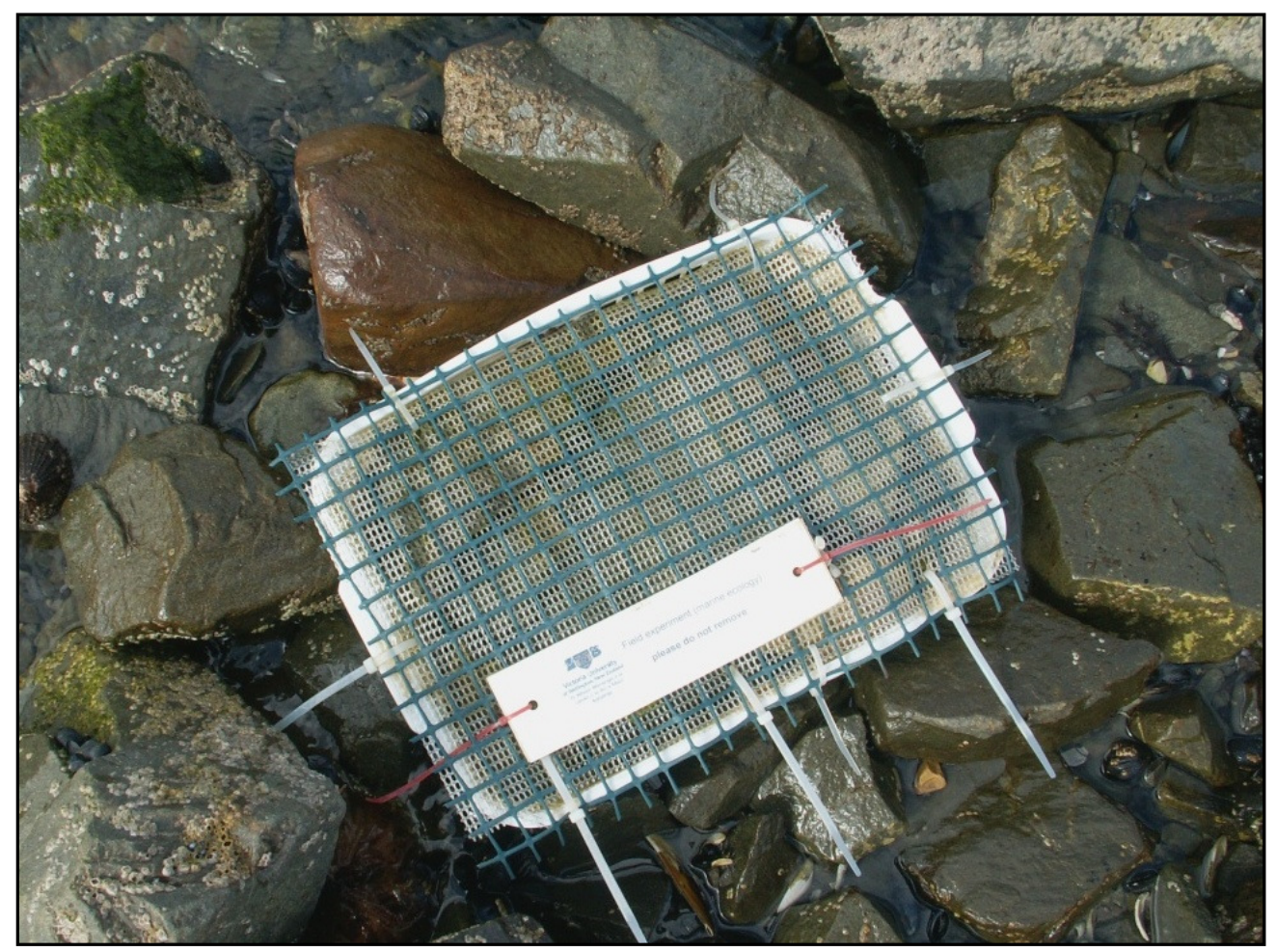

Fig 4.3: Basket trap in an intertidal boulderfield with a high abundance of Petrolisthes elongatus (at Hutt River mouth). The coarse mesh prevents cobbles inside the trap from falling out, while the fine mesh allows larvae to settle but prevents larger crabs from colonizing or escaping from the trap (in case of the "adults present"-treatment).

\subsection{Results}

4.3.1 Attraction effects on larvae and juveniles caused by conspecific adults and other potential sources of settlement cues in a laboratory experiment

\subsubsection{Effect of potential settlement cues on larvae}

Compared to the control where swimming direction appears randomly distributed around the point of release (within $2.5 \mathrm{~cm}$ on either side), P. elongatus larvae were attracted to conspecific adults (Fig. 4.4 a,b,c). At the end of the observation time $\left(\mathrm{t}_{240}\right), 57-70 \%$ of the larvae were sitting as close as possible to the 4 conspecifics in the source compartment (Fig. 4.6). The response was similar for the two treatments " 4 conspecific females" and " 4 conspecific males" (Fig. 4.4xb \& c; Fig. 4.6) and all treatments involving conspecific adults were significant (Table 4.3). Biofilms as well as biofilms combined with coralline crusts (Lithothamnion sp., Rhodophyceae) did not attract $P$. elongatus larvae (Fig. $4.4 \mathrm{f}$ $\& \mathrm{~g}$; Table 4.3). However, in the presence of coralline crusts $43 \%$ of the larvae 
were in section +5 at the end of the observation (Fig. 4.6) and the sample mean at $\mathrm{t}_{240}$ was positive (Fig. 4.4; Appendix 4.2.1), suggesting a possible weak attraction effect. Larvae were not attracted by 10 conspecific larvae (Fig. 4.4 d). The presence of a sympatric species, Heterotius rotundifrons (Fig.4.4 e), also had no effect on the swimming direction of $P$. elongatus larvae.

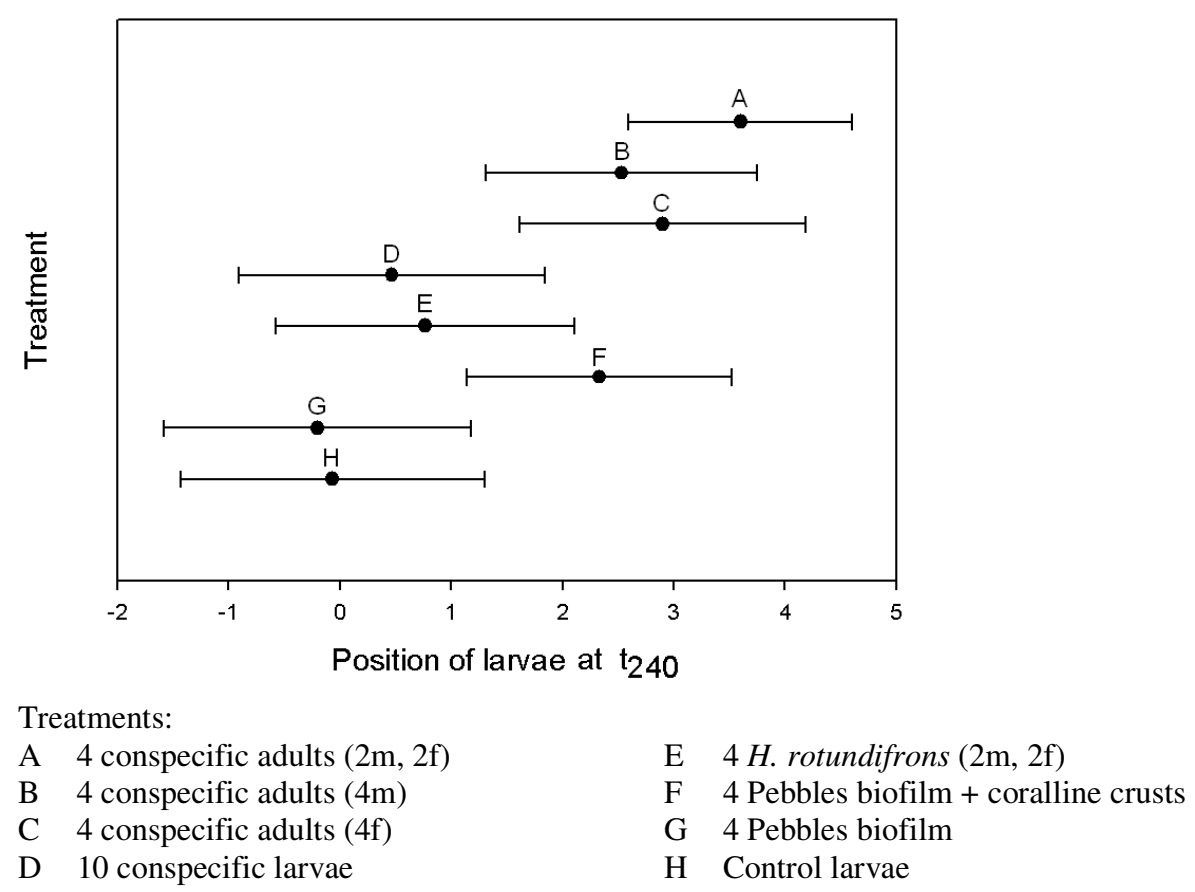

Fig. 4.4: Mean position of larvae within the choice chamber at the end of the observation time $\left(\mathrm{t}_{240}\right)$. The $\mathrm{x}$-axis represents the subdivision of the choice chamber, where 0 is the point of release of larvae at $t_{0}$, and 5 directly adjacent to the compartment containing the source of a potential settlement cue (empty in control). There is a positive response to the presence of conspecifics (a,b,c) and even though not statistically significant, to coralline crusts (f), as well. Error bars represent $95 \%$ confidence intervals.

In Appendix $4.1-4.3$, the mean values (and standard errors) of the positions of larvae and juveniles are shown for all time points $\left(t_{0}-t_{240}\right)$ for all treatments, resulting in "probability paths" for the responses to potential cues over time. These results visualise the chronological sequence of the average position of larvae and juveniles within the choice chamber, their average swimming direction (i.e. towards the source of the cue, away from it or randomly distributed) and provide evidence that the chosen total observation time (240sec.) was sufficient for the determination of the final response. 


\subsubsection{Effect of potential settlement cues on juveniles}

Juveniles showed no significant response to conspecific adults (Table 4.5). However, at the end of the observation time, 53\% of both size class 1 and 2 juveniles showed a positive response as opposed to $7 \%$ that had moved to the far end of the choice chamber (Fig. 4.6). Additionally, juveniles spent 34\% (s.cl.1) and $44 \%$ (s.cl.2) of the total time (i.e. the entire duration of the experiment) in section +5 , as opposed to $10 \%$ and $15 \%$ at the opposite side (Appendix 4.3). Therefore, and despite non-significant results of Pearson's chi-square statistic, it is likely that recruits do not lose their ability to detect and respond to conspecific cues at metamorphosis.

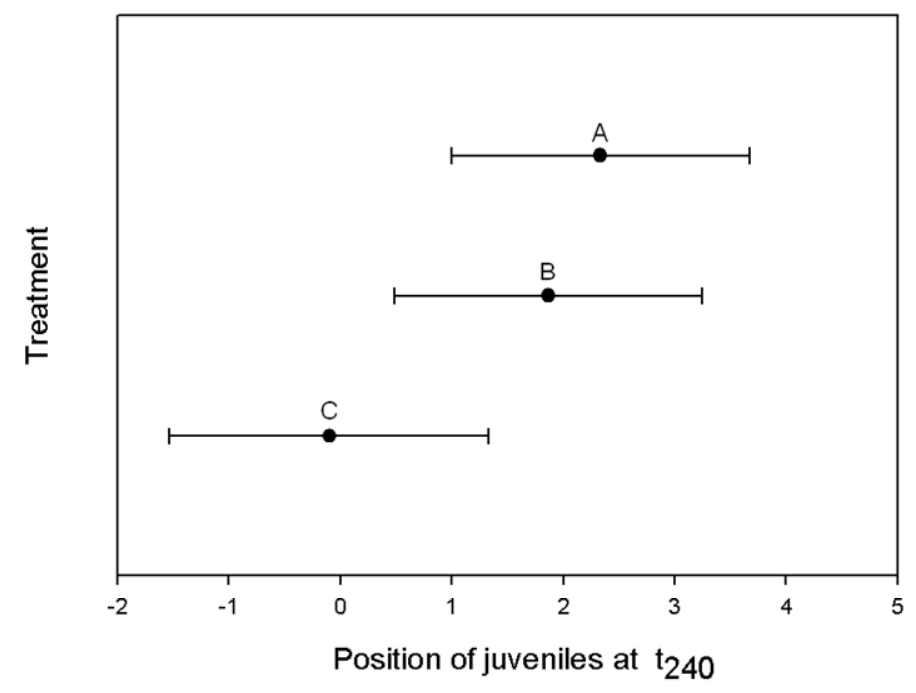

Treatments:

A 4 conspecific adults $(2 \mathrm{~m}, 2 \mathrm{f})$ tested on juveniles of size class $1(3.0-5.0 \mathrm{~mm} \mathrm{CW})$

B 4 conspecific adults $(2 \mathrm{~m}, 2 \mathrm{f})$ tested on juveniles of size class $2(5.0-7.0 \mathrm{~mm} \mathrm{CW})$

C Control juveniles (15x 3.0-5.0mm CW \& 15x 5.0-7.0mm CW)

Fig. 4.5: Mean position of juveniles within the choice chamber at the end of the observation time $\left(t_{240}\right)$. The $\mathrm{x}$-axis represents the subdivision of the choice chamber, where 0 is the point of release of larvae at $t_{0}$, and +5 directly adjacent to the compartment containing the source of a potential settlement cue (empty in control). Despite positive sample means there is no significant response of size class 1 and 2 juveniles to the presence of adults (see Table 4.5). Error bars represent 95\% confidence intervals. 


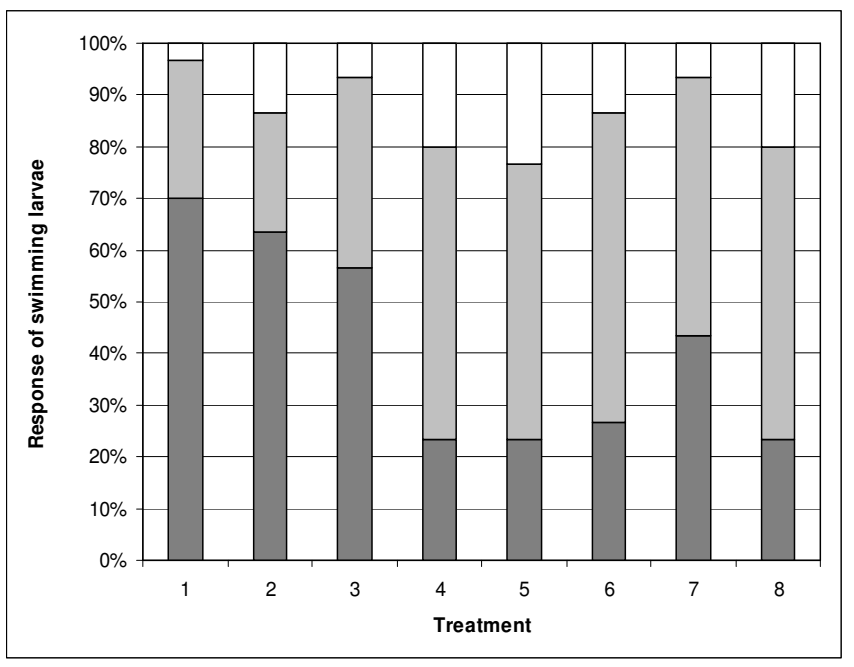

Positive response

Neutral response

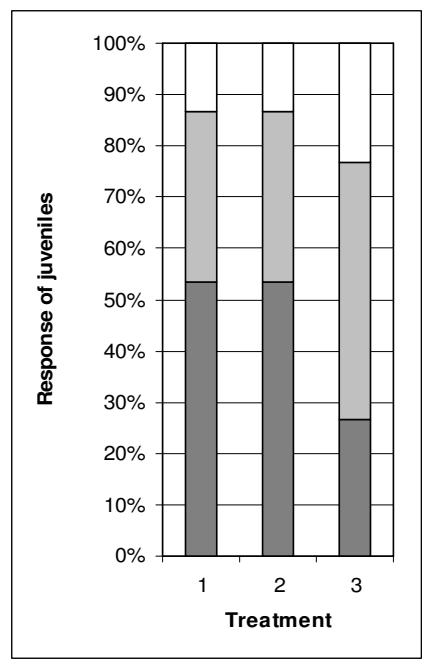

Negative response
Treatments:

1) 4 conspec. adults $(2 \mathrm{~m}, 2 \mathrm{f})$

2) 4 conspec. adults (4m)

3) 4 conspec. adults (4f)

4) 10 conspec. Larvae
5) $4 H$. rotundifrons (2m, 2f)

6) Pebbles biofilm

7) Pebbles biofilm + crusts

8) Control larvae 1a) 4 conspec. adults Juveniles size class 1

2a) 4 conspec. adults Juveniles size class 2

3a) Control juveniles

Fig. 4.6: Distribution of responses of $P$. elongatus larvae (on left) and juveniles (on right) in percent at the end of the observation $\left(\mathrm{t}_{240}\right)$. A positive response was recorded when the larva or juvenile was located directly adjacent to the source compartment of the choice chamber (section +5 ), a negative response, when the larva or the juvenile had moved to the opposite end of the choice chamber (section -5), and a neutral response for all positions in between (sections +4 to -4 ).

\begin{tabular}{|c|c|c|c|c|c|c|c|c|c|}
\hline & $\begin{array}{l}1 \\
2 \mathrm{~m} 2 \mathrm{f}\end{array}$ & $\begin{array}{l}2 \\
4 m\end{array}$ & $\begin{array}{l}3 \\
4 f\end{array}$ & $\begin{array}{l}4 \\
10 L\end{array}$ & $\begin{array}{l}5 \\
4 \text { H.rot }\end{array}$ & $\begin{array}{l}6 \\
\mathrm{~Pb}\end{array}$ & $\begin{array}{l}7 \\
P b+c\end{array}$ & $\begin{array}{l}8 \\
\text { Contr }\end{array}$ & $\begin{array}{l}\text { Row } \\
\text { total }\end{array}$ \\
\hline Positive & $\begin{array}{l}21 \\
(12.38)\end{array}$ & $\begin{array}{l}19 \\
(12.38)\end{array}$ & $\begin{array}{l}17 \\
(12.38)\end{array}$ & $\begin{array}{l}7 \\
(12.38)\end{array}$ & $\begin{array}{l}7 \\
(12.38)\end{array}$ & $\begin{array}{l}8 \\
(12.38)\end{array}$ & $\begin{array}{l}13 \\
(12.38)\end{array}$ & $\begin{array}{l}7 \\
(12.38)\end{array}$ & 99 \\
\hline Neutral & $\begin{array}{l}8 \\
(13.63)\end{array}$ & $\begin{array}{l}7 \\
(13.63)\end{array}$ & $\begin{array}{l}11 \\
(13.63)\end{array}$ & $\begin{array}{l}17 \\
(13.63)\end{array}$ & $\begin{array}{l}16 \\
(13.63)\end{array}$ & $\begin{array}{l}18 \\
(13.63)\end{array}$ & $\begin{array}{l}15 \\
(13.63)\end{array}$ & $\begin{array}{l}17 \\
(13.63)\end{array}$ & 109 \\
\hline Negative & $\begin{array}{l}1 \\
\text { (4) }\end{array}$ & $\begin{array}{l}4 \\
\text { (4) }\end{array}$ & $\begin{array}{l}2 \\
(4)\end{array}$ & $\begin{array}{l}6 \\
(4)\end{array}$ & $\begin{array}{l}7 \\
\text { (4) }\end{array}$ & $\begin{array}{l}4 \\
\text { (4) }\end{array}$ & $\begin{array}{l}2 \\
(4)\end{array}$ & $\begin{array}{l}6 \\
(4)\end{array}$ & 32 \\
\hline $\begin{array}{l}\text { Column } \\
\text { total }\end{array}$ & 30 & 30 & 30 & 30 & 30 & 30 & 30 & 30 & 240 \\
\hline
\end{tabular}

$\mathrm{Chi}^{2}$ Pearson $=38.0476 ; \mathrm{df}=14 ; \mathrm{p}=\mathbf{0 . 0 0 0 5 1}$

Table 4.2: Contingency table for larval responses (rows) for all treatments (columns). Shown are the observed values (based on total counts) and, in brackets, the expected values (post hoc, based on the ratio of product of row total and column total to grand total, rounded). The Pearson chi-square statistic result indicates highly significant differences between larval responses in different treatments. 


\begin{tabular}{|c|c|c|c|c|}
\hline \multicolumn{2}{|c|}{ Treatment } & \multirow{2}{*}{$\begin{array}{l}\mathbf{C h i}^{\mathbf{2}}{ }_{\text {Pearson }} \\
13.8114\end{array}$} & \multirow{2}{*}{$\frac{\text { df }}{2}$} & \multirow{2}{*}{$\begin{array}{c}p \\
0.0010\end{array}$} \\
\hline A & 4 conspecific adults $(2 \mathrm{~m}, 2 \mathrm{f})$ & & & \\
\hline B & 4 conspecific adults $(4 \mathrm{~m})$ & 7.4524 & 2 & 0.0241 \\
\hline $\mathrm{C}$ & 4 conspecific adults $(4 \mathrm{f})$ & 10.1051 & 2 & 0.0064 \\
\hline $\mathrm{D}$ & 10 conspecific larvae & 0 & 2 & 1.0000 \\
\hline $\mathrm{E}$ & $4 \mathrm{H}$. rotundifrons $(2 \mathrm{~m}, 2 \mathrm{f})$ & 0.1072 & 2 & 0.9478 \\
\hline $\mathrm{F}$ & 4 Pebbles biofilm & 0.4952 & 2 & 0.7807 \\
\hline G & 4 Pebbles biofilm + coralline crusts & 3.9250 & 2 & 0.1405 \\
\hline
\end{tabular}

Table 4.3: Significance values for the final positions of larvae (at the end of observation, $\mathrm{t}_{240}$ ) for each cue type compared to the control by Pearson's chisquare statistic with three outcomes (positive, neutral, and negative response; observed and expected values). For each treatment 30 runs with newly replaced larvae and cue sources were conducted. A significantly positive response of larvae regarding their swimming direction was detected for conspecific adults, only.

\begin{tabular}{|c|c|c|c|c|}
\hline & $\begin{array}{l}1 \\
\text { S.cl. } 1\end{array}$ & $\begin{array}{l}2 \\
\text { S.cl. } 2\end{array}$ & $\begin{array}{l}3 \\
\text { Contr. }\end{array}$ & Row total \\
\hline Positive & $16(13.33)$ & $16(13.33)$ & $8(13.33)$ & 40 \\
\hline Neutral & 10 (11.67) & 10 (11.67) & 15 (11.67) & 35 \\
\hline Negative & $4(5)$ & $4(5)$ & 7 (5) & 15 \\
\hline $\begin{array}{l}\text { Column } \\
\text { total }\end{array}$ & 30 & 30 & 30 & 90 \\
\hline
\end{tabular}

$\mathrm{Chi}^{2}{ }_{\text {Pearson }} \sim 15.6161 ; \mathrm{df}=4 ; \mathrm{p}=0.2123$

Table 4.4: Contingency table for juvenile responses (rows) for all treatments (columns). Shown are the observed values (based on total counts) and the expected values (based on the ratio of product of row total and column total to grand total, rounded) in brackets. The Pearson chi-square statistic result indicates highly significant differences between juvenile responses in different treatments.

\begin{tabular}{|l|l|l|l|}
\hline Treatment & $\mathbf{C h i}^{\mathbf{2}}$ Pearson & df & $\mathbf{p}$ \\
\hline A $\quad$ 4 conspec. \& juv. s.cl. 1 & 0.9569 & 2 & 0.0882 \\
B $\quad$ 4 conspec. \& juv. s.cl. 2 & 0.9569 & 2 & 0.0882 \\
\hline
\end{tabular}

Table 4.5: Significance values for the final positions of juveniles (at the end of observation, $\mathrm{t}_{240}$ ) for both cue types compared to the control by Pearson's chisquare statistic with three outcomes (positive, neutral, and negative response; observed and expected values).

Pearson's chi-square statistic results on the relative frequency distribution of larval responses indicated highly significant differences between the observed 
frequency distributions in all treatments (Table 4.4). For juveniles no overall differences were detected (Table 4.5). However, comparing the observed frequencies of responses (twice as many positive outcomes in the presence of conspecific adults than in the control) it is likely that juveniles are responding to conspecific cues, as well.

\subsubsection{Attraction effects on larvae caused by conspecific adults (field experiment)}

In the field, presence of conspecifics had a highly significant effect on larval settlement of $P$. elongatus. Densities of newly settled larvae were four times higher in basket traps that contained conspecific adults compared to those where adults were absent (Fig. 4.7).

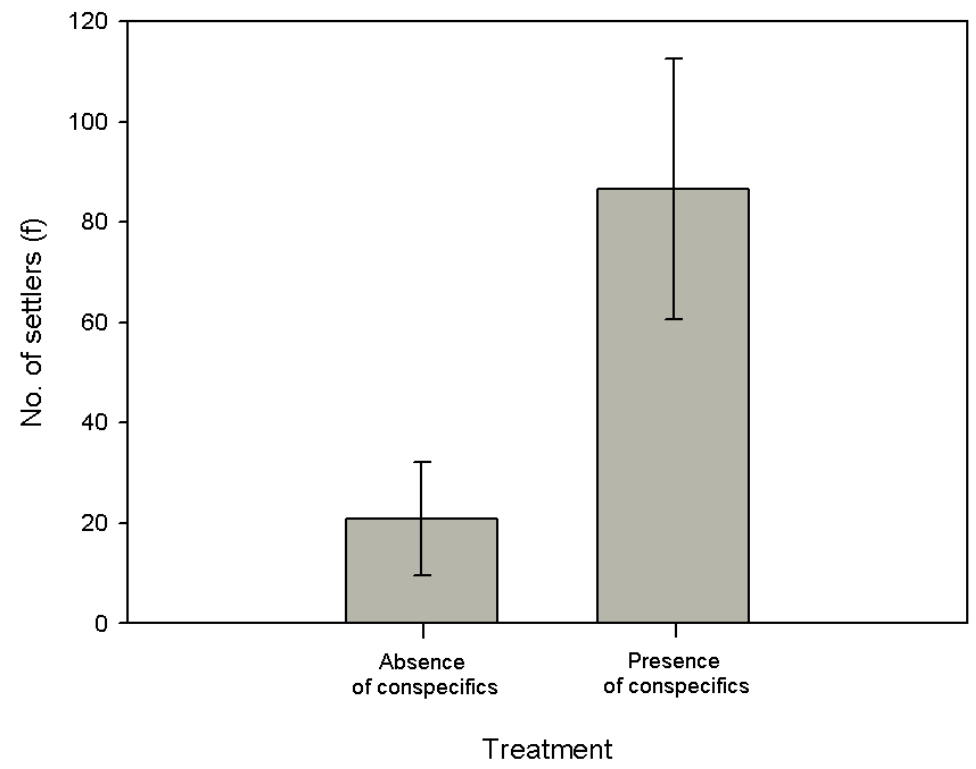

$\mathrm{Chi}^{2}=14.3872 ; \mathrm{df}=7 ; \mathrm{p}<\mathbf{0 . 0 0 0 1}$

Fig. 4.7: Mean number of $P$. elongatus settlers in absence or presence of conspecific adults in basket traps deployed in the field. There were approx. 4 times as many settlers in traps with encaged conspecifics in the field. Error bars represent $95 \%$ confidence intervals. 


\subsection{Discussion}

The results from the choice chamber experiments provide strong evidence that adults of $P$. elongatus, both females and males, release a waterborne chemical cue that attracts conspecific settlement stage larvae and post-metamorphic juveniles. This evidence is supported by results obtained in the field, demonstrating that P. elongatus settlement was four times higher in baskets with conspecific adults compared to those without. These results are consistent with studies of conspecific attraction in other Petrolisthes species. Jensen (1989, 1991) demonstrated that larvae of $P$. cinctipes (Randall) and $P$. eriomerus Stimpson are attracted to conspecific adults both under laboratory conditions and in the field. Additionally, Jensen (1991) presented strong evidence for an extended period of competency for settlement: While newly moulted megalopae of $P$. cinctipes settled within 2-4days when conspecific adults were present, those held without adults delayed settlement for 2-3weeks. Field observations suggest that megalopae of two other porcellanids, Pachycheles rudis Stimpson and $P$. pubescens Holmes, also settle in response to conspecific adults and remain closely associated with them (Jensen, 1989). The protection-seeking behaviour in megalopae as well as in juveniles is possibly mediated by the persistent responsiveness to the waterborne settlement-inducing cue released by conspecific adults. Megalopae as well as juvenile instars gain protection by hiding among and underneath conspecific adults (Jensen, 1991 and own observation); this behaviour

significantly reduced predation in a laboratory experiment (Jensen, 1991) and could reduce post-settlement mortality in $P$. elongatus.

\section{Conspecific attraction of juveniles}

Juveniles of the southern rock lobster, Jasus edwardsii, become increasingly attracted to conspecific adults as they grow larger (MacDiarmid, 1994), due to an ontogenetic change in the response to conspecific cues (Butler et al., 1999). It is likely that a similar ontogenetic change takes place in Petrolisthes ssp.; however, it is unknown whether earlier larval stages (zoea larvae) respond to conspecific cues. Baeza \& Stotz (1998) demonstrated that juveniles and adults of the porcellanid Allopetrolisthes spinifrons (H. Milne Edwards, 1837) exhibit a high host specificity (to a sea anemone) that appears to be less pronounced in larvae at the time of settlement, possibly mediated by an increasing sensitivity to cues with advancing development. Similar to J. edwardsii, later stage juveniles of 
Caribbean spiny lobsters, Panulirus argus, become attracted to conspecific odours (Ratchford \& Eggleston, 1998). Zito-Livingston \& Childress (2009) suggested that in this species postlarval settlement may be influenced by conspecific density. $P$. argus adults, both the males and females, shelter gregariously (Herrnkind et al., 2001), whereby shelter choice is significantly influenced by chemical cues associated with conspecific urine of either sex (Horner et al., 2006). Even though the American lobster, Homarus americanus, is non-gregarious, early juvenile stages are attracted to conspecific odours (Boudreau et al., 1993) and frequently share shelters with adults (Lawton \& Lavalli, 1995). Thus, conspecific cueing may play a role in site selection and induction of settlement in H. americanus (Childress \& Jury, 2006).

\section{Conspecific attraction among larvae}

Under laboratory conditions, competent $P$. elongatus megalopa larvae were not attracted by 10 conspecific larvae of the same stage, indicating the crabs begin to produce the attractant after metamorphosis. This seems logical insofar that a selfreleased odour would obliterate the settlement cue gradients and densities guiding the larvae to inhabited coastal sites with high habitat quality. Alternatively, the 10 megalopae in the "source" compartment may not have been enough to release a sufficient amount of odour to successfully attract others. Several studies have demonstrated that some larvae are chemically attracted to other larvae or recently settled juveniles (Keough, 1984; Wethey, 1984; Marsden, 1991). Wear (1965b) reported that zoea larvae of $P$. elongatus were occasionally found in large numbers close to the shore in shallow water; however, it is likely that these distributional patterns partly arise from hydrodynamic processes. Jensen (1991) and Mascetti \& Wehrtmann (1996) observed positive thigmotaxis of Petrolisthes laevigatus megalopae with floating objects, including other larvae, often forming ball-like aggregations. This behaviour has also been observed in early life history stages of other decapods (Wehrtmann \& Dittel, 1990).

\section{Effects of adult density on patterns of settlement and recruitment}

Typically, the conspecific attraction results in gregariousness and is most likely density dependent because the density of conspecific individuals within a given habitat patch will in large part determine the local cue concentration. Donahue (2006) manipulated the density of $P$. cinctipes in field enclosures and found that 
the number of settlers increased with conspecific density. Despite the turbulent flow conditions within the natural habitat of P. elongatus on one hand and the relatively small size of the basket traps on the other, the larvae settled "patchily" on a scale of tens of centimetres by showing a significant preference for inhabited traps. Since juveniles are attracted to adults, as well (Fig. 4.5), and tend not to migrate long distances (see chapter 2), settlement patterns are likely maintained for some time after settlement. Therefore, recruitment patterns of $P$. elongatus are likely influenced by local adult density due to differential cue concentrations even on a surprisingly small scale. In contrast to $P$. elongatus postlarvae (megalopae) and juveniles, the aggregating behaviour in adults appears to be mediated by shelter targeting behaviour (see chapter 2), combined with the use of vision for shelter seeking (Meyer-Rochow \& Meha, 1994), and negative phototaxis (Scott, 1958), rather than by conspecific cueing.

\section{Crustose coralline red algae as sources of settlement cues}

In addition to conspecific cues, coralline crusts frequently found in intertidal boulder fields, composed of red algae of the genera Lithothamnion and Lithophyllum, also release an effective positive cue that attracts P. elongatus (Fig. 4.4 and 4.6). For Porcellanidae, this has not been reported to date. However, crustose coralline algae have been shown to release a potent chemical attractant for larvae of chitons (Barnes \& Gonor, 1973), limpets (Steneck, 1982), abalone Haliotis ssp. (Morse et al., 1980; Morse \& Morse, 1984; Daume et al., 1999), sea urchins (Pearce \& Scheibling 1990; Swanson et al., 2006; Scheibling \& Robinson, 2008), as well as for planula larvae of reef building corals (Price, 2010). Swanson et al. (2006) found evidence that the settlement cue for larvae of the Australian sea urchin from crustose coralline algae may derive from bacteria thriving on their surface. Botero \& Atema (1982) showed that late-stage larvae of Homarus americanus settle preferentially on rocks covered by macroalgae and delay metamorphosis when offered nothing but sand or mud. Pueruli of the spiny lobster Panulirus argus exhibit a preference for intricately branched red algae (Herrnkind \& Butler, 1986). In contrast to the coralline crust, and despite the importance of microbial films in the settlement of many marine invertebrate pelagic larvae (Rodriguez et al., 1993) P. elongatus megalopae did not respond to biofilms composed of diatoms and cyanobacteria (Fig. 4.4 and 4.6). 


\section{Sympatric species}

The sympatric species $H$. rotundifrons is neither a predator for $P$. elongatus nor a competitor for food and space (see chapter 2, Figs. 2.13 and 2.14). This usually far less abundant species also occupies a different ecological niche: It buries itself in sand and gravel and feeds on brown algae such as Hormosira sp. (McLay, 1988). Additionally, P. elongatus (Anomura) and H. rotundifrons, a brachyuran crab, are not closely related. Therefore, it is not surprising that competent P. elongatus larvae were not attracted or repelled by odours from this coexisting species. Any other crustaceans, such as the purple rock crab, Hemigrapsus edwardsi (Hilgendorf, 1882), or Elamena producta Kirk, 1878, were relatively rare and were only found at one of the sample sites throughout the study.

\section{Methodology: laboratory versus field conditions}

Within the choice chamber, it is possible that larvae may not have responded to the cue despite perceiving it, e.g. due to high stress levels after handling procedures and concerning the non-natural conditions. The limited water volume could have lead to unnaturally high cue concentrations that may have influenced the larval behaviour due to habituation (see Trapido-Rosenthal \& Morse, 1986; Morse 1991). In the field, turbulent flow results in complex fluctuating structure of the odour plume (Balkovsky \& Shraiman, 2002), may provide and distribute waterborne settlement cues and mediates their concentration (Abelson \& Denny, 1997). The resulting on/off response of larvae enhances their transport to high quality sites (Koehl et al., 2007). Additionally, flow velocity and turbulence could also influence larval behaviour directly (Tamburri et al., 1996). It was therefore crucial to verify the choice chamber results by a field experiment to confirm whether larvae actually settle dependent on presence and density of conspecifics in the eulittoral zone, under natural conditions.

\section{Settlement patterns and substratum selection in the field}

The search for suitable sites for settlement operates at several different spatial scales, with different biological and physical influences (LeTourneux \& Bourget 1988). Chabot \& Bourget (1988), for example, found that selection by larvae of the barnacle Semibalanus balanoides was related to the heterogeneity of the substratum at a large scale whereas at a smaller scale settlement was influenced by the presence or absence of conspecific individuals. Butman (1987) indicated 
that while hydrodynamic processes and passive transport determine larval distribution at a large spatial scale, the patterns on a smaller scale could be the consequence of a subsequent redistribution that may be influenced by larval behaviour. Although many invertebrate larvae are weak swimmers (Chia et al., 1984; Young, 1995), other pre-settlement forms should actually be considered as mikronekton rather than plankton due to their high level of mobility (Zeldis, 1985; Luckenbach \& Orth, 1992). Megalopae of Petrolisthes sp. were measured at speeds up to $5 \mathrm{~cm} / \mathrm{s}$, and appeared capable of exploring an extensive area of the intertidal zone within a single flood tide (Jensen, 1991).

Meadows \& Campbell (1972) hypothesised that a hierarchy of cues guides invertebrate larvae towards a generally favourable habitat and finally determines the selection of a specific site (for a review, see Kingsford et al., 2002; for a more recent study, see Ettinger-Epstein et al., 2008). While cues from coralline crusts that are common in intertidal boulder fields may work on a larger scale (hundreds of meters) and attract $P$. elongatus larvae to coastal sections with potentially suitable habitat, conspecific cueing appears to work on small scale (tens of centimetres), manifested in the preference of high density patches. There could even exist another hierarchical level on an even smaller scale (centimeters, single boulders), that has not been tested in this study: larvae may preferably settle on boulders with a high surface roughness that provides more friction in flow. If one of these biological or physical conditions is not met, the larva will most likely reject the site and continues its explorative behaviour. Compared to sessile barnacles, however, the selection of a suitable habitat seems to be less critical for motile crustaceans as the benthic post-settlement stages are able to emigrate to more favourable sites (Moksnes et al., 2003; Moksnes, 2004).

Megalopae typically respond to odours from conspecifics (Forward et al., 2003) or congenerics (Gebauer et al., 2002). Some crab species moult sooner in the presence of odours from conspecifics (O’Connor \& Gregg, 1998) and/or when exposed to environmental cues that are characteristic of the parental habitat (O'Connor \& Judge, 2004). The ability of crustaceans to accurately respond to chemical cues is well documented and indicates a sophisticated chemosensory apparatus that can adapt to varying cue concentrations (Zimmer et al., 1999; 
Finelli et al., 2000). Many crab larvae are highly selective and display dosedependent responses to cues (e.g. Pawlik, 1992; Fitzgerald et al., 1998).

\section{Cue specificity and directions for future research}

The waterborne settlement cue released by conspecific P. elongatus adults that has yet to be characterised is most likely a pheromone, e.g. a polypeptide isolated from arthropod cuticles, "arthropodin" (Pawlik, 1992 and literature therein), but could also be an excretory product (Burke, 1986). Settlement in barnacle cyprids, for example, is mediated by a suite of chemical cues originating from both larvae and adults (for a review, see Clare \& Matsumura, 2000). While larvae release the cyprid antennular secretion pheromone (Clare et al., 1994), cues from adults comprise a settlement-inducing protein complex (SIPC) (Crisp \& Meadows, 1963; Matsumura et al., 2000; Elbourne \& Clare, in press). SIPC's work as species-specific attractants for barnacles (Dreanno et al., 2007) and have been characterised as cuticular glycoproteins (Dreanno et al., 2006a,b). Other active compounds of attracting odours may be free fatty acids, phenols and polysaccharides (Burke, 1986; Pawlik, 1986). However, it can be expected that the biochemical properties of cue molecules lead to a species specific attraction, even if several different substances are involved. Petrolisthes novaezelandiae Filhol, 1885 and P. spinosus Miers, 1876 megalopae settle subtidally (Wear, 1964, 1965b), indicating that their conspecific adults may release cues that are biochemically different. Additionally, these larvae may respond differently to physical cues such as water pressure and light conditions.

Despite the fact that chemical cues have been widely considered in studies of settlement, few natural attractants and settlement inducers, other than from barnacles, have been identified, isolated and characterized (Pawlik 1986; Rodriguez, 1993). Knowledge about the species-specificity of the attractant and the level of dependency of the larva on one hand and patterns of distribution of settlement-inducing substrata as well as differential cue densities in the field on the other may help to more precisely predict population and community patterns (Rodriguez et al., 1993). Hadfield (1986) pointed out that for the determination of the specificity of an inducer it is critical to know its physico-chemical structure as well as the nature of the inducers in related species. Gebauer et al. (2002), for example, demonstrated that not only odours from conspecific adults but also 
those released by closely related species are effective for stimulating metamorphosis in a semiterrestrial grapsid crab, Sesarma curacaoense. These authors showed that with increasing phylogenetic distance the strength of the larval response decreased (see also Dreanno et al., 2007). Thus, the knowledge of the chemical structure of settlement-inducing cues at different taxonomic levels could be a useful tool in the study of phylogenetic relations between taxa (Rodriguez et al., 1993), implying that the response to species-specific cues represents a heritable trait which is subject to natural selection (Anger, 2006).

\section{Conclusions}

For Petrolisthes elongatus, the behavioural selection of high quality habitat patches using waterborne chemical cues from conspecifics on a small scale as well as from crustose coralline algae, presumably on a larger scale, likely reduces the risk of mortality and enhances connectivity between geographically isolated metapopulations. The significance of chemical communication for both larval survival and biotic interactions as well as their effects on marine ecosystems remains a challenge for future research. A characterisation of the settlement inducer released by $P$. elongatus on a molecular level and physiological studies of cue perception would help to understand the adaptive evolution of conspecific cueing as well as how chemical cues regulate critical aspects of the behaviour of marine organisms. 


\section{References}

Abelson, A. \& Denny, M., 1997. Settlement of marine organisms in flow. Annu. Rev. Ecol. Syst. 28: 317-339.

Anger, K., 2006. Contributions of larval biology to crustacean research: a review. Invert. Reprod. Dev. 49(3): 175-205.

Baeza, J.A. \& W. Stotz, 1998. Selección del hábitat durante el asentamiento larval de Allopetrolisthes spinifrons (H.Milne Edwards, 1837) (Decapoda: Anomura: Porcellanidae), un cangrejo comensal de la anémona Phymactis clematis (Drayton, 1798) (Coelenterata: Anthozoa). Revista de Biología Marina \& Oceanografía, Valparaíso 33: 331-343.

Balkovsky, E. \& Shraiman, B.I., 2002. Olfactory search at high Reynolds number. PNAS 99(20): 12589-12593.

Barnes, J.R. \& Gonor, J.J., 1973. The larval settling response of the lined chiton Tonicella Lineata. Mar. Biol. 20: 259-264.

Berntsson, K.M.; Jonsson, P.R.; Larsson, A.I. \& Holdt, S., 2004. Rejection of unsuitable substrata as a potential driver of aggregated settlement in the barnacle Balanus improvisus. Mar. Ecol. Prog. Ser. 275: 199-210.

Bertness, M.D., 1989. Intraspecific competition and facilitation in a northern acorn barnacle population. Ecology 70: 257-268.

Bertness, M.D. \& Grosholz, E., 1985. Population dynamics of the ribbed mussel, Geukensia demissa: the costs and benefits of an aggregated distribution. Oecologia 67:192-204.

Boone, E.T.; Boettcher, A.A.; Sherman, T.D. \& O’Brien, J.J., 2003. Characterization of settlement cues used by the rhizocephalan barnacle Loxothylacus texanus. Mar. Ecol. Prog. Ser. 252: 187-197.

Botero, L. \& Atema, J., 1982. Behavior and substrate selection during larval settling in the lobster Homarus americanus. J. Crust. Biol. 2(1): 59-69.

Boudreau, B.; Bourget, E. \& Simard, Y., 1993. Behavioural responses of competent lobster postlarvae to odor plumes. Mar. Biol. 117: 63-69.

Burke, R.D., 1986. Pheromones and the gregarious settlement of marine invertebrate larvae. Bull. Mar. Sci. 39(2): 323-331.

Butler, M.J.; MacDiarmid, A.B. \& Booth, J.D., 1999. The cause and consequence of ontogenetic changes in social aggregation in New Zealand spiny lobsters. Mar. Ecol. Prog. Ser. 188: 179-191.

Butman, C.A., 1987. Larval settlement of soft-sediment invertebrates: the spatial scales of pattern explained by activehabitat selectionand the emerging role of hydrodynamical processes. Oceanogr. Mar. Biol. Annu. Rev. 25: 113-165. 
Chabot, R. \& Bourget, E., 1988. Influence of substratum heterogeneity and settled barnacle density on the settlement of cypris larvae. Mar. Biol. 97: 45-56.

Chia, F.S.; Buckland-Nicks, S.J. \& Young, C.M., 1984. Locomotion of marine invertebrate larvae: a review. Can. J. Zool. 62: 1205-1222.

Childress, M.J. \& Jury, S.H., 2006. Behaviour. In: Lobsters: Biology, Management, Aquaculture and Fisheries. B.F. Phillips (ed.). Blackwell Publishing. Oxford, UK. 78-112 pp.

Clare, A.S.; Freet, R.K. \& McClary, M., 1994. On the antennular secretion of the cyprid of Balanus amphitrite amphitrite, and its role as a settlement pheromone. J. Mar. Biol. Assoc. U.K. 74: 243-250.

Clare, A.S. \& Matsumura, K., 2000. Nature and perception of barnacle settlement pheromones, Biofouling 15: 57-71.

Cole, H.A. \& Knight-Jones, E.W., 1939. Some observations and experiments on the settling behaviour of larvae of Ostrea edulis. J. Cons., Cons. Int. Explor. Mer. 14: 86-105.

Cowen, R.K. \& Sponaugle, S. 2009. Larval dispersal and marine population connectivity. Annu. Rev. Mar. Sci. 1: 443-466.

Crisp, D.J., 1979. Dispersal and re-aggregation in sessile marine invertebrates, particularly barnacles. In: Marine Organisms - Genetics, Ecology and Evolution. Volume 11. G. Larwood \& B.R. Rosen (eds.), Academic Press, London. Pp. 319-327.

Crisp, D.J., 1984. Overview of research on marine invertebrate larvae, 1940-1980. In: Marine Biodeterioration: An interdisciplinary Study. J.D. Costlow \& R.C. Tipper (eds.). Naval Institute Press, Annapolis, Maryland. Pp. 103-126.

Crisp, D.J. \& Meadows, P.S., 1963. Adsorbed layers: the stimulus to settlement in barnacles. Proc. R. Soc. London, Ser. B 158: 364-387.

Dahms, H.-U., Harder, T. \& Qian, P.-Y., 2007. Selective attraction and reproductive performance of a harpacticoid copepod in a response to biofilms. J. Exp. Mar. Biol. Ecol. 341(2): 228-238.

Daume, S.; Brand-Gardner, S. \& Woelkerling, W.J., 1999. Preferential settlement of abalone larvae: diatom films vs. non-geniculate coralline red algae. Aquaculture 174: 243-254.

Davis, A.R., 1987. Variation in recruitment of the subtidal colonial ascidian Podoclavella cylindrica (Quoy \& Gaimard): the role of substratum choice and early survival. J. Exp. Mar. Biol. Ecol. 106: 57-71. 
Diaz, H.; Orihuela, B.; Forward Jr., R.B. \&. Rittschof, D., 2003. Orientation of juvenile blue crabs, Callinectes sapidus (Rathbun) to currents, chemical and visual cues. J. Crust. Biol. 23: 15-22.

Donahue, M.J., 2004. Size-dependent competition in a gregarious porcelain crab Petrolisthes cinctipes (Anomura: Porcellanidae). Mar. Ecol. Prog. Ser. 267: 219-231.

Donahue, M.J., 2006. Allee effects and conspecific cueing jointly lead to conspecific attraction. Oecologia 149: 33-43.

Dreanno, C.; Matsumura, K.; Dohmae, N.; Takio, K.; Hirota, H.; Kirby, R.R. \& Clare, A.S., 2006a. A novel a2-macroglobulin-like protein is the cue to gregarious settlement of the barnacle Balanus amphitrite. Proc. Natl. Acad. Sci. U. S. A. 103 (39): 14396-14401.

Dreanno, C.; Kirby, R.R. \& Clare, A.S., 2006b. Locating the barnacle settlement pheromone: spatial and ontogenetic expression of the settlement-inducing protein complex (SIPC) of Balanus amphitrite. Proc. R. Soc. Lond. Ser. B 273: $2721-2728$.

Dreanno, C., Kirby, R.R. \& Clare, A.S., 2007. Involvement of the barnacle settlement-inducing protein complex (SIPC) in species recognition at settlement. J. Exp. Mar. Biol. Ecol. 351: 276-282.

Elbourne, P.D. \& Clare, A.S., in press. Ecological relevance of a conspecific, waterborne settlement cue in Balanus amphitrite (Cirripedia). J. Exp. Mar. Biol. Ecol. 8pp.

Ettinger-Epstein, P.; Whalan, S.; Battershill, C.N. \& de Nys, R., 2008. A hierarchy of settlement cues influences larval behaviour in a coral reef sponge. Mar. Ecol. Prog. Ser. 365: 103-113.

Fenaux, L. \& Pedrotti, M.L., 1988. Metamorphose des larves d'echinides en plein eau. Mar. Ecol. 9: 93-107.

Finelli, C.M.; Pentcheff, N.D.; Zimmer, R.K. \& Wethey, D.S., 2000. Physical constraints on ecological processes: a field test of odor mediated foraging. Ecology 81: 784-797.

Fitzgerald, T.P.; Forward, R.B. \& Tankersley, R.A., 1998. Metamorphosis of the estuarine crab Rhithropanopeus harrisii: effect of water type and adult odor. Mar. Ecol. Prog. Ser. 165: 217-223.

Forward, R.B. \& Rittschof, D., 1994. Photoresponses of crab megalopae in offshore and estuarine waters: Implications for transport. J. Exp. Mar. Biol. Ecol. 182: 183-192.

Forward, R.B.; Tankersley, R.A.; Smith, K.A. \& Welch, J.M., 2003, Effects of chemical cues on orientation of blue crab, Callinectes sapidus, megalopae in flow: implications for location of nursery areas. Mar. Biol. 142: 747-756. 
Gaines, S.D. \& Bertness, M., 1993. The dynamics of juvenile dispersal: why field ecologists must integrate. Ecology 74: 2430-2435.

Gaines, S.D. \& Roughgarden, J., 1985. Larval settlement rate: A leading determinant of structure in an ecological community of the marine intertidal zone. Prec. Natl. Acad. Sci. USA 82: 3707-3711.

Gebauer, P.; Walter, I. \& Anger, K., 1997. Effects of substratum and conspecific adults on the metamorphosis of Chasmagnathus granulata (Dana) (Decapoda: Grapsidae) megalopae. J. Exp. Mar. Biol. Ecol. 223: 185-198.

Gebauer, P.; Paschke, K. \& Anger, K., 2002. Metamorphosis in a semiterrestrial crab, Sesarma curacaoense: intra- and interspecific settlement cues from adult odors. J. Exp. Mar. Biol. Ecol. 268: 1-12.

Gebauer, P.; Paschke, K. \& Anger, K., 2003. Delayed metamorphosis in Decapod Crustaceans: evidence and consequences. Rev. Chil. Hist. Nat., 76: 169-175.

Gotelli, N.J., 1987. Spatial and temporal patterns of reproduction, larval settlement, and recruitment of the compound ascidian Aplidium stellatum. Mar. Biol. 94: 45-51.

Gray, J.S., 1974. Animal-sediment relationships. Oceanogr. Mar. Biol. Annu. Rev. 12: 223-261.

Hadfield, M.G., 1986. Settlement and recruitment of marine invertebrates: a perspective and some proposals. Bull. Mar. Sci. 39: 418-425.

Hadfield, M.G. \& Paul, V.J., 2001. Natural chemical cues for settlement and metamorphosis of marine invertebrate larvae. In: Marine Chemical Ecology. J.B. McClintock \& B.J. Baker (eds.). CRC Press, Boca Raton. Pp. 431-461.

Hadfield, M.G. \& Koehl, M.A.R., 2004. Rapid behavioral responses of an invertebrate larva to dissolved settlement cue. Biol. Bull. 207: 28-43.

Hay, M.E., 2009. Marine chemical ecology: chemical signals and cues structure marine populations, communities, and ecosystems. Annu. Rev. Mar. Sci. 1: 193-212.

Hazlett, B.A., 1983. Parental behavior in decapod crustaea. In: Studies in adaptation. The behavior of higher Crustacea. (S. Rebach \& D.W. Dunham, eds.). John Wiley \& Sons, New York. Pp. 171-193.

Herrnkind, W. \& Butler, M., 1986. Factors regulating postlarval settlement and juvenile microhabitat use by spiny lobsters Panulirus argus. Mar. Ecol. Prog. Ser. 34: 23-30.

Herrnkind, W.F.; Childress, M.J. \& Lavalli, K.L., 2001. Cooperative defence and other benefits among exposed spiny lobsters: inferences from group size and behaviour. Mar. Freshw. Res. 52: 1113-1124. 
Hills, J.M. \& Thomason, J.C., 1996. A multi-scale analysis of settlement density and pattern dynamics of the barnacle Semibalanus balanoides. Mar. Ecol. Prog. Ser. 138: 103-115.

Hodgson, G., 1990. Sediment and the settlement of larvae of the reef coral Pocillopora damicornis. Coral Reefs 9: 41-43.

Horner, A.J.; Nickles, S.P.; Weissburg, M.J. \& Derby, C.D., 2006. Source and specificity of chemical cues mediating shelter preference of Caribbean spiny lobsters (Panulirus argus). Biol. Bull. 211: 128-139.

Hurlbut. C.J., 1991. Community recruitment: settlement and juvenile survival of seven CO-occurring species of sessile marine invertebrates. Mar. Biol. 109: 507-515.

Jeffs, A.G.; Tolimieri, N. \& Montgomery, J.C., 2003. Crabs on cue for the coast: the use of underwater sound for orientation by pelagic crab stages. Mar. Fresh. Res. 54: 841-845.

Jensen, G.C., 1989. Gregarious settlement by megalopae of the porcelain crab Petrolisthes cinctipes (Randall) and P. eriomerus Stimpson. J. Exp. Mar. Biol. Ecol. 131: 223-231.

Jensen, G.C., 1991. Competency, settling behaviour, and postsettlement aggregation by porcelain crab megalopae (Anomura: Porcellanidae). J. Exp. Mar. Biol. Ecol. 153: 49-61.

Jensen, G.C. \& Armstrong, D.A., 1991. Intertidal zonation among congeners: factors regulating distribution of porcelain crabs Petrolisthes spp. (Anomura: Porcellanidae). Mar. Ecol. Prog. Ser. 73:47-60.

Jensen, R.A. \& Morse, D.E., 1984. Intraspecific facilitation of larval recruitment: gregarious settlement of the polychaete Phragmatopoma californica (Fewkes). J. Exp. Mar. Biol. Ecol. 83: 107-126

Johnson, C.R. \& Strathmann, R.R., 1989. Settling barnacle larvae avoid substrata previously occupied by a mobile predator. J. Exp. Mar. Biol. Ecol. 128: 87-103.

Keough, M.J., 1984. Kin-recognition and the spatial distribution of larvae of the bryozoan Bugula neritina (L.). Evolution 38: 142-147.

Keough, M.J., 1986. The distribution of a bryozoan on seagrass blades: settlement, growth, and mortality. Ecology 67: 846-857.

Keough, M.J. \& Downes, B.J., 1982. Recruitment of marine invertebrates: the role of active larval choices and early mortality. Oecologia 54: 348-352. 
Keough, M.J. \& Raimondi, P.T., 1995. Responses of settling invertebrate larvae to bioorganic films: effects of different types of films. J. Exp. Mar. Biol. Ecol. 185: 235-253.

Kingsford, M.J.; Leis, J.M.; Shanks, A.; Lindeman, K.C.; Morgan, S.G. \& Pineda, J., 2002. Sensory environments, larval abilities and local self-recruitment. Bull. Mar. Sci. 70(1): 309-340.

Knight-Jones, E.W., 1953. Laboratory experiments on gregariousness during settling in Balanus balanoides and other barnacles. J. Exp. Biol. 30: 584-599.

Knight-Jones, E.W.; Bailey, J.H. \& Isaac, M.J., 1971. Choice of algae by larvae of Spirorbis, particularly Spirorbis syirorbis. In: Fourth European Marine Biological Symposium, D.J. Crisp (ed.), Cambridge University Press, Cambridge, pp. 89-104.

Koehl, M.A.R.; Strother, J.A.; Reidenbach, M.A.; Koseff, J.R. \& Hadfield, M.G., 2007. Individual-based model of larval transport to coral reefs in turbulent, wave-driven flow: behavioral responses to dissolved settlement inducer. Mar. Ecol. Prog. Ser. 335: 1-18.

Krimsby, L.S. \& Epifanio, C.E., 2008. Multiple cues from multiple habitats: effect on metamorphosis of the Florida stone crab, Menippe mercenaria. J. Exp. Mar. Biol. Ecol. 358: 178-184.

Krug, P.J. \& Manzi, A.E., 1999. Waterborne and surface-associated carbohydrates as settlement cues for larvae of the specialist marine herbivore Alderia modesta. Biol. Bull. 197: 94-103.

Lawton, P. \& Lavalli, K.L., 1995. Postlarval, juvenile, adolescent, and adult ecology. In: The biology of the lobster, Homarus americanus. J.R. Factor (ed.). Academic Press, New York. 47-88pp.

LeTourneux, F. \& Bourget, E., 1988. Importance of physical and biological settlement cues used at different spatial scales by the larvae of Semibalanus balanoides. Mar. Biol. 97: 57-66.

Lecchini, D.; Mills, S.C.; Brie, C.; Maurin, R. \& Banaigs, B. 2010. Ecological determinants and sensory mechanisms in habitat selection of crustacean postlarvae. Behav. Ecol. 21: 599-607.

Leis, J.M. \& Carson-Ewart, B.M., 2003. Orientation of pelagic larvae of coralreef fishes in the ocean. Mar. Ecol. Prog. Ser. 252: 239-253.

Luckenbach, M.W. \& Orth, R.J., 1992. Swimming velocities and behavior of blue crab (Callinectes sapidus Rathbun) megalopae in still and flowing water. Estuaries 15: 186-192.

MacDiarmid, A.B., 1994. Cohabitation in the spiny lobster Jasus edwardsii (Hutton 1875). Crustaceana 66(3): 341-355. 
Marsden, J.R., 1991. Responses of planktonic larvae of the serpulid polychaete Spirorbis polycerus var. augeneri to an alga, adult tubes and conspecific larvae. Mar. Ecol. Prog. Ser. 71: 245-251.

Mascetti, P. \& Wehrtmann, I.S., 1996. Aspects of the reproductive biology of Petrolisthes laevigatus (Guerin, 1835) (Decapoda, Anomura, Porcellanidae). Part III: Effects of starvation and different types of diet on larval development under laboratory conditions. Arch. Fish. Mar. Res. 43(2): 159-170.

Matsumura, K.; Hills, J.M.; Thomason, P.O.; Thomason, J.C. \& Clare, A.S., 2000. Discrimination at settlement in barnacles: laboratory and field experiments on settlement behaviour in response to settlement-inducing protein complexes. Biofouling 16: 181-190.

McLay, C., 1988. Brachyura and crab-like anomura of New Zealand. Leigh Laboratory Bulletin 22. Pp. 463.

Meadows, P.S. \& Campbell, J.I., 1972. Habitat selection by aquatic invertebrates. Adv. Mar. Biol. 10: 271-382.

Menge, B.A., 1991. Relative importance of recruitment and other causes of variation in rock intertidal community structure. J. Exp. Mar. Biol. Ecol. 146: 69-100.

Meyer-Rochow, V.B. \& Meha, W.P., 1994. Tidal rhythm and the role of vision in shelter-seeking behaviour of the half-crab Petrolisthes elongatus (Crustacea; Anomura; Porcellanidae). J. Royal Soc. New Zealand 24(4): 423-427.

Minchinton, T.E. \& Scheibling, R.E., 1991. The Influence of Larval Supply and Settlement on the Population Structure of Barnacles. Ecology 72(5): 1867-1879.

Minchinton, T.E. \& Scheibling, R.E., 1993. Free space availability and larval substratum selection as determinants of barnacle population structure in developing rocky intertidal community. Mar. Ecol. Prog. Ser. 95: 233-244.

Moksnes, P.O., 2004. Interference competition for space in nursery habitats: density-dependent effects on growth and dispersal in juvenile shore crabs Carcinus maenas. Mar. Ecol. Prog. Ser. 281: 181-191.

Moksnes, P.O.; Hedvall, O. \& Reinwald, T., 2003. Settlement behavior in shore crabs Carcinus maenas: why do postlarvae emigrate from nursery habitats? Mar. Ecol. Prog. Ser. 250: 215-230.

Montfrans, J.; Ryer, C.H. \& Orth, R.J., 2003. Substrate selection by blue crab Callinectes sapidus megalopae and first juvenile instars. Mar. Ecol. Prog. Ser. 260: 209-217.

Montgomery, J.C.; Jeffs, A.; Simpson, S.D.; Meekan, M. \& Tindle, C., 2006. Sound as an orientation cue for the pelagic larvae of reef fishes and decapod crustaceans. Adv. Mar. Biol. 51: 143-196. 
Morse, A.N.C., 1991. How do planktonic larvae know where to settle? Am Scient. 79: 154-167.

Morse, A.N.C. \& Morse, D.E., 1984. Recruitment and metamorphosis of Haliotis larvae induced by molecules uniquely available at the surfaces of crustose red algae. J. Exp. Mar Biol. Ecol. 75: 191-215.

Morse, D.E., 1990. Recent progress in larval settlement and metamorphosis: closing the gaps between molecular biology and ecology. Bull. Mar. Sci. 46: 465-483.

Morse, D.E.; Hooker, N.; Duncan, H. \& Jensen, L., 1979. $\gamma$-aminobutyric acid, a neurotransmitter, induces planktonic abalone larvae to settle and begin metamorphosis. Science 204: 407-410.

Morse, D.E.; Tegner, M.; Duncan, H.; Hooker, N.; Trevelyan, G. \& Cameron, A., 1980. Induction of settling and metamorphosis of planktonic molluscan (Haliotis) larvae. III: signalling by metabolites of intact algae is dependent on contact. In: Chemical Signals. D. Müller-Schwarze \& R.M. Silverstein (eds.). Plenum Press, New York. Pp 67-86.

O'Connor, N.J., 2007. Stimulation of molting in megalopae of the Asian shore crab Hemigrapsus sanguineus: physical and chemical cues. Mar. Ecol. Prog. Ser. 352: 1-8.

O’Connor, N.J. \& Gregg, A.S., 1998. Influence of potential habitat cues on duration of the megalopal stage of the fiddler crab Uca pugnax. J. Crustac. Biol. 18: 700-709.

O'Connor, N.J. \& Judge, M.L., 2004. Molting of fiddler crab larvae Uca minax megalopae: stimulatory cues are specific to salt marshes. Mar. Ecol. Prog. Ser. 282: 229-236.

Osmann, R.W.; Whitlatch, R.B. \& Zajac, R.N., 1989. Effect of resident species on recruitment into a community; larval settlement versus post-settlement mortality in the oyster Crassostrea virginica. Mar. Ecol. Prog. Ser. 54: 61-73.

Pawlik, J.R., 1986. Chemical induction of larval settlement and metamorphosis in the reef-building tube worm Phragmatopoma californica (Sabellariidae Polychaeta). Mar. Biol. 91: 59-68.

Pawlik, J.R., 1992. Chemical ecology of the settlement of benthic marine invertebrates. Oceanogr. Mar. Biol. Annu. Rev. 30: 273-335.

Pawlik, J.R.; Butman, C.A. \& Starczak, V.R., 1991. Hydrodynamic facilitation of gregarious settlement of a reef-building tube worm. Science 251: 421-424.

Pearce, C.M. \& Scheibling, R.E., 1990. Induction of metamorphosis of larvae of the green sea urchin, Strongylocentrotus droebachiensis, by coralline red algae. Biol. Bull. 179: 304-311. 
Pechenik, J.A., 1990. Delayed metamorphosis by larvae of benthic marine invertebrates: does it occur? Is there a price to pay? Ophelia 32: 63-94.

Pechenik, J.A., 1999. On the advantages and disadvantages of larval stages in benthic marine invertebrate life cycles. Mar. Ecol. Prog. Ser. 177: 269-297.

Phillips, B.F. \& Penrose, J.D., 1985. The puerulus stage of the spiny (rock) lobster and its ability to locate the coast. School of Physics and Geosciences, Western Australian Institute of Technology, Report SPG 374/1985/AP92. Pp. 48.

Pineda, J., 2000. Linking larval settlement to larval transport: Assumptions, potentials, and pitfalls. Oceanography of the Eastern Pacific 1: 84-105.

Pineda, J.; Hare, J.A. \& Sponaugle, S., 2007. Larval transport and dispersal in the coastal ocean and consequences for population connectivity. Oceanography 20(3): 22-39.

Price, N., 2010. Habitat selection, facilitation, and biotic settlement cues affect distribution and performance of coral recruits in French Polynesia. Oecologia 163: 747-758.

Raimondi, P.T., 1988a. Rock type affects settlement, recruitment, and zonation of the barnacle Chtalamus anisopoma Pilsbry. J. Exp. Mar. Biol. Ecol. 123: 253-267.

Raimondi, P.T., 1988b. Settlement cues and determination of the vertical limit of an intertidal barnacle. Ecology 69: 400-407.

Raimondi, P.T., 1990. Patterns, mechanisms, consequences of variability in settlement and recruitment of an intertidal barnacle. Ecol. Monogr. 60: 283309.

Raimondi, P.T., 1991. Settlement behavior of Chthamalus anisopoma larvae largely determines the adult distribution. Oecologia 85: 349-360.

Ratchford, S.G. \& Eggleston, D.B., 1998. Size and scale dependent chemical attraction contribute to an ontogenetic shift in sociality. Animal Behav. 56: 1027-1034.

Ray, M. \& Stoner, A.W., 1994. Experimental analysis of growth and survivorship in a marine gastropod aggregation: balancing growth with safety in numbers. Mar. Ecol. Prog. Ser.105: 47-59.

Rittschof, D.; Forward, R.B.; Cannon, G.; Welch, J.M.; McClary, M.; Holm, E.R.; Clare, A.S.; Conova, S.; McKelvey, L.M.; Bryan, P.; van-Dover, C.L.; Clare, A.S.; Fusetani, N. \& Jones, M.B., 1998. Cues and context: larval responses to physical and chemical cues. Biofouling 12: 31-44. 
Rodriguez, S.R.; Ojeda, F.P.; Inestrosa, N.C., 1993. Settlement of benthic marine invertebrates. Mar. Ecol. Prog. Ser. 97: 193-207.

Salierno, J.D.; Rebach, S. \& Christman, M.C., 2003. The effects of interspecific competition and prey odor on foraging behavior in the rock crab, Cancer irrogatus (Say). J. Exp. Mar. Biol. Ecol. 287: 249-260.

Sastry A.N., 1983. Ecological aspects of reproduction. In: The Biology of Crustacea. D. Bliss (ed.). Vol. 8, Academic Press, London. Pp.179-269.

Scheibling, R.E. \& Robinson, M.C., 2008. Settlement behaviour and early postsettlement predation of the sea urchin Strongylocentrotus droebachiensis. J. Exp. Mar. Biol. Ecol. 365: 59-66.

Scheltema, R.S., 1961. Metamorphosis of the veliger larva of Nassarius obsoletus (Gastropopoda) in response to bottom sediment. Biol. Bull. 120: 92-109.

Scheltema, R.S., 1974. Biological interactions determining larval settlement of marine invertebrates. Thalassia Jugosl. 10: 263-296.

Scott, M.S., 1958. Studies on the false crab, Petrolisthes elongatus Milne Edwards. M.Sc.-thesis, Canterbury University, Christchurch, NZ.

Snelgrove, P.V.R.; Grassle, J.P. \& Butman, C.A., 1998. Sediment choice by settling larvae of the bivalve, Spisula solidissima (Dillwyn), in flow and still water. J. Exp. Mar. Biol. Ecol. 231(2):171-190.

Stamps, J. \& Krishnan, V.V., 2005. Nonintuitive cue use in habitat selection. Ecology 86(11): 2860-2867.

Stelinski, L.L.; Gut, L.J. \& Vogel, K.J., 2003. Behaviours of naïve vs. pheromone exposed leafroller moths in plumes from high-dosage pheromone dispensers in a sustained flight wind tunnel: implications for mating disruption of these species. J. Insect Behav. 17(4): 533-554.

Steneck. R.S., 1982. A limpet-coralline alga association: adaptations and defences between a selective herbivore and its prey. Ecology 63: 507-522.

Sulkin, S.D. \& Van Heukelum, W., 1982. Larval recruitment in the crab Callinectes sapidus Rathbun: an amendment to the concept of larval retention in estuaries. In: Estuarine comparisons. V.S. Kennedy (ed.), Academic Press, New York. Pp. 459-476.

Swanson, R.L.; Marshall, D.J. \& Steinberg, P.D., 2007. Larval desperation and histamine: how simple responses can lead to complex changes in larval behaviour. J. Exp. Biol. 210: 3228-3235.

Tamburri, M.N.; Finelli, C.M.; Wethey, D.S. \& Zimmer-Faust, R.K. (1996) Chemical induction of larval settlement behavior in flow. Biol. Bull. 191: 367-373. 
Thorson, G., 1950. Reproductive and larval ecology of marine bottom invertebrates. Biol. Rev. (Cambridge) 25(1): 1-45.

Thorson, G., 1964. Light as an ecological factor in the dispersal and settlement of larvae of marine bottom invertebrates. Ophelia 1: 167-208.

Todd, C.D., 1998. Inhibition and facilitation of settlement of epifaunal marine invertebrate larvae by microbial biofilm cues. Biofouling 12 (1-3): $81-118$.

Toonen, R.J. \& Pawlik, J.R., 1994. Foundations of gregariousness. Nature 370: 511-512.

Toonen, R.J. \& Pawlik, J.R., 2001a. Settlement of the gregarious tube worm Hydroides dianthus (Polychaeta: Serpulidae). I. Gregarious and nongregarious settlement. Mar. Ecol. Prog. Ser. 224: 103-114.

Toonen, R.J. \& Pawlik, J.R., 2001b. Settlement of the gregarious tube worm Hydroides dianthus (Polychaeta: Serpulidae). II. Testing the desperate larva hypothesis. Mar. Ecol. Prog. Ser. 224: 115-131.

Trapido-Rosenthal, H.G. \& Morse, D.E., 1986. Regulation of receptor-mediated settlement and metamorphosis in larvae of a gastropod mollusc (Haliotis rufescens). Bull. Mar. Sci. 39: 383-392.

Vermeij, M.J.A., 2005. Substrate composition and adult distribution determine recruitment patterns in a Caribbean brooding coral. Mar. Ecol. Prog. Ser. 295: 123-133.

Walters, L.J. \& Wethey, D.S., 1996. Settlement and early post-settlement survival of sessile marine invertebrates on topographically complex surfaces: the importance of refuge dimensions and adult morphology. Mar. Ecol. Prog. Ser. 137: 161-171.

Wear, R.G., 1964. Larvae of Petrolisthes novaezelandiae Filhol, 1885 (Crustacea, Decapoda, Anomura). Trans. Royal Soc. New Zealand 4(18): 229-244.

Wear, R.G., 1965a. Breeding cycles and pre-zoea larva of Petrolisthes elongatus (Milne Edwards, 1837). (Crustacea, Decapoda). Trans. Royal Soc. New Zealand 13(5): 169-175.

Wear, R.G., 1965b. Larvae of Petrolisthes spinosus Miers, 1876 (Crustacea, Decapoda, Anomura) with keys to New Zealand porcellanid larvae. Trans. Royal Soc. New Zealand 5(12): 147-168.

Wehrtmann, I.S. \& Dittel, A.I., 1990. Utilization of floating mangrove leaves as a transport mechanism of estuarine organisms, with emphasis on decapod crustacean. Mar. Ecol. Prog. Ser. 60: 67-73. 
Welch, J.M.; Rittschof, D.; Bullock, T.M. \& Forward, R.B., 1997. Effects of chemical cues on settlement behaviour of blue crab Callinectes sapidus postlarvae. Mar. Ecol. Prog. Ser. 154: 143-153.

Wethey, D.S., 1983. Effects of crowding on fecundity in barnacles: Semibalanus (Balanus) balanoides, Balanus glandula, and Chthamalus dalli. Can. J. Zool. 62: 1788-1795.

Wethey, D.S., 1984. Spatial pattern in barnacle settlement: day to day changes during the settlement season. J. Mar. Biol. Assoc. U.K. 64: 687-698.

Wethey, D.S., Luckenbach, M.W. \& Kelly, C.A., 1988. Larval settlement in barnacles: influence of water flow. In: Marine Biodeterioration. M.F. Thompson et al., Oxford and IBH, New Delhi. Pp. 151-163.

Young, C.M., 1990. Larval ecology of marine invertebrates: A sesquicentennial history. Ophelia 32: 1-2.

Young, C.M., 1995. Behaviour and locomotion during the dispersal phase of larval life. In: Ecology of Marine Invertebrate Larvae. L. McEdward (ed.). CRC Press, Boca Raton, Florida. Pp. 249-278.

Young, C.M. \& Chia, F.S., 1984. Microhabitat-associated variability in survival and growth of subtidal solitary ascidians during the first 21 days after settlement. Mar. Biol. 81: 61-68.

Zeldis, J.R., 1985. Ecology of Munida gegaria (Decapoda: Anomura): distribution and abundance, population dynamics and fisheries. Mar. Ecol. Prog. Ser. 22: 77-99.

Zimmer, R.K.; Commins, J.E. \& Browne, K.A., 1999. Regulatory effects of environmental chemical signals on search behavior and foraging success. Ecology 80: 1432-1446.

Zito-Livingston, A.M. \& Childress, M.J., 2009. Does conspecific density influence the settlement of Caribbean spiny lobster Panulirus argus postlarvae? New Zealand J. Mar. Fresh. Res. 43: 313-325. 


\section{Appendix 4}

\subsection{Potential conspecific cues (larvae)}
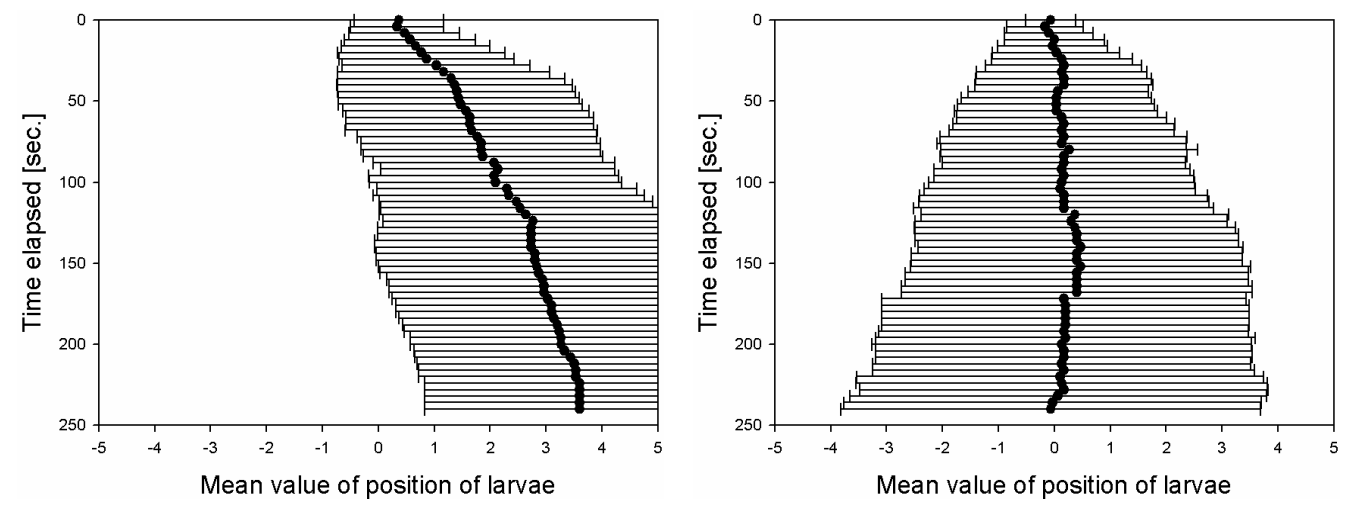

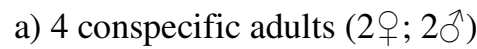

b) Control
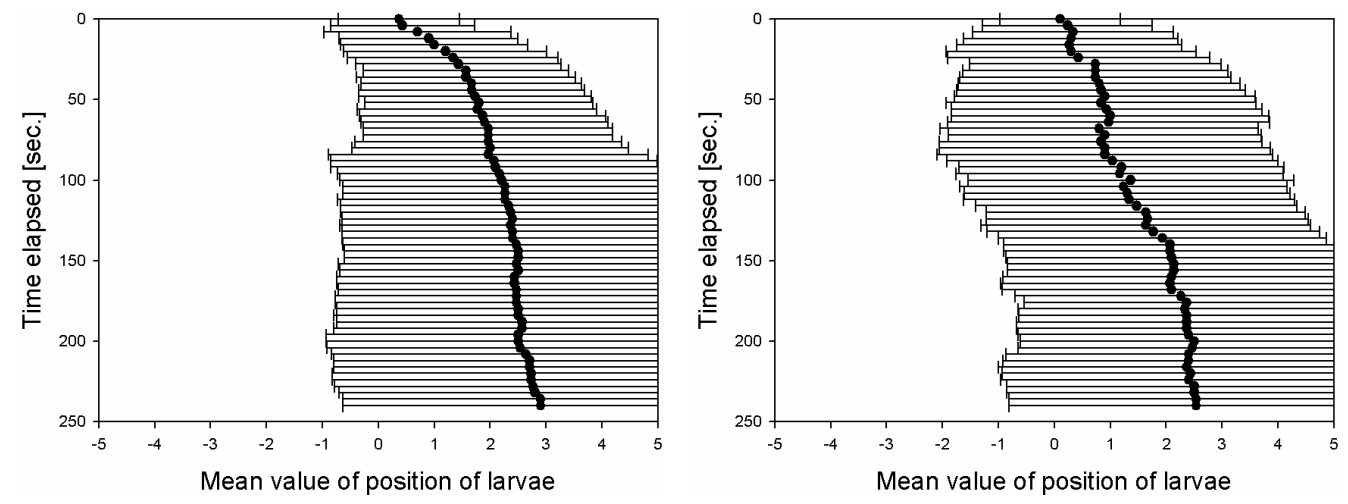

c) 4 conspecific adults $(4$ ㅇ $)$

d) 4 conspecific adults $\left(4{ }^{\Uparrow}\right)$

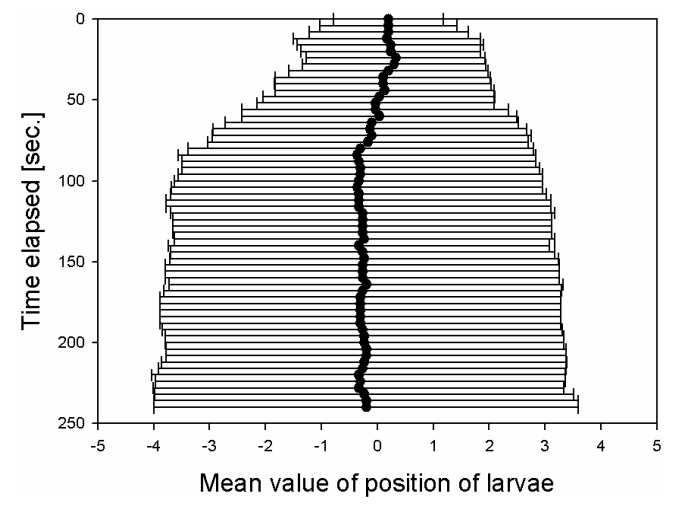

e) 10 conspecific larvae (megalopae)

Appendix 4.1.1: "Probability paths" of swimming P. elongatus larvae (megalopae) in a single-option choice chamber in presence of conspecific adults (a, c, d) as well as conspecific larvae (e). The $\mathrm{x}$-axis represents the subdivision of the choice chamber, where 0 is the point of release of larvae at $t_{0}, 5$ is directly adjacent to the compartment containing the source of a potential settlement cue (empty in control, b), and -5 marks the opposite side of the choice chamber. Error bars represent standard deviations. 


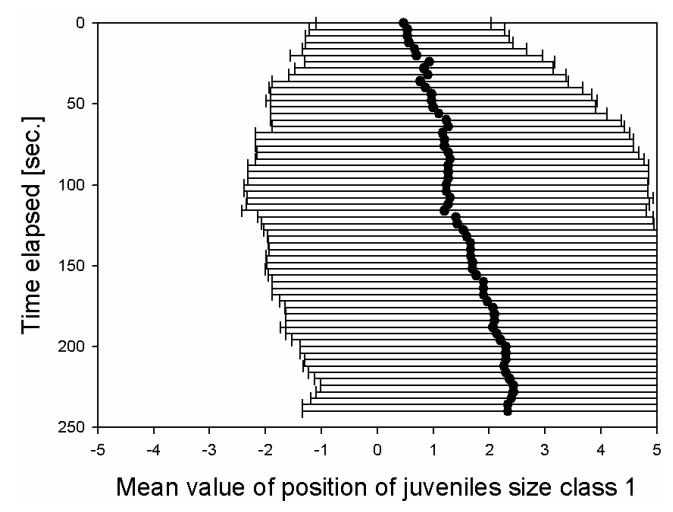

a) 4 conspecific adults $(2 \odot ; 2 \widehat{\jmath})$ on juveniles size class 1 (3.0-5.0mm CW)

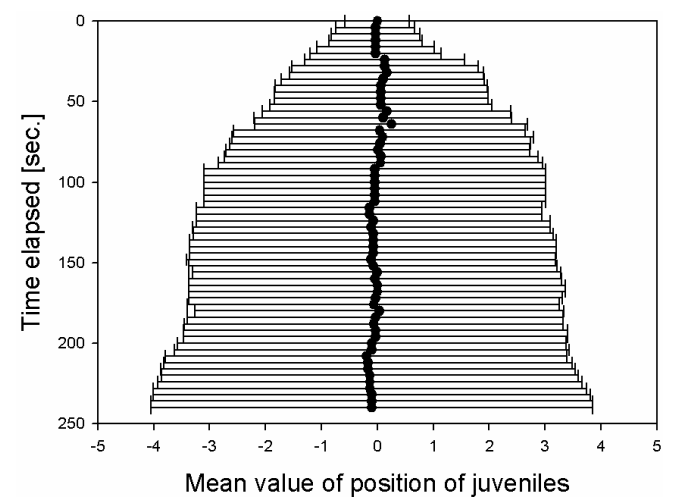

c) Control for juveniles (both size classes are equally represented)

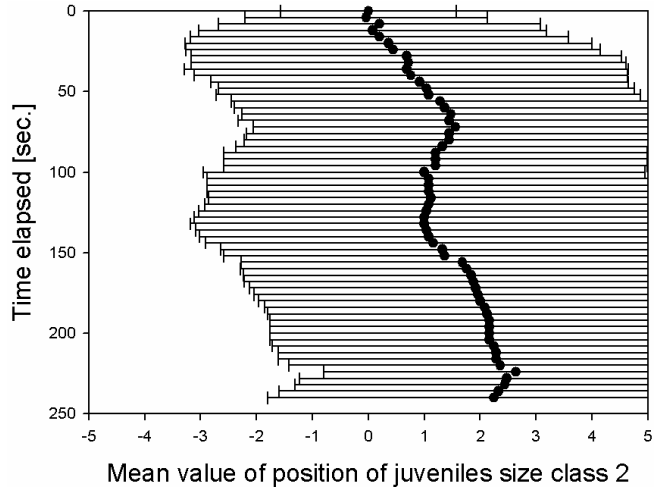

b) 4 conspecific adults $(2 \circ ; 2 \overbrace{}^{\Uparrow})$ on juveniles size class 2 (5.0-7.0mm CW)

Appendix 4.1.2: "Probability paths" of $P$. elongatus juveniles (after metamorphosis) in a single-option choice chamber in presence of conspecific adults. As above, the $\mathrm{x}$-axis represents the subdivision of the choice chamber. Error bars represent standard deviations; p-values represent paired t-test results. 


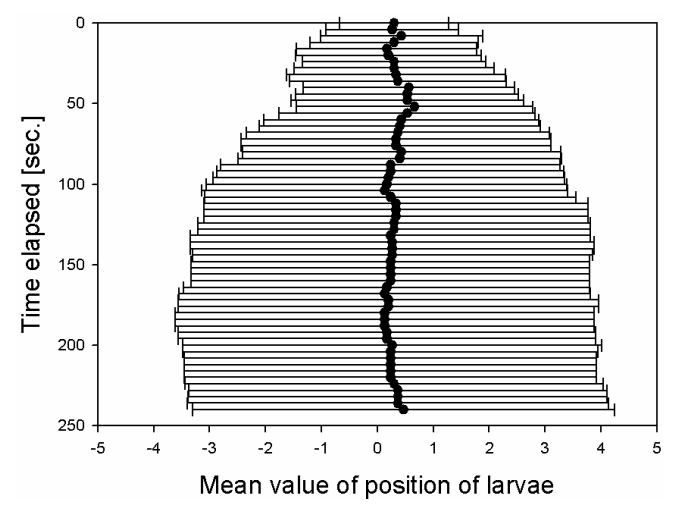

a) 4 adults $H$. rotundifrons $(2 \subsetneq ; 2 \widehat{\bigcirc})$

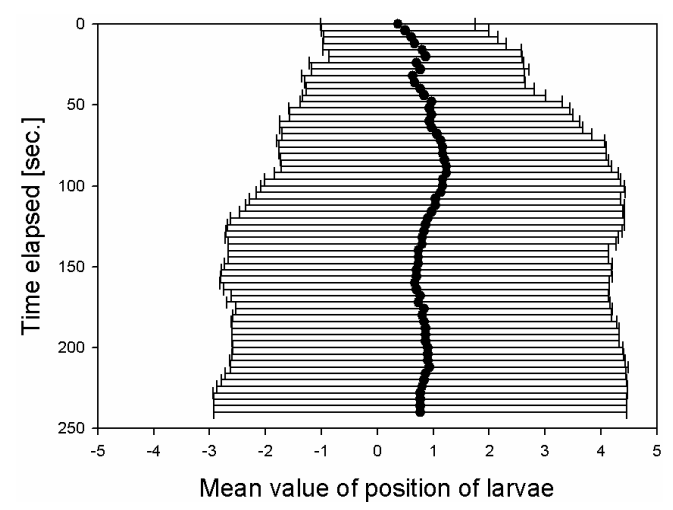

c) 4 pebbles with biofilms

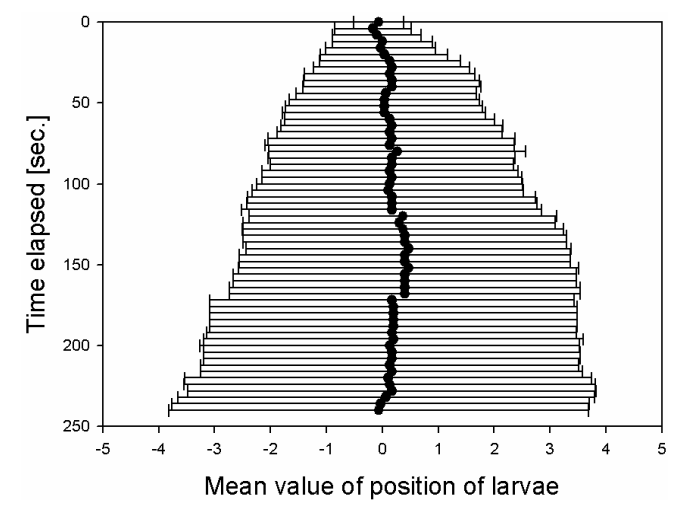

b) Control

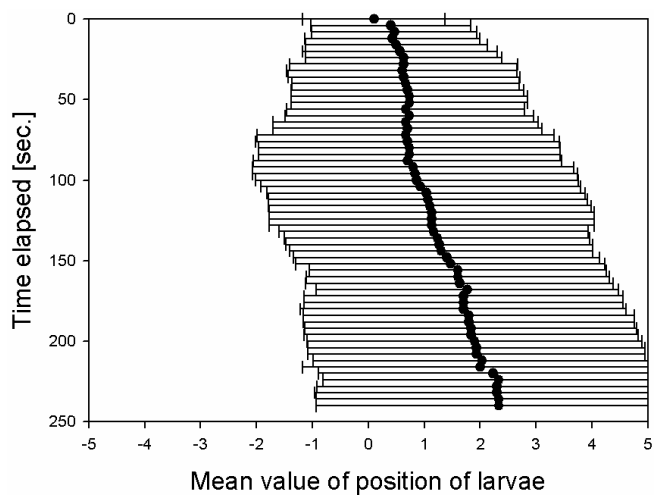

d) 4 pebbles with biofilms \& coralline crusts

Appendix 4.2.1: "Probability paths" of swimming P. elongatus larvae (megalopae) in a single-option choice chamber in presence of non-conspecific sources of potential settlement cues. As above, the x-axis represents the subdivision of the choice chamber. Error bars represent standard deviations; p-values represent paired t-test results. 

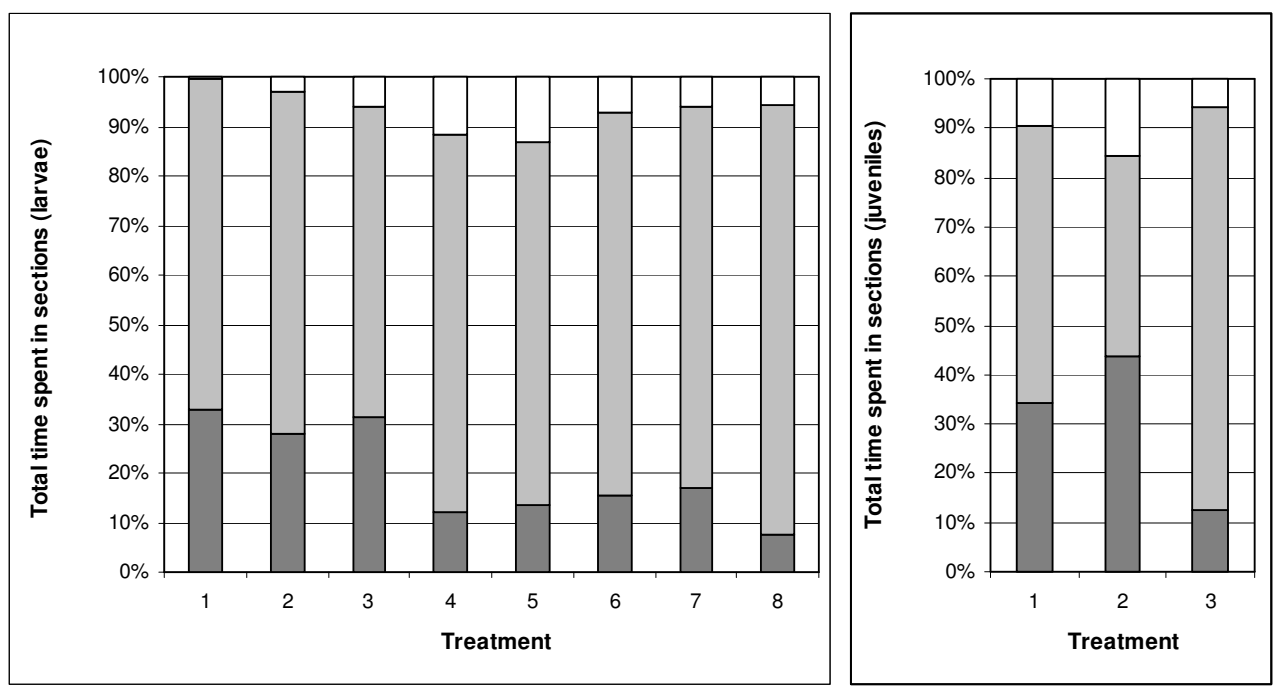

Section +5

Sections +4 to -4

Section -5

Treatments:

1) 4 conspec. adults $(2 \mathrm{~m}, 2 \mathrm{f})$

2) 4 conspec. adults (4m)

3) 4 conspec. adults (4f)

4) 10 conspec. Larvae
5) $4 \mathrm{H}$. rotundifrons (2m, 2f)

6) Pebbles biofilm

7) Pebbles biofilm + crusts

8) Control larvae 1a) 4 conspec. adults Juveniles size class 1

2a) 4 conspec. adults Juveniles size class 2 3a) Control juveniles

Appendix 4.3: The total time P. elongatus larvae (on left) and juveniles (on right) spent in sections of the choice chamber in percent of total observation time $\left(t_{0}-t_{240}\right)$. Section +5 was located directly adjacent to the source compartment of the choice chamber, section -5 at the opposite end, and sections +4 to -4 were located in between (see Fig. 4.1). The overall durations of stay are similar to the distribution of responses of larvae and juveniles at the end of observation $\left(\mathrm{t}_{240}\right)$ shown in Fig. 4.6: Larvae as well as juveniles exhibit a positive response to conspecific cues. 


\section{Chapter 5}

\section{Density dependence: Effects of conspecific density on survival, individual growth, feeding efficiency and reproduction.}

\subsection{Introduction}

Petrolisthes elongatus (Milne Edwards, 1837) lives in dense multi-size aggregations under boulders, within the interstitial space of cobble beaches as well as among mussel beds in the intertidal zone of rocky shores (Morton \& Miller, 1973) throughout Tasmania and New Zealand (Haig, 1960, 1964; McLay, 1988). Even though density dependence is a ubiquitous phenomenon it has been widely acknowledged that aggregation may be associated with a number of benefits, especially at intermediate densities and in social species. The advantages of conspecific attraction and gregariousness comprise conspecific cueing (using conspecifics as an indicator of habitat quality) (Raimondi, 1988; Jensen, 1989), access to mates (Burke, 1986; Metaxas et al., 2002), greater reproductive output (Wethey, 1984), improved feeding efficiency (Bertness et al., 1998), increased survival (Bertness, 1989; Leslie, 2005), reduced predation risk (Jensen \& Armstrong, 1991; Ray \& Stoner, 1994), habitat amelioration (Bertness et al., 1991; Bertness \& Leonard, 1997), reduced desiccation risk as an aspect of facilitation (Bertness, 1989), as well as Allee effects (i.e., positive density dependence) (Allee, 1931; Allee et al., 1949; Donahue, 2006). Due to these benefits, aggregation has been viewed as an evolutionary advantageous state, traded off against the costs of limiting resources (Parrish \& Edelstein-Keshet, 1999). Because areas of suitable habitat for $P$. elongatus are limited and patchy on a wide range of spatial scales, competition for space seems inevitable. However, intraspecific competition but may be comparatively weak due to an apparent selection pressure towards gregariousness (Donahue, 2004). It is therefore likely that in aggregating species such as porcelain crabs the benefits of a clustered distribution outweigh the costs even at higher densities (Leslie, 2005; Donahue, 2006), dependent on the specific carrying capacity of a habitat patch. 
As suspension feeders, porcelain crabs use their setose $3^{\text {rd }}$ maxillipeds for active and passive filtration (Wicksten, 1973; Caine, 1975), dependent on flow speed (Trager \& Genin, 1993; Achituv \& Pedrotti, 1999). As an adaptation to hydrodynamic conditions of the surf zone to optimize feeding efficiency, feeding motions are synchronized with flow oscillations (Trager et al., 1992; Valdivia \& Stotz, 2006). Molenock (1976) and Jensen (1990) suggested that Petrolisthes ssp. compete for high quality feeding spots characterized by high flow velocities. Donahue (2004) found that porcelain crabs fed less frequently at high density which is consistent with exploitative competition due to an impact of density on food availability. Competition for food depends on both food availability and population density and may result in size-dependent agonistic interactions that have effects on feeding rate and, ultimately, on growth rate (Donahue, 2004).

Generally, growth rates of intertidal suspension feeders depend on local environmental factors such as hydrodynamic conditions, the degree of parasite infestation as well as on regional environmental factors such as water temperature, salinity, and richness in suspended nutrients (Crisp, 1960). In turn, carrying capacity and thus population density is regulated by physical conditions, availability of food and suitable habitat, as well as inter- and intraspecific interactions, all of which may spatio-temporally fluctuate. While the underlying mechanism of self-thinning, a concept traditionally proposed for plant populations (e.g. Odum, 1971; Westoby, 1981), is most likely density dependent mortality in sessile populations (e.g. barnacles, Whethey, 1983), local density in mobile organisms (e.g. crabs, Pile et al., 1996) may be regulated by migration.

Short-term and small-scale variation in seston availability and quality within nearshore environments has been documented by various authors (e.g. Fegley et al., 1992; Wilson-Ormond et al., 1996; Chaparro et al., 2008). This variation of food conditions can have significant effects on individual and population characteristics of benthic suspension feeders such as reproduction (Hines, 1978; Soniat \& Ray, 1985) and growth rates (Cahalan et al., 1989; Lesser et al., 1994), as well as productivity (MacDonald \& Thompson, 1985; Brown, 1988) and spatial distributions (Wildish \& Kristmanson, 1979). The dynamics of sessile suspension feeders, such as mussels, bryozoans, and zoanthids, are substantially regulated by density-dependent food consumption (Frechette \& Lefaivre, 1990; 
Frechette et al., 1992; Okamura, 1992; Tanner, 2002), and not just by competition for space (Connell, 1961; Dayton, 1971; Paine, 1974). If growth is density dependent, reproductive traits are likely to be affected as well, since generally, female body size is the principal determinant of reproductive output (Annala, 1991; Hines, 1991; Corey \& Reid, 1991; Reid \& Corey, 1991).

The level of density-dependent intraspecific competition in Petrolisthes spp. may not only be reflected by growth rate but also by frequency of limb loss, due to claw use in physical contests during competitive interactions (Molenock, 1976; Jensen \& Armstrong, 1991; Donahue, 2004; Wasson \& Lyon, 2005; Rypien \& Palmer, 2007). In turn, the energy allocation for limb regeneration is likely to affect individual growth rate (Donahue, 2004) and fitness. In Petrolisthes spp. in general (Wasson et al., 2002) and P. elongatus in particular (Hazlett et al., 2000, 2004) chelipeds and walking legs are autotomized as an important defence mechanism when attempting to escape mechanical (Scott, 1958; McLay, 1988) or physiological stress (own obs.). Rypien \& Palmer (2007) found significantly higher proportions of puncture wounds on chelipeds of $P$. cinctipes at sites with higher densities and wave exposure. Autotomy, the reflex severance of an appendage at a predetermined breakage plane in the basi-ischium (Wood \& Wood, 1932; Hopkins, 1993), is a strategy that may provide immediate survival benefits such as predator avoidance and wound limitation in many decapods (Bliss, 1960; McVean, 1982). However, the loss of one or more limbs can result in long-term functional and energetic costs that may have profound effects on the population and community (Juanes \& Smith, 1995, and literature therein).

In this chapter, I use manipulative experiments to investigate the costs of gregariousness by examining the effect of conspecific density on size-dependent growth rates, mortality, feeding activity, and limb loss. Because of its ecology, $P$. elongatus is a good model organism to study the trade-offs between survival benefits and growth costs of aggregation. Further, I analyse the long term effects of resource allocation for limb regeneration on both growth rate and reproductive output. 


\subsection{Materials and Methods}

\subsubsection{Effect of population density and food availability on growth rate}

Petrolisthes elongatus of various sizes and of both sexes were collected from the intertidal zone at the river mouth of the Hutt River $\left(41^{\circ} 14^{\prime} 49.50^{\prime \prime} \mathrm{S}, 174^{\circ}\right.$ 53'57.00" E, Fig.5.1), the site with the highest population densities throughout the Wellington region (chapter 2). The crabs were transported to the Victoria University Coastal Ecology Laboratory (VUCEL, formerly Island Bay Marine Laboratory) where the experiments were conducted. Prior the start of any experiment, the animals were held for at least $24 \mathrm{~h}$ in tanks supplied with unfiltered seawater.

For the examination of the effect of population density and food availability on growth rate of Petrolisthes elongatus, a laboratory experiment with a fully crossed factorial design was conducted, based on a design used by Donahue (2004) using Petrolisthes cinctipes as model species. Two food levels (FL) crossed with two density treatments (D) were tested: FL1/D1; FL1/D2; FL2/D1 and FL2/D2. For each treatment, 6 replicate tanks $(30 \mathrm{~cm} \times 30 \mathrm{~cm} \times 30 \mathrm{~cm})$ were used, filled with $15 \mathrm{~L}$ filtered seawater $(10 \mu \mathrm{m}$ mesh size $)$ at $12-15^{\circ} \mathrm{C}$. Ventilation, agitation and flow were ensured by airstones connected to air pumps via PVC tubing. As a food source, Spirulina spp. flakes were fed to the crabs, ground with mortar and pestle until a fine powder was obtained. Dried Spirulina (more correctly: Arthrospira spp.) was chosen due to its high contents of proteins and minerals (Belay, 1997; Othes \& Pire, 2001) similar to the natural food sources of P. elongatus (i.e. detritus and phytoplankton) and recommended for feeding Porcellanidae by various aquarists (e.g. http://reefkeeping.com/issues/2007-05/as/index.php). The concentrations used in the two food level treatments were based on estimates of natural food levels at south coast sites as well as in Wellington Harbour investigated by various authors (Gardner, 2000; Gardner \& Thompson, 2001; Helson et al., 2007). For FL1, 100mg of Spirulina powder were added to $15 \mathrm{~L}$ filtered seawater; for FL2 800mg.

Density treatments were designed to match high and low density patches observed in the field (chapter 2): I used 12 (low density) or 36 (high density), crabs respectively, divided into four size classes: A) $3.5 \mathrm{~mm}-5.5 \mathrm{~mm}$, B) $6.0 \mathrm{~mm}$ $8.5 \mathrm{~mm}$, C) $9.0 \mathrm{~mm}-11.5 \mathrm{~mm}$, and D) $12.0 \mathrm{~mm}-15.0 \mathrm{~mm}$ carapace width $(\mathrm{CW})$. 
Since in natural multi-size populations smaller individuals are more frequent than larger ones the distribution of size classes in both density treatments was 1): 4:4:2:2 (A:B:C:D) for the low density treatment, and 12:12:6:6 (A:B:C:D) for the high density treatment. All individuals were marked with coloured and numbered "Queen Bee" tags (manufacturer: E.H.Thorne Ltd., Beehive Works, Wragby, Market Rasen, Lincolnshire, U.K., http://www.thorne.co.uk/index.htm) glued onto the carapace. In order to reduce stress levels, provide a substrate for the crabs to hold on to, and shelter from light, each tank contained a number of cobbles taken from the natural habitat that were thoroughly rinsed with freshwater before.

The experiment commenced after an adjustment period of 3 weeks due to high initial mortality rates $(>25 \%)$, and terminated after further 70 days. Twice per week, the crabs were fed, the tanks were cleaned and the seawater was renewed. The CW of each animal was measured weekly with a digital calliper, and individual wet weight determined by weighing on an electronic balance after quickly drying off excess water on a paper tissue. If necessary (i.e. after moulting), crabs were retagged; dead individuals were replaced to maintain initial densities. Due to different light conditions and performance of the airstones, the crabs were assigned to the tanks randomly each week after measurements were taken.

Individual growth rate (the response variable, IGR) was calculated as the daily wet body weight $(\mathrm{BW})$ increase for each crab: $\left[\ln \left(\mathrm{BW}_{\text {final }}\right)-\ln \left(\mathrm{BW}_{\text {initial }}\right)\right] /$ no. of days. Only the 382 crabs that retained both chelipeds and had been in the experiment for at least 70 days between initial and final measurements were used in the analysis. A general linear model (GLM) was used to analyze the effect of density (D), food level (F), size-class (S), and aquarium (A) on IGR: IGR D + F $+\mathrm{S}+(\mathrm{D} \times \mathrm{F})+(\mathrm{D} \times \mathrm{S})+(\mathrm{F} \times \mathrm{S})+(\mathrm{D} \times \mathrm{F} \times \mathrm{S})+\mathrm{A}(\mathrm{D} \times \mathrm{F})+\varepsilon$, in which $\mathrm{A}(\mathrm{D} \times \mathrm{F})$ is the error term for $\mathrm{D}, \mathrm{F}$, and $\mathrm{D} \times \mathrm{F}$, and $\varepsilon$ is the error term for $\mathrm{S}, \mathrm{D} \times \mathrm{S}, \mathrm{F} \times \mathrm{S}$, and D x F x S. Since there was significant non-normality and heteroscedasticity in the data, S represents the natural logarithm of initial carapace width as a continuous variable instead of the categorical variable size class. The residuals of the transformed model met the assumptions of normality and homogeneity of variance. While I present significance levels of the transformed model, I plotted individual growth rates against categorized size classes to ease interpretation. 
The average mortality rates over 10 weeks (in \% of number of crabs within size class and treatment) were estimated by the frequency of first replacements of crabs. Similar to the GLM above I analyzed the effect of density (D), food level (F), size-class (as natural logarithm of initial carapace width) (S), and aquarium (A) on mortality rate: $\mathrm{M} \sim \mathrm{D}+\mathrm{F}+\mathrm{S}+(\mathrm{D} \times \mathrm{F})+(\mathrm{D} \times \mathrm{S})+(\mathrm{F} \times \mathrm{S})+(\mathrm{D} \times \mathrm{F} \times \mathrm{S})+$ $\mathrm{A}(\mathrm{D} \times \mathrm{F})+\varepsilon$, where $\mathrm{M}$ is the square root arcsine transformed average mortality for each aquarium. Statistical analyses were calculated using JMP 4.0.4 (SAS Institute, September 2001).

\subsubsection{Effect of density and food level on frequency of filter-feeding}

For this experiment, the same setup including density- and food level treatments described in 5.2.1 were used, apart from a replacement of the natural boulders by a propped up concrete slab (one per tank) to facilitate observation and counting. Feeding activity of all crabs within 4 size classes and 6 replicate tanks was observed every two hours for $24 \mathrm{~h}$ from $8 \mathrm{am}$ to $8 \mathrm{am}$ on the following day. During a 2 minute observation period the numbers of individuals per size class displaying feeding behaviour were recorded from each tank. This experiment was conducted three times spread over three months with different individuals for each run. A 3-way repeated measures ANOVA was performed to analyze the effect of density (D), food level $(\mathrm{F})$, and size-class $(\mathrm{S})$ on the frequency of filter-feeding (FF) (i.e. the proportion of crabs feeding at each time point), using the model $\mathrm{FF} \sim \mathrm{D}+\mathrm{F}+\mathrm{S}+(\mathrm{D} \times \mathrm{F})+(\mathrm{D} \times \mathrm{S})+(\mathrm{F} \times \mathrm{S})+(\mathrm{D} \times \mathrm{F} \times \mathrm{S})$. Sphericity was assumed due to the non-significant result of Mauchly's test $(p=0.2172)$. Before post hoc tests were applied, $\alpha$-levels of the results were Bonferroni adjusted. The proportion of crabs feeding within each tank, size class and treatment were arcsine transformed to meet the normality assumption. A one-way GLM ANOVA showed no significant difference between the three replicate observations $(\mathrm{p}=0.0716)$. Further, no differences between density and food level treatments could be detected; hence, the datasets were combined for the analysis.

\subsubsection{Effects of limb loss on growth rate}

To investigate the effect of limb loss on growth rate of Petrolisthes elongatus, the changes in body mass and $\mathrm{CW}$ over time were recorded, with either removed chelipeds (by induced autotomy) or with all limbs present. The experiment was conducted at the National Institute of Water and Atmospheric Research (NIWA) 
facility in Wellington, New Zealand. Per treatment, 8 replicate tanks $(30 \mathrm{~cm} \mathrm{x}$ $30 \mathrm{~cm} \times 30 \mathrm{~cm}$ ) were used, each containing 32 crabs in four size classes 1) $3.5 \mathrm{~mm}$ $5.5 \mathrm{~mm}, 2) 6.0 \mathrm{~mm}-8.5 \mathrm{~mm}, 3) 9.0 \mathrm{~mm}-11.5 \mathrm{~mm}$, and 4) $12.0 \mathrm{~mm}-15.0 \mathrm{~mm}$ ) with 8 individuals per size class. At the beginning of the experiment all crabs as well as removed chelipeds were individually weighed on an electronic balance after drying off excess water on a paper tissue. Crabs in the limb regeneration treatment were weighed after cheliped removal. The weighing was repeated every 3-4 days. Additionally, CW was measured with a digital calliper. In both treatments, dead animals as well as crabs with additional missing limbs were replaced by crabs of the same size that were marked with a tag glued onto their carapace. These individuals were solely used to retain initial densities and were not included in the estimate of differential growth dependent on limb loss. The tanks were filled with $15 \mathrm{~L}$ unfiltered seawater that was replaced every 2 days. At the same time, all aquaria were cleaned and the crabs re-randomized in position in order to avoid a confounding effect of aquarium. In addition to the organic matter and plankton naturally present in the seawater, 500mg ground Spirulina flakes were added to the water of each tank in order to ensure sufficient food resources at all times. The experiment was terminated after 70 days when $80 \%$ of the animals with initially autotomized limbs had chelipeds that had been regenerated to at least $75 \%$ of their original size. The individual growth rate (IGR) was calculated as daily wet body weight $(\mathrm{BW})$ increase: IGR $=\left[\left(\mathrm{BW}_{\text {final }}\right)-\left(\mathrm{BW}_{\text {initial }}\right)\right] /$ length of the experiment in no. of days. For the individual body size increase (ISI), the difference between initial and final carapace width $(\mathrm{CW})$ was used: $\mathrm{ISI}=\left[\left(\mathrm{CW}_{\text {final }}\right)-\left(\mathrm{CW}_{\text {initial }}\right)\right] /$ length of the experiment in no. of days. The effects of treatment (chelipeds present vs. clipped-off), and size class as well as the treatment $\mathrm{x}$ size interaction were calculated according to the 2-way ANOVA models: IGR $\sim \mathrm{T}+\mathrm{S}+(\mathrm{T} \times \mathrm{S})$, and ISI $\sim \mathrm{T}+\mathrm{S}+(\mathrm{T} \times \mathrm{S})$. To highlight the comparatively large size of the claws and the associated amount of energy that must be allocated for their regeneration, I regressed body mass versus cheliped weight, as well as body size vs. body mass as allometric reference. 


\subsubsection{Population density, frequency of limb loss, and reproductive output in crabs}

from the field

The frequency of limb loss in relation to population density and body size was obtained using artificial substrates (i.e. basket traps) in the field. These sampling units were colonised by the crabs during exposure and consisted of plastic baskets $(30 \mathrm{~cm} \times 20 \mathrm{~cm} \times 15 \mathrm{~cm})$ filled with greywacke rocks taken from the natural habitat of $P$. elongatus. To prevent rocks from getting washed out a PVC mesh (mesh size 10 by $10 \mathrm{~mm}$ ) covered the baskets, tied down with cable ties. The mesh size of basket and mesh cover allowed crabs to freely move in and out of the sampling unit. Each basket was anchored by two steel pegs made of sharpened waratah stakes (Y posts) cut into $50 \mathrm{~cm}$ pieces with a welded-on, bent reinforcing rod to hold down the basket. At each of 5 sites (Hutt River mouth (HRM), 41 ${ }^{\circ} 14^{\prime} 49.50$ "'

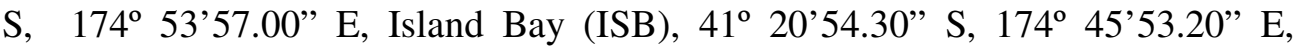

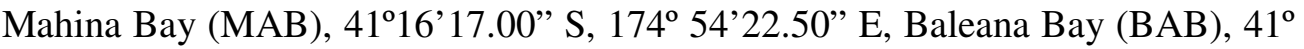

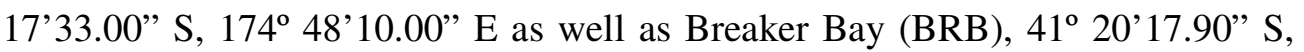
$174^{\circ} 49^{\prime} 26.60^{\prime}$ E, Fig.5.1) eight replicate artificial substrates were deployed in January 2006 and recovered after 4 weeks to allow an undisturbed colonization process under near-natural conditions. At ISB, all crabs were extracted from the sampling units by separately transferring the contents into a double sieve $(5 \mathrm{~mm}$ and $1 \mathrm{~mm}$ mesh size). The rocks and other accumulated material were rinsed with seawater, washing all crabs into the fine sieve underneath. Crabs were transferred into labelled sample jars and preserved in $95 \%$ ethanol on the same day. Later, the animals were sexed and measured with a dissecting microscope at 45-fold magnification.

Due to the fact that $P$. elongatus individuals easily autotomizes its limbs (Hazlett et al., 2000, and pers. obs.), especially when handling or during transport, the frequency of regenerating limbs was used as a reliable indicator of frequency of limb loss. Regenerating limbs (from visible budding stage to final hardening of exoskeleton; corresponding to approximately 5 to $75 \%$ regeneration of limbs) were recorded as well as their position ( $1^{\text {st }}$ to $4^{\text {th }}$ pereiopod). Eggs of all ovigerous females were counted, subdivided into four developmental stages and the wet weight of each clutch as well as the body weight of the females was determined. The ratio of clutch weight to body weight as a measure of reproductive output (RO) was calculated using the formula: clutch wet weight / body wet weight * 
100. Differences of this ratio in relation to the regeneration of limbs (Reg) as well as in relation to local density (D) were analyzed by ANCOVA: RO $\sim \operatorname{Reg}+\mathrm{D}+$ (Reg x D), with density as covariate. Because egg size (and therefore clutch weight) strongly varies with developmental stage (see chapter 2), only clutches consisting of stage $1 \& 2$ eggs were taken for the analysis. Further, only females with a body size between $7.5 \mathrm{~mm}$ and $9.0 \mathrm{~mm} \mathrm{CW}$ were included to avoid possible confounding effects of a strongly positive relationship between crab size and egg number (chapter 2). Sample sizes for ovigerous females with regenerating limbs that met the above conditions were generally low; hence, samples (i.e. animals from separate artificial substrates) and the associated densities were compared for one site only (ISB).

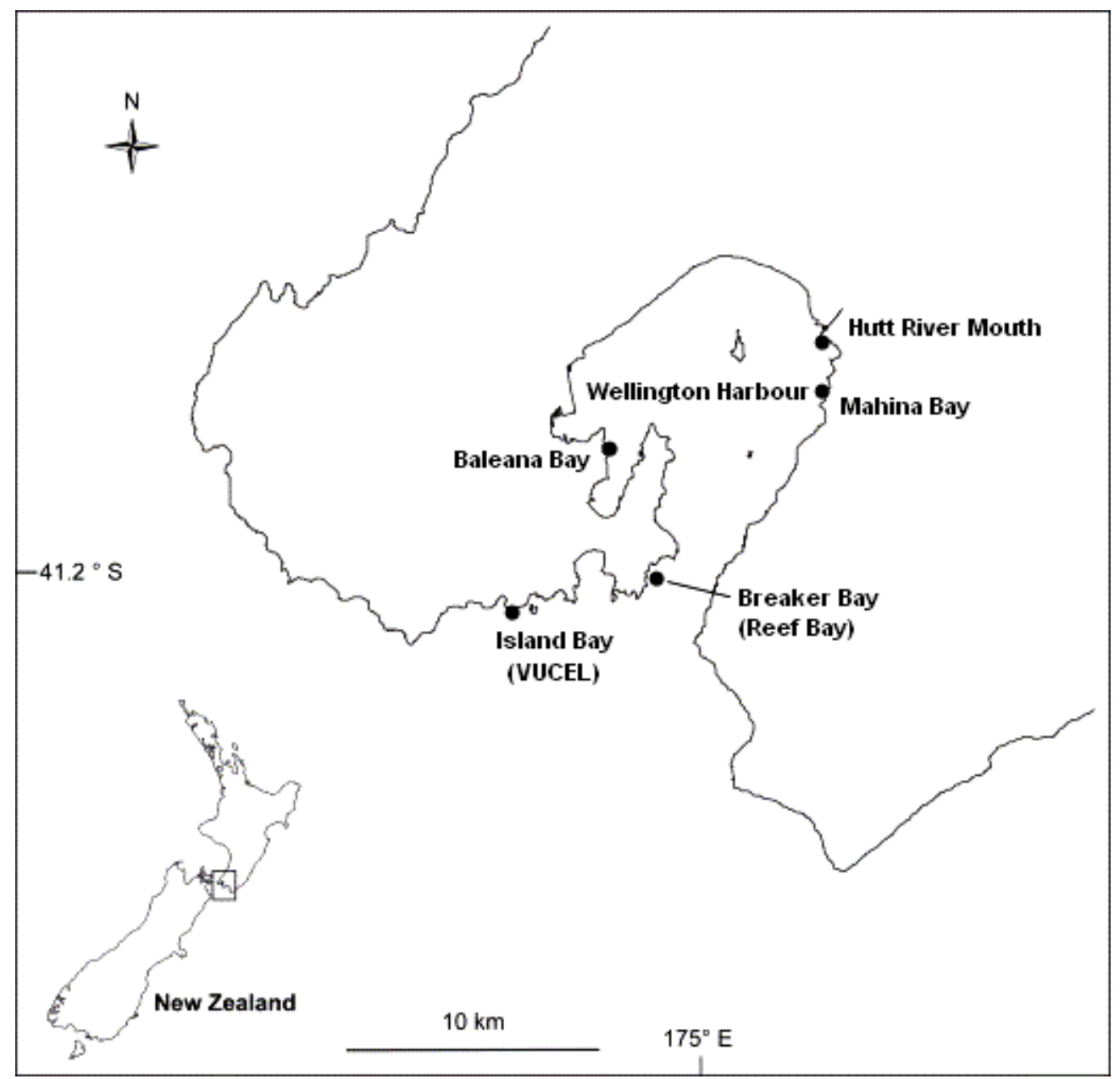

Fig. 5.1: Map of sample sites in Wellington Harbour and Cook Strait at Island Bay (at the Victoria University Coastal Ecology Laboratory, VUCEL), at the harbour entrance (Breaker Bay), and within Wellington Harbour at Baleana Bay, Mahina Bay and on the true left bank of Hutt River mouth. 


\subsection{Results}

\subsubsection{Effect of population density and food availability on growth rate}

The significant 3-way interaction of density x food x size (Table 5.1) was mainly caused by a strong effect of density (as well as potentially a weaker effect of size): Tukey's HSD revealed significant differences of group means within density whereas the results for food level were non-significant. The interaction density x size was significant (Table 5.1). Individual growth rate (IGR) varied with density and crabs had higher IGR values at low density (Fig. 5.2). IGR was significantly different for different size classes (Table 5.1): Small crabs grew faster than large ones (Fig. 5.2). There was no effect of food level on IGR, density $\mathrm{x}$ food level, and food level $\mathrm{x}$ size (Table 5.1). However, there was a significant effect of aquarium $(\mathrm{p}<0.0001)$ (Table 5.1).

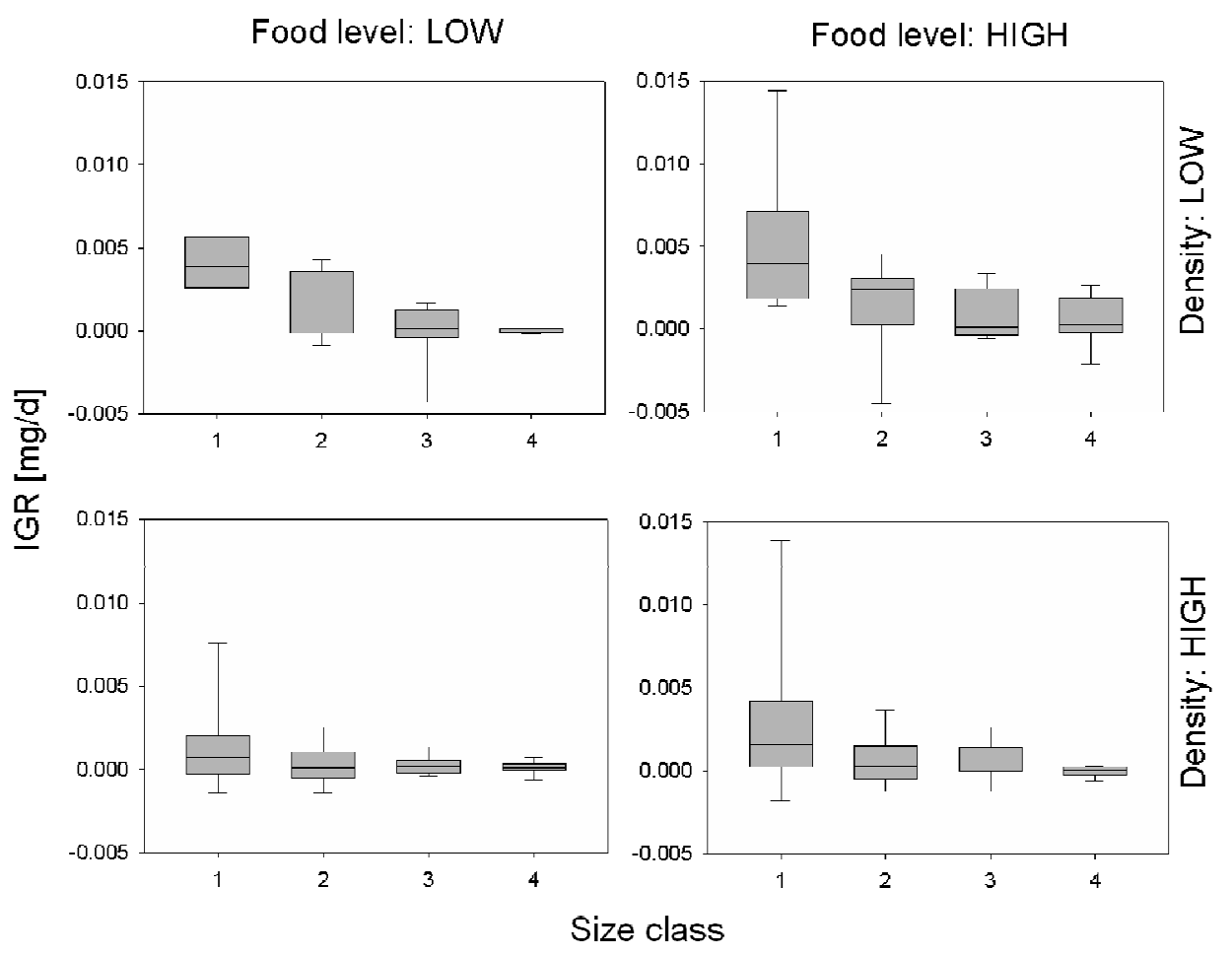

Size classes (mm carapace width):
1: $3.5-5.5$
2: $6.0-8.5$
3: $9.0-11.5$
4: $12.0-15.0$

Fig. 5.2: Individual growth rate (IGR), measured as daily increase in wet weight of crabs in four size classes in a fully crossed design comprising two density and two food level treatments. At lower densities, crabs had higher individual growth rates (i.e. gained more weight). Smaller crabs (size class 1) grew faster than larger ones. Food level had no effect on growth rate. Error bars represent 5th and 95th percentiles; the solid line median values. 
Table 5.1: GLM results for IGR of crabs within all size classes and treatments show that growth rate strongly varied with density and size but were not affected by food level. However, there were significant interactions between density and food level as well as density and size. Despite the efforts to re-randomize crabs over aquaria on a regular basis, the effect of aquarium within each treatment was highly significant.

\begin{tabular}{|l|lllc|}
\hline $\begin{array}{l}\text { All size classes combined } \\
\text { Source }\end{array}$ & SS & df & F & p \\
\hline & & & & \\
Density & 0.00007057 & 1 & 28.9545 & $<\mathbf{0 . 0 0 0 1}$ \\
Food level & 0.00000347 & 1 & 1.4238 & 0.2336 \\
Size & 0.00011598 & 1 & 47.5876 & $<\mathbf{0 . 0 0 0 1}$ \\
Density * food level & 0.00000007 & 1 & 0.0299 & 0.8628 \\
Density * size & 0.00001927 & 1 & 7.9072 & $\mathbf{0 . 0 0 5 2}$ \\
Food level * size & 0.00000199 & 1 & 0.8148 & 0.3673 \\
Density * food * size & 0.00001501 & 1 & 6.1607 & $\mathbf{0 . 0 0 1 3 6}$ \\
Aquarium (density * food) & 0.00014725 & 20 & 3.0209 & $<\mathbf{0 . 0 0 0 1}$ \\
Error & 0.00081647 & 335 & & \\
\hline
\end{tabular}

Mortality varied with density and size (Table 5.2, Fig 5.3). The effect of density was highly significant (Table 5.2) and according to Tukey's HSD all group means for density were significantly different but non-significant for food level. Smaller crabs died more frequently than larger ones (Fig. 5.3): The mortality of size class 1 crabs (all treatments combined) was 2.1 to 3.6-fold higher than within other size classes.

Table 5.2: GLM results for mortality within all size classes and treatments show that mortality rate is strongly influenced by density and is different between size classes; however, the food levels used in this experiment did not affect survival.

\begin{tabular}{|l|llll|}
\hline All size classes combined & df & F & p \\
\hline Source & SS & df & \\
Density & 0.13405868 & 1 & 20.5656 & $<\mathbf{0 . 0 0 0 1}$ \\
Food level & 0.01816064 & 1 & 2.7860 & 0.0999 \\
Size & 0.05043513 & 1 & 7.7371 & $\mathbf{0 . 0 0 7 1}$ \\
Density * food level & 0.01212862 & 1 & 1.8606 & 0.1773 \\
Density * size & 0.01292819 & 1 & 1.9833 & 0.1638 \\
Food level * size & 0.00229549 & 1 & 0.3521 & 0.5550 \\
Density * food * size & 0.00019630 & 1 & 0.0301 & 0.8628 \\
Aquarium (density * food) & 0.19691304 & 20 & 1.5104 & 0.1082 \\
Error & 0.42370899 & 65 & & \\
\hline
\end{tabular}



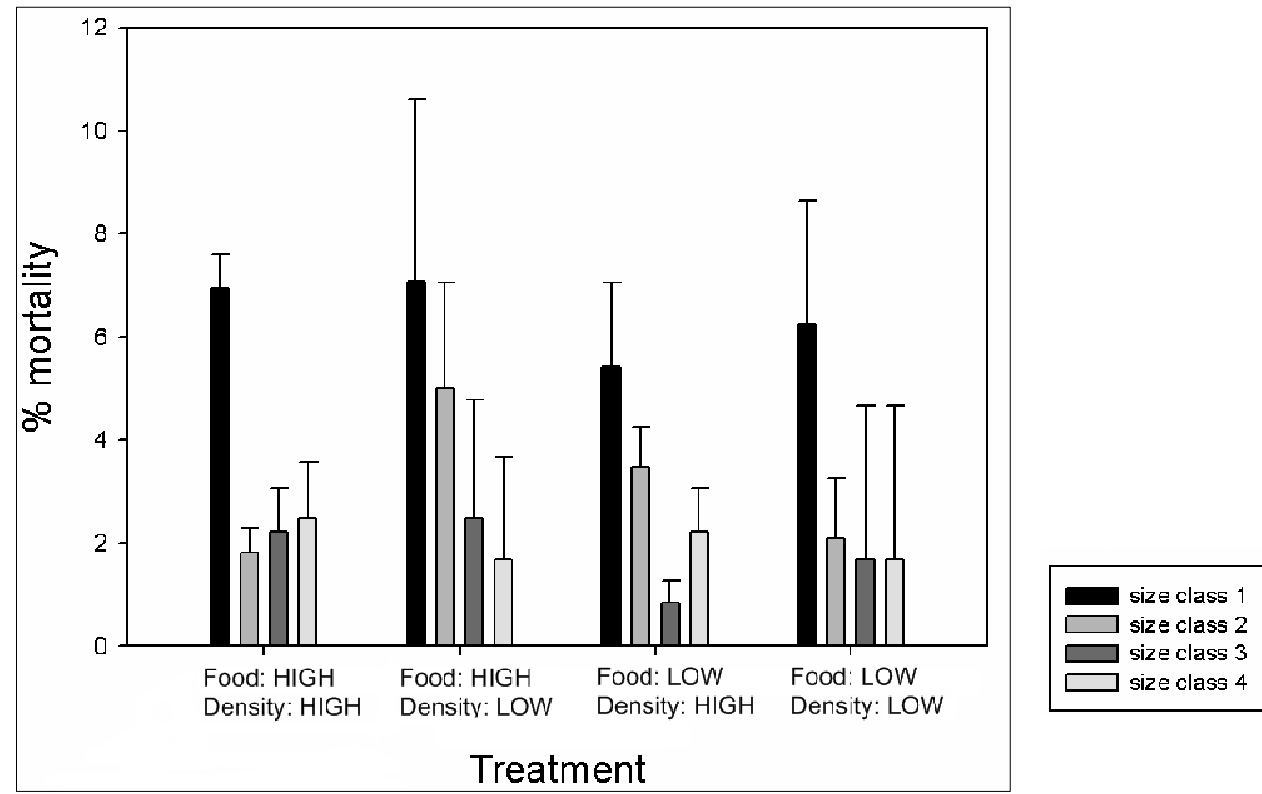

Size classes (mm carapace width):
1: $3.5-5.5$
2: $6.0-8.5$
3: $9.0-11.5$
4: $12.0-15.0$

Fig. 5.3: Average mortality over 10 weeks, shown as percent of crabs within each size class that had died over the course of the experiment at different densities and with different food supply. The mortality of size class 1 crabs is significantly higher compared to other size classes. Error bars represent $95 \%$ confidence intervals.

\subsubsection{Effect of density on frequency of filter-feeding}

The 3-way repeated measures ANOVA, analyzing the effect of density on frequency of filter-feeding, shows a significant time $\mathrm{x}$ food $\mathrm{x}$ size class interaction, as well as a highly significant time $\mathrm{x}$ size class interaction (Table 5.3). Consistent with a highly significant effect of size class $(p<0.0001)$ in the ANOVA results, post hoc analysis with Bonferroni adjusted $\alpha$ revealed that size class had the strongest influence on the significance level within those interactions, followed by the time effect. Due to the non-significant interactions between time and density, time and food level, time x density x food x size class, as well as non-significant effects of density and food level I conclude there were no treatment effects. In accordance with the 3-way repeated measures ANOVA results, feeding activity varies with body size and daytime (Fig. 5.4): The larger the crabs, the more individuals were observed feeding. Even though feeding activity was inconsistent across size classes on a 2-hourly basis, there was a 2 to 3 -fold increase of individuals observed feeding at night time (between 6pm and 6am) compared to day time (Fig. 5.4 and Table 5.4). 
Table 5.3: The 3-way repeated measures ANOVA results show that frequency of filter-feeding strongly varied with crab size and time of the day; however, food level and conspecific density had no effect. ${ }^{1}$ Wilks' Lambda; all other values given as uncorrected F-test results. The Bonferroni adjusted $\alpha$ is 0.0125 for 'between subjects' results and 0.0071 for 'within subjects' results.

\begin{tabular}{|c|c|c|c|c|}
\hline $\begin{array}{l}\text { Between subjects } \\
\text { Source }\end{array}$ & Value & df & $\mathbf{F}$ & $\mathbf{p}$ \\
\hline All between & 0.8872205 & 15 & 16.0883 & $<0.0001$ \\
\hline Intercept & 0.1115189 & 1 & 30.3332 & $<0.0001$ \\
\hline Density & 0.0015129 & 1 & 0.4115 & 0.5218 \\
\hline Food level & 0.0064121 & 1 & 1.7441 & 0.1877 \\
\hline Size class & 0.264044 & 3 & 23.9400 & $<0.0001$ \\
\hline Density $*$ food level & 0.0071359 & 1 & 1.9410 & 0.1647 \\
\hline Density $*$ size class & 0.0187257 & 3 & 1.6978 & 0.1678 \\
\hline Food level $*$ size class & 0.00953 & 3 & 0.8641 & 0.4602 \\
\hline Density $*$ food $*$ size & 0.019796 & 3 & 1.7948 & 0.1484 \\
\hline $\begin{array}{l}\text { Within subjects } \\
\text { Source }\end{array}$ & Value & df & $\mathbf{F}$ & $\mathbf{p}$ \\
\hline All within & 0.2612141 & 180 & 2.1124 & $<0.0001$ \\
\hline Time & 0.0823161 & 12 & 1.7904 & 0.0498 \\
\hline Time $*$ density & 0.0217225 & 12 & 0.4725 & 0.9297 \\
\hline Time $*$ food level & 0.0268556 & 12 & 0.5841 & 0.8544 \\
\hline Time $^{*}$ size class ${ }^{1}$ & 0.6726501 & 36 & 3.0796 & $<0.0001$ \\
\hline Time $*$ density $*$ food & 0.0161893 & 12 & 0.3521 & 0.9780 \\
\hline Time $^{*}$ density $*$ size $^{1}$ & 0.8476566 & 36 & 1.2336 & 0.1659 \\
\hline Time $*$ food $*$ size $^{1}$ & 0.7774879 & 36 & 1.9065 & 0.0012 \\
\hline Time $^{*}$ density $*$ food $*$ size $^{1}$ & 0.8001615 & 36 & 1.6805 & 0.0081 \\
\hline
\end{tabular}

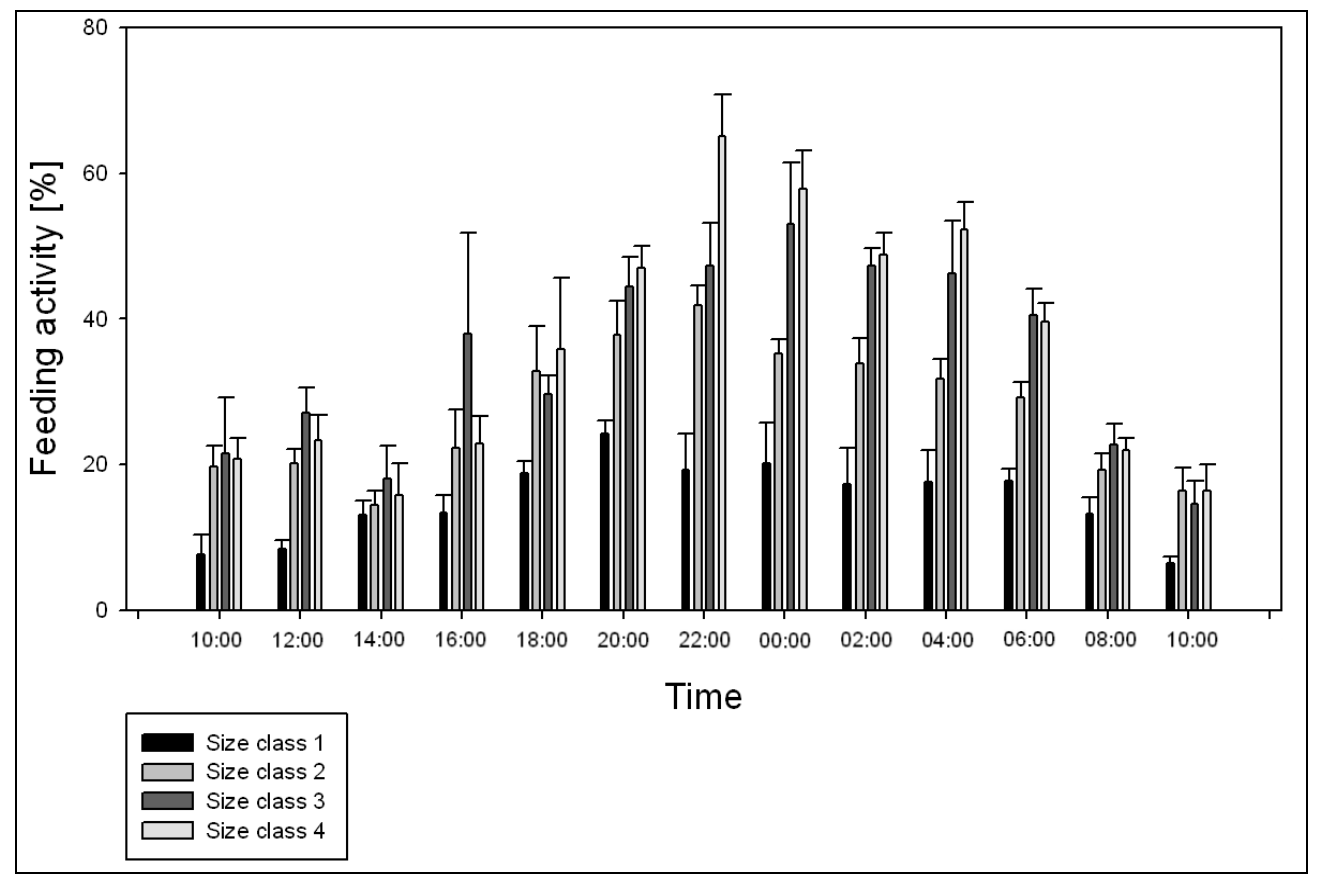

Fig. 5.4: Feeding activity of crabs over $24 \mathrm{~h}$ within 4 size classes, assessed in 2hourly intervals. Due to an undetectable treatment effect and no differences between the 3 replicate runs, data were pooled. More crabs were observed feeding at night time than during the day. Larger the crabs exhibit higher feeding activity compared to small individuals. Error bars represent $95 \%$ confidence intervals. 
Table 5.4: The percentages of feeding individuals within each size class allow the comparison of relative (average) frequencies of filter-feeding individuals within 2 time intervals. There was an increase of feeding activity from daytime (6am to $4 \mathrm{pm})$ to night time (6pm to $4 \mathrm{am}$ ) in all size classes of crabs. Pooled data of 3 replicate runs and all treatments were used for the calculation, including standard errors.

\begin{tabular}{|c|c|c|c|}
\hline Size class & $\begin{array}{c}\text { 6am - 4pm } \\
\text { Feeding individuals [\%] }\end{array}$ & $\begin{array}{c}\text { 6pm - 4am } \\
\text { Feeding individuals [\%] }\end{array}$ & $\begin{array}{c}\text { Increase } \mathrm{x} \text {-fold } \\
\text { Day vs. night }\end{array}$ \\
\hline 1 & $7.24 \pm 0.9$ & $15.05 \pm 2.0$ & 2.08 \\
2 & $12.9 \pm 1.7$ & $32.00 \pm 3.0$ & 2.48 \\
3 & $22.92 \pm 4.3$ & $43.75 \pm 3.8$ & 1.91 \\
4 & $17.46 \pm 2.8$ & $55.79 \pm 5.4$ & 3.20 \\
\hline
\end{tabular}

\subsubsection{Effects of limb loss on growth rate}

Table 5.5 2-way ANOVA results: individual growth rate IGR T + S + (T x S) The growth rate of crabs (i.e. the relative changes in individual wet weight over time) strongly varied with body size. There were significant differences between individual growth rate between uninjured crabs and those with regenerating limbs.

\begin{tabular}{|l|lrrr|}
\hline Source & SS & df & F & p \\
\hline Intercept & & 1 & & $<\mathbf{0 . 0 0 0 1}$ \\
Treatment & 0.7774939 & 1 & 5.9608 & $\mathbf{0 . 0 1 5 3}$ \\
Size class & 1.5869329 & 3 & 4.0555 & $\mathbf{0 . 0 0 7 7}$ \\
Treatment $*$ size class & 0.6891910 & 3 & 1.7613 & 0.1549 \\
Error & 34.695749 & 266 & & \\
\hline
\end{tabular}

Table 5.6 2-way ANOVA results: ind. body size increase ISI $\sim \mathrm{T}+\mathrm{S}+(\mathrm{T} \times \mathrm{S})$ The individual body size increase (i.e. the relative changes in individual carapace width over time) were significantly different between size classes of crabs; however, there was no effect of treatment.

\begin{tabular}{|l|lrlr|}
\hline Source & SS & df & F & p \\
\hline Intercept & & 1 & & 0.0938 \\
Treatment & 95.00 & 1 & 0.0051 & 0.9432 \\
Size class & 637661.92 & 3 & 11.3773 & $<\mathbf{0 . 0 0 0 1}$ \\
Treatment $*$ size class & 495117.98 & 3 & 8.8340 & $<\mathbf{0 . 0 0 0 1}$ \\
Error & 4969487.2 & 266 & & \\
\hline
\end{tabular}

For the initial growth rate (IGR) the 2-way ANOVA results show no significant treatment $x$ size class interaction $(\mathrm{p}=0.1549)$ (Table 5.5), with only one significant difference between size class 1 and 4 within treatment "all limbs present" according to Tukey's HSD. However, the effect of treatment $(\mathrm{p}=0.0153)$, as well as the effect of size class ( $\mathrm{p}=0.0077$ ) were both significant (Table 5.5). While post hoc tests showed that for the treatment effect all group means were significantly different, only the means for size class 1 and 4 were significantly different. Figure 5.5 reflects these results: crabs with removed chelipeds gained more weight over the entire duration of the experiment than those with all limbs present. While the 
difference in weight change between the two treatments was small in size class 1 individuals, the increase in body mass of larger crabs (size classes 2, 3, and 4) was approximately 2 to 4 times higher among those individuals with clipped-off chelipeds after 7 weeks of observation (Fig. 5.5). For the weekly changes in \% body mass see Appendix 5.1. Regardless of being injured or not, small crabs gain relatively more weight than larger ones (Fig. 5.5), which is consistent with the significant effect of size class on IGR.

In terms of body size (carapace width, $\mathrm{CW}$ ), there was a highly significant treatment $\mathrm{x}$ size class interaction (Table 5.5) that can be mostly explained by 6 significantly different group means of size classes when comparing both treatments, followed by 4 significant differences within treatment "removed chelipeds" according to Tukey's HSD. Within treatment "all limbs present", however, there were no significant differences at all. The main effect of size class on individual body size increase (ISI) was highly significant (Table 5.6). Posthoc tests showed significant differences between size classes $1 \& 3,1 \& 4$, and $2 \& 4$. The effect of treatment, however, $(\mathrm{p}=0.9432)$ is not significant and, according to Tukey's HSD, all group means for treatment effect on ISI are non-significant. However, when comparing mean and median values in Figure 5.6, there was a trend for size class 1 and 3 crabs to grow slower (i.e. their CW increased at a smaller rate) when regenerating limbs. Moulting may have occurred in only a few individuals. Consistent with the significant effect of size class on ISI, the average increase in body size over the duration of the experiment was dependent on initial body size (i.e. size class): the smaller the crabs the larger their increase in body size over time (Fig. 5.6). For weekly body size changes see Appendix 5.2.

An overview of the frequencies of developmental stages of limb regeneration within all size classes over the duration of the experiment shows that after 7 weeks, $80 \%$ of the animals with autotomized limbs had regenerated chelipeds with $75 \%$ of their original size (Appendix 5.3); small crabs regenerated limbs faster than large individuals. In the field, the chelipeds (1st pereiopods) are the limbs most frequently regenerated; they were found replaced approximately twice more frequently then all other limbs (5.7\% \pm 0.91 vs. approx. 3\%) (Appendix 5.4). In large crabs (size class 4 and 5) the highest percentages of limb regeneration were found (Appendix 5.5), whereas size class 1 crabs, the smallest individuals, were found more frequently with regenerated limbs than size class 2 and 3 crabs. 


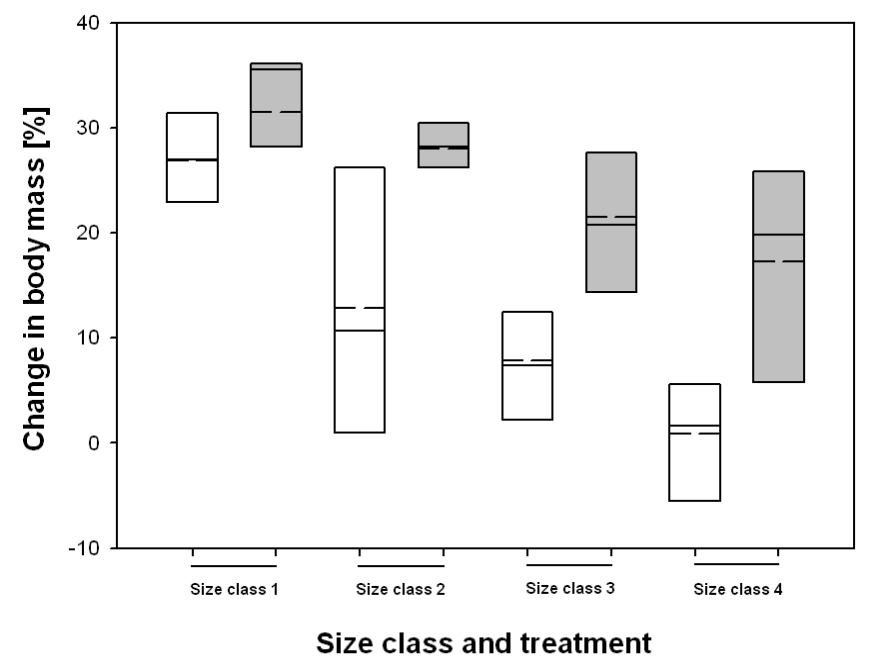

Fig. 5.5: Change in body mass [\%] in uninjured crabs and individuals with removed chelipeds over 7 weeks within 4 size classes. Regardless of body size, crabs with removed chelipeds (grey) gain significantly more weight compared to uninjured crabs, mainly due to the regeneration process (i.e. cheliped growth). The dashed line represents the mean, the solid line the median values.

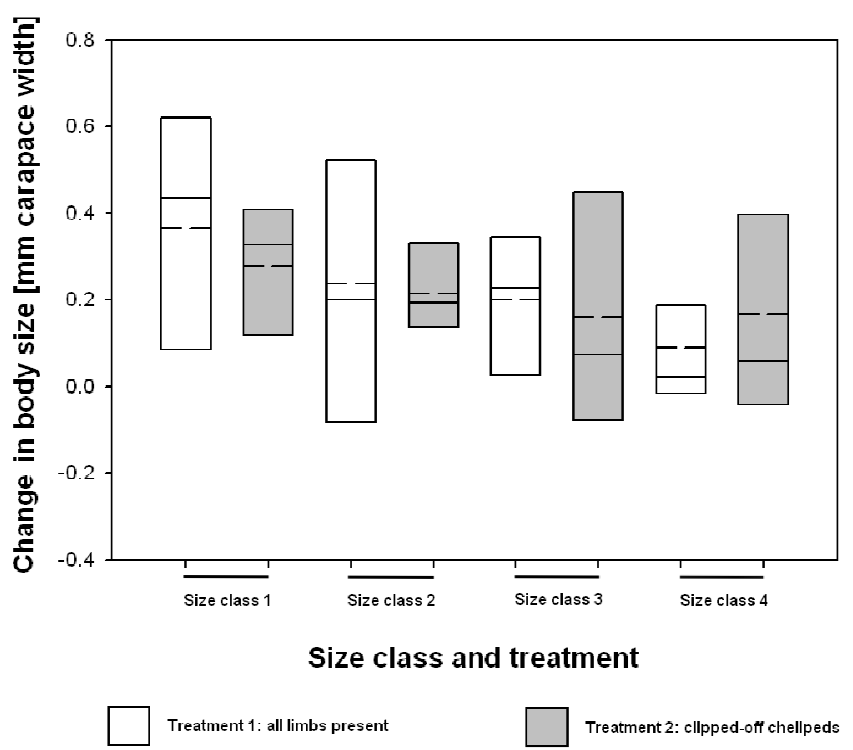

Fig. 5.6: Change in body size $[\mathrm{mm}]$ in uninjured crabs and individuals with removed chelipeds over 7 weeks within 4 size classes. The regeneration of chelipeds does not affect changes in body size over time (i.e. growth rate in $\mathrm{mm}$ $\mathrm{CW}$ ); however, moulting may not have taken place in most individuals over the course of the experiment. The dashed line represents the mean, the solid line the median values. 

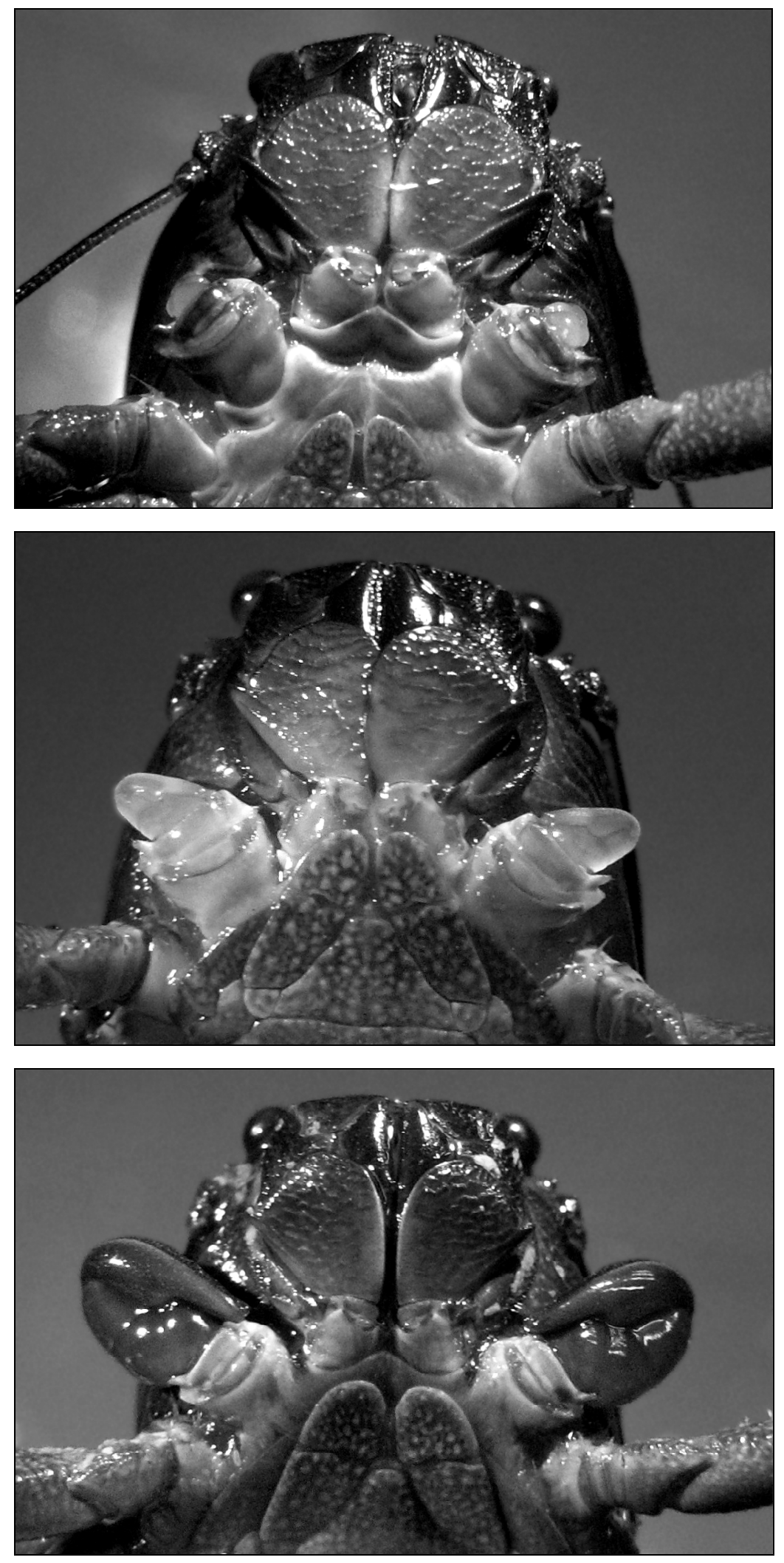

Fig. 5.7: Early developmental stages of cheliped regeneration in P. elongatus at approx. 5\%, 10\% and 30\% of its original size. Note the soft transparent tissue of early growth ("budding") and the subsequent pigmentation and hardening of the exoskeleton that is independent of moulting. 
In $P$. elongatus, as well as in other decapods, the time span between physical stress induced autotomy and beginning of cheliped regeneration depends on body size. While in small individuals (size class 1 ) initial growth became visible after 3 to 6 days, it took up to 20 days in large males and females (size class 4) (own obs., compare Appendix 5.3). The initial or basal growth is moult-independent and has been compared to a budding process (e.g. Hopkins, 2001) due to an initially cone shaped germinative protuberance consisting of soft, unsegmented and unpigmented, semi-transparent tissue (Fig. 5.7). At approximately $10 \%$ of its original size, the limb segments become visible and at approximately $25 \%$ of its original size, pigmentation of the tissue as well as epidermis hardening begins (Fig. 5.7).

For the body size / body mass relationship (Fig. 5.8) a cubic polynomial regression provided the best fit. A crab at $12 \mathrm{~mm} \mathrm{CW}$, for instance, was 9 times heavier than a crab at $6 \mathrm{~mm}$. The body mass / cheliped weight correlation was best described by a quadratic regression (Fig. 5.9). A crab above a body weight of $800 \mathrm{mg}$ (without 1st pair of pereiopods) had heavier chelipeds than cephalothorax, abdomen and walking legs combined; crabs with lower bodyweight had relatively lighter claws.

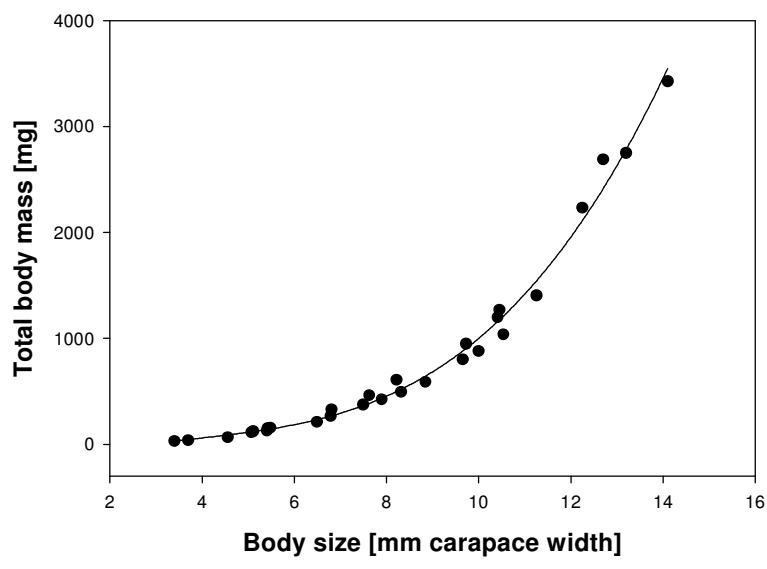

Fig. 5.8:

Body size (carapace width) versus total body mass (wet weight)

$\mathrm{R}^{2}=0.989 ; \mathrm{p}<\mathbf{0 . 0 0 0 1}$

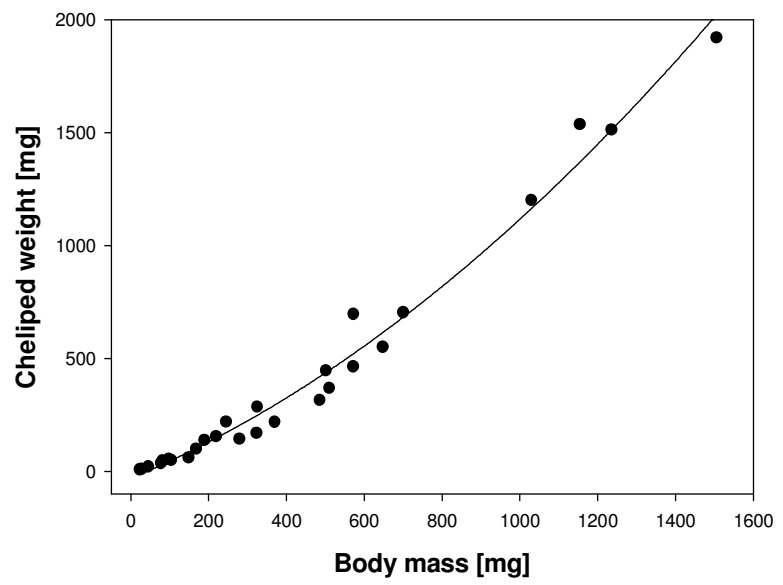

Fig. 5.9:

Body mass (without Chelipeds, wet weight) versus cheliped weight (both chelipeds, wet weight)

$\mathrm{R}^{2}=0.984 ; \mathrm{p}<\mathbf{0 . 0 0 0 1}$ 


\subsubsection{Effects of population density on frequency of limb loss and limb loss on reproductive output}

The percentages of individuals with regenerated limbs were negatively correlated with the total number of crabs per basket (i.e. the local density, Fig. 5.10). However, the results of a quadrat sampling experiment covering 15 times $0.25 \mathrm{~m}^{2}$ at three sites (see 2.2.4.1 in chapter 2 for a description of the method; due to the relevance within the present context these results are referred to here; see Appendix 5.6 and 5.7) indicate that the proportion of individuals with regenerating limbs did not vary with density (i.e. individuals per sample quadrat) and site (2-way ANOVA, Appendix 5.7), even though the slope of the regression line (Appendix 5.6) suggests a similar relationship to the one shown in Fig. 5.10. While in basket traps the relative frequency of injured crabs does not appear to be affected by intraspecific competition (i.e. the frequency of antagonistic behaviour), predation rate and environmental conditions (i.e. physiological stress, grinding rocks due to strong water movement) may lead to both lower densities and an increased risk to lose a limb.

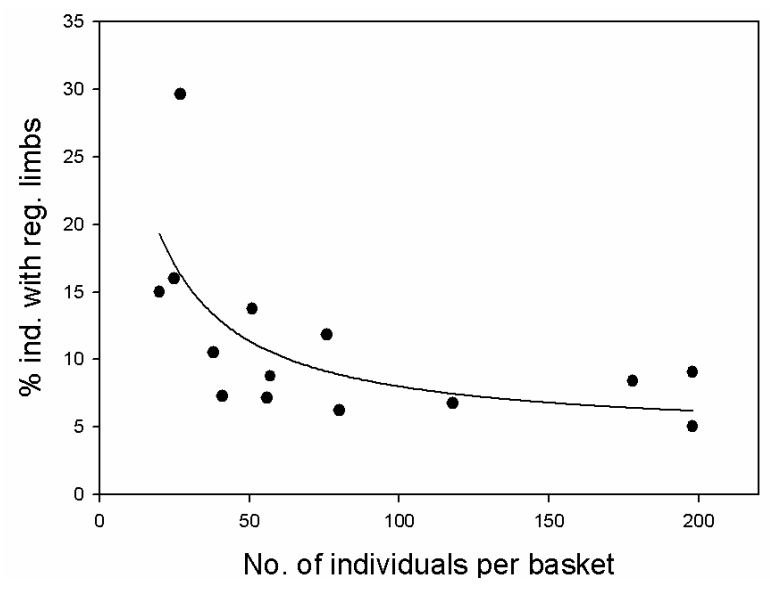

$\mathrm{R}^{2}=0.989 ; \mathrm{p}=\mathbf{0 . 0 3 8 7}$

Fig. 5.10: Number of individuals per basket trap (as a measure of local population density) versus percent values of individuals with regenerated limbs. The percentages of individuals with regenerated limbs were negatively correlated with the total number of crabs per basket, suggesting that limb loss is not affected by intraspecific competition, but may rather depend on environmental conditions and the rate of (attempted) predation that also affect density itself. 
The reproductive output (RO), measured as the ratio of clutch weight to body weight, did not vary with density and was not different between females with regenerating limbs and uninjured animals (Fig. 5.11 and Table 5.7). However, the sample size of injured females with $7.5 \mathrm{~mm}-9.0 \mathrm{~mm} \mathrm{CW}$ and developmental stage $1 \& 2$ eggs was small $(<5$ per sample); therefore, this result should be viewed with caution. For a comparison of the proportion of clutch to body weight across sites see section 3.3.6.

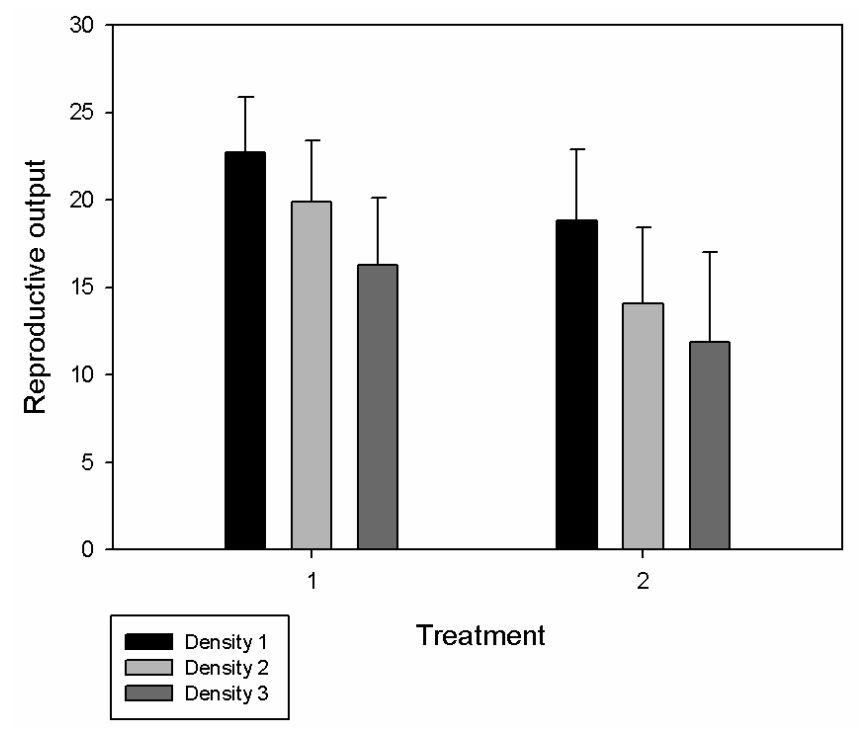

Treatment 1: Uninjured females (all limbs present)

Density 1: 79 adult crabs / basket Treatment 2: Females with regenerating limbs

Density 2: 118 adult crabs / basket

Density 3: 173 adult crabs / basket

Fig. 5.11: Reproductive output (RO), measured as the ratio of clutch weight to body weight, in females with and without regenerating limbs. The clutches of females extracted from three basket traps (with corresponding adult densities) were analyzed, all of which were sampled at ISB. Samples from other sites were excluded due to low sample sizes. Further, only females with $7.5 \mathrm{~mm}-9.0 \mathrm{~mm}$ CW and developmental stage $1 \& 2$ eggs were selected for the analysis. While there is a strikingly clear pattern on the first glance, differences between females with regenerating limbs and uninjured animals as well as between densities (i.e. samples) were non-significant (see below). Error bars represent 95\% confidence intervals.

Table 5.7: ANCOVA results reproductive output: $\mathrm{RO} \sim \operatorname{Reg}+\mathrm{D}+(\operatorname{Reg} \times \mathrm{D})$ show no significant differences between females with regenerating limbs and uninjured animals (Reg). Reproductive output does not vary with density, either.

\begin{tabular}{|l|lrrr|}
\hline Source & SS & df & F & p \\
\hline Reg. & 112.22199 & 1 & 1.8070 & 0.1878 \\
Density & 83.926830 & 1 & 1.3514 & 0.2531 \\
Reg. * density & 1.5798900 & 1 & 0.0245 & 0.8742 \\
Error & 2310.5638 & 37 & & \\
\hline
\end{tabular}




\subsection{Discussion}

In the present study, individual growth rate (IGR) was highest among the smallest individuals at low density (Fig. 5.2). Similarly, daily growth was negatively correlated with body size in Petrolisthes cinctipes (Donahue, 2004) as well as in the freshwater prawn Palaemon lamarrei (Katre \& Reddy, 1977). Body size determines growth for various reasons: Small individuals grow faster due to higher metabolic rates (Peters, 1983), higher growth efficiency (Klein-Breteler, 1975), higher moulting frequencies (López, 1997, Asakura, 1992, and own observation), as well as higher growth increments (Asakura, 1992, Hartnoll, 1982, 1985).

\section{Effects of conspecific density on individual growth rate}

Density was an excellent predictor of IGR (Table 5.1) with generally higher IGR at low density (Fig. 5.2). This is consistent with the findings of Donahue (2004) as well as studies examining the effects of culture density on growth in juvenile spider crabs (Domingues \& Alaminos, 2008), red king crab juveniles (Daly et al., 2009), and the Chinese mitten-handed crab (Wenkuan et al., 2009). However, the effect of conspecific density on IGR was different among size classes without showing a clear pattern. Donahue (2004) found IGR more strongly affected by density in small Petrolisthes cinctipes individuals, indicating smaller individuals suffer more from agonistic interactions than larger ones. Leslie (2005) found that in the intertidal barnacle Balanus balanoides density was negatively correlated to growth and individual reproductive output, but positively correlated to survival, resulting in a positive net effect of increased fitness at high densities. In aggregating species, however, the trade-off between density dependent survival benefits and growth costs may result in optimal group sizes and densities well below theoretical maxima (Booth, 2004), e.g. due to competition for food.

\section{Effects of food level on individual growth rate}

In the present study, IGR did not vary with food level (Table 5.1) except for the largest size class of crabs (Table 5.2), indicating large individuals may be more affected by limited food availability than smaller ones. Gimenez \& Anger (2005) demonstrated that early brachyuran crab larvae are well adapted to the temporary lack of planktonic food. On the contrary, Peters (1983) suggested that smaller organisms are potentially more sensitive to changes in food level due to higher 
metabolic rates. Moreover, intraspecific competition is expected to decrease with increasing body size (Donahue, 2004). The seemingly reversed pattern in the present study as well as the non-significant interaction between density and food level (Table 5.1) remains elusive and may have been influenced by sufficient food resources even in the low food level / high density treatment. Additionally, higher filtration efficiencies among smaller crabs could have been caused by a relatively high proportion of very small food particles due to the grinding of freeze-dried spirulina fish flakes. In Porcellanidae, the third maxillipeds, densely fringed with plumose setae, are used as filter apparatus (Nicol, 1932). Since the spaces between these setae increase with body size (personal obs.) the resulting mesh size, particle size selectivity and filtration efficiency varies. The "specialisation" on different particle sizes, in turn, results in resource partitioning and hence minimizes intraspecific competition for food (Pinn et al., 1998). Size selective suspension feeding has been demonstrated for many taxa, e.g. rotifers (Rothhaupt, 1990), cnidarians (Collin et al., 2003), polychaetes (Ropert \& Goulletquer, 2000), bivalves (Shumway et al., 1985), barnacles (Harvey, 1937), calanoid copepods (Mullin, 1966), penaeid shrimps (Nunes \& Parsons, 1998), thalassinid crabs (Pinn et al., 1998), and fishes (Castillo-Rivera et al., 1996). For a review on motile suspension feeders, see Bushek \& Allen (2005). Trophic plasticity, in terms of food sources and feeding mechanisms, has been reported for Porcellanidae by Caine (1975); Kropp (1981); Stevcic (1988); Trager \& Genin (1993), and Achituv \& Pedrotti (1999). In the field, feeding efficiency in filter feeders is controlled by flow velocity (Trager \& Genin, 1993), immersion time (Bertness \& Grosholz, 1985; Depledge, 1989), the amount of particulate organic matter (POM) in the water column (Helson, 2001), as well as dissolved organic matter (DOM, particle size $<0.45 \mu \mathrm{m})$ (Gili \& Coma, 1998), and seston quality (Helson \& Gardner, 2007).

\section{Feeding activity}

Werner \& Anholt (1992) showed the pivotal importance of food level on feeding activity if the activity level is linearly correlated with both growth and mortality rates. Feeding rates among filter feeders commonly decrease with decreased food availability (Sanford et al., 1994). In the present study, however, neither food level nor density had a significant effect on feeding activity (i.e. the number of individuals within a particular size class feeding at a time) which may have been 
related to sufficient food resources even in the low food level / high density treatment. It was therefore difficult to distinguish the relative effects of exploitative and interference competition as Anholt (1990), Fradkin (1995), and Schmitt (1996) were able to quantify. Under food scarcity, effects of exploitative competition should have been reflected as reduced feeding activity and eventually in lower growth rates, especially in small crabs. Donahue (2004) reported lower feeding activities at higher density, presumably due to depleted food resources within the aquaria she used as rearing system. In the field, Barange \& Gili (1988) and Klimmerer et al. (1994) demonstrated substantial local declines in phytoplankton due to the feeding ability of highly abundant filter feeders that are likely to regulate primary production directly and secondary production indirectly.

Porcelain crabs may compete for good filter-feeding locations (Donahue, 2004) in the field as well as in captivity, since the animals tend to congregate in locations with high flow in aquaria (Jensen, 1990; Donahue, 2004, and pers. obs.). Within these aggregations, agonistic behaviours described by Molenock (1976) can be frequently observed. Zittin (1979) reported that Petrolisthes cinctipes forms dominance hierarchies even in captivity, often with a single male controlling access to prime feeding currents and protective shelter (Jensen, 1990).

Despite higher individual growth rates at smaller body sizes, feeding activity was significantly lower in smaller crabs. Similarly, Donahue (2004) found that the smallest Petrolisthes cinctipes individuals fed significantly less frequently than crabs from all other size classes. However, a lower rate in feeding activity of small crabs does not necessarily indicate lower food intake relative to body weight (e.g. in \% body mass) since the size specific feeding efficiency is unknown. Due to higher metabolic rates small individuals are likely to have relatively higher consumption rates (e.g. Bertalanffy, 1957). Cammen (1980) reviewed the food intake of various species of benthic invertebrate deposit feeders and detritovores and found that relative organic matter ingestion was a function of body size. In the mangrove crab Ucides cordatus (L. 1763), the daily food intake was strongly correlated with body size ranging from $19.8 \%$ of body dry weight in small crabs to $6.0 \%$ in large individuals (Nordhaus et al., 2006). 
The generally higher feeding activity in $P$. elongatus at night has not been reported in earlier studies and may be an adaptation to higher predation risk at day time from visual predators such as fishes and birds. Gonor \& Gonor (1973) observed a periodicity in feeding activity of megalopae of Pachycheles pubescens and $P$. rudis (porcellanidae); however, these authors did not demonstrate an effect of light conditions on feeding behaviour. Förster \& Baeza (2001) reported a higher general activity of females in Petrolisthes violaceus at night compared to day time, even though embryo grooming was significantly higher during the day. However, Ziedins \& Meyer-Rochow (1990) showed that unlike in crayfish (Arechiga \& Wiersma, 1969) and rock lobster (Meyer-Rochow \& Tiang, 1984) visual sensitivity in P. elongatus is not linked to a circadian rhythm.

\section{Mortality}

In captivity, mortality rates among small crabs were generally higher compared to larger size classes, but were not significantly affected by food level. The overall mortality pattern can be identified among the basic schemes suggested by Deevey (1947) and seems to resemble type III, where mortality is high among early life history stages with only a few survivors that have a greater life expectancy. The higher mortality rates at low density contrast with the significantly higher growth rates at low density and may be explained by adverse effects of food particle accumulation in aquaria between cleaning due to lower total consumption rates at low density. In addition to predation in the field, mortality may increase with frequency of limb loss (e.g. Figiel \& Miller, 1995).

\section{Effects of limb regeneration on growth rate and reproductive output}

In contrast to the suggestion of Donahue (2004) that cheliped loss is a potentially important cost of agonistic interactions, the relative frequency of injured crabs did not appear to be affected by intraspecific competition in the present study. Most intraspecific competitive interactions in $P$. elongatus, and generally in crustaceans, are highly ritualized and do not result in autotomy (Molenock, 1975, Juanes \& Smith, 1995, and literature therein). The percentages of crabs with regenerating limbs were higher at lower densities, suggesting that, rather than agonistic behaviour, the rate of attempted predation as well as environmental conditions may be related to an increased risk of limb loss. Habitat factors such as wave exposure and rock size (i.e. substrate stability) may simultaneously increase 
the rate of limb loss and mortality by crushing extremities and individuals. In turn, mortality rates could negatively affect local density. In the common shore crab Carcinus maenas, McVean (2003) found a higher frequency of limb loss at an exposed shore compared to sheltered sites. Additionally or alternatively, the local predator abundance could explain this pattern, dependent on habitat structure (i.e. availability of refuges for crabs vs. interstitial space amongst boulders accessible to predator species).

Limb regeneration requires resource allocation for this process that may result in a decreased carapace growth (Donahue, 2004; for reviews, see Juanes \& Smith, 1995, Mariappan et al., 2000). In the present study, however, individuals with removed chelae gained 2 to 4 times more weight compared to uninjured crabs, probably due to the process of limb regeneration itself. Additionally, cheliped removal did not seem to affect growth rate in terms of body size, but molting may have occurred only in a few individuals within the limited duration of the experiment. The costs of limb loss in Petrolisthes may be compensated by an increase in food intake (Wasson et al., 2002; Donahue, 2004) but may negatively affect individual growth rates under food scarcity. Compared to other limb types the replacement of chelipeds should divert the greatest amount of energy from growth due to their relatively large proportion of the total body weight ( $>50 \%$ in large adults). The more limbs are regenerating at a time, the more evident is the effect on increase in body size per moult (Juanes \& Smith, 1995, and literature therein). In the fiddler crab Uca pugilator, regeneration of a number of limbs may even result in negative growth (Hopkins, 1982). In decapods, limb autotomy commonly affects the moult cycle: Depending on the number of limbs removed and the stage at which injury occurs, ecdysis can be either accelerated or delayed (Hopkins, 1982; Spivak, 1990; Smith, 1992).

The reduced size of regenerated appendages can affect animal performance at many levels (Maginnis, 2006). The effects of limb loss on growth are potentially important for individual fitness of decapods (Juanes \& Smith, 1995) because differences in relative body size have been shown to be critical to reproduction and the outcome of various ecological interactions such as intraspecific competition and predator-prey encounters (Hyatt, 1983; Garvey et al., 1994; Smith, 1995). Limb replacement may also decrease reproductive output directly 
(Hines, 1992; MacDiarmid, 1986; Luppi et al., 1997), the ability to attract mates (e.g. van der Meeren, 1994), or the reproductive potential of a crab population (Lysenko et al., 2000). However, Juanes et al. (2008) suggest that for females, allocating energy to egg production and brood care may be more important than investment in increasing claw size. Comparing the ratio of clutch to body weight between $P$. elongatus females did not reveal a significant difference between injured and uninjured individuals; however, the power to detect such a difference was low due to low numbers of ovigerous females with regenerating limbs found in the field ( $n=9 ; 1.97 \%$ of all females). All of these females had only a single regenerating limb and in two cases a cheliped was regenerating, rather than a walking leg. Interestingly, $83.68 \%$ of the uninjured females were ovigerous whereas only $50.0 \%$ of the females with regenerating limbs carried eggs. While this result should again be treated with caution with regard to sample size, the significant difference in the relative frequency of ovigerous females between these two groups may indicate that limb loss impairs mating success in P. elongatus females. Juanes \& Smith (1995) found that frequency of limb loss is generally independent of sex in most decapods.

A considerable number of studies on agonistic behaviour in decapods had shown that body or chelae size determines competitive capability (e.g. Garvey \& Stein, 1993; Sneddon et al., 1997). Body size determined the success in agonistic interactions between pairs of Petrolisthes cinctipes (Molenock, 1976) and Allopetrolisthes spinifrons (Baeza et al., 2002). Contrary to my findings that large crabs had a higher frequency of limb regeneration in the field (Appendix 5.6), Donahue (2004) found that small crabs in captivity were more susceptible to limb loss at low food levels. Wasson \& Lyon (2005) showed that in P. cinctipes and $P$. manimaculis small individuals and females autotomized their limbs more readily than larger ones and males. However, full limb regeneration is a considerably longer process in larger crabs and may therefore be found more frequently in larger individuals in the field. Additionally, since larger crabs are more mobile than smaller individuals, they may be more susceptible to predation and predation attempts.

In addition to claw use in agonistic interactions, the flattened chelae in Petrolisthes are thought to work as current deflectors (Werding, B., pers. comm.). 
The underside of crabs in this family forms a suction cup in which the extremities play a critical role concerning its adhesion efficiency (Molenock, 1976, and pers. obs.). Hence, in P. elongatus, missing chelipeds do not only limit individual defence from competitors and predators but may also impair the ability to cling to the surface of rocks in wave exposed areas (pers. obs.) and therefore further increase predation risk and mortality. Zimmer-Faust (1989) suggested that autotomy may be particularly important in aquatic environments, where waterborne chemical cues of injured individuals can attract predators. Hazlett (2000) and Hazlett et al. (2000) found that P. elongatus decreased locomotion and other movements upon introduction of an alarm odour released by crushed conspecifics. If this cue alerts predators is unknown to date. Based on relatively lower frequencies of regenerated than missing limbs found in the field McVean \& Findlay (1979) and Shirley \& Shirley (1988) suggested that injury may increase mortality in decapods. Harris (1989) emphasized the importance of non-lethal injury as a regulating factor of population size in some species if injury is density dependent and decreases reproduction.

The regeneration of autotomised limbs begins with moult-independent basal growth of soft, unsegmented and unpigmented, semi-transparent tissue (compare Fig. 5.7) that involves mitosis and differentiation, followed by a second phase of proecdysial growth that is partly under direct hormonal stimulation (Bliss, 1956; Hopkins, 1993, 2001). In crustaceans, total recovery of a limb following autotomy generally requires a minimum of two moults (e.g. Miller \& Watson, 1976; Smith, 1990) but may require up to seven moults over seven years in the blue king crab, Paralithodes platypus (Lysenko et al., 2000). Furthermore, limb recovery is dependent on the moult frequency as well as the proportion of limb length replaced at each ecdysis (Goss, 1969; Skinner, 1985). The time required to regenerate a limb to normal size may vary dramatically with temperature (e.g. Weis, 1976) as well as between life history stages and species of crabs (Juanes \& Smith, 1995). Because in crustaceans moulting frequency typically declines with age (Hartnoll, 1982), regeneration takes longer in older individuals (Smith \& Hines, 1991). In Petrolisthes elongatus, the complete regeneration of the chelipeds takes between 9 and 14 weeks (pers. obs.) at $15^{\circ} \mathrm{C}$, with significantly faster rates in smaller crabs (Appendix 4.5). In the paddle crab Ovalipes trimaculatus, the complete regeneration of the $4^{\text {th }}$ pereiopod took between 9 and 
10 weeks (Alvarez \& Meruane, 2009); segmentation of the limb bud became visible after 4 weeks, pigmentation started after 6 and cuticle hardening after 7 weeks. Infestations with parasites such as bopyrids, entoniscids and sacculinids are known to affect the normal growth of chelipeds (O'Brian \& Skinner 1990; Mariappan et al., 2000, and literature therein); however, parasite infested individuals of $P$. elongatus can rarely be found in the Wellington region (own obs.).

\section{Conclusions}

In summary, $P$. elongatus grew faster in captivity at low density with generally higher mortality rates for smaller individuals, indicating that the costs of aggregation are more pronounced for juveniles than for adult crabs. However, there was no effect of food level, presumably due to a sufficient food supply even within the low density treatment. Donahue (2004) conducted a similar laboratory experiment with $P$. cinctipes and filtered versus unfiltered seawater as food level treatments and showed strong effects of density and food level on IGR. Future research may elucidate how growth rates in the field depend on local population density and long term food supply.

The frequency of limb loss appeared to be mainly affected by environmental conditions and attempted predation rather than by conspecific density and agonistic interactions as Donahue (2004) suggested. Besides predator abundance, habitat stability and disturbance that are related to rock size and wave exposure may determine the risk of limb loss in P. elongatus. However, further investigations are necessary to shed light on the costs of autotomy and limb regeneration in porcelain crabs and their implications on individual fitness and survival. 


\section{References}

Aichituv, Y. \& Pedrotti, M.L., 1999. Cost and gains of porcelain crab suspension feeding in different flow conditions. Mar. Ecol. Prog. Ser. 184: 161-169.

Allee, W.C., 1931. Animal aggregations, a study in general sociology. University of Chicago Press, Chicago.

Allee, W.C.; Emerson, A.E.; Park, O.; Park, T. \& Schmidt, K.P., 1949. Principles of Animal Ecology. Saunders, Philadelphia.

Alvarez, J. \& Meruane, J., 2009. Limb regeneration in the paddle crab Ovalipes trimaculatus (de Han, 1833) (Crustacea, Brachyura, Portunidae), and its practical use in aquaculture and fishery. Revista de Biología Marina y Oceanografía 44(2): 285-293.

Anholt, B.R., 1990. An experimental separation of interference and exploitative competition in a larval damselfly. Ecology 71: 1483-1493.

Annala, J.H., 1991. Factors influencing fecundity and population egg production of Jasus species. In: Wenner, A. and Kuris, A. (eds.): Crustacean egg production. Crustacean Issues 7 Rotterdam/Brookfield: A.A. Balkema. Pp. 301-315.

Arechiga, H.; Wiersma, C.A.G. 1969: Circadian rhythm of responsiveness in crayfish visual units. J. Neurobiol. 1: 71-85.

Asakura, A., 1992. Population Ecology of the Sand-Dwelling Hermit Crab Diogenes nitidimanus Terao. 5. Ecological Implications in the Pattern of Molting. Journal of Crustacean Biology 12(4): 537-545.

Baeza, J.A.; Stotz, W. \& Thiel, M, 2002. Agonistic behaviour and development of territoriality during ontogeny of the sea anemone dwelling crab Allopetrolithes spinifrons (H. Milne Edwards, 1837) (Decapoda: Anomura: Porcellanidae). Mar. Fresh. Behav. Physiol. 35(40): 189-202.

Barange, M. \& Gili, J.M., 1988. Feeding cycles and prey capture in Eudendrium racemosum (Cavolini, 1785). J. Exp. Mar. Biol. Ecol. 115: 281-293.

Belay, A., 1997. Mass culture of Spirulina outdoors. -The Earthrise farm experience. In: Vonshak, A., Ed. Spirulina platensis (Arthrospira): Physiology, cell biology and biotechnology. Taylor and Francis. London. Pp. 131-158.

Bertalanffy, L., 1957. Quantitative laws in metabolism and growth. Quart. Rev. Biol. 32(3): 217-231.

Bertness, M.D., 1989. Intraspecific competition and facilitation in a northern acorn barnacle population. Ecology 70: 257-268. 
Bertness, M.D. \& Grosholz, E., 1985. Population dynamics of the ribbed mussel, Geukensia demissa: the costs and benefits of an aggregated distribution. Oecologia 67: 192-204.

Bertness, M.D.; Gaines, S.; Bermudez, D. \& Sanford, E., 1991. Extreme spatial variation in the growth and reproductive output of the acorn barnacle Semibalanus balanoides. Mar. Ecol. Prog. Ser. 75: 91-100.

Bertness, M.D. \& Leonard, G.H., 1997. The role of positive interactions in communities: lessons from intertidal habitats. Ecology 78: 1976-1989.

Bliss, D.E., 1956. Neurosecretion and the control of growth in a decapod crustacean. In: Bertil Hanström, Zoological papers in honour of his sixtyfifth birthday. (Wingstrand, K.G., ed.), Zoological Institute, Lund, Sweden. Pp. 56-75.

Bliss, D.E., 1960. Autotomy and regeneration. In: The physiology of Crustacea, Vol. 1, (T.H. Waterman, ed.), Academic Press, New York, pp. 561-589.

Booth, D.J., 2004. Synergistic effects of conspecifics and food on growth and energy allocation of a damselfish. Ecology 85(10): 2881-2887.

Brown, J.R., 1988. Multivariate analysis of the role of environmental factors in seasonal and site-related growth variation in the Pacific oyster Crassostrea gigas. Mar. Ecol. Prog. Ser. 45: 225-236.

Burke, R.D., 1986. Pheromones and the gregarious settlement of marine invertebrate larvae. Bull. Mar. Sci. 39: 323-331.

Bushek, D. \& Allen, D.M., 2005. Motile suspension-feeders in estuarine and marine ecosystems. In: The Comparative Roles of Suspension-Feeders in Ecosystems. NATO Science Series IV, Springer Netherlands, Volume 47: 53-71.

Caine, E.A., 1975. Feeding and masticatory structures of selected Anomura (Crustacea). Journ. Exp. Mar. Biol. Ecol. 18: 277-301.

Cammen, L.M., 1980. Ingestion rate: An empirical model for aquatic deposit feeders and detritivores. Oecologia 44: 303-310.

Cahalan, J.A.; Siddall, S.E. \& Luckenbach, M., 1989. Effects of flow velocity, food concentration and particle flux on growth rates of juvenile bay scallops, Argopecten irradians. J. Exp. Mar. Biol. Ecol. 129: 45-60.

Castillo-Rivera, M.; Kobelkowsky, A. \& Zamayoa, V., 1996. Food resource partitioning and trophic morphology of Brevoortia gunteri and B. patronus. J. Fish. Biol. 49: 1102-1111.

Chaparro, O.R.; Segura, C.J.; Montiel, Y.A.; Thompson, R.J.; Navarro, J.M., 2008. Variations in the quantity and composition of seston from an estuary in southern Chile on different temporal scales. Estuar. Coast. Shelf Sci. 76(4): 845-860. 
Collin, S.P.; Costello, J.H. \& Klos, E., 2003. In situ swimming and feeding behavior of eight cooccurring hydromedusae. Mar. Ecol. Prog. Ser. 253: 305-309.

Connell, J.H., 1961. The influence of interspecific competition and other factors on the distribution of the barnacle Chthamalus stellatus. Ecology 42(4): 710-723.

Corey, S. \& Reid, D.M., 1991. Comparative fecundity of decapod crustaceans, I. The fecundity of thirty-three species of nine families of caridean shrimp. Crustaceana 60(3): 270-294.

Crisp, D.J., 1960. Factors influencing growth rate in Balanus balanoides. J. Anim. Ecol. 29: 95-116.

Daly, B.; Swingle, J.S. \& Eckert, G.L., 2009. Effects of diet, stocking density, and substrate on survival and growth of hatchery-cultured red king crab (Paralithodes camtschaticus) juveniles in Alaska, USA. Aquaculture 293 (1-2): 68-73.

Dayton, P.K., 1971. Competition, disturbance and community organization: the provision and subsequent utilization of space in a rocky intertidal community. Ecol. Monogr. 41: 351-389.

Deevey, E. S, 1947. Life tables for natural populations of animals. Q. Rev. Biol. 22: $283-314$.

Depledge, M.H., 1989. Observations on the feeding behaviour of Gaetice depressus (Grapsidae: Varuninae) with special reference to suspension feeding. Mar. Biol. 100: 253-259.

Domingues, P. \& Alaminos, J., 2008. Effects of culture density and shelter on growth and survival of juvenile spider crab, Maja brachydactyla (Balss, 1922). Revista de Biologia Marina y Oceanografia 43(1): 121-127.

Donahue, M.J., 2004. Size-dependent competition in a gregarious porcelain crab Petrolisthes cinctipes (Anomura: Porcellanidae). Mar. Ecol. Prog. Ser. 267: 219-231.

Donahue, M.J., 2006. Allee effects and conspecific cueing jointly lead to conspecific attraction. Oecologia 149: 33-43.

Fegley, S.R.; MacDonald, B.A.; Jacobsen, T.R., 1992. Short-term variation in the quantity and quality of seston available to benthic suspension feeders. Estuar. Coast. Shelf Sci. 34: 393-412.

Figiel, C.R. \& Miller, G.L., 1995. The frequency of chelae autotomy and its influence on the growth and survival of crayfish Procamharus clarkii (Girard, 1852) (Decapoda, Cambaridae). Crustaceana 68: 472-383. 
Förster, C. \& Baeza, J.A., 2001. Active brood care in the anomuran crab Petrolisthes violaceus (Decapoda: Anomura: Porcellanidae): grooming of brooded embryos by the fifth pereiopods. J. Crust. Biol. 21(3): 606-615.

Fradkin, S.C., 1995. Effects of interference and exploitative competition from large-bodied cladocerans on rotifer community structure. Hydrobiologia 313/314: 387-393.

Frechette, M. \& Lefaivre, D., 1990. Discriminating between food and space limitation in benthic suspension feeders using self - thinning relationships. Mar. Ecol. Prog. Ser. 65: 15-23.

Frechette, M.; Aitken, A.E. \& Page, L., 1992. Interdependence of food and space limitation of a benthic suspension feeder: consequences for self-thinning relationships. Mar. Ecol. Prog. Ser. 83: 55-62.

Gardner, J.P.A., 2000. Where are the mussels on Cook Strait (New Zealand) shores? Low seston quality as a possible factor limiting multi-species distributions. Mar. Ecol. Prog. Ser. 194: 123-132.

Gardner, J.P.A. \& Thompson, R.J., 2001. Naturally low seston concentration and the net energy balance of the greenshell mussel, (Perna canaliculus) at Island Bay, Cook Strait, New Zealand. NZ J. Mar. Fresh. Res. 35: 457-468.

Garvey, J.E. \& Stein, R.A., 1993. Evaluating how chela size influences the invasion potential of an introduced crayfish (Orconectes rusticus). Am. Midl. Nat. 129: 172-181.

Garvey, J.E.; Stein, R.A. \& Thomas, H.M., 1994. Assessing how fish predation and interspecific prey competition influence a crayfish assemblage. Ecology 75: 532-547.

Gebauer, P.; Paschke, K. \& Moreno, C.A., 2007. Reproductive biology and population parameters of Petrolisthes laevigatus (Anomura: Porcellanidae) in southern Chile: consequences on recruitment. Journal of the Marine Biological Association of the United Kingdom 87: 729-734.

Gili, J.M. \& Coma, R., 1998. Benthic suspension feeders: their paramount role in littoral marine food webs. Trends Ecol. Evol. 13(8): 316-321.

Gimenez, L. \& Anger, K., 2005. Effects of temporary food limitation on survival of brachyuran crab larvae. J. Plankton Res. 27(5): 485-494.

Gonor, S.L. \& Gonor, J.J., 1973. Feeding, cleaning, and swimming behaviour in larval stages of porcellanid crabs (Crustacea: Anomura). Fishery Bulletin 71(1): 225-234.

Goss, R.J., 1969. Molting, metamorphosis and regeneration in arthropods. In: Principles of Regeneration. Academic Press, New York, pp. 91-113.

Haig, J., 1960. The porcellanidae (Crustacea Anomura) of the eastern Pacific. Alan Hancock Pacific Expeditions 24. 440 pp. 
Haig, J., 1964. Papers from Th. Mortensen's pacific expeditions 1914-1916. 81. Porcellanid crabs from the Indo-West pacific. Videnskabelige Meddeleser fra Dansk Naturhistorisk Forening i Kфpenhavn, 126. Pp. 366.

Harris, R.N., 1989. Nonlethal injury to organisms as a mechanism of population regulation. Am. Nat. 134(6): 835-847.

Hartnoll, R.G., 1982. Growth. In: The Biology of Crustacea 2: 111-196, (L.G. Abele, ed.), Academic Press, New York.

Hartnoll, R.G., 1985. Growth, sexual maturity and reproduction. In: A.M. Wenner, ed., Crustacean issues 3. Factors in adult growth. Pp. 101-128. A.A. Balkema, Rotterdam, The Netherlands.

Harvey, H.W., 1937. Note on selective feeding by Calanus. J. Mar. Biol. Assoc. U.K. 22: 97-100.

Hazlett, B.A, 2000. Responses to single and multiple sources of chemical cues by New Zealand crustaceans. Mar. Freshw. Behav. Physiol. 34(1): 1-20.

Hazlett, B.A, 2004. Alternative tactics and responses to conflicting inputs in the porcellanid crab Petrolisthes elongatus. Mar. Fresh. Behav. Physiol. 37: 173-177.

Hazlett, B.A.; Bach, C.E.; McLay, C., \& Thacker, R.W., 2000. A comparative study of the defense syndromes of some New Zealand marine crustaceans. Crustaceana 73 (8): 899-912.

Helson, J.G., 2001. An investigation into the absence of mussels (Perna canaliculus, Aulacomya maoriana \& Mytilus galloprovincialis) from the south coast of Wellington, New Zealand. PhD thesis, Victoria University of Wellington, New Zealand. 183 pp.

Helson, J.G. \& Gardner, J.P.A., 2007. Variation in scope for growth: a test of food limitation among intertidal mussels. Hydrobiologia 586: 373-392.

Helson, J.G.; Pledger, S. \& Gardner, J.P.A., 2007. Does differential particulate food supply explain the presence of mussels in Wellington Harbour (New Zealand) and their absence on neighbouring Cook Strait shores? Estuar. Coast. Shelf Sci. 72(1-2): 223-234.

Hines, A.H., 1978. Reproduction in three species of intertidal barnacles from central California. Biol. Bull. 154(2): 262-281.

Hines, A.H., 1991. Fecundity and reproductive output in nine species of Cancer crabs (Crustacea, Brachyura, Cancridae). Can. J. Fish. Aquat. Sci. 48: 267-275.

Hines, A.H., 1992. Constraint on reproductive output in brachyuran crabs: Pinnotherids test the rule. Am. Zool. 32(3): 503-511. 
Hopkins, P.M., 1982. Growth and regeneration patterns in the fiddler crabs Uca pugilator. Biol. Bull. 163: 301-319.

Hopkins, P.M., 1993. Regeneration of walking legs in the fiddler crab Uca pugilator. Am. Zool. 33(3): 348-356.

Hopkins, P.M., 2001. Limb regeneration in the fiddler crab, Uca pugilator: Hormonal and growth factor control. Am. Zool. 41: 389-398.

Hyatt, G.W., 1983. Qualitative and quantitative dimensions of Crustacean aggression. In: Studies in adaptation: the behavior of higher Crustacea. (S. Rebach \& D.W. Dunham, eds.) J. Wiley \& Sons, New York, pp. 113-142.

Jensen, G.C., 1989. Gregarious settlement by megalopae of the porcelain crab Petrolisthes cinctipes (Randall) and P. eriomerus Stimpson. J. Exp. Mar. Biol. Ecol. 131: 223-231.

Jensen, G.C., 1990. Intertidal zonation of porcelain crabs: Resource partitioning and the role of selective settlement. Washington, Seattle.

Jensen, G.C. \& Armstrong, D.A., 1991. Intertidal zonation among congeners: factors regulating distribution of porcelain crabs Petrolisthes spp. (Anomura: Porcellanidae). Mar. Ecol. Prog. Ser. 73: 47-60.

Juanes, F.; Lee, K.T.; McKnight, A. \& Kellogg, K., 2008. Claw allometry in green crabs, Carcinus maenas: heterochely, handedness, and sex. Mar. Biol. 153: 523-528.

Juanes, F. \& Smith, L.D., 1995. The ecological consequences of limb damage and loss in decapod crustaceans: a review and prospectus. J. Exp. Mar. Biol. Ecol. 193: $197-223$.

Katre, S. \& Reddy, S.R., 1977. Laboratory studies on food intake, growth and conversion efficiency of Palaemon lamarrei in relation to body size. Aquaculture 11(3): 247-261.

Klein-Breteler, W.C.M., 1975. Food consumption, growth and energy metabolism of juvenile shore crabs, Carcinus maenas. Netherlands Journal of Sea Research 9(3-4): 255-272.

Klimmerer, W.J.; Gartside, E. \& Orsi, J.J., 1994. Predation by an introduced clam as the likely cause of substantial declines in zooplankton of San Fancisco Bay. Mar. Ecol. Prog. Ser. 113: 81-93.

Kropp, R.K., 1981. Additional porcelain crab feeding methods (Decapoda, Porcellanidae). Crustaceana 40(3): 307-310.

Leslie, H.M., 2005. Positive intraspecific effects trump negative effects in highdensity barnacle aggregations. Ecology 86(10): 2716-2725. 
Lesser, M.P.; Witman, J.D. \& Sebens, K.P., 1994. Effects of flow and seston availability on scope for growth of benthic suspension-feeding invertebrates from the Gulf of Maine. Biol. Bull. 187(3): 319-335.

López, L., 1997. Adquisición de la madurez sexual y caracterización del patrón de crecimiento y reproducción en Chasmagnathus granulata, DANA 1851 (Brachyura, Grapsidae, Sesarminae) de Bahía Samborombón, Buenos Aires, Argentina. Tesis Doctoral, Universidad de Buenos Aires, 244 pp.

Luppi, A.T.; Bas, C.C.; Spivak, E.D. \& Anger, K., 1997. Fecundity of two grapsid crab species in the Laguna Mar Chiquita, Argentina. Arch. Fish. Mar. Res. 45: 149-166.

Lysenko, V.N.; Selin, N.I. \& Fedotov, P.A., 2000. Autotomy and regeneration of limbs in the male blue king crab Paralithodes platypus from the Bering Sea and the Sea of Okhotsk. Russian Journal of Marine Biology 26(5): 364-366.

MacDiarmid, A.B., 1989. Size at onset of maturity and size-dependent reproductive output of female and male spiny lobsters Jasus edwardsii (Hutton) (Decapoda, Palinuridae) in northern New Zealand. J. Exp. Mar. Biol. Ecol. 127(3): 229-243.

MacDonald, B.A. \& Thompson, R.J., 1985. Influence of temperature and food availability on the ecological energetics of the giant scallop Placopecten magellanicus. II Reproductive output and total production. Mar. Ecol. Prog. Ser. 25: 295-303.

Maginnis, T.L., 2006. The costs of autotomy and regeneration in animals: a review and framework for future research. Behav. Ecol. 17: 857-872.

Mariappan, P.; Balasundaram, C. \& Schmitz, B., 2000. Decapod crustacean chelipeds: an overview. J. Biosci. 25(3): 301-313.

McLay, C., 1988. Brachyura and crab-like anomura of New Zealand. Leigh Laboratory Bulletin 22. Pp. 463.

McVean, A., 1982. Autotomy. In: The Biology of Crustacea, Vol. 4., (D.E. Bliss, ed.), Academic Press, New York, pp. 107-132.

McVean, A., 2003. The incidence of autotomy in Carcinus maenas (L.). J. Exp. Mar. Biol. Ecol. 24(2): 177-187.

McVean, A. \& Findlay, I., 1979. The incidence of autotomy in an estuarine population of the crab Carcinus maenas. J. Mar. Biol. Assoc. U.K. 59: 341354.

Metaxas, A.; Scheibling, R.E. \& Young C.M., 2002. Estimating fertilization success in marine benthic invertebrates: a case study with the tropical sea star Oreaster reticulatus. Mar. Ecol. Prog. Ser. 226: 87-101. 
Meyer-Rochow, V.B. \& Tiang, K.M. 1984. The eye of Jasus edwardsii (Palinuridae, Decapoda, Crustacea) - electrophysiology, histology, and behaviour. Zoologica 45 (134): 1-85.

Meyer-Rochow, V.B. \& Meha, W.P., 1994. Tidal rhythm and the role of vision in shelter-seeking behaviour of the half-crab Petrolisthes elongatus (Crustacea: Anomura: Porcellanidae). J. Royal Soc. New Zealand 24(4): 423-427.

Miller, R.J. \& Watson, J., 1976. Growth per molt and limb regeneration in the spider crab, Chionecetes opilio. J. Fish. Res. Board. Can. 33: 1644-1649.

Molenock, J., 1975. Evolutionary aspects of communication in the courtship behavior of four species of anomuran crabs (Petrolisthes). Behaviour 53 (1/2): $1-30$.

Molenock, J., 1976. Agonistic interactions of the crab Petrolisthes (Crustacea, Anomura). Zeitschr. Tierpsychol. 41: 277-294.

Morton, J. \& Miller, M, 1973. The New Zealand Shore. Collins, Auckland and London. 653 pp.

Mullin, M.M., 1966. Selective feeding by calanoid copepods from the Indian Ocean. See Ref. 57: 545-554.

Nicol, E.A.T., 1932. The feeding habits of Galatheidea. J. Mar. Biol. Assoc. U.K. 18: 87-106.

Nordhaus, I.; Wolff, M. \& Diele, K., 2006. Litter processing and population food intake of the mangrove crab Ucides cordatus in a high intertidal forest in northern Brazil. Estuarine, Coastal and Shelf Science 67: 239-250.

Nunes, A.J.P. \& Parsons, G.J., 1998. Food handling efficiency and particle size selectivity by the southern brown shrimp Penaeus subtilis fed a dry pelleted feed. Mar. Fresh. Behav. Physiol. 31(4): 193 - 213.

O'Brian, J.J. \& Skinner, D.M., 1990. Overriding of the molt-inducing stimulus of multiple limb autotomy in the mud crab Rhithropanopeus harrisii by parasitization with a Rhizocephalan. J. Crust. Biol. 10(3): 440-445.

Odum, E.P., 1971. Fundamentals of Ecology. Saunders, Philadelphia.

Okamura, B., 1992. Microhabitat variation and patterns of colony growth and feeding in a marine bryozoan. Ecology 73: 1502-1513.

Othes, S. \& Pire, R., 2001. Fatty acid composition of Chlorella and Spirulina microalgae species. J. AOAC Int. 84: 1708-1714.

Paine, R.T., 1974. Intertidal community structure. Experimental studies on the relationship between a dominant competitor and its principal predator. Oecologia 15: 93-120. 
Parrish, J.K. \& Edelstein-Keshet, L., 1999. Complexity, pattern, and Evolutionary trade-offs in animal aggregation. Science 284(5411): 99-101.

Peters, R.H., 1982. The ecological implications of body size. Cambridge University Press, Cambridge.

Pile, A.J.; Lipcius, R.N; van Montfrans, J. \& Orth, R.J., 1996. Density-dependent settler-recruit-juvenile relationships in blue crabs. Ecol. Monogr. 66(3): 277-300.

Pinn, E.H.; James, R.; Atkinson, A. \& Rogerson, A, 1998. Particle size selectivity and resource partitioning in five species of Thalassinidea (Crustacea: Decapoda). Mar. Ecol. Prog. Ser. 169: 213-250.

Raimondi, P.T., 1988. Settlement cues and determination of the vertical limit of an intertidal barnacle. Ecology 69: 400-407.

Ray, M. \& Stoner, A.W., 1994. Experimental analysis of growth and survivorship in a marine gastropod aggregation: balancing growth with safety in numbers. Mar. Ecol. Prog. Ser. 105: 47-59.

Reid, D.M. \& Corey, S., 1991. Comparative fecundity of decapod crustaceans, II. The fecundity of fifteen species of anomuran and brachyuran crabs. Crustaceana 61(2): 175-189.

Ropert, M. \& Goulletquer, P., 2000. Comparative physiological energetics of two suspension feeders: polychaete annelid Lanice conchilega (Pallas, 1766) and Pacific cupped oyster Crassostrea gigas (Thunberg 1795). Aquaculture 181: 171-189.

Rothhaupt, K.O., 1990. Differences in particle size-dependent feeding efficiencies of closely related rotifer species. Limnol. Oceanogr. 35(1): 16-23.

Rypien, K.L. \& Palmer, A.R., 2007. The effect of sex, size and habitat on the incidence of puncture wounds in the claws of the porcelain crab Petrolisthes cinctipes (Anomura: Porcellanidae). J. Crust. Biol. 27(1): 59-64.

Sanford, E.; Bermudez, D.; Bertness, M.D. \& Gaines, S.D., 1994. Flow, food supply and acorn barnacle population dynamics. Mar. Ecol. Prog. Ser. 104: 49-62.

Schmitt, R.J., 1996. Exploitation competition in mobile grazers: trade-offs in use of a limited resource. Ecology 77: 408-425.

Scott, M.S., 1958. Studies on a false crab, Petrolisthes elongatus, Milne-Edwards. M.Sc. Thesis, University of Canterbury, Christchurch, New Zealand. 117 pp.

Shirley, S.M. \& Shirley, T.C., 1988. Appendage injury in dungeness crabs, Cancer magister, in southeastern Alaska. Fish. Bull. 86: 156-160. 
Shumway, S.E.; Cucci, T.L.; Newell, R.C. \& Yentsch, C.M., 1985. Particle selection, ingestion, and absorption in filter-feeding bivalves. J. Exp. Mar. Biol. Ecol. 91: 77-92.

Skinner, D. M. 1985. Molting and regeneration. In: The Biology of Crustacea 9: 43-146. (D.E. Bliss, ed.), Academic Press, New York.

Smith, L.D., 1992. The impact of limb autotomy on mate competition in blue crabs Callinectes sapidus Rathbun. Oecologia 89: 494-501.

Smith, L.D., 1995. Effects of limb autotomy and tethering on juvenile blue crab survival from cannibalism. Mar. Ecol. Prog. Ser. 116: 65-74.

Smith, L.D. \& Hines, A.H., 1991. Autotomy in blue crab (Callinectes sapidus Rathburn) populations: geographic, temporal, and ontogenetic variation. Biol. Bull. 180: 416-431.

Sneddon, L.U.; Huntingford, F.A.; Taylor, A.C., 1997. Weapon size versus body size as a predictor of winning in fights between shore crabs, Carcinus maenas (L.). Behav. Ecol. Sociobiol. 41: 237-242.

Soniat, T.M. \& Ray, S.M., 1985. Relationships between possible available food and the composition, condition and reproductive state of oysters from Galveston Bay, Texas. Cont. Mar. Sci. 28: 109-121.

Spivak, E.D., 1990. Limb regeneration in a common South American littoral crab Cyrtograpsus angulatus. J. Nat. Hist. 24: 393-402.

Števčić, Z., 1988. Autecological investigations of the porcelain crab Porcellana platycheles (Pennant) (Decapoda, Anomura) in the Rovinj Area (Northern Adriatic) Crustaceana (55)3: 242-252.

Tanner, J.E., 2002. Consequences of density-dependent heterotrophic feeding for a partial autotroph. Mar. Ecol. Prog. Ser. 227: 293-304.

Tegner M.J. \& Levin, L.A., 1983. Spiny lobsters and sea urchins: analysis of a predator-prey interaction. J. Exp. Mar. Biol. Ecol. 73: 125-150.

Trager, G.C. \& Genin, A., 1993. Flow velocity induces a switch from active to passive suspension feeding in the porcelain crab Petrolisthes leptocheles (Heller). Biol. Bull. 185: 20-27.

Trager, G.C.; Coughlin, D.; Genin, A.; Achituv, Y. \& Gangopadhyay, A., 1992. Foraging to the rhythm of ocean waves: porcelain crabs and barnacles synchronize feeding motions with flow oscillations. J. Exp. Mar. Ecol. 164: 73-86.

Valdivia, N. \& Stotz, W., 2006. Feeding behaviour of the porcellanid crab Allopetrolisthes spinifrons, symbiont of the sea anemone Phymactis papillosa. J. Crust. Biol. 26(3): 308-315. 
Wasson, K.; Lyon, B.E. \& Knope, M., 2002. Hair-trigger autotomy in porcelain crabs is a highly effective escape strategy. Behav. Ecol. 13: 481-486.

Wasson, K. \& Lyon, B.E., 2005. Flight or fight: flexible antipredatory strategies in porcelain crabs. Behav. Ecol. 16: 1037-1041.

Weis, J.S., 1976. Effects of environmental factors on regeneration and moulting in fiddler crabs. Biol. Bull. 150: 152-162.

WenKuan, L.; ZuGuo, X.; XiaoLin, Z.; YongQing, Y.; Hang, J.; ZhongSheng, S., 2009. Effect of initial size and stocking density on growth and yield of Chinese mitten-handed crab Eriochier sinensis in rice fields. Fisheries Science (Dalian) 28 (1): 36-39.

Werding, Prof. Dr. B., Justus Liebig Universität Giessen, Heinrich-Buff-Ring 2632, 35392 Giessen, Germany, Bernd.Werding@allzool.bio.uni-giessen.de

Werner, E.E. \& Anholt, B.R., 1992. Ecological consequences of the trade-off between growth and mortality rates mediated by foraging activity. Am. Nat. 142(2): 242-272.

Westoby, M., 1981. The place of the self-thinning rule in population dynamics. Am. Nat. 118(4): 581-587.

Wethey, D.S. 1983. Intrapopulation variation in growth of sessile organisms: natural populations of the intertidal barnacle Balanus balanoides. Oikos 40: 14-23.

Whethey, D.S., 1984. Effects of crowding on fecundity in barnacles: Semibalanus (Balanus) balanoides, Balanus glandula, and Chthamalus dalli. Can. J. Zool. 62: 1788-1795.

Wicksten, M.K., 1973. Feeding in the porcelain crab, Petrolisthes cinctipes (Randall) (Anomura: Porcellanidae). Bull. So. Calif. Acad. Sci. 72(3): 161162.

Wildish, D.J. \& Kristmanson, D.D., 1985 Control of suspension-feeding bivalve production by current speed. Helgol. Meeresunters. 39: 237-243.

Wildish, D.J. \& Kristmanson, D.D., 1979. Tidal energy and sublittoral macrobenthic animals in estuaries. J. Fish. Res. Can. 36: 1197-1206.

Wilson-Ormond, E.A.; Powell, E.N.; Ray, S.M., 1996. Short-term and small-scale variation in food availability to natural oyster populations: food, flow and flux. Mar. Ecol. 18(1): 1-34.

Wood, F.D. \& Wood, H.E., 1932. Autotomy in Decapod Crustacea. J. Exp. Zool. 62: 1-55.

Ziedins, I. \& Meyer-Rochow, V.B., 1990. ERG-determined spectral and absolute sensitivities in relation to age and size in the halfcrab Petrolisthes elongatus (Crustacea; Decapoda; Anomura). Exp Biol. 48(6): 319-28. 
Zimmer-Faust, R.K., 1989. The relationship between chemoreception and foraging behaviour in crustaceans. Limnol. Oceanogr. 34: 1367-1374.

Zittin, D., 1979. Factors influencing the vertical distribution of two intertidal porcelain crab populations. $\mathrm{PhD}$ thesis, University of British Columbia, Vancouver, $110 \mathrm{pp}$. 


\section{Appendix 5}

Week 1 - 2

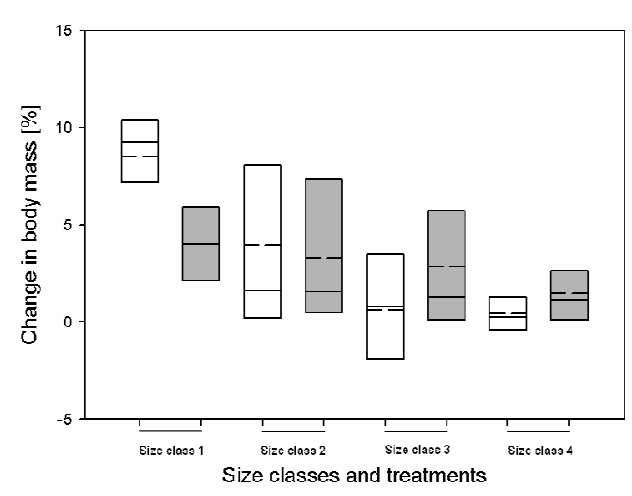

Week $3-4$

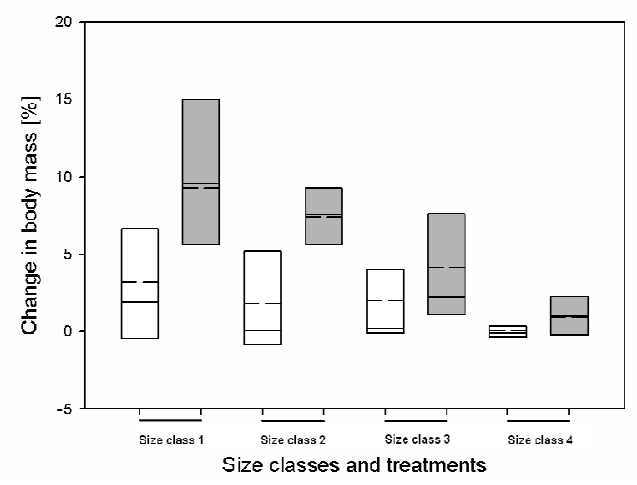

Week 5 - 6

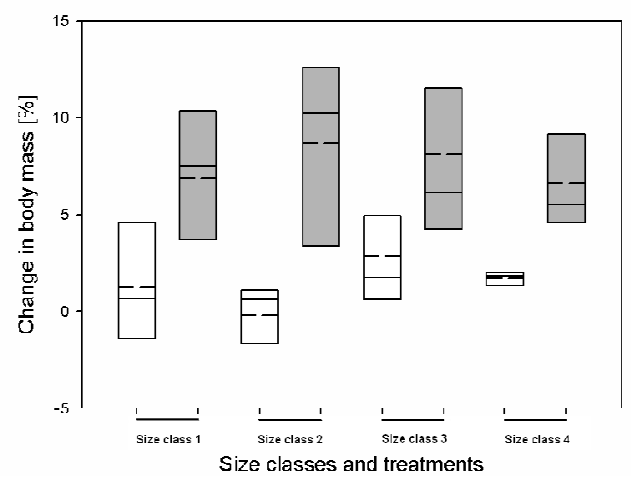

Treatment 1: all limbs present
Week 2 - 3

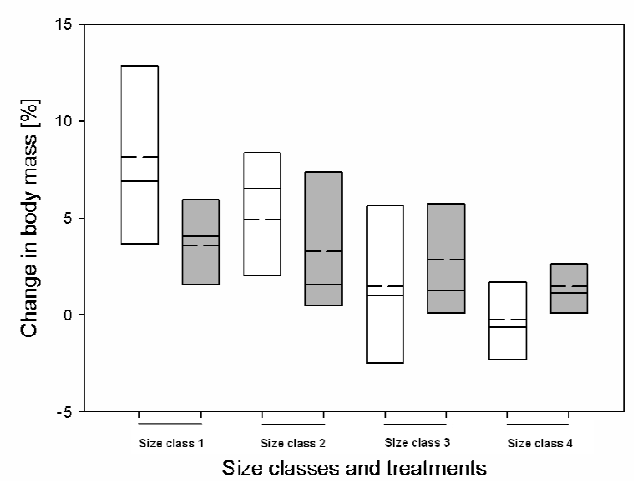

Week 4 - 5

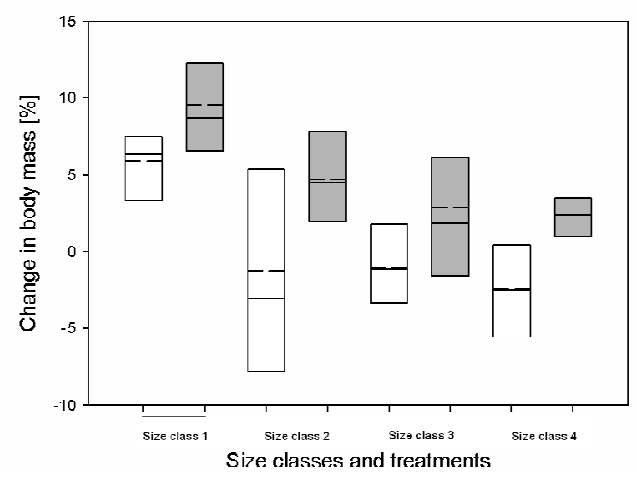

Week 6 - 7

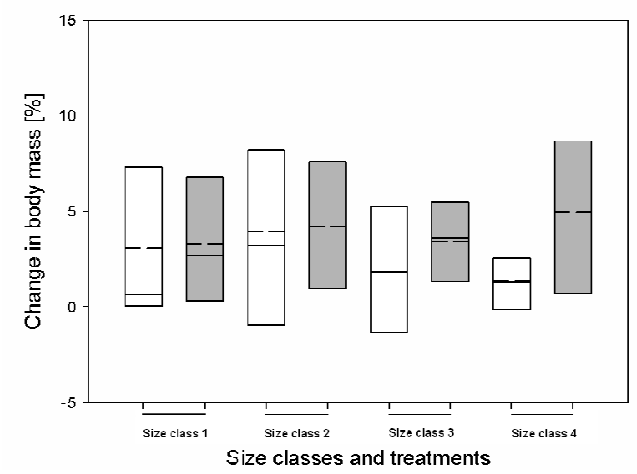

Appendix 5.1: Weekly changes in body mass [\%] in uninjured crabs and animals whose chelipeds had been removed by artificially induced autotomy. 
Week 1 - 2

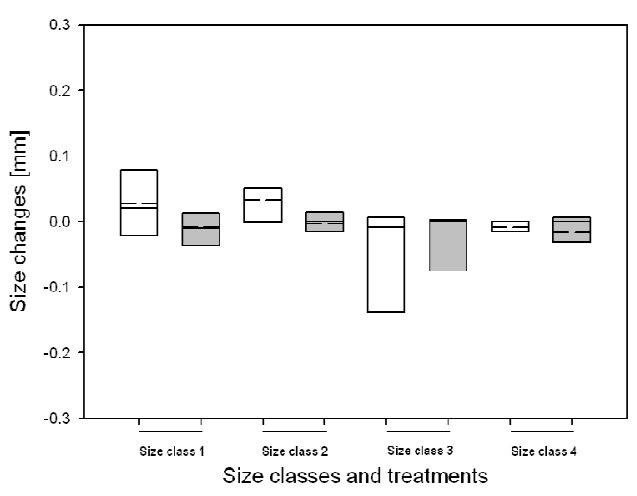

Week $3-4$

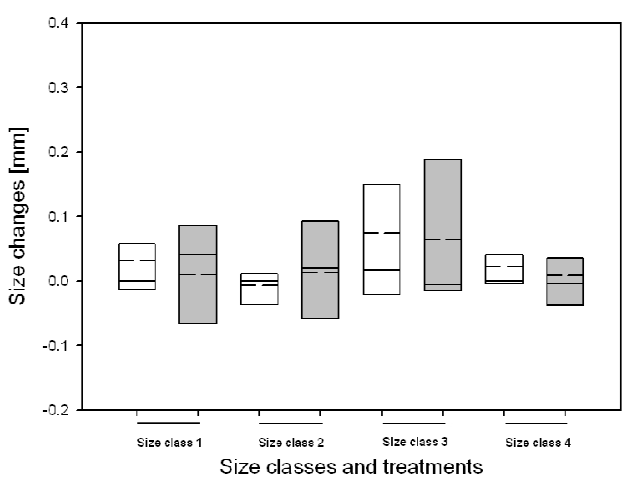

Week $5-6$

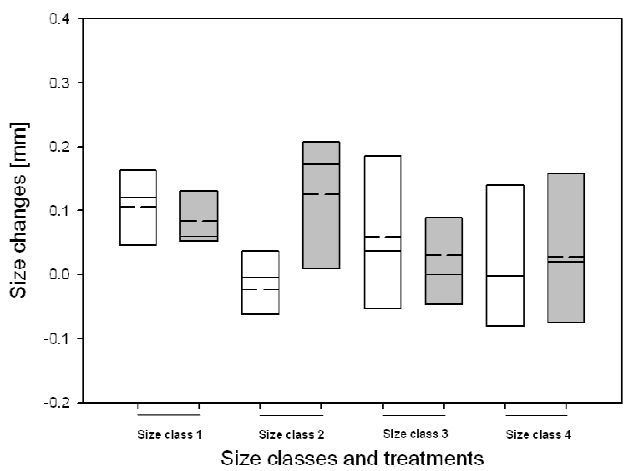

$\square$ Treatment 1: all limbs present
Week 2 - 3

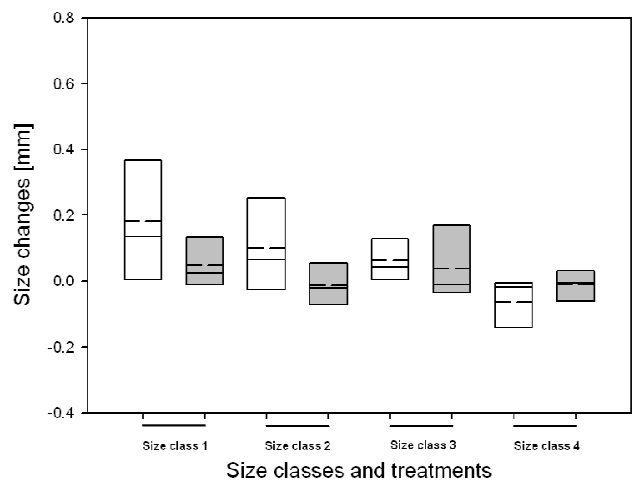

Week 4 - 5

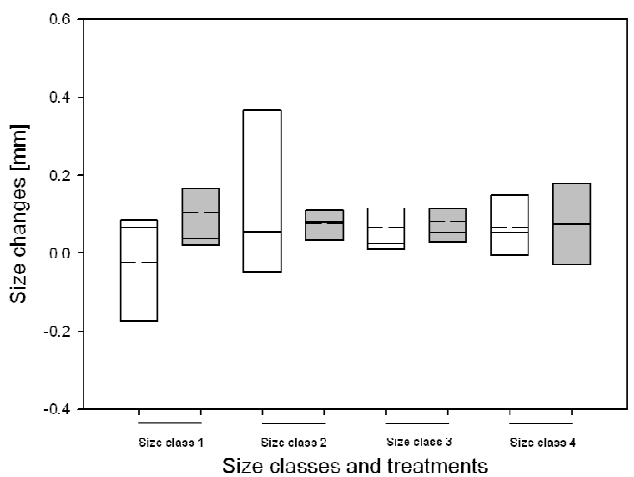

Week 6 - 7

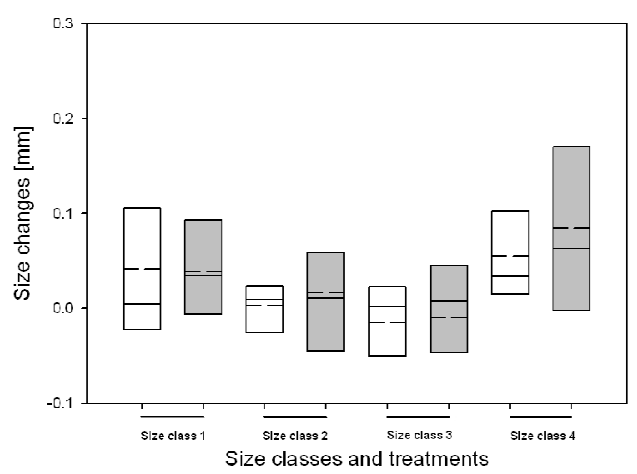

Appendix 5.2: Weekly size changes [mm carapace width] in uninjured crabs and animals with removed and regenerating chelipeds. 


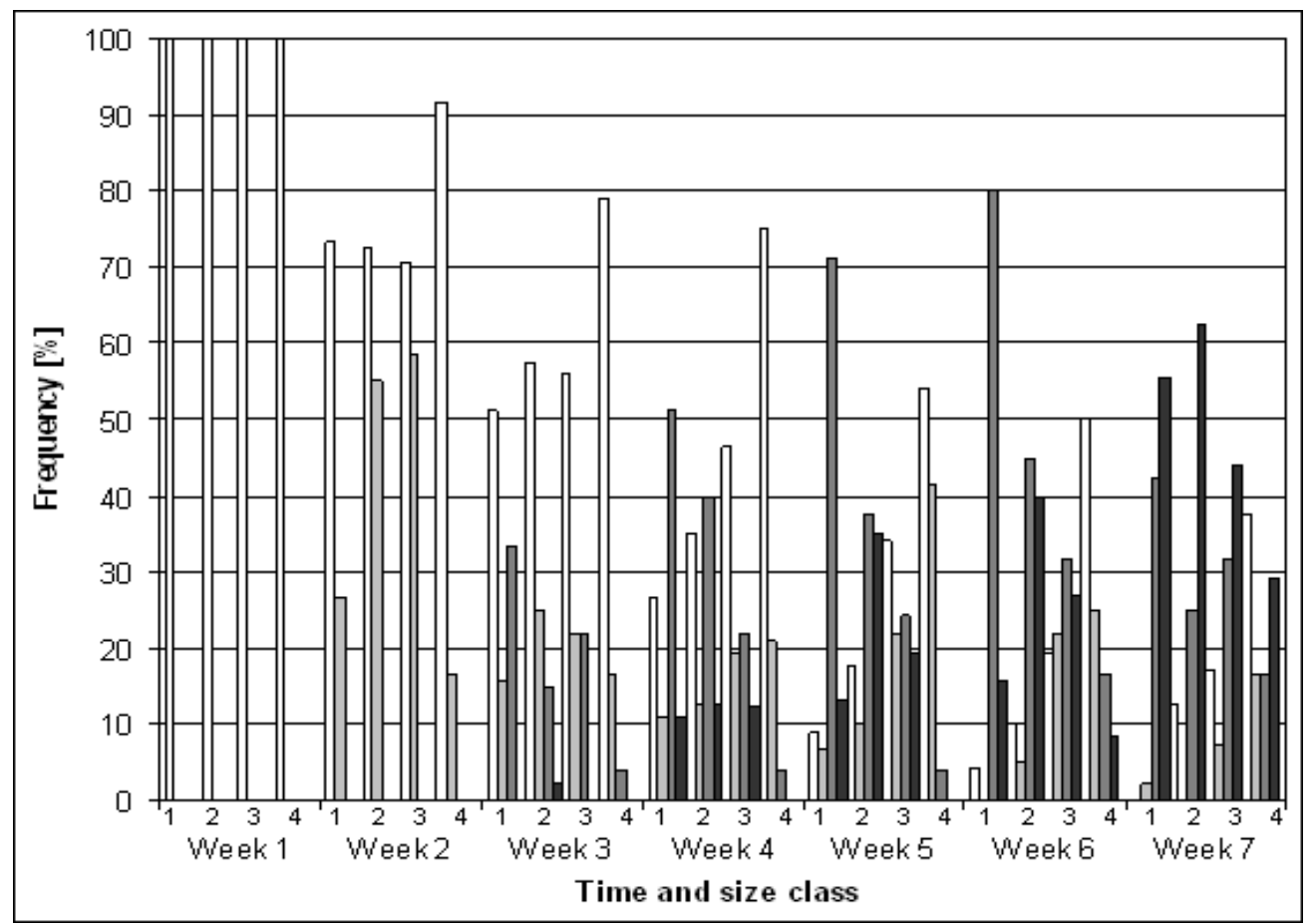

\section{$\square=0-25 \% \quad>25-50 \% \quad \square \quad>50-75 \% \quad \square \quad>75-100 \%$}

Appendix 5.3: Frequency of developmental stages of limb regeneration within 4 size classes over 7 weeks. The full limb regeneration takes between 9 and 14 weeks, independent of moulting but dependent on body size (pers. obs.). Chelipeds in smaller crabs are regenerating much faster than in larger individuals. Differences between sexes were not observed.

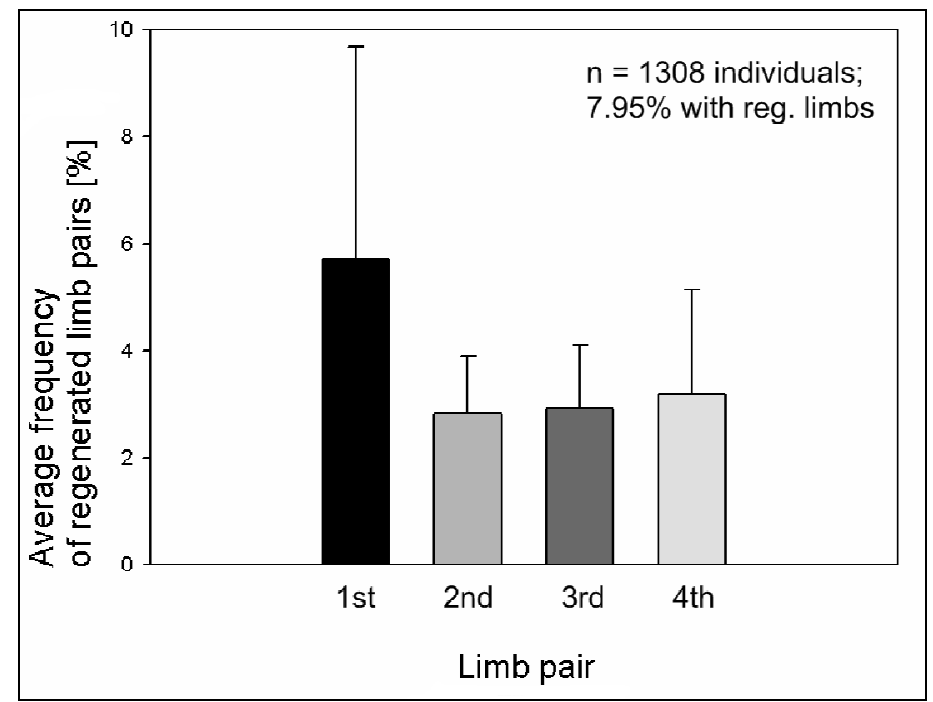

Appendix 5.4: Percentage of the total population at which a limb pair $\left(1^{\text {st }}\right.$ to $4^{\text {th }}$ pereiopods) was found regenerating (i.e. in the process of regeneration). From all limb pairs, regenerating chelipeds ( $1^{\text {st }}$ pereiopods) were found most frequently. Error bars represent $95 \%$ confidence intervals. 


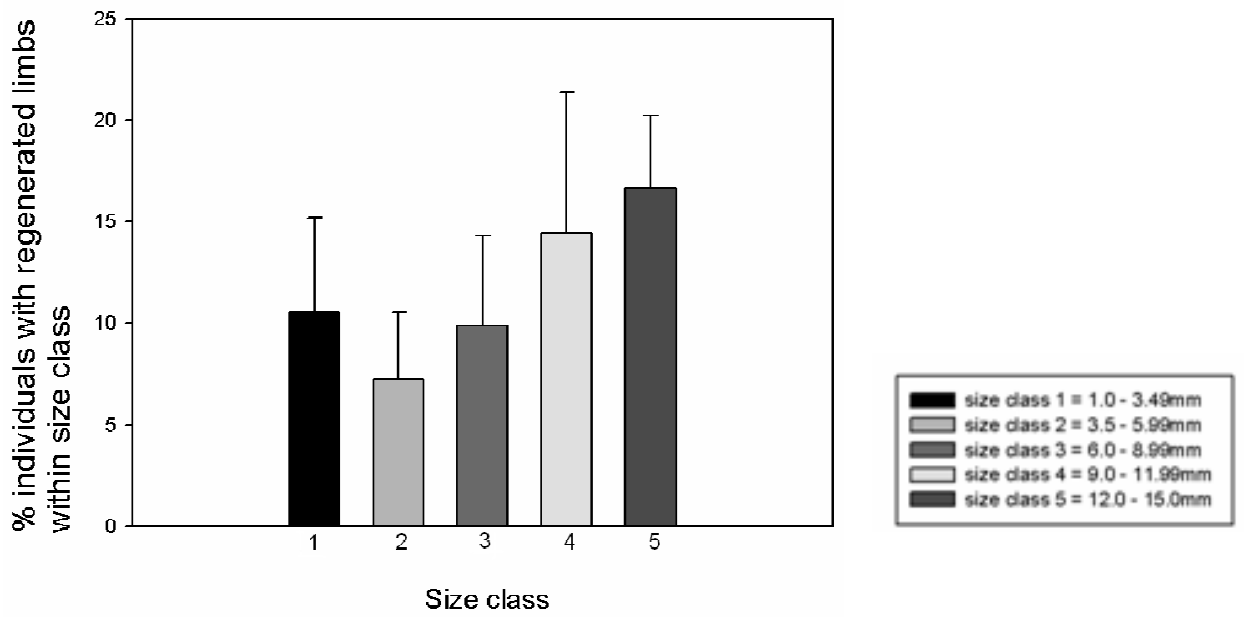

Appendix 5.5: Percent individuals with regenerating limbs within 5 size classes. While size class 1 crabs shed their limbs more readily than larger animals and may be more prone to injury due to environmental conditions, the regeneration process in larger crabs takes longer and, therefore, could be more frequently observable. Additionally, adults may be more prone to injury due to attempted predation since migration rates are higher in larger crabs. Error bars represent $95 \%$ confidence intervals.

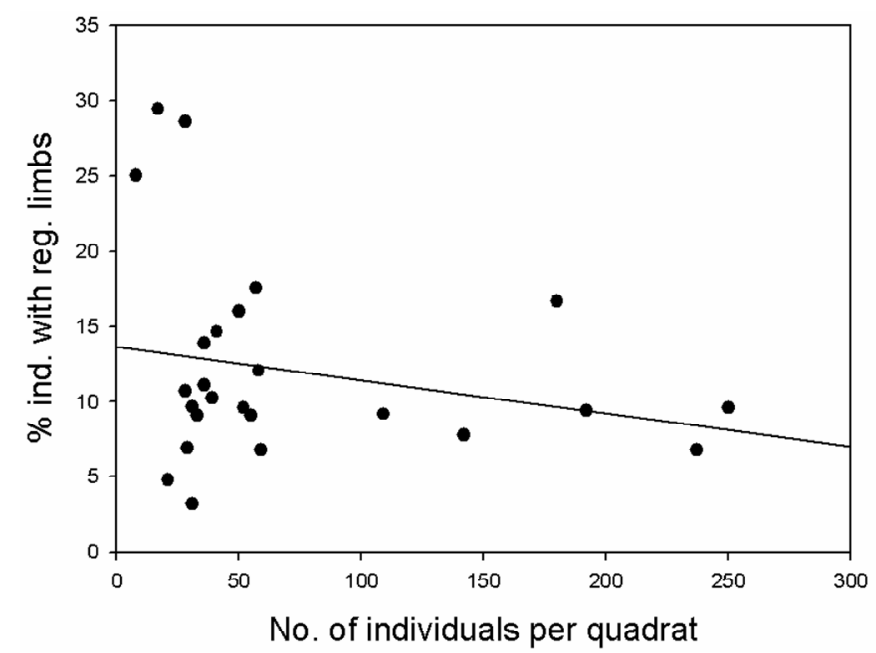

Appendix 5.6: Number of sexually mature individuals per sample quadrat versus percent values of individuals with regenerated limbs. (Results were obtained by quadrat sampling, described in chapter 3.)

Appendix 5.7: 2-way ANOVA results: proportion individuals with regenerated limbs $P R \sim D+S+(D \times S)(D=$ Density: individuals per sample quadrat; $S=$ Site).

\begin{tabular}{|l|lrrl|}
\hline Source & SS & df & F & p \\
\hline Intercept & & 1 & & $<\mathbf{0 . 0 0 0 1}$ \\
Density & 79.6478 & 1 & 1.4392 & $<0.2436$ \\
Site & 37.6037 & 1 & 0.3397 & $<0.7158$ \\
Density * site & 75.7510 & 2 & 0.6844 & $<0.5153$ \\
Error & 1162.1836 & 21 & & $<0.2100$ \\
\hline
\end{tabular}




\section{Chapter 6}

\section{General discussion}

\subsection{Summary of findings}

The examined metapopulations of $P$. elongatus at the south coast as well as within Wellington Harbour exhibited a high variability in population density and reproductive traits across sites and had a patchy distribution on almost all scales of observation. The underlying mechanisms driving the heterogeneity of abundance on a larger scale could not be identified in the present study; however, it is likely that the significantly (6-fold) higher densities of $P$. elongatus within the harbour with up to 843 individuals per sample quadrat $\left(=3372\right.$ ind. $\left./ \mathrm{m}^{2}\right)$ compared to south coast sites can be explained by the varied availability of shelter space as well as by probably significant differences in food and larval supply. Cobble size largely explained the heterogeneity of abundance of $P$. elongatus especially on small scales $(<50 \mathrm{~cm}$ and $<5 \mathrm{~m})$ but also on the large scale (between approximately 5 and $15 \mathrm{~km}$ ) and was generally a suitable predictor for mean carapace width with larger crabs under larger rocks, thereby influencing local population structure. Both, density as well as the mean size of adult crabs appeared to be strongly influenced by substratum constraints, specifically the availability and size of interstitial space between boulders that in turn depend on the size and size frequency distribution of rocks. Cobbles with a surface area smaller than $30 \mathrm{~cm}^{2}$ were not used as shelters at all sites due to a high local disturbance risk (i.e. movement of rocks) and insufficient protection from temperature and desiccation stress.

While the mobility of crabs strongly varied with site, differences in structural complexity did not have a major impact on migration rate. The underlying mechanisms responsible for approx. 50\% shorter migrated distances at Hutt River mouth $(<70 \mathrm{~cm}$ over $25 \mathrm{~h})$ compared to those recorded at the south coast remained unclear but were likely to be influenced by relatively higher levels of intraspecific competition due to significantly higher local densities. Generally, mobility of 
P. elongatus is low compared to other decapods and depended on crab size with higher migration rates in larger crabs.

Conspecific density affected individual growth rate and mortality under laboratory conditions, especially among smaller individuals. Feeding activity, however, was not correlated with density but strongly varied with time of the day (2-4fold increases at night) and size, with higher frequencies of filter feeding in small crabs.

Settlement rates varied on a surprisingly small scale (tens of centimetres), dependent on the presence and density of conspecific adults. Similar to other Petrolisthes species, males and females of P. elongatus release a waterborne settlement cue that attracts conspecific larvae and influences settlement patterns via heterogeneous cue densities. Recruits may still positively respond to these cues, possibly guiding them to aggregations of protecting adults; however, the results in this aspect were inconclusive.

Under laboratory conditions, fish predation on crabs mainly depended on crab size with higher predation among smaller crabs. In the field, however, cobble size may also affect the frequency of predator-prey encounters and therefore predation rate, as well as the risk of limb loss due to predation attempts and shifting and grinding of smaller rocks in the surf. Limb loss was negatively correlated with conspecific density and is most likely related to disturbance rate, wave exposure, and predator abundance. The limb regeneration process is independent of moulting and was responsible for a higher wet weight increase compared to uninjured crabs. Whether the associated energetic costs of limb loss affect growth increment during moults and / or reproductive output remains to be tested.

The reproductive traits of $P$. elongatus were highly variable across sites, with the highest reproductive output per female (i.e. ratio clutch to body weight), and higher egg numbers in similar-sized females at Island Bay compared to other sites. This pattern is probably influenced by lower levels of intraspecific competition at this site compared to other sites, while temperatures at the south coast were generally lower compared to the harbour. However, females with the largest eggs with highest egg water content and highest egg dry weight were 
found at HRM, presumably driven by abundant food and lower salinity. Generally, each of the examined metapopulations is exposed to different environmental conditions that may be responsible for the phenotypic plasticity P. elongatus exhibits. However, in the present study it could not be determined to what degree site specific phenotypic differences occurred as a result of plastic responses to environmental conditions or to what extent these differences were genetically determined.

Generally, $P$. elongatus appears to be well adapted to its patchy and naturally fragmented habitat over a wide range of environmental conditions. Wile population dynamics are largely driven by habitat structure and environmental conditions, life history traits such as high frequency of spawning, phenotypic plasticity, high dispersal capacity due to a long pelagic larval phase and conspecific cueing allow these crabs to thrive in sustained metapopulations reaching higher densities than any other species in intertidal boulder fields.

\subsection{General discussion}

The role of habitat structure in shaping patterns of abundance and population structure

Similar to aggregations of $P$. cinctipes (Donahue, 2004, 2006), P. eriomerus (Jensen, 1989, 1990) and P. laevigatus (Gebauer et al., 2007) in intertidal boulder fields, the highly clumped distribution of $P$. elongatus on small scales is closely related to the availability and size of shelters, combined with shelter targeting behaviour especially during low tide. Ultimately, available shelter space depends on both rock size and habitat structure (i.e. layering, surface rugosity, and the presence or absence of fine sediment). Therefore, small scale variations in habitat structure and complexity are correlated with the patchiness of abundance of crabs inhabiting the interstitial space. It is widely acknowledged that refuge availability, shelter size, and habitat structural complexity can strongly affect the abundance and demography of crab populations (Howard, 1980; Wahle, 1992; Beck, 1995; Sosa-Cordero et al., 1998; Allen et al., 2006). Consequently, and because the degree of environmental heterogeneity varies with spatial scale, patterns of abundance are expected to vary with the scale of observation, as well (Wiens, 
1989; Levin, 1992). P. elongatus prefers larger rocks as shelters over smaller ones, probably due to better protection from desiccation and temperature stress by larger rocks (Stillmann \& Somero, 1996; Stillman, 2002; Emparanza, 2007) as well as from strong water movement and predation. Larger rocks in combination with lower wave exposure may additionally provide more stable microhabitats with lower mortality rates compared to smaller rocks that shift and grind in heavy surge. Because larger crabs (i.e. dominant competitors, see Molenock, 1976) were found under larger rocks, leading to a positive correlation between rock size and mean carapace width, population structure (i.e. the size frequency distribution) is closely associated with shelter size. Additionally, settlement and recruitment rates, in combination with conspecific cueing, strongly influence local population demographics as well as patterns of abundance. Density, in turn, affects individual growth rate (compare Donahue, 2004) and therefore reproductive output since egg numbers per female are strongly associated with body size. Local crab density may be migitated by the (size dependent) movement of individuals competing for optimal feeding locations (Molenock, 1976; Jensen, 1990) during high tide (see below). The underlying mechanisms driving the heterogeneity of abundance on a larger scale were only partly identified in the present study; however, it is likely that the significantly higher densities of P. elongatus within Wellington Harbour compared to south coast sites can be explained by 1) more available shelter space at Hutt River mouth due to a larger range of rock sizes and multiple layers, 2) higher food supply within the harbour according to findings of Gardner (2000, 2002); Gardner \& Thompson (2001); Helson (2001), and Helson et al. (2007), and 3) presumably relatively lower settlement and recruitment rates at Cook Strait due to prevailing currents and higher larval densities within the harbour as presented by Helson \& Gardner (2004) for planktonic larval densities of the bivalves Aulacomya maoriana, Mytilus galloprovincialis and Perna canaliculus.

\section{Influences of settlement and conspecific cueing on patterns of abundance}

In many benthic marine invertebrates settlement crucially depends on the presence of conspecific adults and is delayed in absence of conspecific cues (Pechenik, 1990; Gebauer et al., 2003). Because higher cue concentrations may trigger stronger attraction effects in larvae and waterborne cue density depends on local variations of abundance of adult crabs, settlement rates may vary even on a scale of tens of centimetres in areas with low wave exposure. Jensen (1989), 
Donahue (2006), and Gebauer et al. (2011) presented evidence that megalopae of $P$. cinctipes, $P$. eriomerus and $P$. laevigatus also settle preferably in the presence of conspecific adults, suggesting that conspecific cueing may be common in Petrolisthes spp. Generally, conspecific cueing is common among marine invertebrates including many crustacean species (for reviews, see Meadows \& Campbell, 1972; Crisp, 1974; Burke, 1986; Pawlik, 1992; Rodriguez et al., 1993; Rittschof et al., 1998; Hadfield \& Paul, 2001; Hay, 2009) because it facilitates a higher probability of finding suitable or high quality habitat (Raimondi, 1988; Jensen, 1989). Gregariousness frequently leads to extremely high population densities (Jensen, 1989, 1991; Jensen \& Armstrong, 1991).

\section{Density dependence}

Elevated density may negatively affect individual growth and feeding rates and could lead to increased mortality rates under laboratory conditions with more pronounced effects on smaller individuals of Petrolisthes spp. (compare Donahue, 2004). Hence, the costs of aggregation are higher for recruits than for adult crabs. However, intraspecific competition does not only depend on density but also on availability of resources such as food and shelters. In the field, interference competition for space could decrease individual fitness due to energetic costs of agonistic behaviour. Additionally, the occupancy of shelters by an aggregation of crabs whose larger individuals may be dominant competitors results in the decrease in availability of the critical resource shelter space. Exploitative competition for food in porcellanids, on the other hand, may only play an important role at sites with long term food limitation and low water movement, where the local depletion of food particles could lead to decreased individual growth rates and fitness. Highly abundant filter feeders may be responsible for substantial local plankton declines (Barange \& Gili, 1988; Klimmerer et al., 1994). However, variations in food supply may be partly attenuated by effects of water movement. While food levels are generally higher and wave exposure lower in shallow natural embayments such as Wellington Harbour, the open coast is commonly characterised by high wave exposure (involving constant water movement and mixing processes within the surf zone) but lower levels or particulate organic matter (e.g. Helson et al., 2007). Additionally, similar to bivalves such as Perna canaliculus (Hawkins et al. 1999), porcelain crabs are able to adjust feeding rates over a wide range of plankton concentrations (Kropp, 
1981; Števčić, 1988) and current velocities (Trager \& Genin, 1993; Achituv \& Pedrotti, 1999). However, despite evidence for Allee effects (e.g. decrease in predation on settlers in the presence of conspecific adults, Donahue, 2006) intraspecific competition appears to be generally an important feature in mobile filter feeders such as Petrolisthes spp. (compare Donahue, 2004) as well as in filter feeding sessile invertebrates (reviewed in Branch 1984).

\section{The contribution of mobility to patterns of abundance}

When undisturbed, movement and migration predominantly occurs during high tide, as soon as there is enough water for filter feeding (own obs.). Movement appears to be mainly motivated by the search for optimal feeding spots (Jensen, 1990; Donahue, 2004) at which microhydrodynamic conditions (i.e. small scale current velocities, laminar vs. turbulent flow) maximise feeding efficiency. Additionally, the search for mates as well as agonistic behaviour in Petrolisthes ssp. described by Molenock (1976) may contribute to movement patterns. As soon as the intertidal boulder fields re-emerge with the outgoing tide, shelter targeting behaviour (Meyer-Rochow \& Meha, 1994) in conjunction with a negative phototaxis (Scott, 1958) may become the main driver for migratory activity. The tide dependent variations in movement, short range dispersal and aggregation are very similar to those found in many intertidal hermit crabs (e.g. Gherardi \& Vanini, 1993; Turra \& Leite, 1999). While small individuals remain within crevices and cavities among rocks almost permanently, larger crabs move about during high tide. In addition to active movement, a combination of passive drift and swimming behaviour (by rapidly flapping their abdomen) may occasionally transport individuals to nearby locations after having been dislodged in heavy surf (own obs.). Population density appeared to be negatively correlated with mobility whereby high density patches may act as physical barrier involving agonistic interactions between "intruder" and "local" individuals. Similar to P. cinctipes (see Donahue, 2004), P. elongatus is relatively sedentary compared to other decapods.

\section{The role of predation in relation to habitat structure}

A number of studies suggest that predation effects on crab and reef fish populations are mediated by the protective capacity of a reef or vegetative benthic cover with high structural complexity (e.g. Eggleston \& Lipcius, 1992; Eggleston 
et al., 1997; Moksnes et al., 1998; Thistle et al., 2010). However, despite evidence for a negative correlation between rock size and fish predation rates on small crabs under laboratory conditions, the influence of habitat structure on predation rate and survival in natural conditions was difficult to quantify. In the field, predation effects are far more complex compared to the observed patterns in aquaria, where other predator species and site specific predator abundance as well as abiotic factors such as wave exposure were excluded for simplification.

\section{Reproductive traits and phenotypic plasticity}

P. elongatus exhibits a high variation in life history characteristics across sites that are likely to be influenced by environmental factors such as food supply, temperature and salinity. In turn, the variability of environmental conditions across and within habitat patches leads to a high degree of phenotypic plasticity that is not necessarily adaptive, but rather the physiological and biochemical response of organisms to variable environments. The naturally fragmented habitat that leads to geographically isolated metapopulations selects for an adequate dispersal potential, e.g. a long pelagic larval phase, to ensure connectivity (i.e. sustained gene-flow) and the ability of patch (re-) colonisation as an adaptation to minimize local extinction risk (Hanski, 1998). Additionally, conspecific cueing increases survival because the presence of a benthic population of conspecifics indicates habitat suitability. Generally, the investment in per-capita survival is high in P. elongatus that exhibits low numbers of large eggs relative to similarsized decapods from temperate latitudes. Contrary to the traditional perception that dispersal capacity is closely related to large numbers of small eggs, porcelain crabs appear to have evolved an alternative strategy that compensates fewer eggs per female not only with higher investment in individual survival but also with high frequency of spawning and high reproductive output per female (in terms of the clutch weight to body mass ratio). Further, the egg production per $\mathrm{m}^{2}$ habitat may be high due to commonly high adult densities. However, animals with biphasic life cycles, including porcelain crabs, often experience considerable losses during their early development in plankton due to predation (e.g. Pineda, 2000; Rilov \& Shiel, 2006). 


\subsection{General conclusions}

Clustered distributions of mobile invertebrates in intertidal boulder fields do not necessarily arise from social behaviour or conspecific cueing, but may also be strongly influenced by the response of individuals to structural complexity of the habitat, micro hydrodynamic conditions, and available shelter space. The resulting aggregation is associated with a number of benefits, such as increased reproductive success and the protection of juveniles by adults. However, while aggregating species may have evolved an elevated tolerance for high conspecific densities, intraspecific competition could have adverse effects on individual growth rate, reproductive output and ultimately fitness at densities close to the specific carrying capacity of a habitat patch. To some extent, levels of intraspecific competition could be migitated by migration, dependent on densities and competition in adjacent patches (see Fig. 6.1).

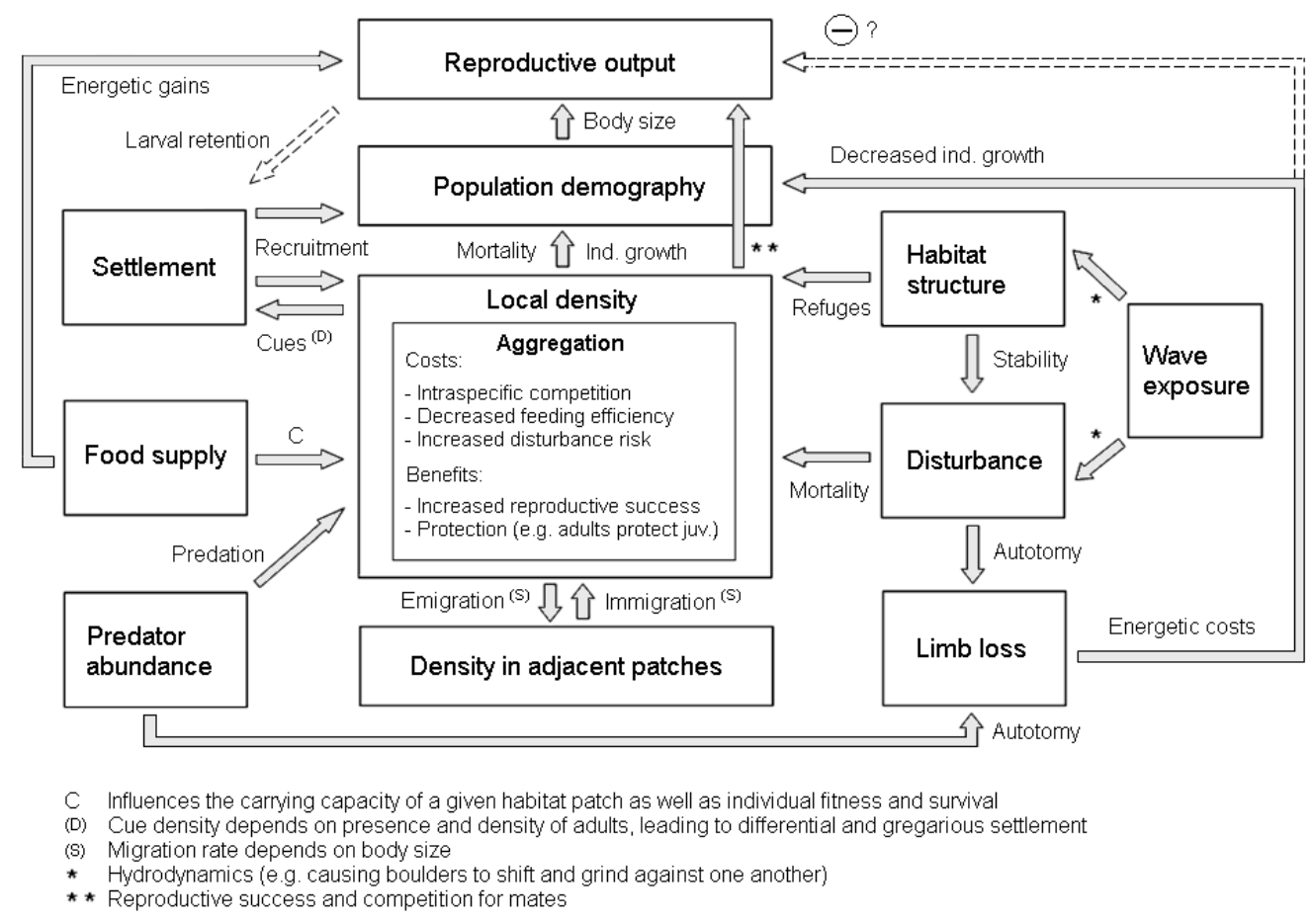

Fig. 6.1: General conceptual model of mechanisms influencing local population density, demography (i.e. size frequency distribution), and reproductivity in intertidal marine invertebrates using the example of porcelain crab populations living in intertidal boulder fields.

VanHorne (1983) noted that population density may be a misleading indicator of habitat quality because intraspecific dominance interactions (e.g. territory 
acquisition by dominant males) may lead to the displacement of less dominant individuals to low quality habitat patches. Within a "saturated" habitat, mortality regulates maximum population density. Both mortality and migration rate may be size (or age) dependent, shaping the local population structure. Additionally, individual growth rate is commonly influenced by intraspecific competition, leading to decreased individual reproductive output because, in decapods, female body size determines the number of offspring. Food limitation due to low food supply and / or exploitative competition may further reduce reproductive output, directly or indirectly. Gregarious settlement typically involves conspecific cueing that leads to higher settlement rates in patches with higher benthic populations of conspecific adults, thereby influencing local density and population demography (i.e. size structure). Predator abundance in conjunction with the availability of shelters influences predation rate that may be selective with regards to prey size (e.g. higher among small individuals). On the other hand, the frequency of predator-prey encounters that is dependent on habitat structural complexity may increase the risk of limb loss due to attempted predation and a successfully applied escape strategy (i.e. autotomy). Limb loss may also depend on disturbance rate, potentially leading to decreased individual growth and / or reproductive output due to resource allocation to limb regeneration.

Since habitat structure and specifically interstitial space among boulders is critical for the survival of mobile intertidal invertebrates, the availability of shelters (that is closely related to cobble size) is an important indicator of habitat quality for species such as porcellanids and hermit crabs. Interstitial space may strongly affect local population density and population structure either directly (shelter space as limiting resource) or indirectly (e.g. via the influence of cavity size on predation rate).

While high spatio-temporal variations in environmental conditions within and across habitat patches may lead to heterogeneous patterns of abundance and select for a high phenotypic plasticity in reproductive traits, many life history characteristics can be viewed as specific adaptations to environmental factors. If for example the natural fragmentation of suitable habitat requires a high dispersal potential there may be alternative stable states or strategies within and across species that successfully achieve persistence and fitness maximisation. 


\subsection{Future research}

\section{Further analysis of spatial distribution of individuals}

Crowding represents the level of local density (and hence intraspecific competition) that the average individual experiences (Lloyd, 1967; Hartley \& Shorrocks, 2002). The quadrat sampling data analyzed in section 2.3.1 may provide information on mean crowding per habitat patch (i.e. per quadrat, nest and site), since the size frequency distribution and number of crabs was recorded for each rock within each quadrat. Mean crowding is defined as the "number of other (i.e. non-self) individuals in a patch, averaged across individuals" including the relationship between variance and mean $(\square=\mathrm{M}+(\mathrm{V} / \mathrm{M})-1)$. In addition to mean crowding, the Index of Aggregation (IA), introduced by Ives (1988) could be useful to further analyse quadrat sampling data. This index measures "the level of within-patch density, averaged across individuals, relative to a random distribution of the same regional mean", IA $=(\mathrm{V}-\mathrm{M}) / \mathrm{M}^{2}=(\square / \mathrm{M})-1$ (see Hartley \& Shorrocks, 2002). In aggregated populations mean crowding is significantly elevated compared to the mean number of individuals per patch, whereas for a random (Poisson) distribution no difference is detectable. However, Neuhäuser et al. (2010) pointed out that crowding data consist of values that are not statistically independent since, by definition, all individuals have the same number of neighbours within a certain patch and subpopulation. In order to avoid pseudoreplication according to the definition of Hurlbert (1984), classic statistical methods cannot be applied (see Reiczigel et al., 2005, 2008). A different kind of statistical non-independence (i.e. spatial autocorrelation) could arise from the mobility and migratory activity of individuals. The number of crabs under a certain rock may be influenced by the number of crabs under a neighbouring rock, dependent on relative distance. Spatial autocorrelation statistics such as Moran's I or Geary's C could be used that, generally, analyse the degree of dependency among observations in a geographic space (see Getis \& Ord, 1992; Perry, 1995; Fortin et al., 2002). Such tests require a spatial weights matrix that reflects the intensity of the geographic relationship between observations in a neighbourhood, e.g. the distances between neighbours, the lengths of shared border, or whether they fall into a specified directional class. This information could be obtained by measuring the distances between all boulders within each quadrat on digital images of all sampling areas, using image processing software such as 
"ImagePro" (Media Cybernetics). Additionally, gravity models may yield illuminating information on how individuals will distribute over time in a given landscape (e.g. with certain rock sizes), taking into account migration rates (see section 2.3.4), distance between patches (e.g. rocks), topology (e.g. surface roughness), negative phototaxis, conspecific attraction (e.g. of larvae by the presence of adults, influencing local settlement rates, see section 4.3.2), and tidal oscillation (i.e. alternation between submerged and emerged state).

\section{An estimate of interstitial space}

Rather than rock size, interstitial space between rocks provides a more accurate and relevant measure of available refuges within a defined habitat patch and therefore may be a more suitable predictor for local abundance of P. elongatus. Interstitial space could be estimated by using a plastic container with a known volume, ideally with volumetric scale and reasonably large in order to minimise errors due to edge effects. The container could be filled with all rocks found within a defined area of cobble beach (e.g. a sampling quadrat $50 \times 50 \mathrm{~cm}$ ) down to the level where fine-grained sediment is clogging the cavities. Rocks should be stacked as densely as possible and similar to their three-dimensional position on the beach. The height of rocks within the container determines the total volume, whereas the interstitial volume is measured by filling the spaces between pebbles and boulders with water, using a bucket or large beaker with volumetric scale. The ratio between total and interstitial volume could then be plotted against average rock surface area to test whether mean rock size is a reliable measure of interstitial space.

\section{Relative contribution of genetic \& environmental factors to phenotypic plasticity}

To examine to what degree site specific phenotypic differences occurred as a result of plastic responses to environmental conditions or whether they were mainly genetically determined, reciprocal transplant experiments of crabs have proven useful (e.g. Brazeiro, 2005; Pascoal et al., 2012). Specifically, reproductive traits of female $P$. elongatus could be examined at the Wellington south coast and within the harbour compared to transplanted female subpopulations, e.g. using basket traps with mesh inlay similar to those described in section 4.2.2 of the present study. Further, the quantification of larval retention and connectivity between metapopulations on various spatial scales (e.g. within 
Wellington region and across Cook Strait) may elucidate the level of gene flow between sites (for a review of methods, see Thorrold et al., 2002).

\section{Effects of limb loss on reproductive output}

In the present study it could not be determined with certainty whether reproductive output (measured as the ratio of clutch weight vs. body weight, see section 5.3.4) is affected by limb loss and local density. This was mainly due to a low sample size of injured females. Additionally, none of the females used in the experiment to test growth rates in relation to cheliped loss (section 5.3.3) became ovigerous while in captivity. Hence, it remains unclear whether in P. elongatus energy allocation for the regeneration of limbs decreases fecundity directly as in many brachyuran decapods (see Hines, 1982, 1991, 1992; MacDiarmid, 1986; Norman \& Jones, 1993; Luppi et al., 1997), or whether egg production has priority over allocating energy to increasing claw size as suggested by Juanes et al. (2008). Additionally, fecundity may be affected indirectly via disadvantages in competition for mates (Smith, 1991; Abello et al., 1994; reviewed in Juanes \& Smith, 1995). A field experiment, conducted during the reproductive season, with encaged males and females with removed chelipeds may be useful to shed light on the trade-off between limb regeneration, somatic growth, and reproductivity (reviewed in Maginnis, 2006) under near-natural conditions.

\section{Variability of colouration in P. elongatus adults}

The role of colour morphs for predator avoidance on various substrates and predation rates in response to "matched" and "mismatched" colouration would be an interesting field for future studies (see p.52, Chapter 2). Similar to classic examples of phenotypic plasticity, such as the Peppered moth (Biston betularia) (e.g. Kettlewell, 1958; Grant, 1999) and the Grove snail (Cepaea nemoralis) (e.g. Cain \& Sheppard, 1953; Silvertown et al., 2011), P. elongatus audults exhibit a high variability of coloration which is presumably heritable and appears to be an adaptation to the diversity of microhabitats in order to be optimally camouflaged on differently coloured substrates such as rocks, biofilms and shingle (i.e. mollusc shells) (own observation). While the blue, black and grey types seemed to be relatively more abundant at HRM amongst dark grey rocks and purple-bluish shell fragments of Aulacomya maoriana and Mytilus galloprovincialis, the majority of $P$. elongatus individuals at BRB appeared to be red-brown and 
greenish brown, amongst grey-brown boulders and many thallus fragments of green-, brown- and red macroalgae. A laboratory-based experiment testing predation (i.e. survival) rates dependent on carapace colour versus colour of the substrate could involve the spatial separation of certain colour morphs and exposure to the same predators (e.g. in a choice chamber type set-up) with standardised densities and sizes, e.g. spotty (Notolabrus celidotus), red cod (Pseudophycis bachus) (see Graham, 1938), and olive rockfish (Acaththoclinus fuscus). Additionally, it is relatively easy to collect porcelain crabs in sufficient sample sizes for a quantification of potential differences of frequencies of colour variations across sites. Alternatively to "destructive" sampling, digital images could be taken from a short-term disturbed habitat patch (i.e. with boulders being flipped over quickly before the image is taken and the put back into place). Since there are no distinct colourations but rather a continuous transition of shades, the determination of certain "types" may be somewhat arbitrary. The preservation of samples for processing at a later stage by other means than deep freezing, however, could be difficult as colour complexes are not stable in ethanol and formalin. A similar study has been conducted on juveniles of a freshwater isopod with habitat specific varied pigmentation that is only displayed during the juvenile phase (Hargeby et al., 2004). Additionally, the associated genetic mechanism of colouration might yield valuable information on the biochemical basis of camouflage strategies. 


\section{References}

Abello, P.; Warman, C.G.; Reid, D.G. \& Naylor, E., 1994. Chela loss in the shore crab Carcinus maenas (Crustacea: Brachyura) and its effect on mating success. Mar. Biol. 121: 247-252.

Aichituv, Y. \& Pedrotti, M.L., 1999. Cost and gains of porcelain crab suspension feeding in different flow conditions. Mar. Ecol. Prog. Ser. 184: 161-169.

Allen, L.G.; Pondella, D.J. \& Horn, M.H., 2006. Ecology of marine fishes: California and adjacent waters. University of California Press, 660 pp.

Barange, M. \& Gili, J.M., 1988. Feeding cycles and prey capture in Eudendrium racemosum (Cavolini, 1785). J. Exp. Mar. Biol. Ecol. 115: 281-293.

Beck, M.W., 1995. Size-specific shelter limitation in Stone Crabs: a test of the demographic bottleneck hypothesis. Ecology 76: 968-980.

Branch, G.M., 1984. Competition between marine organisms: ecological and evolutionary implications. Annu. Rev. Oceanogr. Mar. Biol. 22: 429-593.

Brazeiro, A., 2005. Geomorphology induces life history changes in invertebrates of sandy beaches: the case of the mole crab Emerita analoga in Chile. J. Mar. Biol. Assoc. U.K. 85: 113-120.

Burke, R.D., 1986. Pheromones and the gregarious settlement of marine invertebrate larvae. Bull. Mar. Sci. 39(2): 323-331.

Cain, A.J. \& Sheppard, P.M., 1953. Natural selection in Cepaea. Genetics 39 (1): 89-116.

Crisp, D.J., 1974. Factors influencing the settlement of marine invertebrate larvae. In: Chemoreception in marine organisms. P.T. Grant \& A.M. Mackie (eds.), Academic Press, London, pp. 177-265.

Donahue, M.J., 2004. Size-dependent competition in a gregarious porcelain crab Petrolisthes cinctipes (Anomura: Porcellanidae). Mar. Ecol. Prog. Ser. 267: 219-231.

Donahue, M.J., 2006. Allee effects and conspecific cueing jointly lead to conspecific attraction. Oecologia 149: 33-43.

Eggleston, D.B. \& Lipcius, R.N., 1992. Shelter selection by Spiny Lobster under variable predation risk, social conditions, and shelter size. Ecology 73: 992-1011.

Eggleston, D.B.; Lipcius, R.N. \& Grover, J.J., 1997. Predator and shelter-size effects on coral reef fish and spiny lobster prey. Mar. Ecol. Prog. Ser. 149: 43-59. 
Emparanza, E.J.M., 2007. Patterns of distribution of dominant porcelain crabs (Decapoda: Porcellanidae) under boulders in the intertidal of northern Chile. J. Mar. Biol. Assoc. U.K. 87: 523-531.

Fortin, M.J.; Dale, M.R.T.; Hoef, J., 2002. Spatial analysis in ecology. In: Encyclopedia of Environmetrics. A.H. El-Shaarawi \& W.W. Piegorsch (Eds.) Vol. 4, pp. 2051-2058.

Gardner, J.P.A., 2000. Where are the mussels on Cook Strait (New Zealand) shores? Low seston quality as a possible factor limiting multi-species distributions. Mar. Ecol. Prog. Ser. 194: 123-132.

Gardner, J.P.A., 2002. Effects of seston variability on the clearance rate and absorption efficiency of the mussels Aulacomya maoriana, Mytilus galloprovincialis and Perna canaliculus from New Zealand. J. Exp. Mar. Biol. Ecol. 268: 83-101.

Gardner, J.P.A. \& Thompson, R.J., 2001. Naturally low seston concentration and the net energy balance of the greenshell mussel, (Perna canaliculus) at Island Bay, Cook Strait, New Zealand. NZ J. Mar. Fresh. Res. 35: 457-468.

Gebauer, P.; Paschke, K. \& Anger, K., 2003. Delayed metamorphosis in decapod crustaceans: evidence and consequences. Rev. Chil. Hist. Nat. 76: 169-175.

Gebauer, P.; Paschke, K. \& Anger, K., 2007. Reproductive biology and population parameters of Petrolisthes laevigatus (Anomura: Porcellanidae) in Southern Chile: consequences on recruitment. J. Mar. Biol. Ass. U.K. 87: 729734.

Gebauer, P.; Freire, M.; Barria, A. \& Paschke, K., 2011. Effect of conspecific density on the settlement of Petrolisthes laevigatus (Decapoda: Porcellanidae). J. Mar. Biol. Assoc. U.K. 91: 1453-1458.

Getis, A. \& Ord, J.K., 1992. The analysis of spatial association by use of distance statistics. Geogr. Analysis 24(3): 189-206.

Gherardi, F. \& Vanini, M., 1992. Hypotheses on ultimate and proximate factors influencing clustering in tropical hermit crab Clibanarius laevimanus. Ethol. Ecol. Evol. Special Issue 2: 17-22.

Graham, D.H., 1938. Food of the fishes of Otago Harbour and adjacent sea. Trans. Proc. Royal Soc. New Zealand 68(3): 399-419.

Grant, B.S., 1999. Fine tuning the Peppered moth paradigm. Evolution 53 (3): 980-984.

Hadfield, M.G. \& Paul, V.J., 2001. Natural chemical cues for settlement and metamorphosis of marine invertebrate larvae. In: Marine Chemical Ecology. J.B. McClintock \& B.J. Baker (eds.). CRC Press, Boca Raton. Pp. 431-461.

Hanski, I., 1998. Metapopulation dynamics. Nature 396: 41-49. 
Hargeby, A.; Johansson, J. \& Ahnesjö, J., 2004. Habitat-specific pigmentation in a freshwater isopod: adaptive evolution over a small spatio-temporal scale. Evolution 58(1): 81-94.

Hartley, S. \& Shorrocks, B., 2002. A general framework for the aggregation model of coexistence. J. Animal Ecol. 71: 651-662.

Hawkins, A.J.S.; James, M.R.; Hickman, R.W.; Hatton, S. \& Weatherhead, M. 1999. Modelling of suspension-feeding and growth in the green-lipped mussel Perna canaliculus exposed to natural and experimental variations of seston availability in the Marlborough Sounds, New Zealand. Mar. Ecol. Prog. Ser. 191: 217-232.

Hay, M.E., 2009. Marine chemical ecology: chemical signals and cues structure marine populations, communities, and ecosystems. Annu. Rev. Mar. Sci. 1: 193-212.

Helson, J.G., 2001. An investigation into the absence of mussels (Perna canaliculus, Aulacomya maoriana \& Mytilus galloprovincialis) from the south coast of Wellington, New Zealand. PhD thesis, Victoria University of Wellington, New Zealand. Pp. 183.

Helson, J.G. \& Gardner, J.P.A., 2007. Variation in scope for growth: a test of food limitation among intertidal mussels. Hydrobiologia 586: 373-392.

Helson, J.G.; Pledger, S. \& Gardner, J.P.A., 2007. Does differential particulate food supply explain the presence of mussels in Wellington Harbour (New Zealand) and their absence on neighbouring Cook Strait shores? Estuar. Coast. Shelf Sci. 72(1-2): 223-234.

Hines, A.H., 1982. Allometric constraints and variables of reproductive effort in brachyuran crabs. Mar. Biol. 69: 309-320.

Hines, A.H., 1991. Fecundity and reproductive output in nine species of Cancer crabs (Crustacea, Brachyura, Cancridae). Can. J. Fish. Aquat. Sci. 48: 267-275.

Hines, A.H., 1992. Constraint on reproductive output in brachyuran crabs: Pinnotherids test the rule. Am. Zool. 32(3): 503-511.

Howard, A.E., 1980. Substrate controls on the size composition of lobster (Homarus gammarus) populations. J. Cons. Int. Explor. Mer 39 (2): 130-133.

Hurlbert, S.H., 1984. Pseudoreplication and the design of ecological field experiments. Ecological Monographs 54(2): 187-211.

Ives, A.R., 1988. Aggregation and coexistence of competitors. Annales Zoologici Fennici 25: 75-88. 
Jensen, G.C., 1989. Gregarious settlement by megalopae of the porcelain crabs Petrolisthes cinctipes (Randall) and P. eriomerus Stimpson. J. Exp. Mar. Biol. Ecol. 131(3): 223-231.

Jensen, G.C., 1990. Intertidal zonation of porcelain crabs: Resource partitioning and the role of selective settlement. Washington, Seattle.

Jensen, G.C., 1991. Competency, settling behavior, and postsettlement aggregation by porcelain crab megalopae (Anomura: Porcellanidae). J. Exp. Mar. Biol. Ecol. 153: 49-61.

Jensen, G.C. \& Armstrong, D.A., 1991. Intertidal zonation among congeners: factors regulating distribution of porcelain crabs Petrolisthes spp. (Anomura: Porcellanidae). Mar. Ecol. Prog. Ser. 73: 47-60.

Juanes, F. \& Smith, L.D., 1995. The ecological consequences of limb damage and loss in decapod crustaceans: a review and prospectus. J. Exp. Mar. Biol. Ecol. 193: $197-223$.

Juanes, F.; Lee, K.T.; McKnight, A. \& Kellogg, K., 2008. Claw allometry in green crabs, Carcinus maenas: heterochely, handedness, and sex. Mar. Biol. 153: 523-528.

Kareiva, P., 1990. Population dynamics in spatially complex environments: theory and data. Phil. Trans. R. Soc. Lond. B 330: 175-190.

Kettlewell, H.B.D., 1958. A survey of the frequencies of Biston betularia (L.) (Lep.) and its melanic forms in Great Britain. Heredity 12: 51-72.

Klimmerer, W.J.; Gartside, E. \& Orsi, J.J., 1994. Predation by an introduced clam as the likely cause of substantial declines in zooplankton of San Fancisco Bay. Mar. Ecol. Prog. Ser. 113: 81-93.

Kotliar, N.B. \& Wiens, J.A., 1990. Multiple scales of patchiness and patch structure: a hierarchical framework for the study of heterogeneity. Oikos 59: 252-260.

Kropp, R.K., 1981. Additional porcelain crab feeding methods (Decapoda, Porcellanidae). Crustaceana 40(3): 307-310.

Levin, S.A., 1992. The problem of pattern and scale in ecology. Ecology 73: 1943-1967.

Lloyd, M. (1967) Mean crowding. Journal of Animal Ecology 36: 1-30.

Luppi, A.T.; Bas, C.C.; Spivak, E.D. \& Anger, K., 1997. Fecundity of two grapsid crab species in the Laguna Mar Chiquita, Argentina. Arch. Fish. Mar. Res. 45: 149-166. 
MacDiarmid, A.B., 1989. Size at onset of maturity and size-dependent reproductive output of female and male spiny lobsters Jasus edwardsii (Hutton) (Decapoda, Palinuridae) in northern New Zealand. J. Exp. Mar. Biol. Ecol. 127(3): 229-243.

Maginnis, T.L., 2006. The costs of autotomy and regeneration in animals: a review and framework for future research. Behav. Ecol. 17: 857-872.

Meadows, P.S. \& Campbell, J.I., 1972. Habitat selection by aquatic invertebrates. Adv. Mar. Biol. 10: 271-382.

Meyer-Rochow, V.B. \& Meha, W.P., 1994. Tidal rhythm and the role of vision in shelter-seeking behaviour of the half-crab Petrolisthes elongatus (Crustacea: Anomura: Porcellanidae). J. Royal. Soc. New Zealand 24(4): 423-427.

Moksnes, P.-O.; Pihl, L. \& Montfrans, J. van, 1998. Predation on postlarvae and juveniles of the shore crab Carcinus maenas: importance of shelter, size and cannibalism. Mar. Ecol. Prog. Ser. 166: 211-225.

Molenock, J., 1976. Agonistic interactions of the crab Petrolisthes (Crustacea, Anomura). Zeitschr. Tierpsychol. 41: 277-294.

Neuhäuser, M.; Kotzmann, J.; Walier, M.; Poulin, R., 2010. The comparison of mean crowding between two groups. J. Parasitol. 96(3): 477-481.

Norman, C.P. \& Jones, M.B., 1993. Reproduction ecology of the velvet swimming crab, Necora puber (Brachyura: Portunidae), at Plymouth; J. Mar. Biol. Assoc. U.K. 73: 379-389.

Oden, N., 1995. Adjusting Moran's I for population density. Stat. Med. 14(1):1726.

Pascoal, S.; Carvalho, G.; Creer, S.; Rock, J.; Kawaii, K.; Mendo, S. \& Hughes, R., 2012. Plastic and heritable components of phenotypic variation in Nucella lapillus: an assessment using reciprocal transplant and common garden experiments. PLoS ONE 7(1): e30289. doi:10.1371/journal.pone. 0030289

Pawlik, J.R., 1992. Chemical ecology of the settlement of benthic marine invertebrates. Oceanogr. Mar. Biol. Annu. Rev. 30: 273-335.

Pechenik, J.A., 1990. Delayed metamorphosis by larvae of benthic marine invertebrates: does it occur? Is there a price to pay? Ophelia 332: 63-94.

Perry, J.N., 1995. Spatial analysis by distance indices. J. Anim. Ecol. 64: 303-314.

Pineda, J., 2000. Linking larval settlement to larval transport: assumptions, potentials, and pitfalls. In: Oceanography of the Eastern Pacific, J. FärberLorda (Ed.), 1. CICESE, Ensenada, pp. 84-105. 
Raimondi, P.T., 1988. Settlement cues and determination of the vertical limit of an intertidal barnacle. Ecology 69: 400-407.

Reiczigel, J.; Zang, Z.; Rosza, L.; Tothmeresz, B., 2005. Properties of crowding indices and statistical tools to analyze parasite crowding data. J. Parasitol. 91: 245-252.

Reiczigel, J.; Zang, Z.; Rosza, L.; Tothmeresz, B., 2008. Measures of sociality: Two different views of group size. Animal Behaviour 75: 715-721.

Rittschof, D.; Forward, R.B.; Cannon, G.; Welch, J.M.; McClary, M.; Holm, E.R.; Clare, A.S.; Conova, S.; McKelvey, L.M.; Bryan, P.; van-Dover, C.L.; Clare, A.S.; Fusetani, N. \& Jones, M.B., 1998. Cues and context: larval responses to physical and chemical cues. Biofouling 12: 31-44.

Rodriguez, S.R.; Ojeda, F.P.; Inestrosa, N.C., 1993. Settlement of benthic marine invertebrates. Mar. Ecol. Prog. Ser. 97: 193-207.

Rilov, G. \& Schiel, D.R., 2006. Seascape-dependent subtidal-intertidal trophic linkages. Ecology 87(3): 731-744.

Scott, M.S., 1958. Studies on a false crab, Petrolisthes elongatus, Milne-Edwards. M.Sc. Thesis, University of Canterbury, Christchurch, New Zealand. 117 pp.

Silvertown, J.; Cook, L.; Cameron, R.; Dodd, M.; McConway, K.; Worthington, J.; Skelton, P.; Anton, C.; Bossdorf, O.; Baur, B.; Schilthuizen, M.; Fontaine, B.; Sattmann, H.; Bertorelle, G.; Correia, M.; Oliveira, C.; Pokryszko, B.; Ożgo, M.; Stalažs, A.; Gill, E.; Rammul, Ü.; Sólymos, P.; Féher, Z. \& Juan, X., 2011. Citizen science reveals unexpected continental-scale evolutionary change in a model organism. PLoS One 6(4): e18927. doi: 10.1371/ journal.pone.0018927.

Smith, L.D., 1992. The impact of limb autotomy on mate competition in blue crabs Callinectes sapidus Rathbun. Oecologia 89: 494-501.

Sosa-Cordero, E.; Arce, A. M.; Aguilar-Dávila, W. \& Ramírez-González, A., 1998. Artificial shelters for spiny lobster Panulirus argus (Latreille): an evaluation of occupancy in different benthic habitats. J. Exp. Mar. Biol. Ecol. 229 (1): 1-18.

Števčić, Z., 1988. Autecological investigations of the porcelain crab Porcellana platycheles (Pennant) (Decapoda, Anomura) in the Rovinj Area (Northern Adriatic) Crustaceana (55)3: 242-252.

Stillman, J.H., 2002. Causes and consequences of thermal tolerance limits in rocky intertidal porcelain crabs, genus Petrolisthes. Integ. Comp. Biol. 42: 790-796. 
Stillmann, J.H. \& Somero, G.N., 1996. Adaptation to temperature stress and aerial exposure in congeneric specias of intertidal porcelain crabs (genus Petrolisthes): correlation of physiology, biochemistry and morphology with vertical distribution. J. Exp. Biol. 199: 1845-1855.

Thistle, M.E.; Schneider, D.C.; Gregory, R.S. \& Wells, N.J., 2010. Fractal measures of habitat structure: maximum densities of juvenile cod occur at intermediate eelgrass complexity. Mar. Ecol. Prog. Ser. 405: 39-56.

Thorrold, S.R.; Jones, G.P.; Hellberg, M.E.; Burton, R.S.; Swearer, S.E.; Neigel, J.E.; Morgan, S.G. \& Warner, R.R., 2002. Quantifying larval retention and connectivity in marine populations with artificial and natural markers. Bull. Mar Sci. 70(1): 291-308

Trager, G.C. \& Genin, A., 1993. Flow velocity induces a switch from active to passive suspension feeding in the porcelain crab Petrolisthes leptocheles (Heller). Biol. Bull. 185: 20-27.

Turra, A. \& Leite, F.P.P., 1999. Clustering behaviour of hermit crabs (Decapoda, Anomura) in an intertidal rocky shore at São Sebastião, southeastern Brazil. Rev. Brasil. Biol. 60(1): 39-44.

Van Horne, B., 1983. Density as a misleading indicator of habitat quality. J. Wildl. Managem. 47(4): 893-901.

Wahle, R.A., 1992. Substratum constraints on body size and the behavioral scope of shelter use in the American lobster. J. Exp. Mar. Biol. Ecol. 159 (1): 59-75.

Wasson, K.; Lyon, B.E. \& Knope, M., 2002. Hair-trigger autotomy in porcelain crabs is a highly effective escape strategy. Behav. Ecol. 13: 481-486.

Wiens, J.A., 1989. Spatial scaling in ecology. Funct. Ecol. 3: 385-397. 